AUTARQUIA ASSOCIADA À UNIVERSIDADE DE SÃO PAULO

\title{
ESTUDO DA POLUIÇÃO AÉREA DE ELEMENTOS QUÍMICOS PELAS ANÁLISES DE CASCAS DE ÁRVORE
}

\author{
ELIANE CONCEIÇÃO DOS SANTOS
}

\begin{abstract}
Dissertação apresentada como parte dos requisitos para obtenção do Grau de Mestre em Ciências na Área de Tecnologia Nuclear - Aplicações
\end{abstract}

Orientadora:

Profa. Dra. Mitiko Saiki 
INSTITUTO DE PESQUISAS ENERGÉTICAS E NUCLEARES

Autarquia associada à Universidade de São Paulo

\section{ESTUDO DA POLUIÇÃO AÉREA DE ELEMENTOS QUÍMICOS PELAS ANÁLISES DE CASCAS DE ÁRVORE}

\section{ELIANE CONCEIÇÃO DOS SANTOS}

Dissertação apresentada como parte dos
requisitos para obtenção do Grau de
Mestre em Ciências na Área
de Tecnologia Nuclear - Aplicações

Orientadora:

Profa. Dra. Mitiko Saiki

Versão Corrigida

Versão Original disponível no IPEN

São Paulo

2017 
Dedico à minha mãe pelas orações $e$ incentivos, e ao meu pai por me apoiar nesta jornada. 


\section{AGRADECIMENTOS}

À Dra. Mitiko Saiki, por todos os anos de orientação pelos quais me transmitiram muitos conhecimentos valiosos para minha formação acadêmica e pessoal.

À Dra. Vera Akiko Maihara, pela proposta e execução das análises por espectrometria de absorção atômica das minhas amostras, pelos diversos conselhos dados e pela constante motivação.

Ao Dr. Edson Gonçalves Moreira, por ter me auxiliado na análise por espectrometria de absorção atômica, pelos conselhos e pela motivação.

À Dra. Ana Maria Graciano Figueiredo, pelas valiosas contribuições a este trabalho.

À Dra. Deborah Inês Teixeira Favaro, por ter dedicado seu tempo para me auxiliar nas análises por espectrometria de absorção atômica.

Ao Dr. Maurício Moralles, pela atenção e orientação dada quanto aos testes estatísticos.

Ao Dr. Frederico A. Genezini, pela orientação quanto ao rumo a ser dado ao tratamento dos dados.

Ao Dr. Guilherme Zahn por tirar minhas dúvidas com relação às estatísticas.

Ao Luís Amato, por ter me auxiliado na coleta das amostras em São Miguel Paulista.

Ao Vice-Diretor da UNESP de Presidente Prudente Dr. José Carlos Silva Camargo, pela autorização dada para coletar as amostras de cascas de árvore dentro da universidade.

Ao Sr. Edvaldo de Oliveira, por toda a atenção dada para possibilitar a coleta das amostras no campus da UNESP.

Ao Instituto de Pesquisas Energéticas e Nucleares, IPEN-CNEN/SP pela oportunidade concedida para executar este trabalho.

À Coordenação de Aperfeiçoamento de Pessoal de Nível Superior, CAPES, pela concessão da bolsa de estudos. 
À Fundação de Amparo à Pesquisa do Estado de São Paulo, FAPESP, e ao Conselho Nacional de Desenvolvimento Científico de Tecnológico, CNPq, pelo auxílio financeiro concedido.

Ao meu pai, por ter topado a aventura de coletar amostras e de viajar $500 \mathrm{~km}$ de madrugada para coletar cascas de árvore. Obrigada por todo o apoio e por acreditar que apesar das dificuldades, eu tenho capacidade de trilhar este caminho tão longo da vida acadêmica.

À minha mãe, por sempre acreditar em mim e me apoiar nesta minha empreitada acadêmica. Por me confortar nos momentos de desânimo, pelas muitas velas acesas e orações a mim feitas. Obrigada por ser a melhor mãe do mundo.

A todos os amigos do Centro do Reator de Pesquisas (CRPq) pelas conversas, conselhos, risadas, apoio psicológico e amizade verdadeira. Espero levar para o resto da vida.

A todas as pessoas que, de alguma forma, contribuíram para a realização deste trabalho. 


\title{
ESTUDO DA POLUIÇÃO AÉREA DE ELEMENTOS QUÍMICOS PELAS ANÁLISES DE CASCAS DE ÁRVORE
}

\author{
ELIANE CONCEIÇÃO DOS SANTOS
}

\begin{abstract}
RESUMO
A avaliação da qualidade do ar é um assunto de grande importância uma vez que os contaminantes da atmosfera podem causar efeitos danosos à saúde e ao meio ambiente. Nos últimos anos as cascas de árvores têm sido estudadas como biomonitores da poluição atmosférica devido à facilidade de amostragem, ampla disponibilidade e resistência das espécies arbóreas quanto às variações ambientais. No presente trabalho, um estudo da poluição aérea de elementos químicos foi realizado pela análise de cascas de Tipuana (Tipuana tipu) e Sibipiruna (Poincianella pluviosa). As cascas de árvore foram coletadas em diferentes locais da Região Metropolitana de São Paulo (RMSP) e em dois locais no interior do estado de São Paulo considerados como regiões controle. As amostras de cascas foram analisadas por meio da análise por ativação neutrônica (NAA) para a determinação de $\mathrm{As}, \mathrm{Br}, \mathrm{Ca}, \mathrm{Cl}, \mathrm{Co}, \mathrm{Cr}$, Cs, Fe, K, La, Mg, Mn, Ni, Rb, Sb, Sc, Ve $Z n$ e pela espectrometria por absorção atômica com forno de grafite (GF AAS), na determinação de $\mathrm{Cd}$, $\mathrm{Cu}$ e $\mathrm{Pb}$. No controle da qualidade analítica, os resultados das análises dos materiais de referência certificados apresentaram boa exatidão, com valores de $\mid Z$ score $\mid \leq 2$. Ensaios preliminares foram realizados para estabelecer as condições experimentais adequadas para coleta e preparo das amostras das cascas de árvore. As cascas foram coletadas em todas as possíveis faces do tronco da árvore e uma espessura de $2 \mathrm{~mm}$ da camada superficial da casca foi ralada e homogeneizada para as análises. Os resultados indicaram variabilidade nas concentrações dos elementos nas cascas em função da proximidade e intensidade das fontes de emissão. Além disso, os resultados indicaram quatro possíveis fontes de poluentes, sendo estes, veicular, industrial, aerossol marinho e a própria composição da casca de árvore. Os fatores de enriquecimento para os elementos determinados nas cascas de árvore indicaram maiores concentrações nas
\end{abstract}


amostras coletadas na RMSP do que aqueles obtidos nas regiões controle. As concentrações de $\mathrm{As}, \mathrm{Cd}, \mathrm{Co}, \mathrm{Pb}$ e $\mathrm{Zn}$ obtidas nas cascas de árvores apresentaram associação com as concentrações de material particulado $\left(\mathrm{MP}_{10}\right)$ medidas pela Companhia Ambiental do Estado de São Paulo (CETESB). Os elementos $\mathrm{Cl}$, Co, $\mathrm{Mg}$ e Ni das cascas, apresentaram correlação com as taxas de mortalidade por doenças cardiorrespiratórias em adultos. Os resultados deste estudo indicam a viabilidade do uso de cascas de árvores em estudos de poluição atmosférica de elementos químicos, especialmente nas regiões em que não há sistema de monitoramento da poluição do ar.

Palavras-chave: cascas de árvores, elementos químicos, poluição atmosférica, biomonitoramento 


\title{
A STUDY ON AERIAL POLLUTION OF CHEMICAL ELEMENTS BY TREE BARK ANALYSES
}

\section{ELIANE CONCEIÇÃO DOS SANTOS}

\begin{abstract}
The assessment of air quality is a matter of great importance since the pollutants of the atmosphere can cause harmful effects to health and the environment. In recent years tree barks have been studied as biomonitors of atmospheric pollution due to their easy of sampling, wide availability and resistance to environmental variations. In the present study on aerial pollution of chemical elements, the analyses of Tipuana (Tipuana tipu) and Sibipiruna (Poincianella pluviosa) tree barks were performed. The tree barks were collected at different sites in the Metropolitan Region of São Paulo (MRSP) and in two small cities of São Paulo state considered as control regions. The bark samples were analyzed by neutron activation analysis (NAA) for As, $\mathrm{Br}, \mathrm{Ca}, \mathrm{Cl}, \mathrm{Co}, \mathrm{Cr}, \mathrm{Cs}, \mathrm{Fe}, \mathrm{K}, \mathrm{La}, \mathrm{Mg}, \mathrm{Mn}, \mathrm{Ni}, \mathrm{Rb}$, $\mathrm{Sb}$, Sc, V, and $\mathrm{Zn}$ determinations and by graphite furnace atomic absorption spectrometry (GF AAS) for $\mathrm{Cd}, \mathrm{Cu}$ and $\mathrm{Pb}$. In the analytical quality control, the certified reference materials results presented good accuracy, with values of $\mid Z$ score $\mid \leq 2$. Preliminary tests were performed to establish adequate experimental conditions for collection and preparation of the tree barks samples. The barks were collected in all possible faces of the tree trunk and a thickness of $2 \mathrm{~mm}$ of the bark surface layer was grated and homogenized for the analyses. Data analyses of the samples indicated variability in the element concentrations depending on the proximity and intensity of the emission sources. Furthermore, these results indicated four possible pollutants sources, those being, vehicular plus soil resuspension, industrial, marine aerosols and the tree bark composition itself. Enrichment factors obtained for the elements determined in tree barks indicated higher concentrations in samples collected in the MRSP than those obtained in the control regions. The As, $\mathrm{Cd}, \mathrm{Co}, \mathrm{Pb}$ and $\mathrm{Zn}$ concentrations found in tree barks presented an association with the concentrations of particulate matter $\left(\mathrm{PM}_{10}\right)$ measured at the Environmental Company of the State of São Paulo (CETESB). In the following elements, Cl, Co,
\end{abstract}


$\mathrm{Mg}$ and $\mathrm{Ni}$ found in tree barks there was a correlation with mortality rates due to cardiorespiratory diseases in adults. The findings of this study indicated the viability of the use of tree barks in air pollution studies of chemical elements, especially in those regions in which there is no air pollution monitoring network system.

Keywords: Tree barks, Chemical elements, Air pollution, Biomonitoring 


\section{SUMÁRIO}

\section{Página}

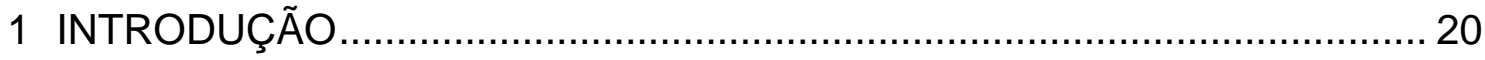

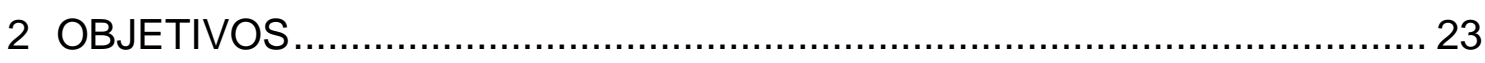

3 CONSIDERAÇÕES SOBRE A UTILIZAÇÃO DAS CASCAS DE ÁRVORE NO BIOMONITORAMENTO DA POLUIÇÃO ATMOSFÉRICA ............................. 24

3.1 Anatomia do tronco das espécies arbóreas estudadas ...................... 24

3.2 Composição elementar das cascas de árvores ............................... 25

3.3 Considerações sobre as espécies arbóreas utilizadas .......................26

3.4 Uso das cascas de árvore como biomonitores da poluição do ar de elementos químicos

3.5 Aplicações das cascas de árvores no biomonitoramento da poluição do ar 30

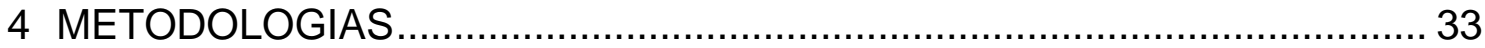

4.1 Análise por ativação com nêutrons (NAA) ….................................. 33

4.2 Espectrometria de absorção atômica com forno de grafite (GF AAS) . 36





5.2 Coleta e tratamento das amostras de cascas de árvore.................... 41

5.3 Procedimento para análise por ativação com nêutrons ...................... 42

5.3.1 Preparo dos padrões sintéticos dos elementos ................................ 42

5.3.2 Materiais de referência certificados .................................................. 43

5.3.3 Procedimento para irradiações longas ........................................... 43

5.3.4 Procedimento para irradiações curtas........................................... 45

5.4 Procedimento de análise por espectrometria de absorção atômica .... 46

5.4.1 Preparo das amostras e materiais de referência ............................... 46

5.4.2 Procedimento para determinação de $\mathrm{Cd}$, $\mathrm{Cu}$ e $\mathrm{Pb}$.............................. 47

5.5 Cálculos e tratamento dos dados obtidos ........................................49 49

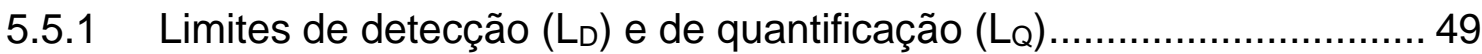

5.5.2 Diferença padronizada $-Z$ score ............................................ 50

5.5.3 Correlação de Pearson................................................................ 50

5.5 .4 Fator de Enriquecimento (FE) ........................................... 50

5.5.5 Índice de Geoacumulação (IGeo) ................................................ 52 


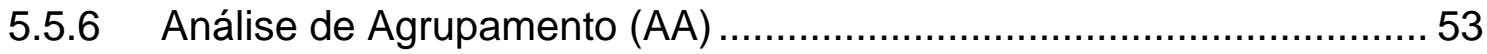

5.5.7 Análise de Componentes Principais (PCA) ...................................... 53

5.5.8 Mortalidade proporcional por grupo de causa.................................... 54

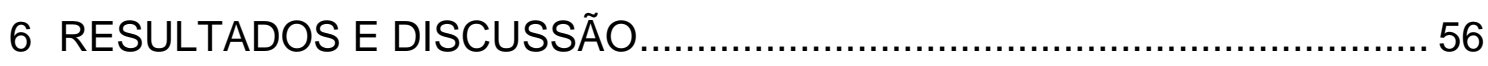

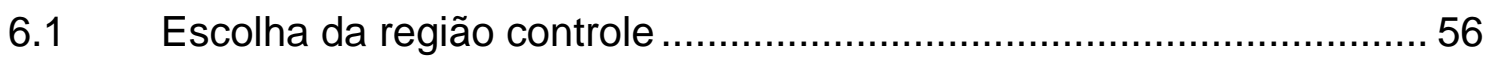

6.2 Controle de qualidade analítico dos resultados ................................. 57

6.2.1 Resultados das análises dos materiais de referência certificados ...... 57

6.3 Estabelecimento das condições para o tratamento das cascas de árvore para análise

6.3.1 Verificação da homogeneidade da amostra de casca de árvore .......... 62

6.3.2 Limite de detecção e de quantificação dos elementos na análise de cascas de árvore.

6.3.3 Concentrações dos elementos em função da espessura da casca analisada.

6.3.4 Concentrações dos elementos em cascas coletadas de diferentes faces do tronco das árvores.

6.4 Concentrações de elementos obtidos nas análises das amostras de casca de árvore

6.4.1 Comparação entre as espécies Tipuana e Sibipiruna com relação aos teores dos elementos presentes nas cascas.

6.4.2 Concentrações de elementos nas cascas de árvores de diferentes regiões de amostragem

6.4.3 Estudo da correlação das concentrações de elementos obtidos nas cascas de árvore

6.4.3.1 Correlação entre os elementos ……………................................ 78

6.4.3.2 Análise de agrupamento (AA) dos elementos .................................. 81

6.4.3.3 Análise de componentes principais (PCA) dos dados de elementos químicos.

6.4.4 Estudo da correlação entre as regiões de amostragem ..................... 84

6.4.4.1 Análise de agrupamento (AA) das regiões de amostragem ................ 85

6.4.4.2 Análise de componentes principais (PCA) das regiões de amostragem

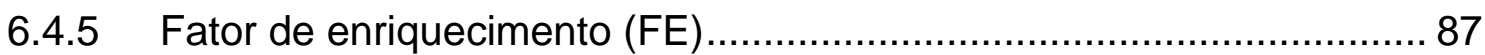


6.4.6 Índice de geoacumulação (IGeo) 89

6.4.7 Avaliação da relação entre concentrações de elementos obtidos nas cascas de árvore com as concentrações de material particulado e com dados de mortalidade.

6.4.7.1 Avaliação da relação existente entre as concentrações dos elementos das cascas de Sibipiruna e as de material particulado ( $\left.\mathrm{MP}_{10}\right)$ 90

6.4.7.2 Correlação entre as concentrações dos elementos das cascas de Sibipiruna e as taxas de mortalidade de adultos por doenças cardiorrespiratórias. 92

7 CONCLUSÕES 94

APÊNDICE A - Dados das amostras coletadas em Cerqueira César, Congonhas, Parque Dom Pedro II, Pinheiros, Santo André - Capuava, Santo André - Paço Municipal, Marília e Presidente Prudente. 98 APÊNDICE B - Localização dos pontos de amostragem das regiões Cerqueira César, Congonhas, Parque Dom Pedro II, Pinheiros, Santo André - Capuava, Santo André - Paço Municipal, São Miguel Paulista, Marília, Presidente Prudente. 103

APÊNDICE C - Concentrações dos elementos $\left(\mathrm{mg} \mathrm{kg}^{-1}\right)$ determinados nas cascas de árvore. 108 APÊNDICE D - Concentrações dos elementos determinados nas cascas de Tipuana e Sibipiruna coletadas na RMSP e regiões controle. 111 APÊNDICE E - Resultados obtidos pela análise de componentes principais (PCA) aplicada às concentrações dos elementos determinados nas cascas de Sibipiruna. 116

APÊNDICE F- Resultados obtidos pela análise de componentes principais (PCA) aplicada às concentrações médias dos elementos determinados nas diferentes regiões de amostragem para as cascas de árvore da espécie Sibipiruna.

APÊNDICE G - Relação das concentrações dos elementos determinados nas cascas de Sibipiruna e com as concentrações de material particulado grosso $\left(\mathrm{MP}_{10}\right)$. 
APÊNDICE H-Relação entre as concentrações do elementos determinados nas cascas de árvore e as taxas de mortalidade de adultos por doenças cardiorrespiratórias. 


\section{LISTA DE TABELAS}

Página

Tabela 1. Principais características das regiões de amostragem das cascas de árvore 40

Tabela 2. Dados das soluções padrão sintéticos dos elementos. 42

Tabela 3. Tempos de contagem utilizados em cada medida das amostras e padrões das irradiações longas no reator. 44

Tabela 4. Características nucleares dos radioisótopos medidos das irradiações longas no reator.

Tabela 5. Características nucleares dos radioisótopos medidos das irradiações curtas 46

Tabela 6. Parâmetros instrumentais utilizados na análise por GF AAS. 47 Tabela 7. Condições de temperatura, rampa de aquecimento, patamar e fluxo interno de argônio para cada etapa de aquecimento do forno de grafite na análise por GF AAS para as determinações de $\mathrm{Cd}$, $\mathrm{Cu}$ e $\mathrm{Pb}$ 48

Tabela 8. Valores de concentrações para obtenção das curvas de calibração para $\mathrm{Cd}, \mathrm{Cu}$ e $\mathrm{Pb}$ e seus respectivos coeficientes obtidos.

Tabela 9. Classificações da intensidade de poluição do ambiente em função dos índices de geoacumulação (IGeo) (MÜLLER, 1969). 52 Tabela 10. Concentrações dos elementos no MRC INCT-OBTL-5 Oriental Basma Tobacco Leaves determinados pelo método de NAA. 58 Tabela 11. Concentrações dos elementos nos MRCs INCT-MPH-2 Mixed Polish Herbs e CTA-VTL-2 Virginia Tobacco Leaves determinados pelo método de NAA.

Tabela 12. Concentrações dos elementos $\mathrm{Cd}$, $\mathrm{Cu}$ e $\mathrm{Pb}$ nos MRCs INCT-MPH-2 Mixed Polish Herbs e CTA-VTL-2 Virginia Tobacco Leaves determinados pelo método de AAS.

Tabela 13. Média das concentrações de elementos da análise de uma amostra de casca de árvore em triplicatas determinados por NAA e AAS.

Tabela 14. Limites de detecção, de quantificação e concentrações de elementos obtidos em cascas de árvore das espécies Tipuana e Sibipiruna por NAA...... 63 
Tabela 15. Médias, intervalo de concentrações, limites de detecção e de quantificação de elementos nas análises de cascas de Tipuana e Sibipiruna por AAS.

Tabela 16. Matriz de correlação de Pearson entre as concentrações dos elementos determinados nas cascas de Sibipiruna e Tipuana. 80 Tabela 17. Autovalores e percentual da variância explicada das componentes extraída. 82

Tabela 18. Autovalores e percentual da variância explicada das componentes extraídas a partir das médias das concentrações dos elementos presentes nas cascas de Sibipiruna.

Tabela 19. Fatores de enriquecimento (FEs) obtidos usando concentrações dos elementos nas cascas da espécie Sibipiruna coletadas nas diferentes regiões. 88

Tabela 20. Índices de geoacumulação (IGeo) dos elementos determinados em cascas da espécie Sibipiruna para diferentes pontos de amostragem 90 Tabela A. 1 - Dados das amostras de cascas de árvore coletadas em Cerqueira César e Congonhas. 98

Tabela A. 2 - Dados das amostras de cascas de árvore coletadas no Parque Dom Pedro II e em Pinheiros. 99

Tabela A. 3 - Dados das amostras de cascas de árvore coletadas em São Miguel Paulista. 100

Tabela A. 4 - Dados das amostras de cascas de árvore coletadas em Santo André - Capuava e Santo André - Paço Municipal. 101

Tabela A. 5 - Dados das amostras de cascas de árvore coletadas em Marília e Presidente Prudente. 102 Tabela C. 1 - Concentrações dos elementos $\left(\mathrm{mg} \mathrm{kg}^{-1}\right) \mathrm{As}, \mathrm{Br}, \mathrm{Ca}, \mathrm{Cd}, \mathrm{Cl}$, Co e $\mathrm{Cr}$ determinados nas cascas de árvore. 108 Tabela C. 2 - Concentrações dos elementos $\left(\mathrm{mg} \mathrm{kg}^{-1}\right) \mathrm{Cs}, \mathrm{Cu}, \mathrm{Fe}, \mathrm{K}, \mathrm{La}, \mathrm{Mg}$ e $\mathrm{Mn}$ determinados nas cascas de árvore 109 Tabela C. 3 - Concentrações dos elementos $\left(\mathrm{mg} \mathrm{kg}^{-1}\right) \mathrm{Ni}, \mathrm{Pb}, \mathrm{Rb}, \mathrm{Sb}, \mathrm{Sc}, \mathrm{V}$ e $\mathrm{Zn}$ determinados nas cascas de árvore. 
Tabela D. 1 - Concentrações médias e faixas de concentrações dos elementos em cascas de árvore coletadas nas regiões Cerqueira César e Congonhas. 111 Tabela D. 2 - Concentrações médias e respectivas faixas de concentrações de elementos em amostras de cascas de árvore coletadas nas regiões Parque Dom Pedro II e Pinheiros.

Tabela D. 3 - Concentrações médias e respectivas faixas de concentrações de elementos determinados em cascas de árvore coletadas nas regiões Santo André - Capuava e Santo André - Paço Municipal. 113 Tabela D. 4 - Concentrações médias e respectivas faixas de concentrações de elementos em cascas de árvore coletadas em São Miguel Paulista. 114 Tabela D. 5 - Concentrações médias e respectivas faixas de concentrações dos elementos em cascas de árvore coletadas em Marília e Presidente Prudente. 115

Tabela E. 1 - Matriz de correlação entre os elementos determinados nas cascas de árvore da espécie Sibipiruna e as componentes principais extraídas. 116 Tabela F. 1 - Matriz de correlação entre as regiões de amostragem e as componentes principais extraídas das médias das concentrações dos elementos em cascas de Sibipiruna.

Tabela H. 1 - Concentrações médias de elementos em cascas de Sibipiruna e taxas de mortalidade por região de amostragem. 120

Tabela H. 2 - Concentrações médias de elementos em cascas de Sibipiruna e taxas de mortalidade por região de amostragem (continuação). 121 


\section{LISTA DE FIGURAS}

Página

Figura 1. Seção transversal do tronco de uma árvore (Lepage, 1986). 24

Figura 2. Representação do acúmulo de elementos químicos nas cascas de árvore (Adaptado de Bargagli, 1998). 25

Figura 3. Foto da árvore da espécie Tipuana (a) (CASIMIRO, SD) e da árvore da espécie Sibipiruna (b) (CAMILO, 2014).

Figura 4. Foto das cascas das espécies Tipuana (a) (MARTIN, SD) e Sibipiruna presente nas dependências da Universidade de São Paulo (b) (Fonte: autora). 28

Figura 5. Representação esquemática da reação nuclear do tipo $(n, \gamma)$. 33

Figura 6. Representação esquemática dos principais componentes para espectrometria por absorção atômica por forno de grafite (GF AAS). 37

Figura 7. Localização das regiões de amostragem das cascas de árvore na RMSP e nas regiões controle.

Figura 8. Médias das concentrações mensais de $\mathrm{MP}_{10}$ obtidas nas estações de monitoramento da qualidade do ar no período de 2010 a 2016 nas regiões em estudo neste trabalho (CETESB, SD). 56

Figura 9. Valores de $Z$ score obtidos para os materiais de referência certificados INCT-MPH-2 Mixed Polish Herbs, CTA-VTL-2 Virginia Tobacco Leaves e INCTOBTL-5 Oriental Basma Tobacco Leaves analisados pelo método de NAA.... 61 Figura 10. Valores de $Z$ score obtidos para os materiais de referência certificados INCT-MPH-2 Mixed Polish Herbs, CTA-VTL-2 Virginia Tobacco Leaves analisados pelo método de AAS.

Figura 11. Gráfico das concentrações dos elementos (em $\mu \mathrm{g} \mathrm{kg}^{-1} \mathrm{e}^{*} \mathrm{mg} \mathrm{kg}^{-1}$ ) presentes na camada externa e camada interna das cascas de Sibipiruna e Tipuana. 65

Figura 12. Concentrações dos elementos $\left(\mu \mathrm{g} \mathrm{kg}^{-1} \mathrm{e}^{*} \mathrm{mg} \mathrm{kg}^{-1}\right)$ nas cascas de árvore da espécie Tipuana coletadas nas faces norte e sul do tronco. 66 Figura 13. Concentrações dos elementos (em $\mathrm{\mu g} \mathrm{kg}^{-1} \mathrm{e}^{*} \mathrm{mg} \mathrm{kg}^{-1}$ ) presentes nas cascas das espécies Sibipiruna e Tipuana nas regiões de Cerqueira César, Congonhas e Parque Dom Pedro II. 



nas cascas das espécies Sibipiruna e Tipuana nas regiões de Pinheiros, Santo André - Paço Municipal e São Miguel Paulista 68

Figura 15. Concentrações médias de $\mathrm{As}, \mathrm{Br}, \mathrm{Ca}, \mathrm{Cd}, \mathrm{Cl}, \mathrm{Co}, \mathrm{Cr}$ e Cs nas cascas de Tipuana e Sibipiruna coletadas em Cerqueira César (CC), Congonhas (CG), Parque Dom Pedro II (PDP), Pinheiros (PN), Santo André - Capuava (SAC), Santo André Paço municipal (SAP), São São Miguel Paulista (SMP), Marília (MA) e Presidente Prudente (PP). 70

Figura 16. Concentrações médias de $\mathrm{Cu}, \mathrm{Fe}, \mathrm{K}, \mathrm{La}, \mathrm{Mg}, \mathrm{Mn}, \mathrm{Ni}, \mathrm{Pb}$ nas cascas de Tipuana e Sibipiruna coletadas em Cerqueira César (CC), Congonhas (CG), Parque Dom Pedro II (PDP), Pinheiros (PN), Santo André - Capuava (SAC), Santo André Paço municipal (SAP), São Miguel Paulista (SMP), Marília (MA) e Presidente Prudente (PP).

Figura 17. Concentrações médias de Rb, Sb, Sc, V e Zn nas cascas de Tipuana e Sibipiruna coletadas em Cerqueira César (CC), Congonhas (CG), Parque Dom Pedro II (PDP), Pinheiros (PN), Santo André - Capuava (SAC), Santo André Paço municipal (SAP), São Miguel Paulista (SMP), Marília (MA) e Presidente Prudente (PP). 72

Figura 18. Dendrograma obtido pela análise de agrupamento das concentrações dos elementos obtidas pela análise das cascas de árvore das espécies Sibipiruna e Tipuana.

Figura 19. Gráfico das duas componentes principais (CP1 e CP2) da análise efetuada nos resultados de cascas de árvore. 83

Figura 20. Gráfico das duas componentes principais (CP3 e CP4) da análise efetuada nos resultados de cascas de árvore. 84

Figura 21. Dendrograma obtido na análise de agrupamento para as diferentes regiões de amostragem. 85

Figura 22. Gráfico representando as componentes principais (CP1 e CP2) e as regiões de amostragem.

Figura 23. Representação box plot das concentrações de MP10 em função da faixa de teores dos elementos $\mathrm{As}, \mathrm{Cd}, \mathrm{Co}, \mathrm{Pb}$ e $\mathrm{Zn}$ determinados nas cascas de árvore da espécie Sibipiruna. 
Figura 24. Taxas de mortalidade por doenças cardiorrespiratórias em função das concentrações médias de $\mathrm{Cl}, \mathrm{Co}, \mathrm{Mg}$ e Ni obtidas nas cascas de Sibipiruna. . 93 Figura B. 1 - Pontos de amostragem das cascas de árvores e localização da estação de monitoramento automático da CETESB na região Cerqueira César. 103

Figura B. 2 - Pontos de amostragem das cascas de árvores e localização da estação de monitoramento automático da CETESB na região Congonhas. .. 103 Figura B. 3 - Pontos de amostragem das cascas de árvores e localização da estação de monitoramento automático da CETESB na região Parque Dom Pedro II. 104

Figura B. 4 - Pontos de amostragem das cascas de árvores e localização da estação de monitoramento automático da CETESB na região Pinheiros....... 104 Figura B. 5 - Pontos de amostragem das cascas de árvores e localização da estação de monitoramento automático da CETESB na região Santo André Capuava. 105

Figura B. 6 - Pontos de amostragem das cascas de árvores e localização da estação de monitoramento automático da CETESB na região Santo André - Paço Municipal. 105

Figura B. 7 - Pontos de amostragem das cascas de árvores e localização da estação de monitoramento automático da CETESB na região São Miguel Paulista. 106

Figura B. 8 - Pontos de amostragem das cascas de árvores e localização da estação de monitoramento automático da CETESB na região Marília. 106 Figura B. 9 - Pontos de amostragem das cascas de árvores e localização da estação de monitoramento automático da CETESB na região Presidente Prudente. 107

Figura G. 1 - Representação box plot da variação na concentração de $\mathrm{MP}_{10}$ medido pelas estações de monitoramento da CETESB entre 2009 e 2016 em função das concentrações de $\mathrm{Ca}, \mathrm{Cl}, \mathrm{Cs}, \mathrm{Fe}, \mathrm{K}$ e La determinados nas cascas de árvore da espécie Sibipiruna.

Figura G. 2 - Representação box plot da variação na concentração de $\mathrm{MP}_{10}$ medido pelas estações de monitoramento da CETESB entre 2009 e 2016 em 
função das concentrações de $\mathrm{Mg}, \mathrm{Mn}, \mathrm{Rb}, \mathrm{Sb}$, Sc e V determinados nas cascas de árvore da espécie Sibipiruna. 


\section{INTRODUÇÃO}

Nas últimas décadas, diferentes métodos de avaliação da poluição atmosférica vêm sendo amplamente estudados e utilizados, uma vez que há um grande interesse de relacionar os valores confiáveis dos poluentes com os efeitos adversos à saúde e ao meio ambiente. Os padrões de qualidade do ar estabelecidos por órgãos regulamentadores são classificados com base nas concentrações de diferentes poluentes atmosféricos a fim de investigar fontes poluidoras, e contribuir para o desenvolvimento e implementação de políticas públicas para a proteção ambiental, e consequentemente da saúde humana. No estado de São Paulo, a agência responsável pelo monitoramento dos padrões de qualidade do ar é a Companhia Ambiental do Estado de São Paulo (CETESB).

Usualmente, as concentrações dos poluentes atmosféricos são medidas a partir de métodos físico-químicos instrumentais, muitas vezes envolvendo equipamentos automáticos de instalações fixas ou móveis. A CETESB utiliza redes de estações de monitoramento automático nas quais são medidos os níveis de gases poluentes ( $\mathrm{CO}, \mathrm{SO}_{2}, \mathrm{O}_{3}, \mathrm{NO}$ e $\mathrm{NO}_{2}$ ), e os materiais particulados grosso $\left(\mathrm{MP}_{10}\right)$ e fino $\left(\mathrm{MP}_{2,5}\right)$, bem como redes de monitoramento manual, onde são medidos fumaça, $\mathrm{SO}_{2}, \mathrm{MP}_{2,5} \mathrm{MP}_{10}$, partículas totais em suspensão (PTS), acetaldeído (ACETAL) e formaldeído (FORMAL) (CETESB, 2013).

A instalação e manutenção das redes de monitoramento automático envolve alto custo, além disso, as medidas fornecidas são representativas dentro de uma pequena área, no caso dos dados fornecidos pela CETESB, a agência considera que as concentrações dos poluentes medidos são representativas em um raio de $100 \mathrm{~m}$ no entorno da estação (CETESB, 2013). Entretanto, Habermann e Gouveia (2012) mostraram que as medidas de MP 10 das estações da CETESB fornecem dados representativos dentro de um raio de $250 \mathrm{~m}$. Estes dados implicam na instalação de muitas estações para que se possa monitorar amplas regiões geográficas, podendo ser uma forma inviável de para medição dos poluentes atmosféricos em regiões com poucos recursos financeiros. 
Como alternativa aos métodos instrumentais de determinação dos poluentes atmosféricos, o uso de diferentes organismos vivos que fornecem informações quantificáveis da qualidade ambiental vem sendo amplamente estudado, sendo estes organismos conhecidos como biomonitores (BARGAGLI, 1998). As análises químicas de biomonitores da poluição atmosférica como algumas espécies de plantas, líquens, musgos, briófitas e fungos não liqenizados têm se mostrado como importantes ferramentas para a avaliação da poluição do ar (PACHECO et al., 2008). Muitos estudos da poluição atmosférica foram realizados na Região Metropolitana do Estado de São Paulo (RMSP), pela análise de alguns destes biomonitores, como plantas das espécies Tradescantia pallida (AMATOLOURENCO et al., 2017; SAVÓIA et al., 2009), líquens (FUGA et al., 2008; SAIKI et al., 2014) e bromélias da espécie Tillandsia usneoides L. (AMATO-LOURENCO et al., 2016; FIGUEIREDO et al., 2007).

A utilização de cascas de árvores tem se tornado de grande interesse para o biomonitoramento da poluição atmosférica devido às suas diversas vantagens frente aos demais biomonitores como ampla disponibilidade em extensas regiões geográficas, resistência às variações ambientais, facilidade na coleta e tratamento das amostras e retenção de partículas aerossóis na superfície das cascas devido à sua porosidade estrutural. Em áreas urbanas, industriais e principalmente em áreas remotas, as cascas de árvore podem ser excelentes auxiliares em relação ao monitoramento convencional, no sentido de estabelecer e manter um sistema de monitoramento de larga escala, ou para verificar modelos de dispersão de poluentes em torno de uma variedade de pontos de estudo (BARGAGLI, 1995).

Recentemente as cascas de árvore têm se tornado destaque nos estudos da poluição atmosférica na RMSP por meio da determinação de elementos químicos em cascas de árvore e suas correlações com diferentes níveis de tráfego veicular (MOREIRA et al., 2016), com dados de mortalidade por doenças respiratórias (CARVALHO-OLIVEIRA et al., 2017) e com os efeitos genotóxicos em plantas (AMATO-LOURENCO et al., 2017).

Dando continuidade aos estudos do biomonitoramento da RMSP utilizando cascas de árvore, decidiu-se utilizar cascas de duas espécies 
amplamente utilizadas na arborização da cidade de São Paulo, Sibipiruna (Poincianella pluviosa) e Tipuana (Tipuana tipu).

A RMSP é composta por 39 municípios habitados por aproximadamente 22 milhões de pessoas (IBGE, 2016) e centraliza importantes centros comerciais, industriais e financeiros, além disso, detém a maior frota de veículos do país, com aproximadamente 12 milhões de unidades (SEADE, 2014). Este conjunto de fatores favorece uma maior exposição da população aos poluentes atmosféricos.

A avaliação contínua da poluição atmosférica da RMSP é feita por 30 estações de monitoramento automático espalhadas pela metrópole, entretanto, suas medidas não caracterizam o material particulado quanto à composição de elementos químicos. Visto que a RMSP apresenta perfil de poluição bastante complexo com emissões atmosféricas características, julgou-se de grande importância utilizar como biomonitor cascas de árvores para identificar as regiões quanto suas principais fontes de emissões bem como correlacionar com os dados de $\mathrm{MP}_{10}$ medidos pela CETESB. As concentrações de elementos em cascas de árvore obtidas foram também utilizadas para o estudo da correlação com dados de mortalidade por doenças cardiorrespiratórias.

Os dados obtidos neste trabalho são de grande importância no sentido de utilizar cascas de árvore para a identificação de fontes poluidoras bem como para verificar se há correlações com dados de monitoramento automático e mortalidade por doenças cardiorrespiratórias. 


\section{OBJETIVOS}

O objetivo geral desta pesquisa foi utilizar cascas de árvore como biomonitores da poluição atmosférica de elementos químicos a fim de identificar as regiões da RMSP quanto às suas principais fontes de emissões e verificar se há uma correlação entre as concentrações dos elementos determinados nas cascas com as concentrações de material particulado $\left(\mathrm{MP}_{10}\right)$ medidos pela CETESB e com as taxas de mortalidade por doenças cardiorrespiratórias.

Para atingir este objetivo, foi proposta a realização das seguintes atividades:

- estabelecimento das condições de coleta e tratamento da amostra de casca de árvore;

- definição as regiões de amostragem;

- determinação das concentrações dos elementos químicos das cascas de árvore;

- avaliação da qualidade dos resultados analíticos obtidos;

- avaliação da distribuição dos elementos químicos nas regiões de amostragem;

- identificação das possíveis fontes de emissão dos poluentes;

- comparação das concentrações de elementos entre as regiões de amostragem;

- estudo da correlação entre os resultados das cascas de árvores com as concentrações de $\mathrm{MP}_{10}$ medidos pelas estações de monitoramento automático da CETESB e com os dados de mortalidade por doenças cardiorrespiratórias em pessoas adultas. 


\section{CONSIDERAÇÕES SOBRE A UTILIZAÇÃO DAS CASCAS DE ÁRVORE NO BIOMONITORAMENTO DA POLUIÇÃO ATMOSFÉRICA}

\subsection{Anatomia do tronco das espécies arbóreas estudadas}

A composição elementar das cascas de árvores depende, além dos fatores ambientais, da estrutura das cascas, influenciando na deposição e retenção das partículas aerossóis.

Na Figura 1 é apresentada uma representação esquemática da seção transversal do tronco de uma árvore (LEPAGE, 1986). A casca de árvore apresenta duas diferentes estruturas, composta por uma parte interna chamada de floema onde ocorre o fluxo de nutrientes e outra parte externa chamada de ritidoma, sendo esta composta por tecido sem atividade metabólica. Para o presente estudo, a parte externa da casca foi utilizada para coleta das amostras. Devido à falta de atividade metabólica do ritidoma, pode-se considerar a utilização desta região da casca como um amostrador passivo de poluentes atmosféricos.



Figura 1. Seção transversal do tronco de uma árvore (LEPAGE, 1986). 


\subsection{Composição elementar das cascas de árvores}

As cascas de árvore são praticamente inertes na presença de substâncias orgânicas e inorgânicas acumuladas devido a sua porosidade estrutural o que potencializa o acumulo de partículas de aerossóis, fazendo com que sejam um material adequado para o monitoramento de poluição atmosférica.

A composição elementar da casca de árvore é influenciada por diferentes fatores, incluindo deposição seca por impacto das partículas aerossóis com a superfície da casca, deposição úmida, transporte de poluentes interceptados pela copa e pela captação de elementos via nutrição (BERLIZOV et al., 2007). Os elementos nas cascas de árvore também podem ser removidos via lixiviação pela água da chuva ou pela repulsão das partículas com a superfície da casca. Na Figura 2, está apresentada uma representação esquemática das possíveis entradas e saídas dos elementos presentes nas cascas de árvore. De acordo com Catinon et al. (2012), o depósito na superfície da casca não deve ser considerado como um simples arquivo cumulativo, mas uma fonte de informações que visa principalmente as recentes medidas da poluição atmosférica.

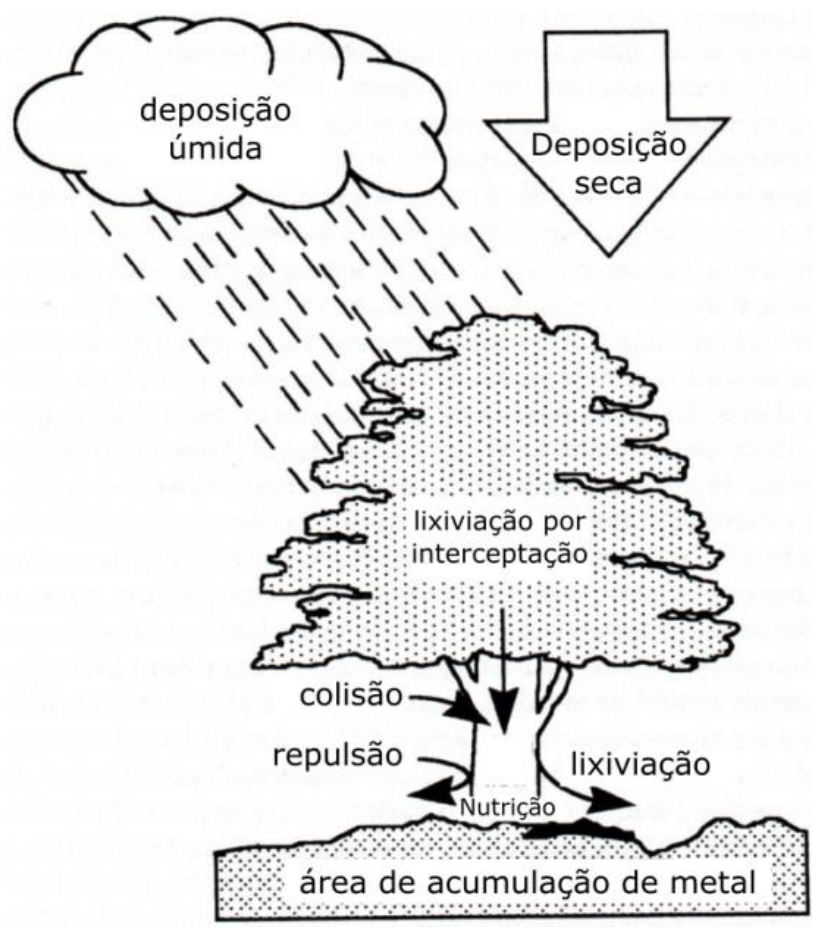

Figura 2. Representação do acúmulo de elementos químicos nas cascas de árvore (Adaptado de Bargagli, 1998). 
Nos trabalhos recentes tem sido investigada a contribuição do solo na composição das cascas de árvores. Na pesquisa feita por Alahabadi et al. (2017), foi estudada a capacidade de bioacumulação entre diferentes espécies arbóreas por meio da determinação de $\mathrm{Cd}, \mathrm{Cu}, \mathrm{Pb}$ e $\mathrm{Zn}$ no solo e nas folhas. Neste trabalho, os autores observaram que as concentrações dos elementos nas cascas foram mais altas em relação às nas folhas devido ao maior tempo de exposição e a porosidade das cascas. Além disso, as concentrações dos elementos nas diferentes partes das plantas variaram com a concentração do elemento no solo, no ar e entre as espécies arbóreas. Algumas árvores apresentaram maior retenção de elementos provenientes do solo e outras acumularam mais elementos de origem atmosférica. Também foi observado neste trabalho, que as concentrações de $\mathrm{Pb}$ presente na composição da árvore são provenientes em maior parte da atmosfera por deposição e sua translocação das raízes para as folhas não foi o caminho predominante para o acumulo deste elemento.

No estudo de Bing et al. (2016) foram determinadas as concentrações de $\mathrm{Cd}, \mathrm{Cr}, \mathrm{Cu}, \mathrm{Ni}, \mathrm{Pb}$ e $\mathrm{Zn}$ e as razões isotópicas de $\mathrm{Pb}\left({ }^{206} \mathrm{~Pb} /{ }^{207} \mathrm{~Pb}\right.$ e $\left.{ }^{208} \mathrm{~Pb} /{ }^{206} \mathrm{~Pb}\right)$ nas folhas, galhos, cascas, raízes de diferentes espécies arbóreas do planalto tibetano glacial e foram calculados os fatores de bioacumulação e bioconcentração. Os resultados obtidos indicaram que o acúmulo de $\mathrm{Cd}, \mathrm{Pb}$ e $\mathrm{Zn}$ nas árvores era proveniente de fronte antrópica e o acúmulo de $\mathrm{Cr}$, Cu e Ni era da absorção das árvores pelas raízes. Além disso, foi observado que a retenção dos elementos químicos varia com a espécie, o tecido e idade das árvores.

Pouco ainda se sabe sobre o peso da contribuição do solo na composição das cascas de árvore em relação ao do material particulado atmosférico. Entretanto, a ausência de processos metabólicos nas cascas de árvores propicia para o menor acúmulo de elementos químicos provenientes do solo (CHIARANTINI et al., 2016; YUAN et al., 2016).

\subsection{Considerações sobre as espécies arbóreas utilizadas}

Neste trabalho as árvores estudadas são de duas espécies frequentemente utilizadas na arborização urbana da cidade de São Paulo, a Tipuana (Tipuana tipu) e a Sibipiruna (Poincianella pluviosa), cujas suas imagens são apresentadas na Figura 3 (a) e 2 (b), respectivamente. 
A Sibipiruna é frequentemente utilizada em áreas urbanas como espécie ornamental e além disso apresenta potencial madeireiro. É uma espécie nativa mas não endêmica do Brasil podendo ser encontrada nos estados do Pará, Mato Grosso, Mato Grosso do Sul, Paraíba, Pernambuco, Bahia, Minas Gerais, Espírito Santo, Rio de Janeiro e Paraná (LEWIS, 2015). Seu porte pode varia entre 8 e 16 metros de altura com copa arredondada de aproximadamente 15 metros de diâmetro (CAMILO, 2014).

A Tipuana é uma árvore nativa da Argentina e Bolívia e foi introduzida em vários outros países como uma espécie ornamental sendo mais comum no sul do Brasil. Seu porte pode atingir até 25 metros de altura, com copa larga de até 20 metros de diâmetro (SILVA et al., 2008).

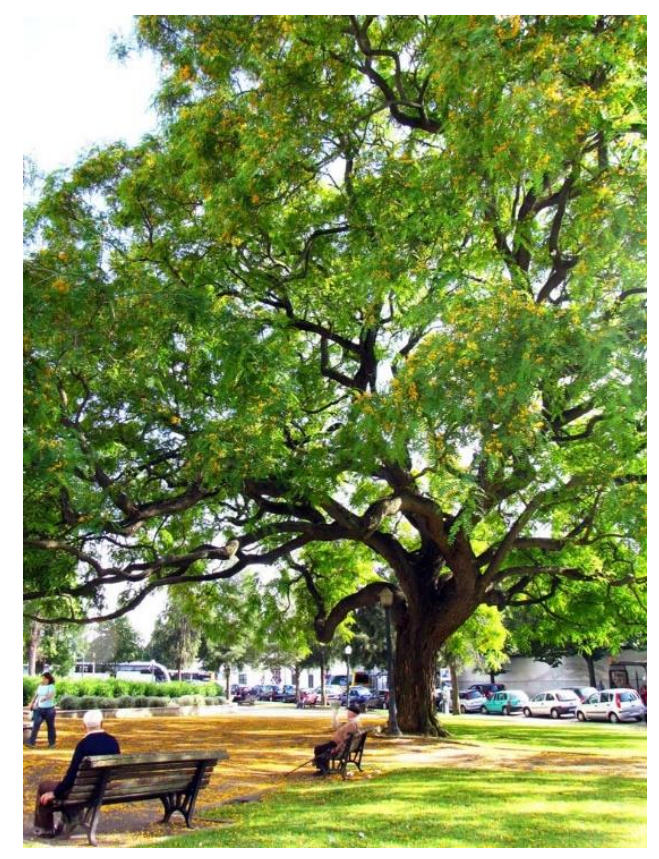

a.

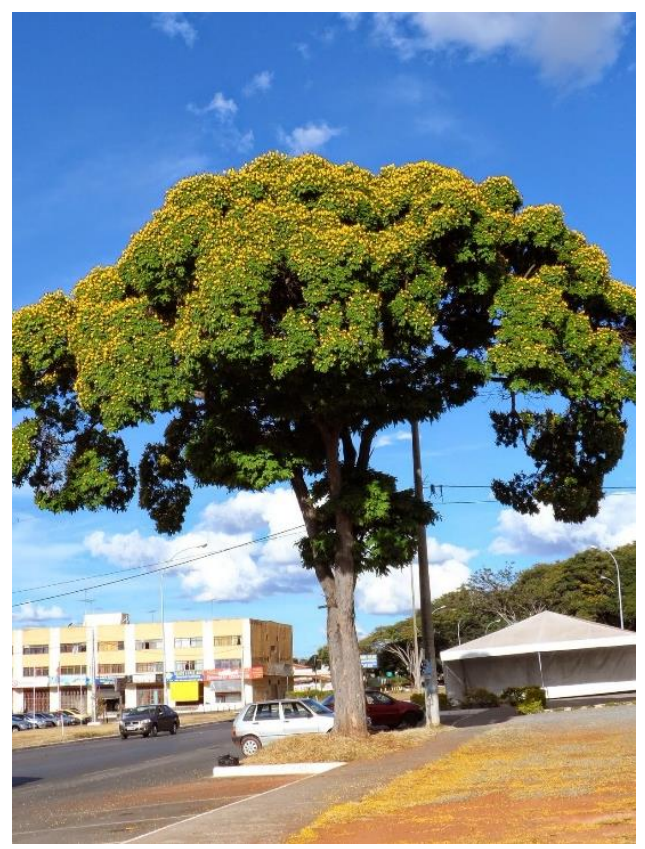

b.

Figura 3. Foto da árvore da espécie Tipuana (a) (CASIMIRO, SD) e da árvore da espécie Sibipiruna (b) (CAMILO, 2014).

As texturas das cascas das duas espécies estudadas são bastante distintas. As cascas de Tipuana apresentam textura rugosa e fissurada Figura 4 (a)), e as cascas de Sibipiruna são lisas, apresentam-se na superfície do tronco na forma de placas (Figura 4 (b)). 


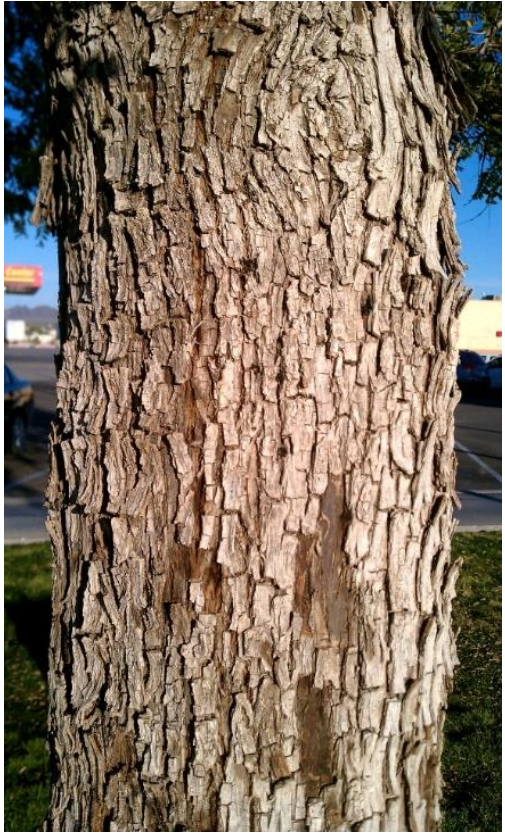

a.

Figura 4. Foto das cascas das espécies Tipuana (a) (MARTIN, SD) e Sibipiruna presente nas dependências da Universidade de São Paulo (b) (Fonte: autora).

A ampla disponibilidade destas espécies arbóreas em áreas urbanas, em especial na RMSP, favorece sua utilização para o biomonitoramento da poluição atmosférica nesta região.

\subsection{Uso das cascas de árvore como biomonitores da poluição do ar de elementos químicos}

A determinação de elementos químicos em cascas de árvores tem sido uma das técnicas mais utilizada, nos últimos anos, para o biomonitoramento da poluição atmosférica, e isto pode estar relacionado às vantagens das cascas em relação à outros tipos de organismos. No caso das cascas de árvores as partículas de aerossóis são facilmente retidas na superfície das cascas

Os aerossóis são partículas em suspensão que podem ser sólidas ou líquidas, formadas por uma mistura de partículas de origem primária ou secundária. As de origem primária são aquelas emitidas diretamente pelas fontes, sejam elas fontes naturais (erupções vulcânicas, incêndios em florestas, pólen, aerossol marinho) ou antrópicas (emissão veicular, industrial, queima de biomassa), 
enquanto que as secundárias não são emitidas diretamente, mas formam-se a partir da transformação dos gases e vapores em partículas (CETESB, 2008).

As partículas constituintes dos aerossóis, também chamadas de material particulado (MP) são classificadas quanto ao seu tamanho. O material particulado grosso, $\left(\mathrm{MP}_{10}\right)$ é aquele que apresenta diâmetro maior que $10 \mu \mathrm{m}$, e o material particulado fino $\left(\mathrm{MP}_{2,5}\right)$ é aquele formado de partículas com diâmetro menor que 2,5 $\mu \mathrm{m}$. Uma vez que a composição química dos MPs varia de acordo com suas origens de formação, relacionar a composição elementar das cascas de árvore com a poluição do ar de elementos químicos tem sido considerado bastante válido.

As análises dos MPs são de grande interesse para avaliação de seus efeitos do ponto de vista da saúde humana, uma vez que as suas partículas são facilmente inaláveis e podem causar diversos danos ao sistema cardiorrespiratório. Segundo a Organização Mundial da Saúde a mortalidade diária ocasionada por todos os diferentes grupos de doenças aumenta de 0,2 a 0,6\% para cada aumento de $10 \mu \mathrm{g} \mathrm{MP}_{10} / \mathrm{m}^{3}$ e a exposição a um longo prazo ao $\mathrm{MP}_{2,5}$ está associada a um aumento do risco de mortalidade cardiopulmonar de 6 a 13\% a cada incremento de $10 \mu \mathrm{g} \mathrm{MP}{ }_{2,5} / \mathrm{m}^{3}$ (WHO, 2013).

Desta maneira as investigações sobre os efeitos dos MPs na saúde humana têm sido objeto de inúmeras pesquisas. No trabalho de Rich et al. (2013) foi estudada a correlação entre o número de indivíduos que tiveram altas hospitalares com diagnóstico primário de infarto agudo do miocárdio com as concentrações de $\mathrm{MP}_{2,5}$ fornecidos pela Qualidade do Ar Multi-escala (Community Multiscale Air Quality) da Agência de Proteção Ambiental dos Estados Unidos. Seus resultados obtidos também indicaram elevada probabilidade de as pessoas sofrerem infarto do miocárdio nos dias de maior formação de $\mathrm{MP}_{2,5}$ secundário na atmosfera.

O trabalho de Habermann e Gouveia (2012) consistiu no estudo da correlação entre a densidade de vias e volume de tráfego veicular com os dados de mortalidade por doenças do aparelho respiratório em homens maiores que 40 anos no município de São Paulo. Os dados de mortalidade utilizados para a realização deste estudo foram coletados do sistema do Programa de Aprimoramento de Informações de Mortalidade do Município de São Paulo (PROAIM) e os dados da densidade de vias e volume de tráfego veicular pela 
Companhia de Engenharia de Tráfego do município de São Paulo (CET). Os resultados obtidos neste trabalho mostraram forte associação entre a mortalidade por doenças do aparelho circulatório e a densidade de vias.

Outro estudo realizado com indivíduos do sexo feminino com idades entre 30 e 55 anos, foi sobre a relação existente entre a incidência de câncer pulmonar com a exposição à material particulado e com a distância de suas residências das vias de tráfego veicular (PUETT et al., 2014).

Trabalhos recentes têm também mostrado que há uma relação entre as concentrações dos elementos determinados em cascas de árvores e os efeitos adversos à saúde. Dentre estes trabalhos destaca-se o de Carvalho-Oliveira et al. (2017), que verificaram a correlação existente entre as concentrações de elementos das cascas e as taxas de mortalidade por doença respiratórias. Além disso, os resultados correlacionaram com os efeitos genotóxicos em flores da espécie Bauhinia sp.

Amato-Lourenco et al. (2017) verificaram a correlação existente entre as concentrações de elementos químicos determinados em cascas de árvores coletadas na RMSP com os efeitos genotóxicos em células de plantas da espécie Tradescantia pallida.

Para estabelecer meios para reduzir a exposição das populações à poluição atmosférica, é essencial identificar as fontes de origem dos poluentes e das atividades que contribuem para aumento de seus níveis. Desta maneira, o conhecimento da composição de elementos químicos do material particulado retido em cascas de árvores é uma importante ferramenta para identificar as diferentes fontes poluidoras.

\subsection{Aplicações das cascas de árvores no biomonitoramento da poluição do ar}

O estudo da poluição atmosférica utilizando cascas de árvore vem sendo feito não só pela análise das concentrações dos elementos presentes nas cascas, mas também pela análise de compostos orgânicos (ODABASI et al., 2015; YUAN, et al., 2016; ZHAO et al., 2008) e das concentrações de radionuclídeos (BELIVERMIS et al., 2010; KILIC, 2012; PATRICK e FARMER, 2007). 
Relativamente a determinação de elementos nas cascas de árvores temse o trabalho de Berlizov et al. (2007) que utilizando o método de análise por ativação com nêutrons, verificaram a possibilidade de usar cascas de álamo como biomonitor da poluição atmosférica para metais potencialmente tóxicos. Os seus resultados obtidos em cascas de árvores foram comparados com os de líquens usado como indicador. A capacidade de acumulo de elementos na casca de álamo foi concordante às obtidas em líquens. Resultados similares foram também obtidos por Pacheco et al. (2001), que aplicaram o método de ativação com nêutrons nas análises das cascas de árvore e verificaram uma boa correlação entre as concentrações de elementos presentes nas cascas e nos líquens.

Guéguen et al. (2011) estudaram o impacto das emissões industriais e das estradas em ambiente urbano determinando compostos orgânicos em cascas de árvore. As cascas foram coletadas entre as cidades de Estrasburgo (França) e Kehl (Alemanha) localizadas no Vale do Rio Reno. Foi verificado que o tempo de residência dos difenil policlorados e dos elementos traço nas cascas de árvores foi maior que 10 anos, sendo que a presença dos dibenzo-p-dixinas e dibenzofurano policlorados foram maior próximo às áreas industrializadas. Em outro trabalho de Géguen et al. (2012) sobe a determinação de elementos químicos em cascas de árvore de uma mesma região, foram obtidos teores mais elevados de $\mathrm{V}, \mathrm{Ni}, \mathrm{Cr}, \mathrm{Sb}$, $\mathrm{Sn}$ e $\mathrm{Pb}$ em cascas de árvores localizadas próximo às vias de tráfego, e em torno de indústrias foram verificadas altas concentrações de $\mathrm{Cr}$, Mo e Cd.

No trabalho de Cucu-Man e Steinnes (2013) foi investigado sobre as concentrações de metais potencialmente tóxicos em musgos e cascas de carvalho na Romênia Oriental. Os musgos foram coletados do mesmo lado do tronco onde foram coletadas as cascas e os seus resultados indicaram transporte a longa distância dos elementos $\mathrm{Zn}, \mathrm{Cd}, \mathrm{Pb}, \mathrm{Bi}$, Mo e Tl. Para os elementos As, Cr, Ni e V as suas origens foram associadas às emissões de indústrias da região, a relação entre $\mathrm{Pb}$ e $\mathrm{Zn}$ ao tráfego rodoviário e entre $\mathrm{Cu}$ e $\mathrm{Zn}$ associados às atividades agrícolas. Os resultados obtidos para as cascas e para os musgos apresentaram variações de mesma magnitude, sendo que para a maioria dos elementos as concentrações mais elevadas foram obtidas para as amostras de musgos. Além disso, os seus resultados indicaram significante correlação entre as concentrações de elementos presentes nas cascas e nos musgos. 
Santamaría e Martín (1997) analisaram cascas de árvores de diferentes pontos das áreas arborizadas da província de Navarra no norte da Espanha e verificaram que o aumento da acidez das cascas coincidia com a localização de importantes fontes poluidoras de sua rota de transporte e dispersão. Nas cascas de carvalho da espécie Quercus ilex foi verificada significante correlação entre a acidez e o nível de dano ocasionado nas folhagens das árvores.

Com relação ao estudo da variação temporal da composição das cascas de árvores, Schulz et al. (1999) verificaram redução nas concentrações de sulfato, nitrato, cálcio, benzo[a]pireno e alfa-hexa-clorociclohexano em cascas a partir do ano de 1991 no oeste da Alemanha. A redução na emissão de compostos ácidos também foi observada por Suchara (2012) medindo as concentrações de $\mathrm{H}^{+}$em extratos obtidos de cascas de árvores, e seus resultados mostraram que há uma relação entre as variações nas emissões veiculares com as deposições nas cascas de árvore.

As considerações sobre a utilização de cascas de árvores apresentadas neste capítulo mostraram que cada vez mais as cascas de árvores vêm sendo analisadas e utilizadas como biomonitores da poluição atmosférica de forma diversificada. Além disso, a análise de cascas de árvore indicam ser uma ferramenta bastante útil para avaliar a poluição do ar, principalmente onde não há rede de monitoramento automático. 


\section{METODOLOGIAS}

\subsection{Análise por ativação com nêutrons (NAA)}

A análise por ativação com nêutrons é um método para análise qualitativa e quantitativa de elementos químicos baseado na medida da radioatividade que é induzida aos elementos da amostra resultante da sua irradiação com nêutrons.

No procedimento de NAA a amostra é bombardeada por nêutrons em um reator nuclear e neste processo os núcleos dos átomos constituintes da amostra sofrem uma reação de captura neutrônica do tipo $(\mathrm{n}, \gamma)$ cuja representação esquemática é apresentada na Figura 5. O núcleo alvo $\left({ }_{\mathrm{Z}}^{\mathrm{A}} \mathrm{X}\right)$ interage com os nêutrons incididos por meio de uma colisão inelástica tornando-se um núcleo composto $\left({ }_{Z}^{\mathrm{A}+1} \mathrm{X}^{*}\right)$ altamente instável que emite quase que instantaneamente raios gama "pronto" para formar um núcleo radioativo $\left({ }_{\mathrm{Z}}^{\mathrm{A}+1} \mathrm{X}\right)$ de configuração mais estável. Este núcleo radioativo frequentemente emite partículas beta menos $\left(\beta^{-}\right)$ formando um novo nuclídeo $\left({ }_{\mathrm{Z}+1}^{\mathrm{A}+1} \mathrm{Y}^{\star}\right)$ que também sofre desexcitação com a emissão de um ou mais raios gama de decaimento característicos.

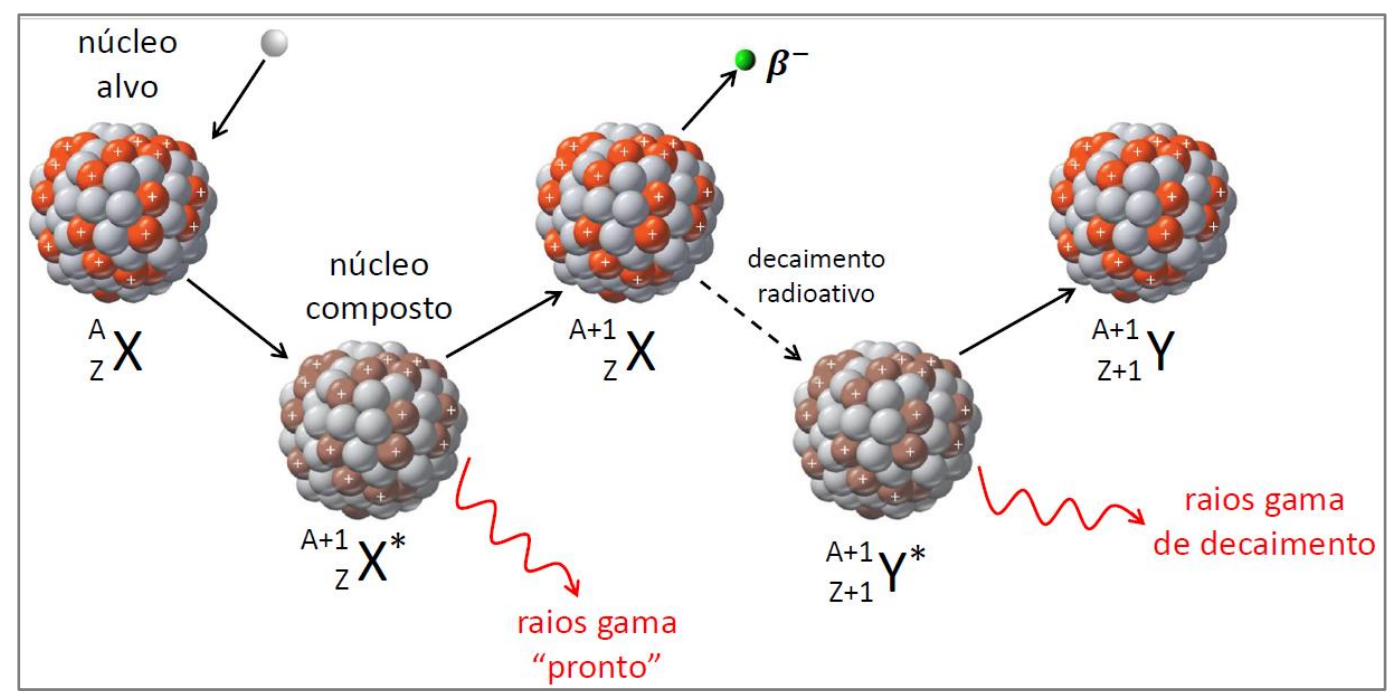

Figura 5. Representação esquemática da reação nuclear do tipo $(n, \gamma)$. 
Os raios gama de decaimento são medidos no método de NAA e a partir de sua detecção é possível fazer uma análise qualitativa e quantitativa dos elementos presentes na amostra.

A atividade gama induzida a um elemento após certo tempo de irradiação é dada pela relação (1) (DE SOETE et al., 1972).

$$
A=\left\{\epsilon \phi \sigma N m f\left[1-e^{-0,693 t / t / 1 / 2}\right]\right\} /[M]
$$

em que $A=$ atividade $; \epsilon=$ coeficiente de detecção ou eficiência do detector; $\phi=$ fluxo de nêutrons, em $\mathrm{n} \mathrm{cm}^{-2} \mathrm{~s}^{-1} ; \sigma=$ secção de choque em $\mathrm{cm}^{2} ; \mathrm{N}=$ constante de Avogadro; $m=$ massa do elemento; $f=$ abundância isotópica do nuclídeo alvo; $\mathrm{M}$ = massa atômica do elemento; $\mathrm{t}_{\mathrm{i}}=$ tempo de irradiação; $\mathrm{t}_{1 / 2}=$ tempo de meia-vida do radionuclídeo considerado.

A massa $m$ da relação (1) pode ser obtida desde que todos os seus parâmetros nucleares (meia vida, massa atômica, abundância isotópica, secção de choque de nêutrons, intensidade de raios gama, etc.) sejam conhecidos. Para evitar o uso destes parâmetros, que nem sempre são disponíveis com uma boa exatidão, é frequente o uso do método comparativo, onde as amostras são irradiadas simultaneamente com os padrões dos elementos a serem determinados e após a irradiação, são medidos na mesma geometria.

Escrevendo a relação (1), para um mesmo elemento da amostra e do padrão, que foram irradiados e medidos na mesma geometria, pode-se obter as seguintes relações para as atividades para tempo de decaimento $t=0$, isto é, no final da irradiação:

$$
\begin{aligned}
& A_{a, 0}=\left\{\epsilon \phi \sigma N m_{a} f\left[1-e^{-0,693 t / / t / 2}\right]\right\} /\{M\} \\
& A_{p, 0}=\left\{\epsilon \phi \sigma N m_{P} f\left[1-e^{-0,693 t / / t / 2}\right]\right\} /\{M\}
\end{aligned}
$$

em que os índices a e p se referem a amostra e padrão, respectivamente. Dividindo-se a relação (2) por (3), e para o tempo de decaimento $\mathrm{t}=\mathrm{t}_{0}=0$, tem-se:

$$
A_{a, 0} / A_{p, 0}=m_{a} / m_{p}
$$


Nesta relação (4) $A_{a, 0}$ e $A_{p, 0}$ são os valores das atividades em taxas de contagens da amostra e padrão medidos para um mesmo tempo de decaimento. Sendo na prática, a amostra e padrão são medidos para diferentes tempos de decaimento, $t_{d a}$ e $t_{d p}$, respectivamente, aplica-se a relação da lei de decaimento radioativo para a correção do tempo de decaimento.

Pela lei de decaimento radioativo tem-se (FRIEDLANDER et al., 1981):

$$
A=A_{0} e^{-0,693 t d / t 1 / 2}
$$

$\mathrm{Na}$ relação (5) A e $\mathrm{A}_{0}$ são as taxas de contagens para tempos de decaimento $t_{d}$ e $t=0$, respectivamente. Escrevendo a relação (5) para amostra e padrão tem se:

$$
A_{a}=A_{0 a} e^{-0,693 \text { tda/t1/2 }}
$$

$$
A_{p}=A_{0 p} e^{-0,693 t d p / t 1 / 2}
$$

Substituindo as equações (6) e (7) na equação (4), tem-se:

$$
m_{a}=\left[m_{p} \cdot A_{a} \cdot e^{-0,693(t d p) / t 1 / 2}\right] /\left[A_{p} e^{-0,693(t d a) / t 1 / 2}\right]
$$

em que a concentração do elemento na amostra $C_{a}=m_{a} / M_{a}$, tem-se

$$
C_{a}=\left[m_{p} \cdot A_{a} \cdot e^{-0,693(t d p) / t 1 / 2}\right] /\left[M_{a} A_{p} e^{-0,693(t d a) / t 1 / 2}\right]
$$

ou

$$
C_{a}=\left[m_{p} \cdot A_{a} \cdot e^{0,693(t d a-t d p) / t 1 / 2}\right] /\left[M_{a} A_{p}\right]
$$

sendo os índices a e p se referem a amostra e padrão, respectivamente; $\mathrm{M}_{\mathrm{a}}=$ massa total de amostra;

$\mathrm{m}_{\mathrm{p}}=$ massa do elemento no padrão;

$\mathrm{C}_{\mathrm{a}}=$ concentração do elemento na amostra;

$\mathrm{t}_{1 / 2}=$ meia vida do radioisótopo considerado;

$\mathrm{td}=$ tempo de decaimento.

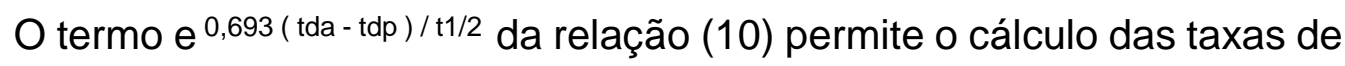
contagens da amostra e do padrão para o mesmo tempo de decaimento. 


\subsection{Espectrometria de absorção atômica com forno de grafite (GF AAS)}

A espectrometria de absorção atômica (AAS) é uma técnica analítica para a determinação quantitativa de elementos químicos, empregando a absorção de radiação óptica de átomos livres no estado gasoso (WELZ e SPERLING, 1999).

O princípio básico da análise por AAS consiste em incidir um feixe de luz de comprimento de onda específico em uma amostra que deve estar no estado gasoso com seus átomos livres e relacionar a intensidade de energia incidente (energia inicial) na amostra com a energia detectada após percorrer a amostra (energia final). Dado uma vez que somente um elemento é capaz de absorver a energia correspondente à faixa de comprimento de onda da luz incidida e a quantidade de energia absorvida sendo proporcional à concentração do elemento presente no caminho óptico, é possível quantificar o elemento de interesse (BEATY e KERBER, 1993).

A representação esquemática da instrumentação para GF AAS é apresentada na Figura 6, sendo composta por:

- fonte de luz: emite o comprimento de onda específico de absorção do elemento de interesse, sendo a lâmpada de catodo oco a fonte de luz mais comumente utilizada. Para a análise de um elemento em particular existe uma lâmpada específica.

- atomizador: fonte de energia para a produção de átomos livres da amostra, podendo ser chama ou forno de grafite, sendo as chamadas espectrometria de absorção atômica por chama (FAAS) e espectrometria de absorção atômica por forno de grafite (GF AAS).

- monocromador: isola o comprimento de onda analítico específico da luz emitida pela lâmpada de catodo oco das linhas não analíticas.

- detector: componente sensível à luz que mede a luz recebida com precisão, usualmente um tubo fotomultiplicador.

- eletrônica: dispositivos adequados que medem a resposta do detector e traduzem em medidas analíticas. 


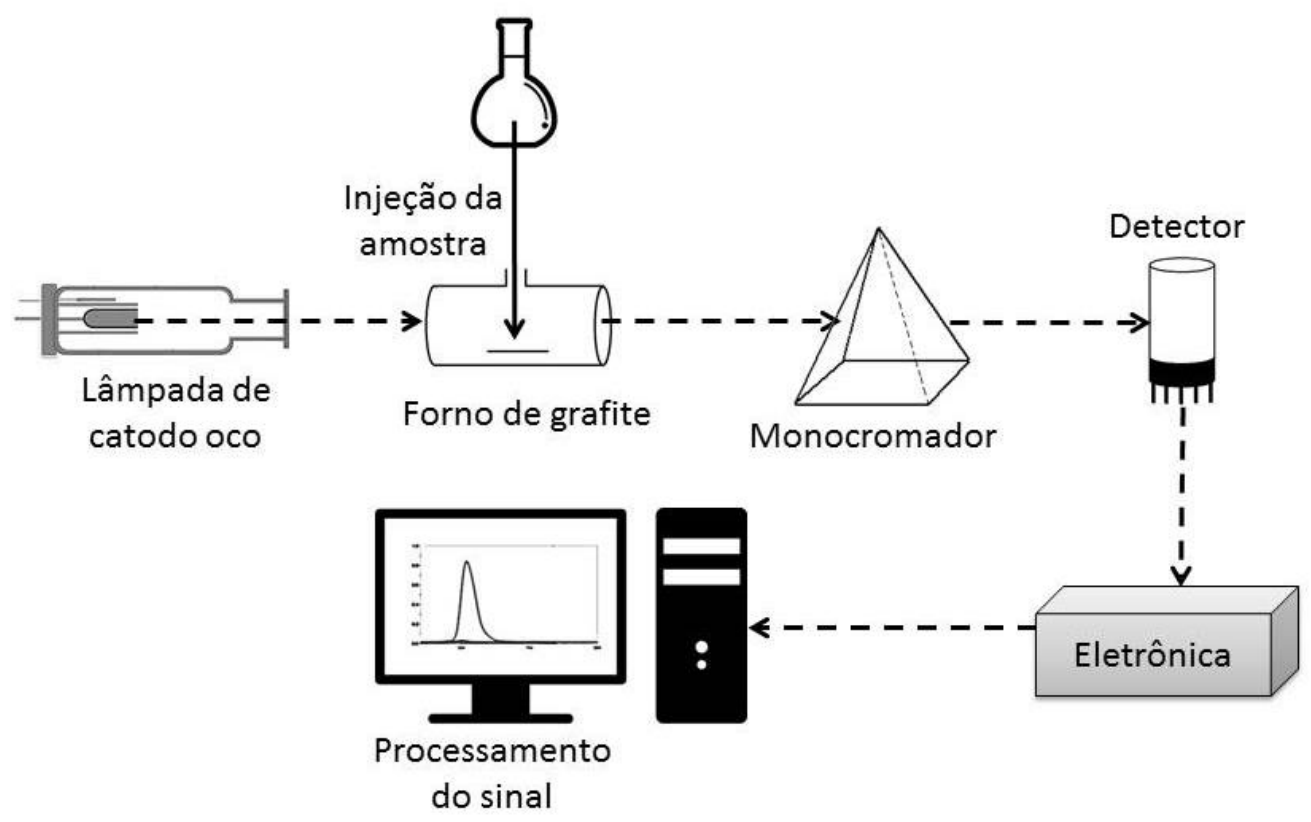

Figura 6. Representação esquemática dos principais componentes para espectrometria por absorção atômica por forno de grafite (GF AAS).

A fração de energia que atinge o detector após ter saído da fonte de luz e atravessado o caminho óptico é chamada de transmitância ( $T$ ) e é dada pela razão entre a intensidade de energia final (I), e inicial (Io). A transmitância percentual (\%T) é dada por (BEATY e KERBER, 1993):

$$
\% \mathrm{~T}=100 \times \mathrm{I} / \mathrm{I}_{0}
$$

A absorção percentual (\%A) é o complemento da porcentagem de transmissão, como indicado na relação (12). Ela define a porcentagem de absorção da intensidade de luz incidente.

$$
\% A=100-\% T
$$

A representação matemática da absorbância (A) é dada pela relação (13).

$$
A=\log \left(1 / l_{0}\right)
$$

A absorbância é a forma mais conveniente para caracterizar a absorção de luz em AAS. A relação entre a absorbância medida e a concentração do elemento presente na amostra é diretamente proporcional e segue a lei de LambertBeer: 


$$
A=a b c
$$

sendo:

A = absorbância;

$a$ = coeficiente de absorção (constante característica da substância absorvedora em um comprimento de onda específico);

$\mathrm{b}=$ caminho óptico no qual a luz percorre através da amostra dentro da célula de absorção;

c = concentração da substância absorvedora.

A lei de Lambert-Beer mostra que a relação entre absorbância e concentração do analito é linear e isto pode ser observado quando plotado um gráfico de absorbância em função da concentração. Uma vez medidas as absorbâncias de soluções padrões de diferentes concentrações conhecidas, podese obter uma curva de calibração do elemento a ser quantificado Com ela é possível calcular a concentração de analito em amostras a partir das medidas de absorbância da amostra por AAS.

Vale ressaltar que para soluções com altas concentrações de analito ocorre desvios da lei de Lambert-Beer, desta maneira deve-se estudar previamente a melhor faixa de concentração a qual deve ser construída a curva de calibração (HOLLER et al., 2007). 


\section{PARTE EXPERIMENTAL}

\subsection{Escolha das regiões de amostragem}

A escolha dos pontos de amostragem das regiões foi baseada na disponibilidade das espécies arbóreas Tipuana e Sibipiruna localizados em um raio de $500 \mathrm{~m}$ de distância das estações de monitoramento da qualidade do ar da CETESB dentro da RMSP. Além disso, as regiões de amostragem escolhidas foram aquelas nas quais as estações de monitoramento medem concentrações de material particulado grosso $\left(\mathrm{MP}_{10}\right)$ para posteriormente efetuar o estudo da correlação com as concentrações dos elementos das cascas de árvore.

O sistema de consulta da qualidade do ar-Qualar (CETESB, SD) foi utilizado para consulta da localização das estações e de suas respectivas medidas de material particulado. O levantamento preliminar da disponibilidade das espécies arbóreas foi feito utilizando o recurso "street view" disponível no Google Maps (https://www.google.com.br/maps) de modo a se fazer a identificação prévia das árvores existente em cada região e o registro das coordenadas geográficas dos pontos de amostragem.

Com base nestes critérios, foram escolhidas 5 regiões de amostragem dentro do município de São Paulo (Parque Dom Pedro II, Cerqueira César, Pinheiros, Congonhas e São Miguel Paulista) e 2 regiões no município de Santo André (Paço Municipal e Capuava), como indicadas na Figura 7.

Em cada região foram coletadas cascas em diferentes pontos de amostragem, isto é, uma área onde as árvores estavam localizadas em até aproximadamente $30 \mathrm{~m}$ de distância entre elas. As características das regiões de amostragem estão descritas na Tabela 1 e as informações sobre período de coleta, espécie arbórea, diâmetro do tronco, amostras simples e amostras compostas estão no Apêndice A. No Apêndice B são apresentados os mapas com as localizações dos pontos de coleta de cada região e pontos da rede de monitoramento da CETESB.

Devido à dificuldade de encontrar as espécies arbóreas Tipuana e Sibipiruna selecionados neste estudo distantes de áreas urbanas, para escolha das 
regiões controle, foi estabelecido como critério selecionar as estações da CETESB que apresentassem as menores médias das concentrações mensais de material particulado $\left(\mathrm{MP}_{10}\right)$ no período entre janeiro de 2010 e dezembro de 2015. Por este critério, foram escolhidas as regiões de Presidente Prudente e Marília.

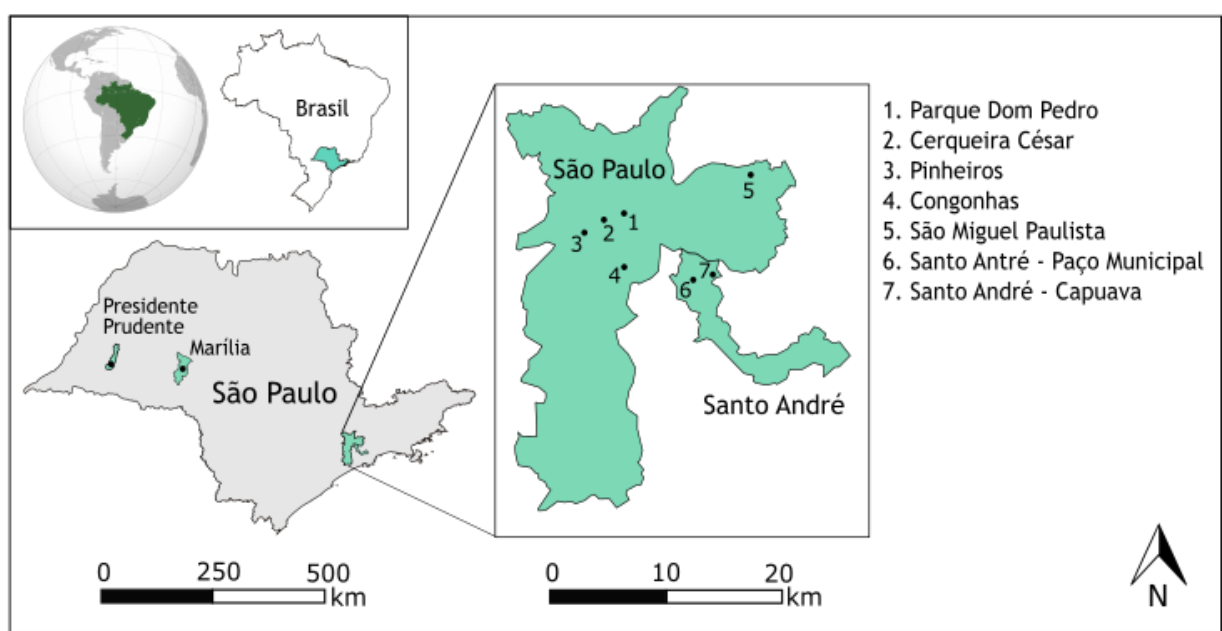

Figura 7. Localização das regiões de amostragem das cascas de árvore na RMSP e nas regiões controle.

Tabela 1. Principais características das regiões de amostragem das cascas de árvore.

Região de amostragem

Principais características

Parque Dom Pedro II

Área do parque pouco arborizada e vias de alto fluxo veicular. Principal via: Av. do Estado

Cerqueira César

Jardim da FMUSP* próximo às vias de intenso fluxo veicular. Principal via: Av. Dr. Arnaldo

Pinheiros

Área residencial próximo às vias de alto fluxo veicular. Principal via: marginal Pinheiros

Congonhas

Área comercial próximo ao aeroporto de Congonhas, corredor Norte-Sul e Av. dos Bandeirantes

São Miguel Paulista

Área residencial próximo à indústria de nitrocelulose e metalúrgica.

Santo André - Capuava

Área residencial, próximo ao polo petroquímico de Capuava (fora do raio de $500 \mathrm{~m}$ )

Santo André - Paço Municipal

Área comercial, encontro de vias de intenso fluxo veicular. Via Principal: Av. José Antônio de Almeida Amazonas

Presidente Prudente

Campus da UNESP** próximo à vias de baixo fluxo veicular

Marília

Parque e área residencial com vias de baixo fluxo veicular

${ }^{*}$ FMUSP $=$ Faculdade de Medicina da Universidade de São Paulo

**UNESP $=$ Universidade Estadual Paulista 


\subsection{Coleta e tratamento das amostras de cascas de árvore}

As cascas foram coletadas a aproximadamente $1,5 \mathrm{~m}$ de altura em relação ao solo utilizando uma faca de aço inoxidável e guardadas em envelopes de papel. O comprimento da circunferência do tronco das árvores escolhidas foi medido na altura de coleta utilizando uma fita métrica.

Preliminarmente, foram realizados dois ensaios para estabelecer condições para coleta e preparo de amostra da casca, avaliando a variação das concentrações dos elementos em função da espessura da casca analisada e em função da face do tronco para a coleta da casca.

Para avaliar a variação das concentrações dos elementos em função da espessura da casca analisada, primeiramente foi ralada uma camada de aproximadamente $1 \mathrm{~mm}$ de espessura da superfície externa (camada externa), e separadamente, foi ralada aproximadamente mais $1 \mathrm{~mm}$ de espessura da camada subsequente da mesma casca utilizada (camada interna). A medida da espessura da casca a ser ralada foi feita com o auxílio de um paquímetro. Com base nos resultados obtidos, foi decidido realizar neste trabalho amostras obtidas de 1 a 2 $\mathrm{mm}$ de espessura da camada superficial da casca. Os resultados obtidos nestes ensaios são apresentados no Capítulo 6.

A variação dos teores dos elementos em função da face do tronco foi verificada fazendo análises de cascas coletadas de faces opostas do tronco da mesma árvore, sendo uma voltada para o lado norte e a outra para o lado sul.

No preparo das cascas, para análise, a sua camada superficial foi limpa com escova dental com cerdas de nylon e depois ralada utilizando um ralador de titânio. Estas amostras foram peneiradas com uma peneira de plástico para se obter amostras com fragmentos menores, os quais foram submetidos a moagem usando o micro moinho vibratório "Pulverisette 0" da Fritsch de ágata. A amostra obtida na forma de fino pó foi colocada em frasco plástico, identificada e guardada em dessecador.

Quando existiam mais de uma árvore da mesma espécie em um mesmo ponto de amostragem, foram preparadas amostras compostas a fim de se obter uma amostra de casca representativa. Para o preparo desta amostra composta, foi feita a pesagem de mesma quantidade entre 150 - $200 \mathrm{mg}$ de cada uma das amostras individuais em um mesmo frasco de polietileno e homogeneizadas. Para 
este trabalho, foram obtidas ao todo 75 amostras de árvores individuais, destas foram preparadas 25 amostras compostas e 11 permaneceram individuais.

\subsection{Procedimento para análise por ativação com nêutrons}

\subsubsection{Preparo dos padrões sintéticos dos elementos}

A partir das soluções padrão certificadas da Spex CertiPrep USA, foram preparadas soluções padrão diluídas simples ou multielementares. $\mathrm{Na}$ Tabela 2 estão as concentrações dos elementos destas soluções padrão codificadas de F3, BR3 S3, L3, NI, CV1, MN1, CL1 e MG1 juntamente com as massas dos elementos utilizados nas análises.

Tabela 2. Dados das soluções padrão sintéticos dos elementos.

\begin{tabular}{cccc}
\hline Padrão & Elemento & $\begin{array}{c}\text { Concentração } \\
\left(\mu \mathrm{g} \mathrm{m}^{-1}\right)\end{array}$ & $\begin{array}{c}\text { Massa do elemento em 50 } \\
\mu \mathrm{L} \text { de solução }(\mu \mathrm{g})\end{array}$ \\
\hline \multirow{2}{*}{ F3 } & $\mathrm{Ca}$ & 9979 & 498,95 \\
& $\mathrm{Rb}$ & 199,807 & 9,9903 \\
& $\mathrm{Fe}$ & 7205,76 & 360,288 \\
BR3 & $\mathrm{Zn}$ & 720,84 & 36,42 \\
\hline \multirow{2}{*}{$\mathrm{S3}$} & $\mathrm{Br}$ & 100,20 & 5,01 \\
& $\mathrm{As}$ & 30,04 & 1,502 \\
& $\mathrm{Cr}$ & 40,219 & 2,01095 \\
& $\mathrm{Sb}$ & 12,018 & 0,6009 \\
\hline $\mathrm{K} 3$ & $\mathrm{~K}$ & 10013 & 500,65 \\
& $\mathrm{La}$ & 12,014 & 0,6007 \\
& $\mathrm{Cs}$ & 12,002 & 0,6001 \\
& $\mathrm{Sc}$ & 1,600 & 0,0800 \\
\hline $\mathrm{NI}$ & $\mathrm{Co}$ & 3,007 & 0,15035 \\
\hline $\mathrm{CV} 1$ & $\mathrm{Ni}$ & 10039,5 & 501,98 \\
\hline $\mathrm{MN1}$ & $\mathrm{V}$ & 479,54 & 23,977 \\
\hline $\mathrm{CL} 1$ & $\mathrm{Cu}$ & 4806,91 & 240,345 \\
\hline $\mathrm{MG1}$ & $\mathrm{Mn}$ & 79,8177 & 3,991 \\
\hline & $\mathrm{Cl}$ & 10000 & 500,0 \\
\hline & $\mathrm{Mg}$ & 9979 & 498,95 \\
\hline
\end{tabular}

Na preparação dos padrões sintéticos, $100 \mu \mathrm{L}$ da solução padrão MG1 e $50 \mu \mathrm{L}$ das demais soluções foram pipetados com o pipetador Biohit Proline sobre tiras de papel de filtro Whatman $n^{\circ} 40$ de dimensões $1,8 \mathrm{~cm} \times 6,0 \mathrm{~cm}$. No caso foi 
utilizado o pipetador previamente verificado quando a sua calibração. Estas tiras de papel foram colocadas em um dessecador para a secagem das alíquotas pipetadas a temperatura ambiente. Posteriormente estas tiras de papel foram dobradas com o auxílio de pinças e colocadas em invólucros de polietileno os quais foram selados. Os invólucros de polietileno foram confeccionados com folhas de polietileno previamente submetidos à limpeza com solução de ácido nítrico p.a diluído e água purificada MilliQ seguida de secagem.

\subsubsection{Materiais de referência certificados}

Os materiais de referência certificados Mixed Polish Herbs (INCT-MPH2), Virginia Tobacco Leaves (CTA-VTL-2) e MRC Oriental Basma Tobacco Leaves (INCT-OBTL-5) todos provenientes do Instituto de Química Nuclear e Tecnologia de Warsana, Polônia, foram analisados para avaliação da exatidão e precisão dos resultados.

Para expressar os resultados das análises destes materiais na base seca, foram feitas as determinações dos teores de umidade. Para isso, alíquotas de cerca de $250 \mathrm{mg}$ de cada material de referência certificado pesados em pesafiltros foram submetidos a secagem em estufa a $85^{\circ} \mathrm{C}$ por um período de 48 horas. Neste processo de secagem foram obtidas as porcentagens de umidade de 2,23; 1,65 e de 6,1\% para os materiais Mixed Polish Herbs (INCT-MPH2) e Virginia Tobacco Leaves (CTA-VTL-2) e Oriental Basma Tobacco Leaves (INCT-OBTL-5), respectivamente. Estes valores de porcentagem de umidade foram utilizados no cálculo das concentrações dos elementos na base seca.

\subsubsection{Procedimento para irradiações longas}

Para determinação dos elementos As, Br, Ca, Co, Cr, Cs, Fe, K, La, Ni, $\mathrm{Rb}, \mathrm{Sb}, \mathrm{Sc}$, Se e $\mathrm{Zn}$ as amostras foram analisadas pelo método de NAA por meio de irradiações longas. Para isto, cerca de 150 a $180 \mathrm{mg}$ de cada material de referência ou da amostra da casca de árvore foram pesados em invólucros de polietileno usando a balança analítica da marca Shimadzu com uma precisão de $0,00001 \mathrm{~g}$.

Para irradiação cada uma das amostras (material de referência ou casca de árvore) e os padrões sintéticos foram envoltos individualmente em folha de 
alumínio. A seguir, o conjunto de três amostras e os padrões sintéticos foi embrulhado em uma nova folha de alumínio e colocado em um dispositivo de alumínio chamado "coelho" para irradiação no reator nuclear IEA - R1 do Instituto de Pesquisas Energéticas e Nucleares (IPEN-CNEN/SP). O tempo de irradiação utilizado foi de 16 horas, sob fluxo térmico da ordem de $4,0 \times 10^{12} \mathrm{n} \mathrm{cm}^{-2} \mathrm{~s}^{-1}$.

Após um tempo de decaimento de cerca de 3 dias, as amostras e os padrões irradiados foram montados em suportes de aço inoxidável denominados de "panelinhas" para as medições das atividades gama induzidas. As contagens foram realizadas no detector de Germânio hiperpuro Modelo GC19020 ligado ao Analisador de Espectro Digital DSA 100, ambos da marca Canberra. A resolução do sistema (FWHM) utilizada foi de 1,00 keV para o pico de 121,97 keV do ${ }^{57} \mathrm{Co}$ e de $1,80 \mathrm{keV}$ para o pico $1332,49 \mathrm{keV}$ do ${ }^{60} \mathrm{Co}$. Para aquisição dos dados espectrais e seu processamento foi utilizado o software Genie 2000 versão 3.1 da Canberra. Diariamente foi feita a verificação do funcionamento do sistema realizando a contagem de uma fonte de ${ }^{57} \mathrm{Co}$ e ${ }^{60} \mathrm{Co}$. Foram realizadas pelo menos três séries de contagens para diferentes tempos de decaimento, sendo a primeira após cerca de 3 dias de decaimento, a segunda após 10 dias e a terceira após 17 dias de decaimento. Os tempos de cada medição para os padrões e para as amostras estão apresentados na Tabela 3.

Tabela 3. Tempos de contagem utilizados em cada medida das amostras e padrões das irradiações longas no reator.

\begin{tabular}{ccc}
\hline Medição & $\begin{array}{c}\text { Tempo de contagem } \\
\text { das amostras (s) }\end{array}$ & $\begin{array}{c}\text { Tempo de contagem dos } \\
\text { padrões(s) }\end{array}$ \\
\hline $1^{\underline{\underline{a}}}$ & 20000 & 5400 \\
$2^{\underline{a}}$ & 36000 & 6000 \\
$3^{\underline{a}}$ & 50000 & 7200 \\
\hline
\end{tabular}

Os radioisótopos dos espectros de raios gama foram identificados pela meia vida e energias dos raios gama. $\mathrm{Na}$

Tabela 4 estão as características nucleares dos radioisótopos detectados na NAA por meio de irradiações longas.

As concentrações dos elementos foram calculadas pelo método comparativo aplicando a equação 10. 
Tabela 4. Características nucleares dos radioisótopos medidos das irradiações longas no reator.

\begin{tabular}{cccc}
\hline Elemento & Radioisótopo & Energia $(\mathrm{keV})$ & Meia vida \\
\hline $\mathrm{As}$ & ${ }^{76} \mathrm{As}$ & 559,10 & $26,32 \mathrm{~h}$ \\
$\mathrm{Br}$ & ${ }^{82} \mathrm{Br}$ & 776,52 & $35,30 \mathrm{~h}$ \\
$\mathrm{Ca}$ & ${ }^{47} \mathrm{Ca}$ & 1297,09 & $4,54 \mathrm{~d}$ \\
$\mathrm{Co}$ & ${ }^{60} \mathrm{Co}$ & 1173,24 & $5,27 \mathrm{a}$ \\
$\mathrm{Cr}$ & ${ }^{51} \mathrm{Cr}$ & 320,08 & $27,7 \mathrm{~d}$ \\
$\mathrm{Cs}$ & ${ }^{134} \mathrm{Cs}$ & 795,85 & $2,06 \mathrm{a}$ \\
$\mathrm{Fe}$ & ${ }^{59} \mathrm{Fe}$ & 1099,25 & $44,50 \mathrm{~d}$ \\
$\mathrm{~K}$ & ${ }^{42} \mathrm{~K}$ & 1524,58 & $12,36 \mathrm{~h}$ \\
$\mathrm{La}$ & ${ }^{140} \mathrm{La}$ & 1596,21 & $40,27 \mathrm{~h}$ \\
$\mathrm{Ni}$ & ${ }^{58} \mathrm{Co}$ & 810,77 & $70,86 \mathrm{~d}$ \\
$\mathrm{Rb}$ & ${ }^{86} \mathrm{Rb}$ & 1076,60 & $18,66 \mathrm{~d}$ \\
$\mathrm{Sb}$ & ${ }^{122} \mathrm{Sb}$ & 564,24 & $2,70 \mathrm{~d}$ \\
$\mathrm{Sc}$ & ${ }^{124} \mathrm{Sb}$ & 1690,98 & $60,2 \mathrm{~d}$ \\
$\mathrm{Zn}$ & ${ }^{46} \mathrm{Sc}$ & 889,25 & $83,81 \mathrm{~d}$ \\
& ${ }^{65} \mathrm{Zn}$ & 1115,55 & $243,9 \mathrm{~d}$ \\
\hline
\end{tabular}

\subsubsection{Procedimento para irradiações curtas}

Os elementos $\mathrm{Cl}, \mathrm{Mg}, \mathrm{Mn}$ e $\mathrm{V}$ foram determinados pelo método de NAA realizando irradiações curtas no reator. As massas das amostras de casca e de MRC foram as mesmas daquelas descritas no item 5.3.3. Para irradiação, os padrões sintéticos e uma amostra foram colocados juntos em um invólucro de polietileno o qual foi inserido em um dispositivo de polietileno para irradiação curta. Este dispositivo foi submetido à irradiação por um período de $25 \mathrm{~s}$ na estação pneumática $\mathrm{n}^{\circ} 4$ do reator nuclear de pesquisa IEA-R1 sob um fluxo de nêutrons térmicos de $1,9 \times 10^{12} \mathrm{n} \mathrm{cm}^{-2} \mathrm{~s}^{-1}$.

Os tempos inicial e final de medição das atividades gama da amostra e dos padrões foram registrados como o auxílio de um cronômetro para posterior cálculo do tempo de decaimento.

As medições das atividades gama da amostra e padrões foram realizadas em dois tempos de decaimento diferentes. A primeira medição foi feita com 4 min de decaimento e o tempo de contagem foi de 300 s para determinação 
do $\mathrm{Mg}, \mathrm{V}$ e $\mathrm{Cu}$. A segunda medição foi feita cerca de $1 \mathrm{~h}$ de decaimento e o tempo de contagem foi de 600 s para determinação de $\mathrm{Cl}$ e $\mathrm{Mn}$.

As medições foram feitas no mesmo sistema de contagens utilizado para irradiações longas, bem como a identificação dos radioisótopos e método de cálculo das concentrações dos elementos. Na Tabela 5 estão as características nucleares dos radioisótopos utilizados na NAA por meio de irradiações curtas.

Tabela 5. Características nucleares dos radioisótopos medidos das irradiações curtas.

\begin{tabular}{cccc}
\hline Elemento & Radioisótopo & Energia (keV) & Meia vida \\
\hline $\mathrm{Cl}$ & ${ }^{38} \mathrm{Cl}$ & 1642,69 & $37,24 \mathrm{~min}$ \\
$\mathrm{Mg}$ & ${ }^{27} \mathrm{Mg}$ & 843,76 & $9,46 \mathrm{~min}$ \\
$\mathrm{Mn}$ & & 1014,43 & $2,58 \mathrm{~h}$ \\
$\mathrm{~V}$ & ${ }^{56} \mathrm{Mn}$ & 1810,72 & $3,75 \mathrm{~min}$ \\
\hline
\end{tabular}

\subsection{Procedimento de análise por espectrometria de absorção atômica}

\subsubsection{Preparo das amostras e materiais de referência}

Para determinação de $\mathrm{Cd}$, $\mathrm{Cu}$ e $\mathrm{Pb}$ foi empregado o procedimento de espectrometria de absorção atômica em forno de grafite (GF AAS). Para isto, aproximadamente $200 \mathrm{mg}$ de cada uma das amostras e de MRCs foram pesados em frascos Nalgene de teflon usando uma balança analítica da marca Ohaus, modelo AR2140 Adventurer com precisão de 0,0001g.

As amostras e os CRMs foram submetidos à digestão ácida que consistiu na adição de $10 \mathrm{~mL}$ de $\mathrm{HNO}_{3}$ concentrado e após 6 horas de repouso foi adicionado $1 \mathrm{~mL}$ de $\mathrm{H}_{2} \mathrm{O}_{2}$ (30 volumes). Essas amostras permaneceram em repouso durante a noite e foram digeridas no dia seguinte por 3 horas em um bloco digestor a $90^{\circ} \mathrm{C}$. Ao final da digestão ácida, as soluções foram avolumadas a 25,3 $\mathrm{mL}$.

Também foi preparado o branco analítico, que consistiu em uma solução preparada exatamente da mesma forma que no procedimento de digestão da amostra com a diferença em que não foi adicionada amostra para dissolução. 


\subsubsection{Procedimento para determinação de $\mathrm{Cd}, \mathrm{Cu}$ e $\mathrm{Pb}$}

As amostras e os MRCs digeridos foram analisados no equipamento de GF AAS modelo AAnalyst 800 da Perkin Elmer no Laboratório de Absorção Atômica do LAN/IPEN-SP para determinação de $\mathrm{Cd}$, $\mathrm{Cu}$ e $\mathrm{Pb}$. Os parâmetros instrumentais utilizados são apresentados na Tabela 6.

Tabela 6. Parâmetros instrumentais utilizados na análise por GF AAS.

\begin{tabular}{lccc}
\hline Parâmetros & $\mathrm{Cd}$ & $\mathrm{Cu}$ & $\mathrm{Pb}$ \\
\hline Lâmpada & $\mathrm{EDL}$ & $\mathrm{LCO}$ & $\mathrm{EDL}$ \\
Comprimento de onda $(\mathrm{nm})$ & 228,8 & 324,8 & 283,3 \\
Corrente da lâmpada $(\mathrm{mA})$ & 230 & 10 & 440 \\
Fenda espectral $(\mathrm{nm})$ & 0,7 & 0,5 & 0,7 \\
Volume de injeção da amostra $(\mu \mathrm{L})$ & 20 & 20 & 20 \\
Volume de injeção do modificador químico $(\mu \mathrm{L})$ & 10 & 10 & 10 \\
\hline
\end{tabular}

Antes de iniciar as etapas de aquecimento, o auto amostrador do equipamento de GF AAS injeta no forno de grafite juntamente com a amostra o modificador químico, uma solução composta por uma mistura de $\mathrm{NH}_{4} \mathrm{H}_{2} \mathrm{PO}_{4}$ 0,5\% $(\mathrm{m} / \mathrm{v})$ e $\mathrm{Mg}\left(\mathrm{NO}_{3}\right)_{2}, 0,03 \%(\mathrm{~m} / \mathrm{v})$ que tem como função reduzir os efeitos da matriz por meio da transformação do analito em uma forma menos volátil, permitindo usar altas temperaturas de pirólise, e com isso, sendo possível a separação do analito dos contaminantes (MORENO, 2001).

O forno de grafite do equipamento de GF AAS utilizado passa por várias etapas de aquecimento eletrotérmico as quais correspondem a uma etapa do procedimento operacional e estas etapas e suas correspondentes temperaturas são apresentadas na Tabela 7, juntamente com as suas taxas de aquecimento (Rampa de aquecimento), tempo de duração de cada etapa (patamar) e fluxo de argônio utilizado. O momento de leitura da absorbância da amostra ocorre na etapa de atomização e após isto, o forno passa pelos processos de limpeza e secagem. Os parâmetros apresentados na Tabela 7 foram os utilizados nas determinações de $\mathrm{Cd}$, Cu e Pb. 
Tabela 7. Condições de temperatura, rampa de aquecimento, patamar e fluxo interno de argônio para cada etapa de aquecimento do forno de grafite na análise por GF AAS para as determinações de Cd, $\mathrm{Cu}$ e Pb.

\begin{tabular}{ccccccc}
\hline Etapa & \multicolumn{2}{c}{ Temperatura $\left({ }^{\circ} \mathrm{C}\right)$} & $\begin{array}{c}\text { Rampa de } \\
\text { aquecimento } \\
\left({ }^{\circ} \mathrm{C} \mathrm{s}^{-1}\right)\end{array}$ & $\begin{array}{c}\text { Patamar } \\
(\mathrm{s})\end{array}$ & $\begin{array}{c}\text { Fluxo interno de } \\
\text { argônio } \\
\left(\mathrm{mL} \mathrm{min}^{-1}\right)\end{array}$ \\
\hline Secagem 1 & 110 & 110 & 110 & 1 & 30 & 250 \\
Secagem 2 & 130 & 130 & 130 & 15 & 30 & 250 \\
Pirólise & 500 & 1200 & 850 & 10 & 20 & 250 \\
Atomização & 1500 & 2000 & 1600 & 0 & 5 & 0 \\
Limpeza & 2450 & 2450 & 2450 & 1 & 3 & 250 \\
\hline
\end{tabular}

Para a construção das curvas de calibração foram utilizadas soluções de $\mathrm{Cd}$, Cu e $\mathrm{Pb}$ previamente preparadas a partir de soluções padrão certificadas da marca Spex CertiPrep USA. Utilizando $\mathrm{HNO}_{3}$ como diluente, o auto amostrador do equipamento de GF AAS realiza sucessivas diluições das soluções para a determinação de suas respectivas absorbâncias. Na Tabela 8 são apresentados os valores de concentração das soluções utilizadas para a construção das curvas de calibração para $\mathrm{Cd}$, Cu e $\mathrm{Pb}$, bem como os valores dos coeficientes angular (slope), linear (intercept) e de determinação $\left(R^{2}\right)$ obtidos a partir do ajuste linear das curvas obtidas.

Tabela 8. Valores de concentrações para obtenção das curvas de calibração para $\mathrm{Cd}$, Cu e $\mathrm{Pb}$ e seus respectivos coeficientes obtidos.

\begin{tabular}{cccc}
\hline Solução padrão & $\begin{array}{c}\mathrm{Cd} \\
\left(\mu \mathrm{g} \mathrm{L}^{-1}\right)\end{array}$ & $\begin{array}{c}\mathrm{Cu} \\
\left(\mu \mathrm{g} \mathrm{L}^{-1}\right)\end{array}$ & $\begin{array}{c}\mathrm{Pb} \\
\left(\mu \mathrm{g} \mathrm{L}^{-1}\right)\end{array}$ \\
\hline Branco & 0 & 0 & 0 \\
1 & 1,3948 & 20,2400 & 23,7500 \\
2 & 2,7896 & 40,4800 & 47,5010 \\
3 & 4,1844 & 60,7200 & 71,2510 \\
5 & 5,5792 & 80,9600 & 95,0020 \\
Coeficiente angular (slope) & 6,9740 & 101,2000 & 118,7520 \\
Coeficiente linear (intercept) & 0,05868 & 0,00525 & 0,00210 \\
Coeficiente de determinação $\left(\mathrm{R}^{2}\right)$ & 0,01417 & 0,00310 & 0,00808 \\
\hline
\end{tabular}


O sinal analítico de absorbância foi determinado a partir da área do pico de absorção e com base nas equações de reta obtidas das curvas de calibração foram calculadas as concentrações dos analito nas amostras, sendo estes cálculos efetuados pelo próprio software do equipamento.

\subsection{Cálculos e tratamento dos dados obtidos}

\subsubsection{Limites de detecção (LD) e de quantificação (LQ)}

O limite de detecção $\left(L_{D}\right)$ é a concentração mínima de uma substância medida e declarada com $95 \%$ ou $99 \%$ de confiança de que a concentração do analito é maior do que zero, ao passo que o limite de quantificação ( $\left.L_{Q}\right)$ é a menor concentração do analito que pode ser determinada com um nível aceitável de exatidão e precisão (INMETRO, 2007).

Para os elementos determinados por NAA, os limites de detecção e de quantificação foram calculados segundo o critério Currie (CURRIE, 1999). O cálculo consiste em, primeiramente, determinar a taxa de contagem correspondente a massa mínima detectável (LDc) ou a taxa de contagem para a massa mínima quantificável (LQc) como apresentado nas relações (11) (12), respectivamente. Nestas relações, BG ou background, é a taxa mínima de contagem da radiação de fundo ou área sob o pico e LT é o tempo de contagem. O valor de BG foi obtido da saída de dados do processamento do espectro de raios gama.

$$
\begin{aligned}
& \mathrm{LDC}=3,29((\sqrt{\mathrm{BG}}) / \mathrm{LT}) \\
& \mathrm{LQc}=10((\sqrt{\mathrm{BG}}) / \mathrm{LT})
\end{aligned}
$$

Uma vez obtidos os valores de LDc e LQc, os valores de $L_{D}$ e $L_{Q}$ em concentração dos elementos foram calculados pelo método comparativo (Relação 10).

Os limites de detecção e de quantificação para os elementos determinados por GF AAS foram calculados pelas equações 13 e 14 (WELZ e SPERLING, 1999), respectivamente, sendo $\sigma_{0} 0$ desvio padrão de dez determinações do branco analítico e a o coeficiente angular da curva analítica de calibração. 


$$
\begin{gathered}
L_{D}=3 \sigma_{0} / \alpha \\
L_{Q}=10 \sigma_{0} / \alpha
\end{gathered}
$$

\subsubsection{Diferença padronizada - Z score}

O controle de qualidade dos resultados com relação à exatidão foi feito pela análise dos MRCs. Para isso, aos resultados das análises obtidos pelas técnicas de NAA e GF AAS foram calculados os parâmetros Z score ou diferença padronizada aplicando a equação 15 (KONIECZKA e NAMIEŚNIK, 2009).

$$
\text { Z score }=\frac{\text { Xlab-Xref }}{\sqrt{\mathrm{SD}^{2}+\mathrm{u}_{(\mathrm{ref})}^{2}}}
$$

Sendo, Xlab o valor obtido experimentalmente, Xref o valor certificado, SD o desvio padrão do valor obtido e $\mathrm{u}^{2}$ (ref) a incerteza combinada do valor certificado. Se $\mid Z$ score $\mid \leq 2$, o resultado obtido é considerado satisfatório.

\subsubsection{Correlação de Pearson}

Para o estudo da correlação existente entre os elementos determinados nas cascas de árvores, foi calculada a matriz de correlação de Pearson e para isso foi utilizado o software Statistica 6.0.

O coeficiente de correlação de Pearson é um indicador da força de uma relação linear entre duas variáveis. Trata-se de uma medida de associação que independe das unidades de medidas das variáveis. Este coeficiente varia entre -1 e 1, sendo que quanto maior a qualidade do ajuste (ou associação linear), mais fortemente correlacionadas estão as variáveis (MARTINS, 2010).

\subsubsection{Fator de Enriquecimento (FE)}

Para a avaliação da poluição nas regiões de amostragem, foi aplicado o cálculo do Fator de Enriquecimento (FE) às concentrações dos elementos determinados nas cascas de árvore. O FE é um fator de impacto ambiental no qual é possível estimar a contribuição antrópica de um determinado elemento químico (GUÉGUEN et al., 2012). 
O FE é muito utilizado no estudo da contaminação de solo e sedimentos por elementos químicos e nos últimos anos vem sendo amplamente empregado nas análises de biomonitores da poluição atmosférica (WANG et al., 2005; ALMEIDA et al., 2012; STEINDOR et al., 2016).

Gresens (1967) define o FE como a dupla razão normalizada para um elemento de referência como apresentado na equação 16.

$$
F E=\frac{\left(C_{i} / C_{\text {ref }}\right)_{\text {amostra }}}{\left(C_{i} / C_{\text {ref }}\right)_{\text {referência }}}
$$

Em que, $\mathrm{C}_{\mathrm{i}}$ a concentração do elemento i e $\mathrm{C}_{\text {ref }}$ a concentração do elemento de referência. $O$ elemento de referência deve ser aquele considerado inteiramente proveniente da crosta terrestre. Os elementos comumente utilizados como referência para o cálculo de $\mathrm{FE}$ são $\mathrm{Al}$, $\mathrm{Fe}$ e Sc e no presente trabalho o Sc foi o elemento escolhido como de referência (ALMEIDA et al., 2012).

Os valores de referência para o cálculo de FE variam entre os autores quando o assunto é voltado para o biomonitoramento da poluição do ar. Alguns autores utilizam valores de concentração do elemento de referência da crosta continental superior (UCC - Upper Continental Crust) (GUÉGUEN et al., 2012), outros utilizam os mesmos ou diferentes biomonitores coletados em regiões consideradas limpas (STEINDOR et al., 2016) e outros utilizam a concentração do elemento presente no solo da região de coleta (BING 2016; FUJIWARA; et al., 2009; BERLIZOV et al., 2007; EL KHOUKHI et al., 2004 ). No presente trabalho o elemento de referência escolhido foi o Sc e os valores utilizados foram os da UCC fornecidos por Wedepohl et al. (1995).

Valores de FE próximos a 1 indicam que a origem do elemento é predominantemente geogênica. Já valores de FE entre 1 e 10 são considerados pouco enriquecidos por fontes antrópicas. Elementos moderadamente enriquecidos apresentam valores de FE entre 10 e 100, ao passo que FE acima de 100 é considerado que o elemento é altamente enriquecido por fontes antrópica (SKRBIC, 2012; WANG et al., 2005) 


\subsection{5 Índice de Geoacumulação (IGeo)}

Semelhante ao FE, o índice de geoacumulação (IGeo) também é um fator de impacto ambiental que permite relacionar os teores de um determinado elemento com sua respectiva concentração de fundo. O IGeo é calculado pela equação 17 (MÜLLER, 1969), sendo Ci a concentração do metal i na amostra e $\mathrm{C}_{\mathrm{BG}}$ a concentração de fundo do metal $\mathrm{i}$, sendo os valores utilizados neste trabalho para esta última variável foram correspondentes a UCC (WEDEPOHL, 1995).

$$
\text { Igeo }=\log _{2}\left(C_{\mathrm{i}} / 1,5 \times C_{B G}\right)
$$

O IGeo apresenta sete classificações do grau de poluição com relação à contaminação de um determinado elemento no ambiente de estudo, sendo estas apresentadas na Tabela 9.

Tabela 9. Classificações da intensidade de poluição do ambiente em função dos índices de geoacumulação (IGeo) (MÜLLER, 1969).

\begin{tabular}{cl}
\hline Índice de geoacumulação & \multicolumn{1}{c}{ Intensidade de poluição } \\
\hline$<0$ & Não poluído \\
$0-1$ & Não poluído a moderadamente poluído \\
$1-2$ & Moderadamente poluído \\
$2-3$ & Moderadamente poluído a poluído \\
$3-4$ & Muito poluído \\
$4-5$ & Muito poluído a altamente poluído \\
$>5$ & Altamente poluído \\
\hline
\end{tabular}

Este índice é comumente utilizado na avaliação da poluição ambiental em sedimentos, entretanto um trabalho no qual foi utilizado cascas de árvores como biomonitores da poluição atmosférica também foi determinado este índice (GUÉGEN et al., 2012). 


\subsubsection{Análise de Agrupamento (AA)}

Para interpretação dos resultados das análises de cascas de árvores com relação aos elementos determinados (variáveis) e com relação às regiões de amostragem (objetos), os resultados das concentrações dos elementos determinados nas amostras foram normalizados e submetidos ao tratamento de análise de agrupamento (ou análise de cluster).

A análise de agrupamento é uma técnica exploratória multivariada na qual permite reconhecer padrões de comportamento entre amostras ou entre variáveis com base em seu perfil multivariado. A finalidade principal da AA é reunir amostras (ou variáveis) de tal modo que aquelas pertencentes a um mesmo grupo sejam mais parecidas entre si do que com os objetos dos outros grupos, maximizando a homogeneidade dentro dos grupos e minimizando a homogeneidade entre grupos (FERREIRA, 2015).

No presente trabalho, a análise de grupos foi feita por meio do software de cálculos estatísticos STATISTICA 6.0. O critério de distância entre os pares de amostras e de variáveis utilizado para a obtenção do dendrograma foi a distância Euclidiana. O método adotado para o agrupamento das amostras e das variáveis foi o de Ward, também conhecido como método da variância mínima o qual minimiza o quadrado da distância Euclidiana às médias dos grupos, ou seja, um grupo será reunido a outro somente se essa reunião proporcionar o menor aumento da variância intragrupo (VICINI e SOUZA, 2005).

\subsubsection{Análise de Componentes Principais (PCA)}

A análise de componentes principais (PCA) foi aplicada aos resultados das concentrações de elementos das cascas de árvore a fim de se confirmar a formação dos grupos e subgrupos obtidos na análise de agrupamento. Para isto foi utilizado o software STATISTICA 6.0.

A PCA é um método estatístico multivariado de transformação de dados que permite transformar um conjunto de variáveis iniciais, correlacionadas entre si, em um outro conjunto de variáveis não correlacionadas que são as chamadas componentes principais, que resultam das combinações lineares dos conjuntos iniciais (VICINI e SOUZA, 2005). 
Para a escolha do número de componentes principais que melhor explica a variabilidade dos resultados obtidos foi utilizado o critério de Kaiser (ou a regra do eigenvalue) que sugere extrair apenas as componentes com valor de eigenvalue acima de um. Isso porque se o fator apresenta baixo eigenvalue, ele está contribuindo pouco para explicar a variância das variáveis originais (FIGUEIREDO FILHO e SILVA JÚNIOR, 2010).

Para se ter uma melhor visualização das variáveis que melhor representam cada componente, foi feita uma rotação nos eixos tipo Varimax normalizada, que o mais comumente utilizado. Este método consiste em minimizar o número de variáveis que apresentam altas cargas em cada fator (FIGUEIREDO FILHO e SILVA JÚNIOR, 2010).

Utilizando essa metodologia de análise de dados é possível identificar, visualmente e interpretar as diferenças existentes entre as variáveis e examinar as relações que podem existir entre as amostras. Além disso, a PCA permite detectar amostras que apresentam um comportamento atípico, pois, com a projeção dos dados, elas tendem a se tornar evidentes (FERREIRA, 2015).

\subsubsection{Mortalidade proporcional por grupo de causa}

Os resultados das concentrações de elementos obtidos nas análises das cascas de árvore foram usados no estudo da correlação com os dados de mortalidade por doenças cardiorrespiratórias por distrito da RMSP para verificar se há relação entre as concentrações dos elementos determinados com a saúde da população. A hipótese é que pode haver uma relação entre o material particulado depositado na superfície das cascas com os possíveis danos à saúde causados pela inalação deste material particulado.

Para isto, foi calculada a taxa de mortalidade (TM) por grupo de causa que pode utilizando a relação 18 (REDE, 2008). Os dados coletados foram correspondentes ao ano de 2014 para adultos acima de 45 anos.

$$
\mathrm{TM}=\frac{\text { Número de óbitos de residentes por grupo de causas definidas }}{\text { Número total de óbitos de residentes, excluídas as causas mal definidas }}
$$


Os grupos de causa são definidos pela Classificação Estatística Internacional de Doenças e Problemas Relacionados com a Saúde, mais conhecido como CID. A CID é uma classificação publicada pela Organização Mundial da Saúde (OMS) composta por 21 capítulos que fornece códigos relativos à classificação de doenças, sintomas e condições sociais que podem afetar a saúde. Atualmente está em sua décima edição, sendo assim, chamada de CID-10.

Os grupos de causa de mortalidade utilizados neste trabalho foram doenças do aparelho circulatório e doenças do aparelho respiratório correspondendo respectivamente aos Capítulos IX e X da CID-10.

$\mathrm{Na}$ capital de São Paulo, o número de óbitos residentes divididos por grupo de causa para cada distrito administrativo é apresentado no Programa de Aprimoramento das Informações de Mortalidade no Município de São Paulo (PROAIM). Este levantamento de dados pode ser consultado no banco de dados disponível no sistema TabNet desenvolvido pelo Departamento de Informática do Sistema Único de Saúde (DATASUS) (DATASUS, SD).

As causas mal definidas correspondem aos Capítulo XVIII do CID-10 (Sintomas, sinais e achados anormais de exames clínicos e de laboratório não classificados em outra parte). Os capítulos XIX (Lesões, envenenamentos e algumas consequências de causas externas) e XXI (fatores que influenciam o estado de Saúde e o contato com os serviços públicos) não são utilizados como causa básica de óbito (REDE, 2008).

Com as taxas de mortalidade por doenças cardiorrespiratórias calculadas para os distritos pertencentes ao município de São Paulo e as concentrações médias dos elementos determinados nas cascas de árvores, será feita a verificação da relação existente entre essas duas variáveis. 


\section{RESULTADOS E DISCUSSÃO}

\subsection{Escolha da região controle}

Para a escolha das regiões controle foi feito um levantamento dos dados de material particulado grosso ( $\mathrm{MP}_{10}$ ) medidos no período de janeiro de 2010 a dezembro de 2015 por todas as estações de monitoramento automático da qualidade do ar da Companhia Ambiental do Estado de São Paulo (CETESB) disponíveis no sistema Qualar (CETESB, SD). Esta escolha foi feita comparando as medidas feitas nas estações de monitoramento existentes no Estado de São Paulo. As regiões onde estavam localizadas as estações que obtiveram menores concentrações de $\mathrm{MP}_{10}$ foram as escolhidas como controle, sendo estas as estações de Marília e Presidente Prudente. A Figura 8 mostra que as estações de Marília e Presidente Prudente apresentaram concentrações de $\mathrm{MP}_{10}$ menores que as estações da RMSP.

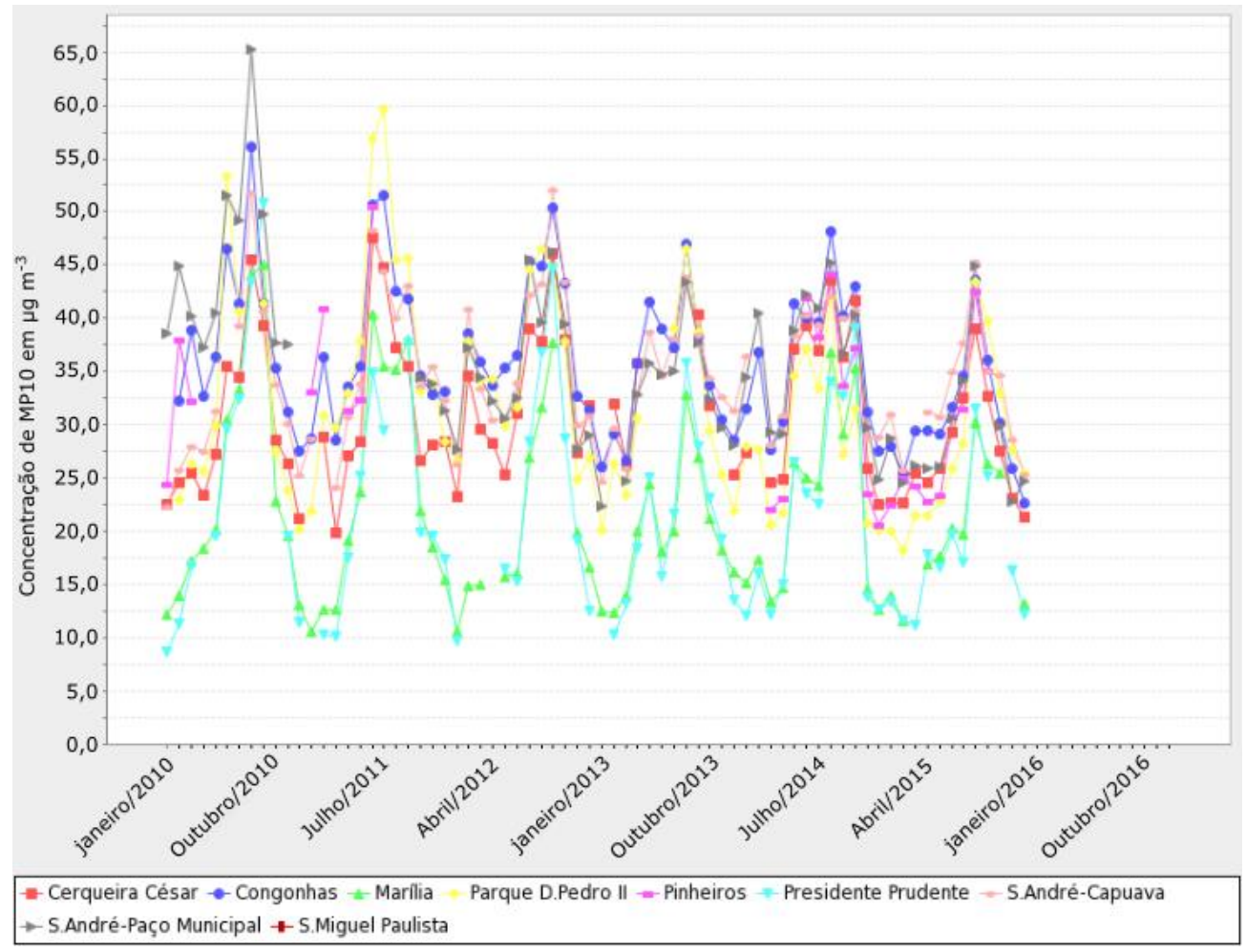

Figura 8. Médias das concentrações mensais de $\mathrm{MP}_{10}$ obtidas nas estações de monitoramento da qualidade do ar no período de 2010 a 2016 nas regiões em estudo neste trabalho (CETESB, SD). 
As estações de monitoramento automático de Marília e de Presidente Prudente estão localizadas dentro da área urbana, entretanto, como pode-se observar pelas medidas de $\mathrm{MP}_{10}$, que em média estas regiões apresentam valores bastante inferiores em relação aos obtidos na RMSP. Uma região controle ideal deve ser afastada de áreas urbanas e de fontes de emissões antrópicas, entretanto, uma área com essas condições não foi possível encontrar devido à dificuldade de encontrar as espécies arbóreas escolhidas para este estudo em regiões com estas características.

\subsection{Controle de qualidade analítico dos resultados}

\subsubsection{Resultados das análises dos materiais de referência certificados}

Os resultados das análises dos materiais de referência certificados Oriental Basma Tobacco Leaves (INCT-OBTL-5), Mixed Polish Herbs (INCT-MPH2) e Virgina Tobacco Leaves (CTA-VTL-2) pelo método de NAA são apresentados juntamente com seus valores certificados nas Tabelas 10 e 11, respectivamente.

Os resultados do MRC INCT-OBTL-5 apresentaram desvios padrão relativos (DPR) variando entre $1,3 \%$ e $8,8 \%$ e erros relativos percentuais (ER) inferiores a 9\% com exceção do elemento As que apresentou ER de 17\% devido à sua baixa concentração no material e à meia vida relativamente curta do ${ }^{76} \mathrm{As}$ de 26,32 h. Este material de referência apresentou alta atividade gama após irradiação, possibilitando iniciar a primeira medida somente após 6 dias de decaimento. Após este período de decaimento o ${ }^{76} \mathrm{As}$ apresentou baixas taxas de contagens com maior erro. O material de referência certificado INCT-MPH-2 apresentou valores de concentrações de As com desvio padrão relativos inferiores a $9 \%$ e erros relativos abaixo de $10,5 \%$. O elemento $V$ foi o que apresentou resultados com maior erro relativo devido às baixas concentrações de $\mathrm{V} e$ consequente baixas taxas de contagem do radioisótopo ${ }^{52} \mathrm{~V}$ e meia vida curta. Os resultados das análises do MRC CTA-VTL-2 apresentaram boa exatidão e precisão, com desvios padrão relativos na faixa de $1,4 \%$ a $9,6 \%$ e erros relativos abaixo de $9,1 \%$.

$\mathrm{Na}$ Tabela 12 são apresentados os resultados obtidos nas análises dos materiais de referência certificados INCT-MPH-2 e CTA-VTL-2 pelo método de AAS. O MRC Mixed Polish Herbs apresentou resultados com boa precisão com 
DPRs entre $5,3 \%$ e $8,3 \%$ e boa exatidão com ERs abaixo de $10,6 \%$. Os DPRs obtidos para os elementos determinados no MRC Virginia Tobacco Leaves foram abaixo de10,5\% e ERs abaixo de 6,3\%, indicando boa precisão e exatidão dos resultados obtidos.

Tabela 10. Concentrações dos elementos no MRC INCT-OBTL-5 Oriental Basma Tobacco Leaves determinados pelo método de NAA.

\begin{tabular}{|c|c|c|c|c|}
\hline Elementos & Valor do certificado & $M \pm D P(n)$ & DPR (\%) & $\operatorname{ER}(\%)$ \\
\hline As, $\mu \mathrm{g} \mathrm{kg}^{-1}$ & $668 \pm 86$ & $556 \pm 49(5)$ & 8,8 & 17,0 \\
\hline $\mathrm{Br}, \mathrm{mg} \mathrm{kg}^{-1}$ & $87,4 \pm 5,4$ & $89,6 \pm 5,4(5)$ & 6,0 & 2,5 \\
\hline $\mathrm{Ca}, \%$ & $3,996 \pm 0,142$ & $4,00 \pm 0,09(5)$ & 2,3 & 0,1 \\
\hline $\mathrm{Cl}, \%$ & $(0,77)^{\star}$ & $0,842 \pm 0,037(11)$ & 4,4 & - \\
\hline Co, $\mu \mathrm{g} \mathrm{kg}^{-1}$ & $981 \pm 67$ & $974 \pm 51(5)$ & 5,2 & 0,7 \\
\hline $\mathrm{Cr}, \mathrm{mg} \mathrm{kg}^{-1}$ & $(6,3)^{*}$ & $9,46 \pm 0,21(5)$ & 2,2 & - \\
\hline Cs, $\mu \mathrm{g} \mathrm{kg}^{-1}$ & $288 \pm 20$ & $288,9 \pm 7,7(5)$ & 2,7 & 0,3 \\
\hline $\mathrm{Fe}, \mathrm{mg} \mathrm{kg}^{-1}$ & $(1490)^{*}$ & $1755 \pm 27(5)$ & 1,5 & - \\
\hline $\mathrm{K}, \%$ & $2,271 \pm 0,076$ & $2,180 \pm 0,075(5)$ & 3,4 & 4,0 \\
\hline $\mathrm{La}, \mu \mathrm{g} \mathrm{kg}^{-1}$ & $1690 \pm 90$ & $1591 \pm 76(5)$ & 4,8 & 5,9 \\
\hline $\mathrm{Mg}, \%$ & $0,853 \pm 0,034$ & $0,839 \pm 0,023(11)$ & 2,7 & 1,6 \\
\hline $\mathrm{Mn}, \mathrm{mg} \mathrm{kg}^{-1}$ & $180,0 \pm 6,0$ & $188 \pm 13$ & 6,9 & 4,4 \\
\hline $\mathrm{Ni}, \mathrm{mg} \mathrm{kg}^{-1}$ & $8,50 \pm 0,49$ & $8,60 \pm 0,24(4)$ & 2,8 & 1,2 \\
\hline $\mathrm{Rb}, \mathrm{mg} \mathrm{kg}^{-1}$ & $19,1 \pm 1,0$ & $18,89 \pm 0,24(5)$ & 1,3 & 1,1 \\
\hline $\mathrm{Sb}, \mu \mathrm{g} \mathrm{kg}^{-1}$ & $76 \pm 13$ & $71,0 \pm 1,5(5)$ & 2,1 & 6,6 \\
\hline Sc, $\mu \mathrm{g} \mathrm{kg}^{-1}$ & $640 \pm 27$ & $650 \pm 21(5)$ & 3,2 & 1,6 \\
\hline $\mathrm{V}, \mathrm{mg} \mathrm{kg}^{-1}$ & $4,12 \pm 0,55$ & $4,49 \pm 0,35(11)$ & 7,8 & 9,0 \\
\hline $\mathrm{Zn}, \mathrm{mg} \mathrm{kg}^{-1}$ & $52,4 \pm 1,8$ & $53,4 \pm 2,1(5)$ & 3,9 & 1,9 \\
\hline
\end{tabular}

M - Média aritmética; DP - Desvio padrão; $n$ - Número de determinações; DPR -

Desvio padrão relativo; ER - Erro relativo; * Valor informativo 
Tabela 11. Concentrações dos elementos nos MRCs INCT-MPH-2 Mixed Polish Herbs e CTA-VTL-2 Virginia Tobacco Leaves determinados pelo método de NAA.

\begin{tabular}{|c|c|c|c|c|c|c|c|c|}
\hline \multirow{2}{*}{ Elementos } & \multicolumn{4}{|c|}{ INCT-MPH-2 Mixed Polish Herbs } & \multicolumn{4}{|c|}{ CTA-VTL-2 Virginia Tobacco Leaves } \\
\hline & Valor do certificado & $M \pm D P(n)$ & DPR $(\%)$ & $\mathrm{ER}(\%)$ & Valor do certificado & $M \pm D P(n)$ & DPR (\%) & $\mathrm{ER}(\%)$ \\
\hline As, $\mu \mathrm{g} \mathrm{kg}^{-1}$ & $191 \pm 23$ & $171 \pm 14(8)$ & 8,2 & 10,5 & $969 \pm 72$ & $956 \pm 34(8)$ & 3,6 & 1,3 \\
\hline $\mathrm{Br}, \mathrm{mg} \mathrm{kg}^{-1}$ & $7,71 \pm 0,61$ & $8,14 \pm 0,73(8)$ & 9,0 & 5,6 & $14,3 \pm 1,4$ & $15,6 \pm 1,5(8)$ & 9,6 & 9,1 \\
\hline $\mathrm{Ca}, \%$ & $1,08 \pm 0,07$ & $1,081 \pm 0,049(8)$ & 4,5 & 0,1 & $3,60 \pm 0,15$ & $3,606 \pm 0,072(8)$ & 2,0 & 0,2 \\
\hline $\mathrm{Cl}, \%$ & $0,284 \pm 0,020$ & $0,271 \pm 0,017(5)$ & 6,3 & 4,6 & $0,743 \pm 0,028$ & $0,722 \pm 0,021(5)$ & 2,9 & 2,8 \\
\hline Co, $\mu \mathrm{g} \mathrm{kg}^{-1}$ & $210 \pm 25$ & $211,6 \pm 5,7(8)$ & 2,7 & 0,8 & $429 \pm 26$ & $427 \pm 22(8)$ & 5,2 & 0,5 \\
\hline $\mathrm{Cr}, \mathrm{mg} \mathrm{kg}^{-1}$ & $1,69 \pm 0,13$ & $1,767 \pm 0,089(8)$ & 5,0 & 4,6 & $1,87 \pm 0,16$ & $2,04 \pm 0,16(8)$ & 7,8 & 9,1 \\
\hline Cs, $\mu \mathrm{g} \mathrm{kg}^{-1}$ & $76 \pm 7$ & $75,2 \pm 1,3(8)$ & 1,7 & 1,1 & $515 \pm 46$ & $521 \pm 15(8)$ & 2,9 & 1,2 \\
\hline $\mathrm{Fe}, \mathrm{mg} \mathrm{kg}^{-1}$ & $(460)^{*}$ & $496 \pm 15(8)$ & 3,0 & - & $1083 \pm 33$ & $1112 \pm 28(8)$ & 2,5 & 2,7 \\
\hline $\mathrm{K}, \%$ & $1,91 \pm 0,12$ & $1,978 \pm 0,078(8)$ & 3,9 & 3,6 & $1,03 \pm 0,04$ & $1,101 \pm 0,049(8)$ & 4,5 & 6,9 \\
\hline $\mathrm{La}, \mu \mathrm{g} \mathrm{kg}^{-1}$ & $571 \pm 46$ & $561 \pm 36(8)$ & 6,4 & 1,8 & $1010 \pm 100$ & $1016 \pm 96(8)$ & 9,4 & 0,6 \\
\hline $\mathrm{Mg}, \%$ & $0,292 \pm 0,018$ & $0,295 \pm 0,015(5)$ & 5,1 & 1,0 & $0,510 \pm 0,023$ & $0,542 \pm 0,033(5)$ & 6,1 & 6,3 \\
\hline $\mathrm{Mn}, \mathrm{mg} \mathrm{kg}^{-1}$ & $191 \pm 12$ & $185,3 \pm 7,4(5)$ & 4,0 & 3,0 & $79,7 \pm 2,6$ & $79,1 \pm 4,2(5)$ & 5,3 & 0,8 \\
\hline $\mathrm{Rb}, \mathrm{mg} \mathrm{kg}^{-1}$ & $10,70 \pm 0,70$ & $10,74 \pm 0,13(8)$ & 1,2 & 0,4 & $48,6 \pm 2,3$ & $47,9 \pm 1,1(8)$ & 2,3 & 1,4 \\
\hline $\mathrm{Sb}, \mu \mathrm{kg}^{-1}$ & $65,5 \pm 9,1$ & $66,3 \pm 3,4(8)$ & 5,1 & 1,2 & $312 \pm 25$ & $313 \pm 21(8)$ & 6,7 & 0,3 \\
\hline Sc, $\mu \mathrm{g} \mathrm{kg}^{-1}$ & $123,0 \pm 9,0$ & $123,4 \pm 3,6(8)$ & 2,9 & 0,3 & $(268)^{*}$ & $312,7 \pm 9,3(8)$ & 3,0 & - \\
\hline $\mathrm{V}, \mathrm{mg} \mathrm{kg}^{-1}$ & $0,95 \pm 0,16$ & $0,819 \pm 0,063(5)$ & 7,7 & 13,8 & $4,00 \pm 0,42$ & $4,22 \pm 0,15(5)$ & 3,6 & 5,5 \\
\hline $\mathrm{Zn}, \mathrm{mg} \mathrm{kg}^{-1}$ & $33,5 \pm 2,1$ & $33,22 \pm 0,46(8)$ & 1,4 & 0,8 & $43,3 \pm 2,1$ & $44,18 \pm 0,62(8)$ & 1,4 & 2,0 \\
\hline
\end{tabular}

M - média aritmética; DP - Desvio Padrão; $n$ - número de determinações; DPR - Desvio Padrão Relativo; ER - Erro Relativo; * valor informativo 
Tabela 12. Concentrações dos elementos $\mathrm{Cd}$, $\mathrm{Cu}$ e Pb nos MRCs INCT-MPH-2 Mixed Polish Herbs e CTA-VTL-2 Virginia Tobacco Leaves determinados pelo método de AAS.

\begin{tabular}{c|cccc}
\hline MRC & Elementos & $\mathrm{Cd}, \mu \mathrm{g} \mathrm{kg}-1$ & $\mathrm{Cu}, \mathrm{mg} \mathrm{kg}^{-1}$ & $\mathrm{~Pb}, \mathrm{mg} \mathrm{kg}^{-1}$ \\
\hline & Valor do certificado & $199 \pm 15$ & $7,77 \pm 0,53$ & $2,16 \pm 0,23$ \\
INCT-MPH-2 & M \pm DP (n) & $209 \pm 11(4)$ & $8,11 \pm 0,52(4)$ & $1,93 \pm 0,16(4)$ \\
Mixed Polish & DPR (\%) & 5,3 & 6,4 & 8,3 \\
Herbs & ER (\%) & 5,0 & 4,4 & 10,6 \\
\hline & Valor do certificado & $1520 \pm 170$ & $18,2 \pm 0,9$ & $22,1 \pm 1,2$ \\
CTA-VTL-2 & M \pm DP (n) & $1424 \pm 150(4)$ & $19,6 \pm 2,8(3)$ & $22,1 \pm 0,7(4)$ \\
Virginia & DPR (\%) & 10,5 & 14,3 & 3,2 \\
Tobacco & ER (\%) & 6,3 & 7,7 & 0,0 \\
Leaves & &
\end{tabular}

M - Média aritmética; DP - Desvio padrão; $n$ - Número de determinações; DPR - Desvio padrão relativo; ER - Erro relativo;

Os baixos valores de desvios padrão relativos e erros relativos obtidos nas análises dos materiais de referência certificados indicam que os métodos de NAA e de AAS indicaram a boa precisão e exatidão dos dados obtidos para análise.

A boa exatidão dos resultados obtidos dos elementos determinados pelos métodos de NAA e AAS pode ser observada pelos baixos valores de ER bem como pelos valores de $Z$ score ou diferença padronizada. Os valores de $Z$ score obtidos pela análise dos MRCs para os métodos de NAA e AAS são apresentados nas Figuras 9 e 10 , respectivamente.

No material de referência certificado CTA-VTL-2 o Pb apresentou erro relativo igual a zero, pois a concentração média obtida experimentalmente foi igual ao valor do certificado como apresentado na Tabela 12, por esse motivo o valor de $Z$ score para este elemento foi igual a zero neste material. Foram obtidos valores de $Z$ score entre - 2 e 2 para todos os elementos determinados nos três MRCs e isto indica que os resultados obtidos estão dentro da faixa dos valores certificados a um nível de confiança de $95 \%$. 


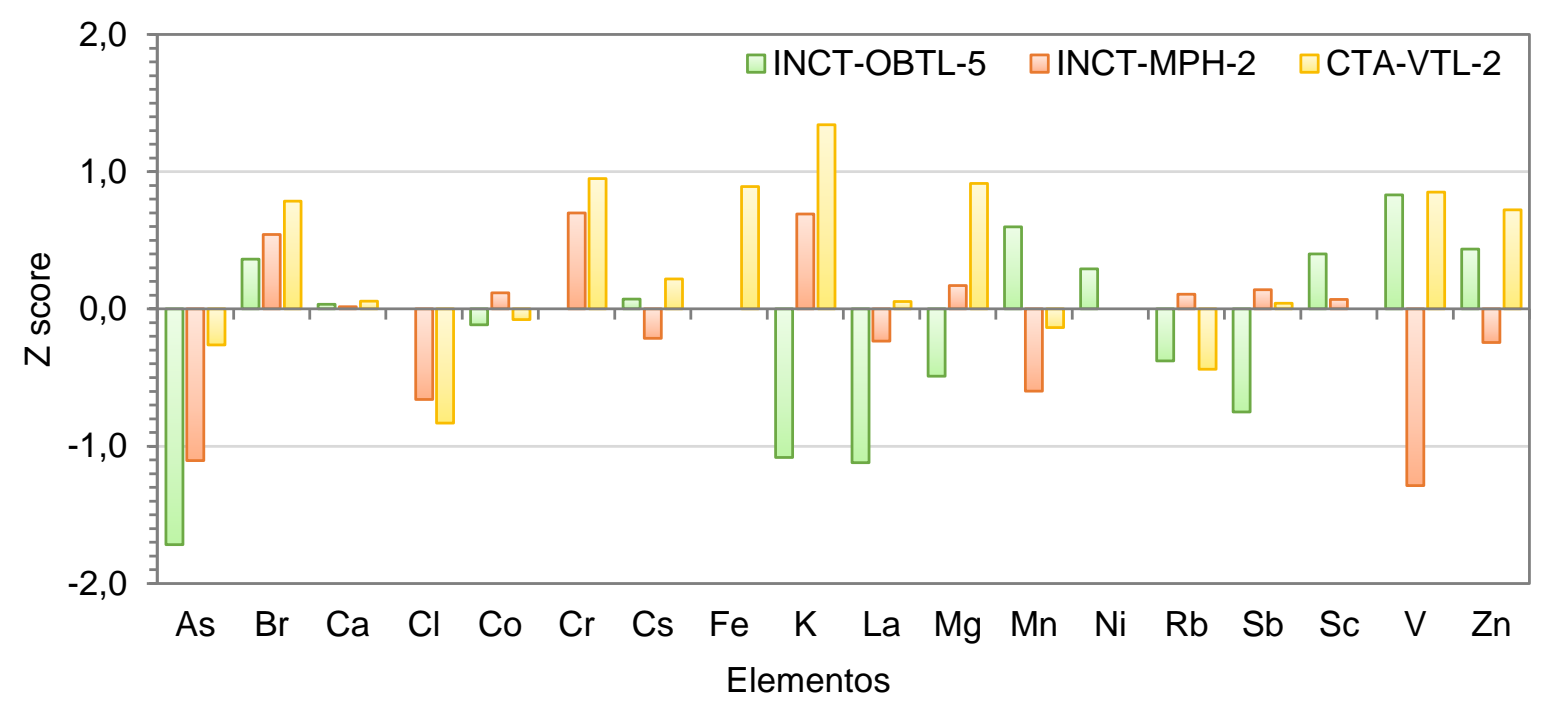

Figura 9. Valores de $Z$ score obtidos para os materiais de referência certificados INCT-MPH-2 Mixed Polish Herbs, CTA-VTL-2 Virginia Tobacco Leaves e INCTOBTL-5 Oriental Basma Tobacco Leaves analisados pelo método de NAA.

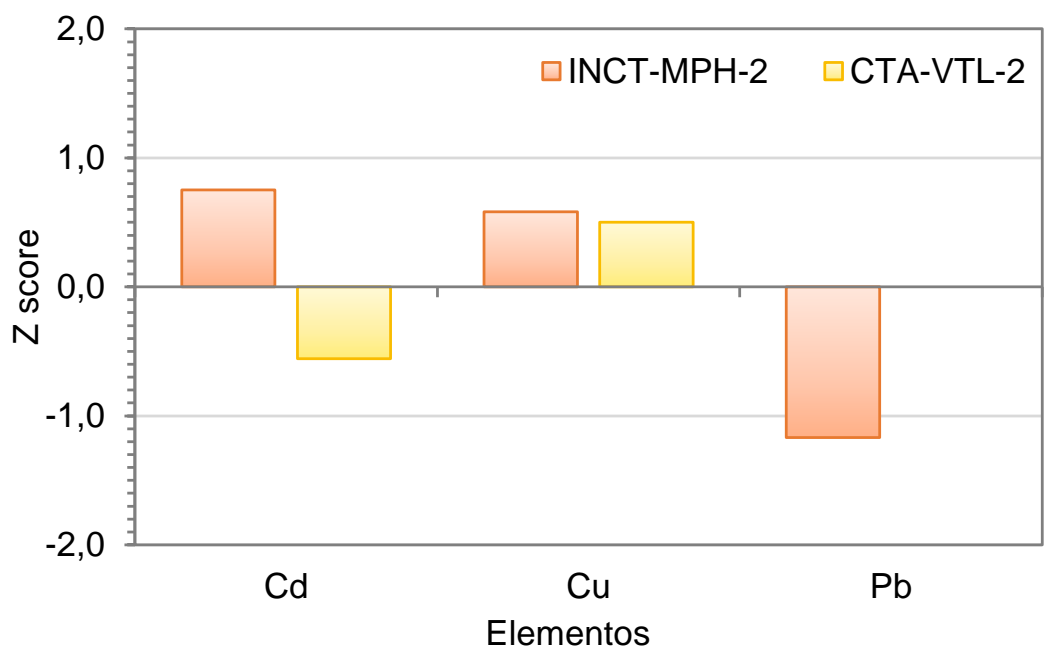

Figura 10. Valores de $Z$ score obtidos para os materiais de referência certificados INCT-MPH-2 Mixed Polish Herbs, CTA-VTL-2 Virginia Tobacco Leaves analisados pelo método de AAS. 


\subsection{Estabelecimento das condições para o tratamento das cascas de árvore para análise}

\subsubsection{Verificação da homogeneidade da amostra de casca de árvore}

A verificação quanto a homogeneidade das amostras preparadas foi realizada pela análise em triplicata de uma amostra de casca de árvore escolhida aleatoriamente pelos métodos de NAA e AAS e cujos resultados obtidos são apresentados na Tabela 13. Os desvios padrão relativos foram inferiores a 11,5\%, indicando boa homogeneidade na amostra preparada com relação aos elementos determinados.

Tabela 13. Média das concentrações de elementos da análise de uma amostra de casca de árvore em triplicatas determinados por NAA e AAS.

\begin{tabular}{|c|c|c|}
\hline Elementos & $\mathrm{M} \pm \mathrm{DP}$ & DPR (\%) \\
\hline As, $\mu \mathrm{g} \mathrm{kg}^{-1}$ & $87 \pm 10$ & 11,5 \\
\hline $\mathrm{Br}, \mathrm{mg} \mathrm{kg}^{-1}$ & $4,03 \pm 0,06$ & 1,5 \\
\hline $\mathrm{Ca}, \%$ & $2,34 \pm 0,017$ & 0,7 \\
\hline $\mathrm{Cd}, \mu \mathrm{g} \mathrm{kg}^{-1}$ & $341,2 \pm 2,1$ & 0,6 \\
\hline $\mathrm{Cl}, \mathrm{mg} \mathrm{kg}^{-1}$ & $78,3 \pm 4,9$ & 6,2 \\
\hline Co, $\mu \mathrm{g} \mathrm{kg}^{-1}$ & $298 \pm 13$ & 4,4 \\
\hline $\mathrm{Cr}, \mu \mathrm{kg}^{-1}$ & $2124,3 \pm 9,9$ & 0,5 \\
\hline Cs, $\mu \mathrm{g} \mathrm{kg}^{-1}$ & $130,8 \pm 5,1$ & 3,9 \\
\hline $\mathrm{Cu}, \mathrm{mg} \mathrm{kg}^{-1}$ & $6,52 \pm 0,47$ & 7,2 \\
\hline $\mathrm{Fe}, \mu \mathrm{g} \mathrm{kg}^{-1}$ & $606 \pm 18$ & 3,0 \\
\hline $\mathrm{K}, \mathrm{mg} \mathrm{kg}^{-1}$ & $1,446 \pm 0,035$ & 2,4 \\
\hline $\mathrm{La}, \mu \mathrm{kg}^{-1}$ & $1223 \pm 32$ & 2,6 \\
\hline $\mathrm{Mg}, \%$ & $0,127 \pm 0,011$ & 8,7 \\
\hline $\mathrm{Mn}, \mathrm{mg} \mathrm{kg}^{-1}$ & $52,1 \pm 2,6$ & 5,0 \\
\hline $\mathrm{Pb}, \mathrm{mg} \mathrm{kg}^{-1}$ & $3,013 \pm 0,021$ & 0,7 \\
\hline $\mathrm{Rb}, \mathrm{mg} \mathrm{kg}^{-1}$ & $5,42 \pm 0,05$ & 0,9 \\
\hline $\mathrm{Sb}, \mu \mathrm{kg}^{-1}$ & $686,1 \pm 6,1$ & 0,9 \\
\hline Sc, $\mu \mathrm{g} \mathrm{kg}^{-1}$ & $112,9 \pm 2,3$ & 2,0 \\
\hline $\mathrm{V}, \mathrm{mg} \mathrm{kg}^{-1}$ & $3,16 \pm 0,36$ & 11,4 \\
\hline $\mathrm{Zn}, \mathrm{mg} \mathrm{kg}^{-1}$ & $58,8 \pm 1,4$ & 2,3 \\
\hline
\end{tabular}

M - Média aritmética; DP - Desvio padrão; DPR - Desvio padrão relativo 


\subsubsection{Limite de detecção e de quantificação dos elementos na análise de cascas de árvore}

Os resultados dos limites de detecção $\left(L_{D}\right)$, de quantificação $\left(L_{Q}\right)$ e das concentrações de elementos na NAA de uma amostra escolhida aleatoriamente de casca das espécies Tipuana e Sibipiruna são apresentados na Tabela 14. Os valores de $L_{D}$ e $L_{Q}$ foram inferiores às concentrações obtidas, indicando que 0 procedimento do método aplicado é adequado para a determinação destes elementos.

Tabela 14. Limites de detecção, de quantificação e concentrações de elementos obtidos em cascas de árvore das espécies Tipuana e Sibipiruna por NAA.

\begin{tabular}{|c|c|c|c|c|c|c|}
\hline & \multicolumn{3}{|c|}{ Tipuana } & \multicolumn{3}{|c|}{ Sibipiruna } \\
\hline & $L_{D}$ & $\mathrm{LQ}_{Q}$ & $C \pm I C$ & $L_{D}$ & $L_{Q}$ & $C \pm I C$ \\
\hline As, $\mu \mathrm{g} \mathrm{kg}^{-1}$ & 13,0 & 39,6 & $451,6 \pm 4,0$ & 6,6 & 20,2 & $105,3 \pm 1,8$ \\
\hline $\mathrm{Br}, \mathrm{mg} \mathrm{kg}^{-1}$ & 0,04 & 0,13 & $9,237 \pm 0,04$ & 0,02 & 0,06 & $1,34 \pm 0,01$ \\
\hline $\mathrm{Ca}, \%$ & 0,007 & 0,021 & $2,991 \pm 0,057$ & 0,005 & 0,016 & $3,043 \pm 0,058$ \\
\hline $\mathrm{Cl}, \mathrm{mg} \mathrm{kg}^{-1}$ & 14 & 44 & $319 \pm 13$ & 9,2 & 27,9 & $39,3 \pm 6,1$ \\
\hline Co $\mu \mathrm{g} \mathrm{kg}^{-1}$ & 2,9 & 8,7 & $526,7 \pm 6,8$ & 2,3 & 6,9 & $297,0 \pm 4,0$ \\
\hline $\mathrm{Cr} \mu \mathrm{g} \mathrm{kg}^{-1}$ & 39 & 119 & $3626 \pm 33$ & 27 & 83 & $2536 \pm 23$ \\
\hline Cs $\mu \mathrm{g} \mathrm{kg}^{-1}$ & 8,2 & 24,9 & $109,1 \pm 2,2$ & 4,3 & 12,9 & $83,4 \pm 1,5$ \\
\hline $\mathrm{Fe}, \mathrm{mg} \mathrm{kg}^{-1}$ & 3,2 & 9,8 & $864,1 \pm 4,7$ & 2,4 & 7,2 & $759,8 \pm 4,1$ \\
\hline $\mathrm{K}, \mathrm{mg} \mathrm{kg}^{-1}$ & 14 & 42 & $1213 \pm 12$ & 5,6 & 17,0 & $1428,2 \pm 7,0$ \\
\hline $\mathrm{La} \mu \mathrm{g} \mathrm{kg}^{-1}$ & 2,5 & 7,5 & $1344,0 \pm 4,5$ & 1,9 & 5,7 & $994,9 \pm 3,3$ \\
\hline $\mathrm{Mg}, \%$ & 0,03 & 0,08 & $0,29 \pm 0,02$ & 0,012 & 0,036 & $0,067 \pm 0,008$ \\
\hline $\mathrm{Mn}, \mathrm{mg} \mathrm{kg}^{-1}$ & 0,41 & 1,24 & $33,51 \pm 0,93$ & 0,35 & 1,06 & $30,50 \pm 0,81$ \\
\hline $\mathrm{Ni}, \mathrm{mg} \mathrm{kg}^{-1}$ & 1,94 & 5,90 & $4,41 \pm 0,42$ & 1,09 & 3,31 & $1,99 \pm 0,24$ \\
\hline $\mathrm{Rb}, \mathrm{mg} \mathrm{kg}^{-1}$ & 0,12 & 0,35 & $4,65 \pm 0,09$ & 0,097 & 0,294 & $3,504 \pm 0,073$ \\
\hline $\mathrm{Sb} \mu \mathrm{g} \mathrm{kg}^{-1}$ & 6,7 & 20,4 & $905 \pm 13,6$ & 6 & 18 & $687 \pm 11$ \\
\hline $\mathrm{Sc} \mu \mathrm{g} \mathrm{kg}^{-1}$ & 0,51 & 1,55 & $177,69 \pm 0,80$ & 0,29 & 0,88 & $132,12 \pm 0,59$ \\
\hline $\mathrm{V}, \mathrm{mg} \mathrm{kg}^{-1}$ & 0,705 & 2,14 & $10,14 \pm 0,51$ & 0,082 & 0,250 & $1,262 \pm 0,062$ \\
\hline $\mathrm{Zn}, \mathrm{mg} \mathrm{kg}^{-1}$ & 0,2 & 0,6 & $472,1 \pm 8,9$ & 0,13 & 0,40 & $47,14 \pm 0,89$ \\
\hline
\end{tabular}

$\mathrm{C} \pm \mathrm{IC}=$ concentração do elemento com a incerteza calculada considerando erros nas taxas de contagens da amostra e padrão.

Na Tabela 15 são apresentados os valores de $L_{D}$ e de $L_{Q}$ determinados para $\mathrm{Cd}$, Cu e Pb para uma massa de amostra de 0,2000 g, bem como as concentrações médias obtidas na análise de cascas de árvore por AAS e seus respectivos intervalos de concentrações. Os limites de detecção e de quantificação 
foram considerados adequados para a utilização do método na AAS na determinação de $\mathrm{Cd}$, $\mathrm{Cu}$ e $\mathrm{Pb}$ nas cascas de árvore, uma vez que estes limites foram inferiores às concentrações das amostras de cascas de árvore.

Tabela 15. Médias, intervalo de concentrações, limites de detecção e de quantificação de elementos nas análises de cascas de Tipuana e Sibipiruna por AAS.

\begin{tabular}{ccccc}
\hline Elemento & $\begin{array}{c}\text { Concentração } \\
\text { média }\left(\mu \mathrm{kg}^{-1}\right)\end{array}$ & $\begin{array}{c}\text { Intervalo de } \\
\text { concentração }\left(\mu \mathrm{kg}^{-1}\right)\end{array}$ & $\mathrm{LD}, \mu \mathrm{g} \mathrm{kg}$ & $\mathrm{LQ}, \mu \mathrm{kg}^{-1}$ \\
\hline $\mathrm{Cd}$ & 514 & $33-3450$ & 1,27 & 4,2 \\
$\mathrm{Cu}$ & 23820 & $5427-92920$ & 0,38 & 1,3 \\
$\mathrm{~Pb}$ & 8832 & $326-52340$ & 34 & 113 \\
\hline
\end{tabular}

\subsubsection{Concentrações dos elementos em função da espessura da casca analisada.}

Os resultados obtidos nas análises de diferentes camadas das cascas de Sibipiruna e Tipuana são apresentados na Figura 11. Em ambas as espécies arbóreas os elementos As, Br, Cr, Fe, La, Pb, Sb Sc e Zn apresentaram altas concentrações na camada externa da casca $(1 \mathrm{~mm}$ de espessura da camada externa) em relação à camada interna (entre 1 e $2 \mathrm{~mm}$ da camada subsequente à remoção da camada externa), e os elementos $\mathrm{Ca}$, Cd e Kapresentaram na mesma ordem de grandeza nas duas camadas. A espécie Sibipiruna apresentou concentração de Co mais alta na camada externa e para os elementos Cs e Rb foram da mesma ordem de grandeza nas duas camadas. Para a espécie Tipuana, o Co apresentou na concentração da mesma ordem de grandeza em ambas as camadas, ao passo que Cs e Rb apresentaram maiores concentrações na camada externa.

A maioria dos elementos determinados apresentaram concentrações mais altas na camada externa das cascas e isto se deve à deposição de material particulado na superfície da casca. 

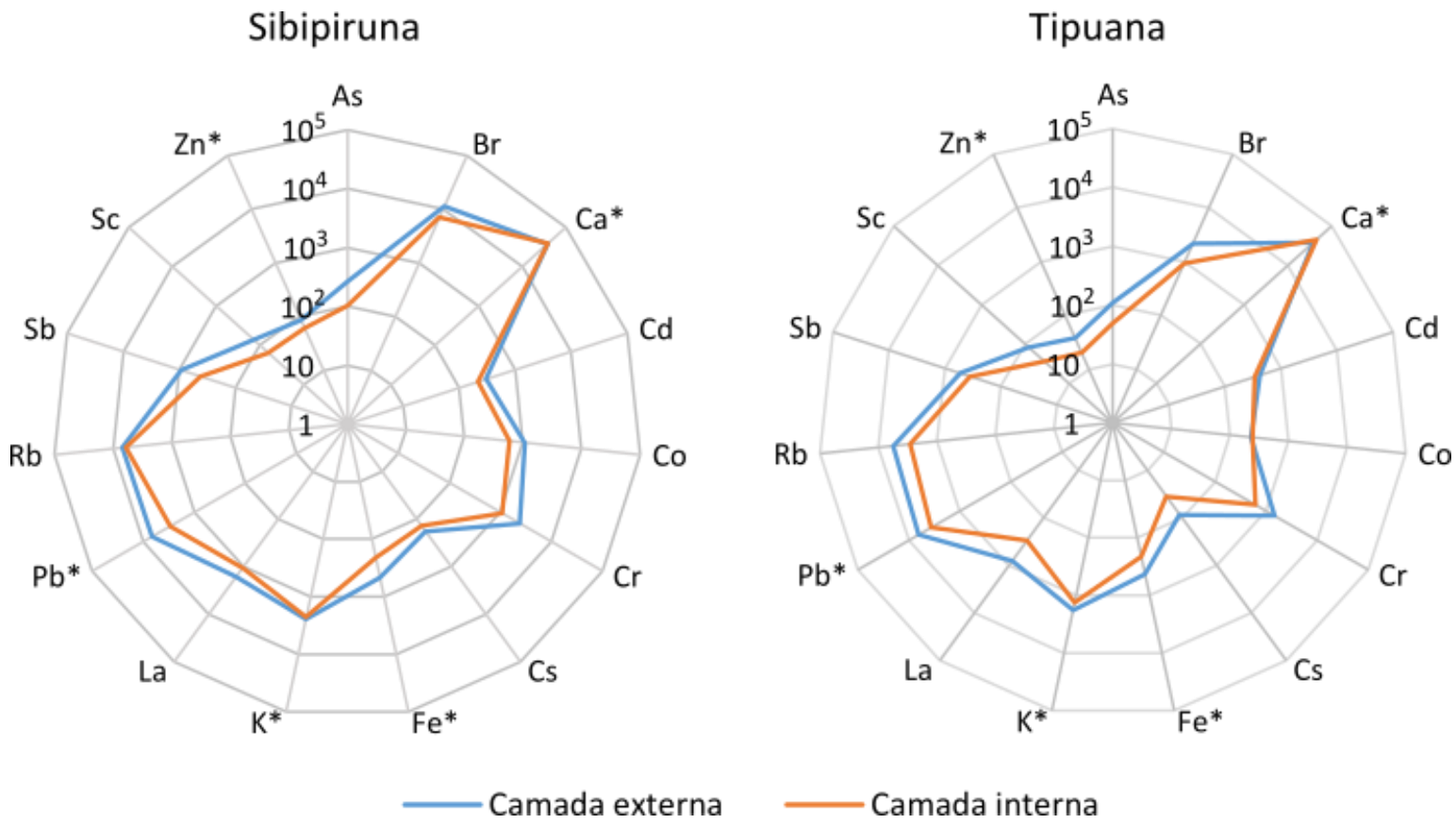

Figura 11. Gráfico das concentrações dos elementos (em $\mu \mathrm{g} \mathrm{kg}^{-1} \mathrm{e}^{*} \mathrm{mg} \mathrm{kg}{ }^{-1}$ ) presentes na camada externa e camada interna das cascas de Sibipiruna e Tipuana.

Devido à variabilidade nas concentrações dos elementos nas diferentes camadas das cascas das árvores, foi estabelecido utilizar para análise os $2 \mathrm{~mm}$ de espessura da camada superficial das cascas de árvore para padronização do preparo das amostras para análise.

\subsubsection{Concentrações dos elementos em cascas coletadas de diferentes faces do tronco das árvores.}

Para verificar se há diferença entre as concentrações dos elementos presentes nas cascas coletadas em faces opostas do tronco de uma mesma árvore da espécie Tipuana foram obtidos os resultados apresentados na Figura 12. Os elementos As, Cd, Cr, Cs, Fe, La, Pb, Sb e Sc apresentaram concentrações mais altas na casca do tronco na face sul e para os elementos $\mathrm{Br}, \mathrm{Ca}, \mathrm{Co}, \mathrm{K}, \mathrm{Rb}$ e $\mathrm{Zn}$ foram da mesma ordem de grandeza em ambas as faces. Estas diferenças nas concentrações dos elementos podem ser devido à influência da direção dos ventos, inclinação da árvore e condições ambientais do entorno (presença de prédios, proximidade das vias ou garagens). Baseado nestes resultados, optou-se para coletar as amostras de cascas de árvore no entorno do tronco, a fim de se obter amostras homogêneas e representativas. 


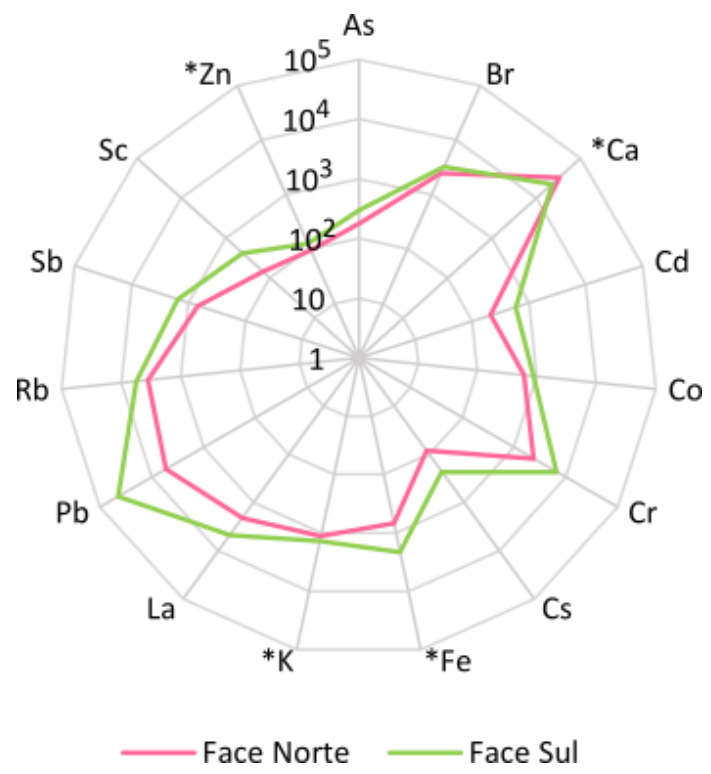

Figura 12. Concentrações dos elementos $\left(\mu \mathrm{g} \mathrm{kg}^{-1} \mathrm{e}^{*} \mathrm{mg} \mathrm{kg}^{-1}\right)$ nas cascas de árvore da espécie Tipuana coletadas nas faces norte e sul do tronco.

\subsection{Concentrações de elementos obtidos nas análises das amostras de casca de árvore}

\subsubsection{Comparação entre as espécies Tipuana e Sibipiruna com relação aos teores dos elementos presentes nas cascas.}

Nas Figuras 13 e 14 são apresentados os resultados das concentrações médias elementos presentes nas cascas das espécies Tipuana e Sibipiruna nas regiões de Cerqueira César, Congonhas, Parque Dom Pedro II, Pinheiros, Santo André - Paço Municipal e São Miguel Paulista, respectivamente.

As concentrações da maioria dos elementos analisados foram da mesma ordem de grandeza ou mais altas na casca da espécie Tipuana nas regiões de Cerqueira César, Congonhas, Parque Dom Pedro II, Pinheiros e Santo André Paço Municipal com exceção para os elementos $\mathrm{Mn}$ e Sb que apresentaram concentrações mais elevadas para a espécie Sibipiruna na região de Cerqueira César. As amostras de Sibipiruna coletadas na região de São Miguel Paulista apresentaram concentrações médias de $\mathrm{Cl}$, Co, Cs e Ni maiores, enquanto que o elemento $\mathrm{Zn}$ foi maior para a espécie Tipuana. Os demais elementos apresentaram concentrações da mesma ordem de grandeza para as duas espécies. O elemento $\mathrm{Ni}$ apresentou concentrações abaixo do limite de detecção para a espécie Sibipiruna nas regiões de Cerqueira César, Pinheiros e Santo André - Paço Municipal. 


\section{Cerqueira César}

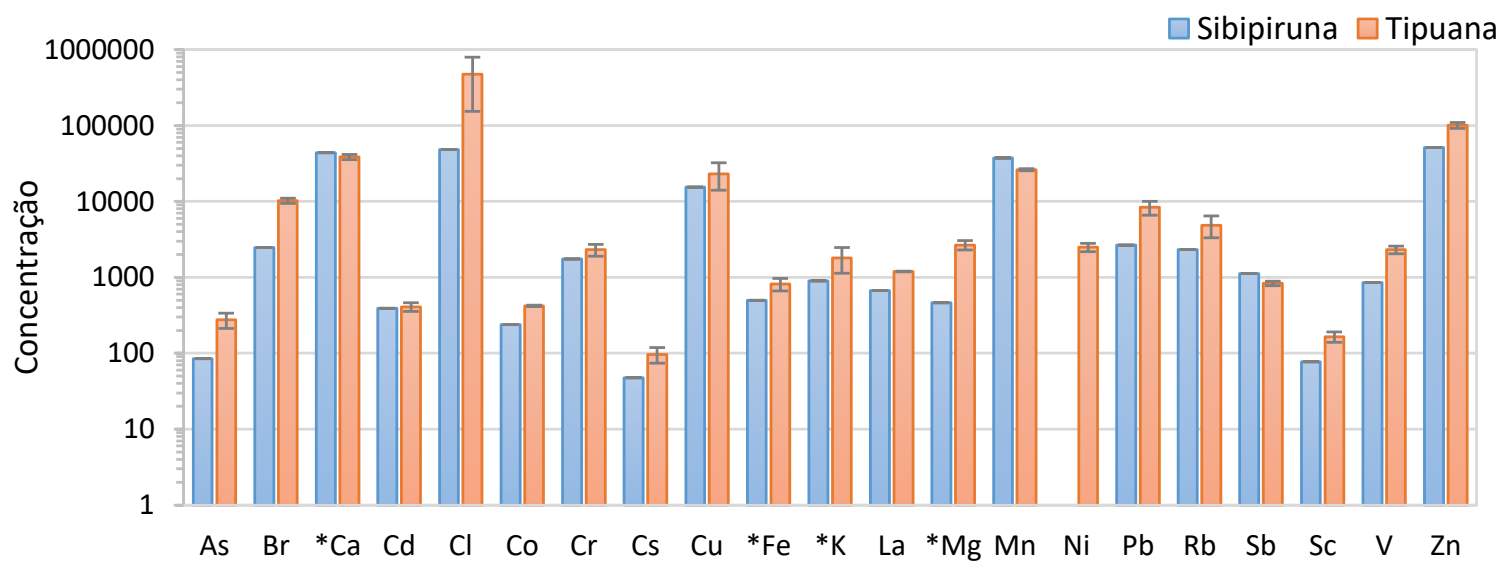

Congonhas

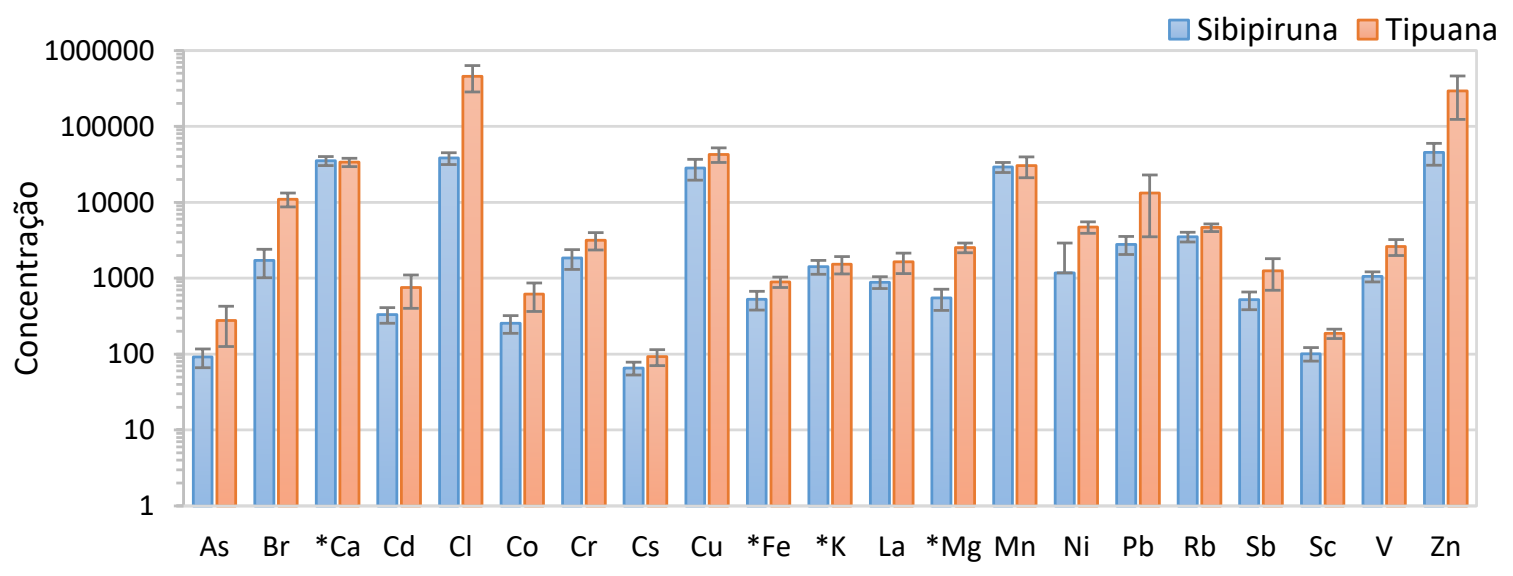

Parque Dom Pedro II

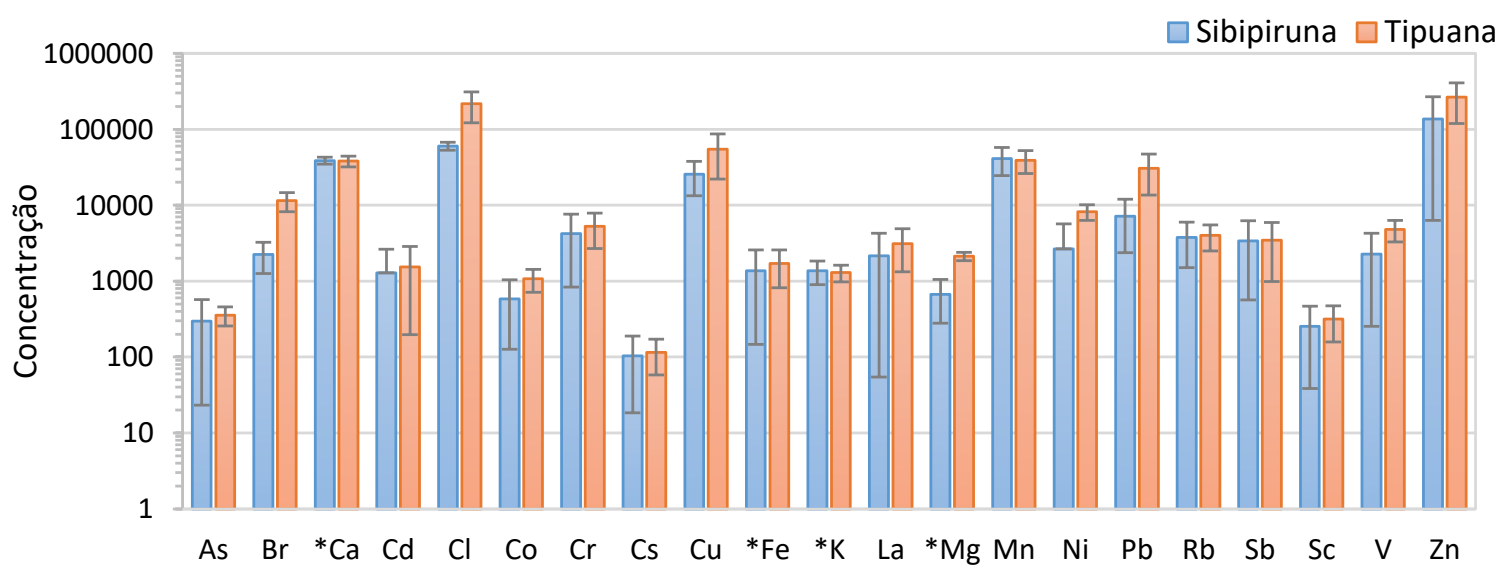

Figura 13. Concentrações dos elementos (em $\mu \mathrm{gg}^{-1} \mathrm{e}^{*} \mathrm{mg} \mathrm{kg}^{-1}$ ) presentes nas cascas das espécies Sibipiruna e Tipuana nas regiões de Cerqueira César, Congonhas e Parque Dom Pedro II. 
Pinheiros



\section{Santo André - Paço Municipal}

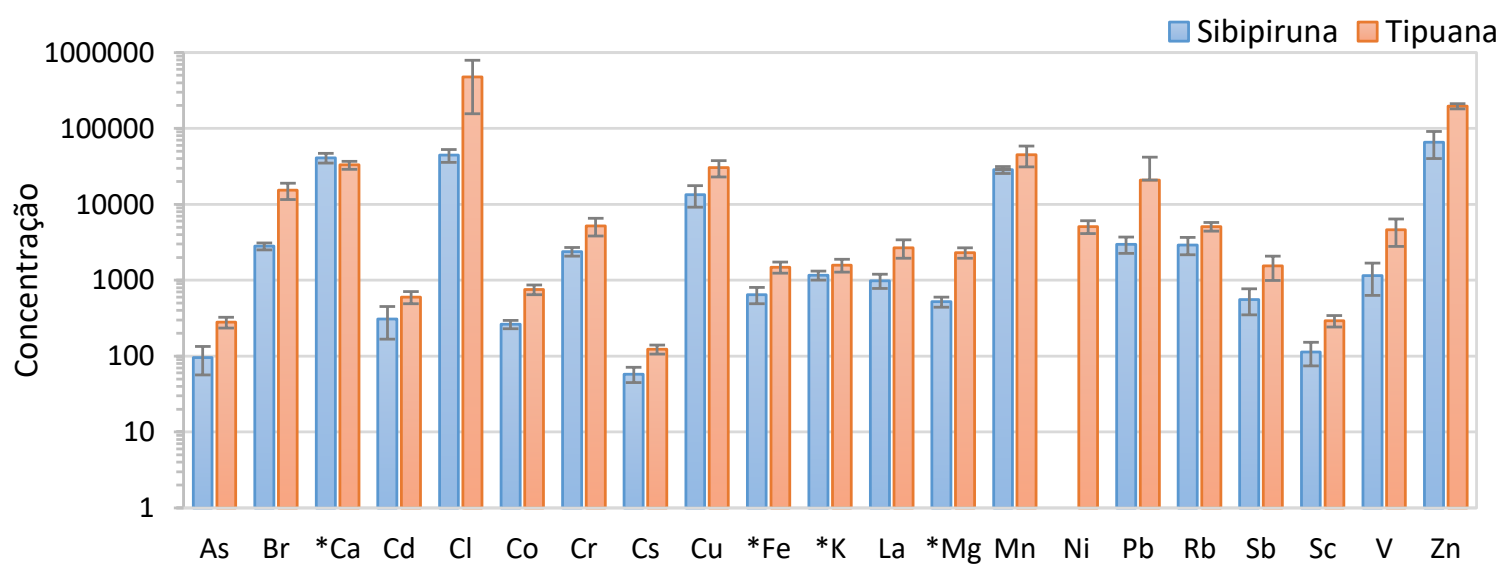

São Miguel Paulista



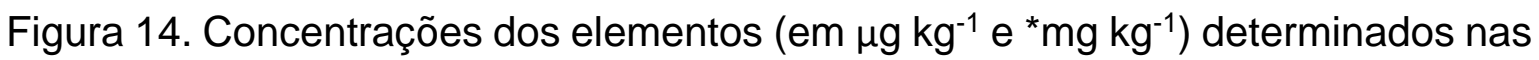
cascas das espécies Sibipiruna e Tipuana nas regiões de Pinheiros, Santo André Paço Municipal e São Miguel Paulista. 
Os resultados obtidos indicaram que a espécie Tipuana apresenta concentrações mais altas para a maioria dos elementos em relação à Sibipiruna, podendo ser devido às diferenças estruturais entre as cascas destas duas espécies. A casca da Tipuana é mais porosa e rugosa em relação a Sibipiruna, o que favorece maior acúmulo de material particulado em sua superfície. Neste sentido, esta espécie seria a mais indicada para o biomonitoramento da poluição do ar. Entretanto, devido à Tipuana não ser uma árvore nativa, sua localização em áreas não poluídas para o estabelecimento de uma amostra controle é dificultada, uma vez que no Brasil, esta árvore é utilizada somente para arborização de centros urbanos. Ao passo que a Sibipiruna é uma espécie nativa da Mata Atlântica, possibilitando sua localização no Brasil em áreas de mais afastadas de emissões antrópicas.

\subsubsection{Concentrações de elementos nas cascas de árvores de diferentes regiões de amostragem}

Os resultados das concentrações de elementos nas amostras de cascas de árvore das espécies Sibipiruna e Tipuana para todos os pontos de amostragem estão nas Tabelas C.1, C.2 e C.3 Apêndice C. Nas Figuras 15, 16 e 17 são apresentadas as concentrações médias dos elementos determinados. Os resultados das concentrações médias por região de amostragem para todos os elementos determinados são apresentados nas Tabelas D.1 a D.5 do Apêndice D.

Em uma avaliação preliminar dos resultados das Figuras 8 e 9 é observada ampla variabilidade nos teores de alguns elementos nas cascas coletadas em determinadas regiões de amostragem. Esta variabilidade está relacionada às características de emissão dos pontos de amostragem. De um modo geral, as cascas que foram coletadas na RMSP apresentaram teores mais elevados de $\mathrm{As}, \mathrm{Cd}, \mathrm{Pb}, \mathrm{Sb}$ e $\mathrm{Zn}$ que podem ser proveniente de ressuspensão do solo e emissões veiculares (Géguen, 2012). Os pontos de amostragem das regiões controle, em sua maioria, apresentaram menores teores de $\mathrm{Cd}, \mathrm{Cu}, \mathrm{Mn}, \mathrm{Pb}, \mathrm{Rb}, \mathrm{Sb}$ e $\mathrm{Zn}$. Moreira et al. (2017) apresentaram em trabalho recente que as vias podem ser classificadas quanto às suas diferentes intensidades de fluxo veicular por meio da determinação de elementos em amostras de cascas de árvore. 
As

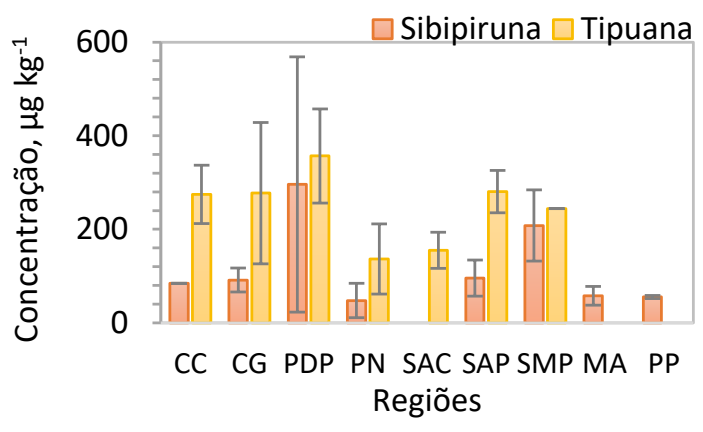

$\mathrm{Ca}$

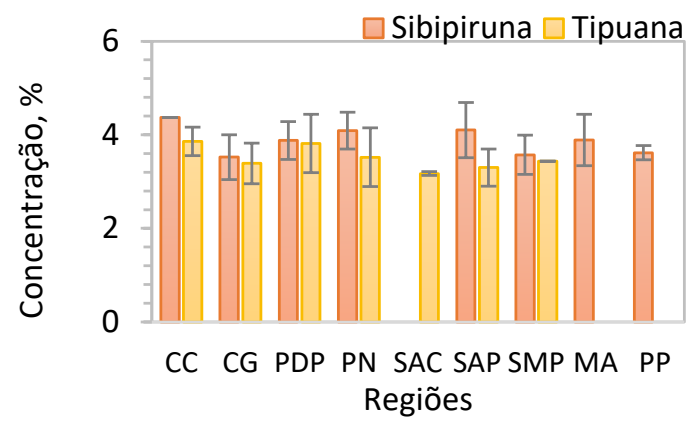

$\mathrm{Cl}$



$\mathrm{Cr}$

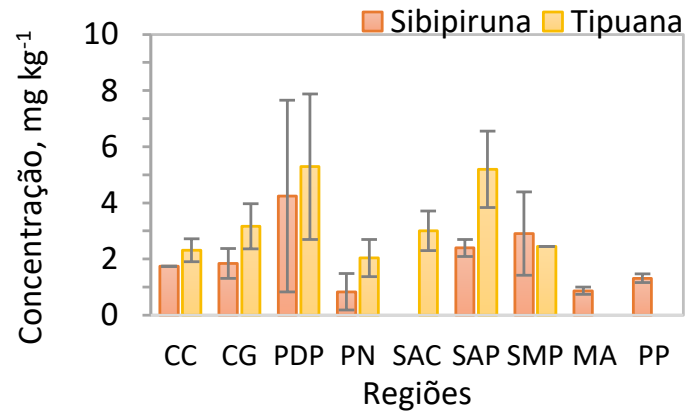

$\mathrm{Br}$

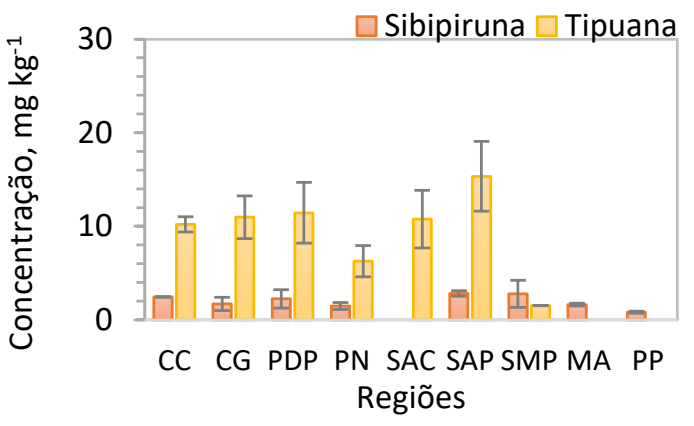

$\mathrm{Cd}$

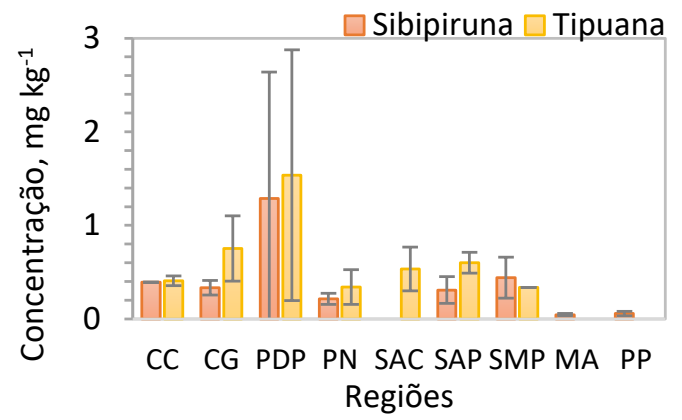

Co



Cs

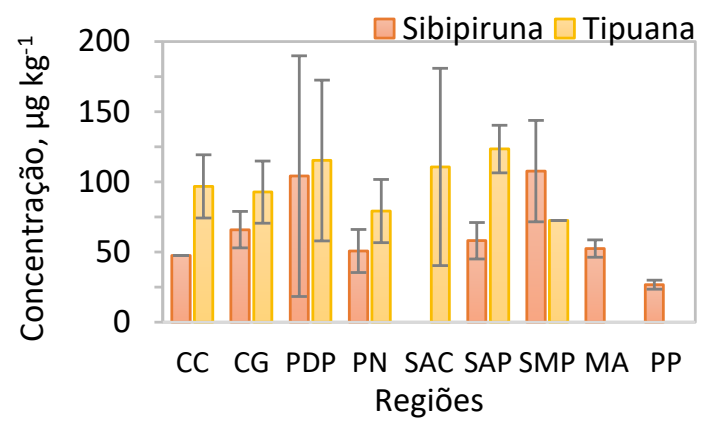

Figura 15. Concentrações médias de $\mathrm{As}, \mathrm{Br}, \mathrm{Ca}, \mathrm{Cd}, \mathrm{Cl}, \mathrm{Co}, \mathrm{Cr}$ e Cs nas cascas de Tipuana e Sibipiruna coletadas em Cerqueira César (CC), Congonhas (CG), Parque Dom Pedro II (PDP), Pinheiros (PN), Santo André - Capuava (SAC), Santo André Paço municipal (SAP), São São Miguel Paulista (SMP), Marília (MA) e Presidente Prudente (PP). 

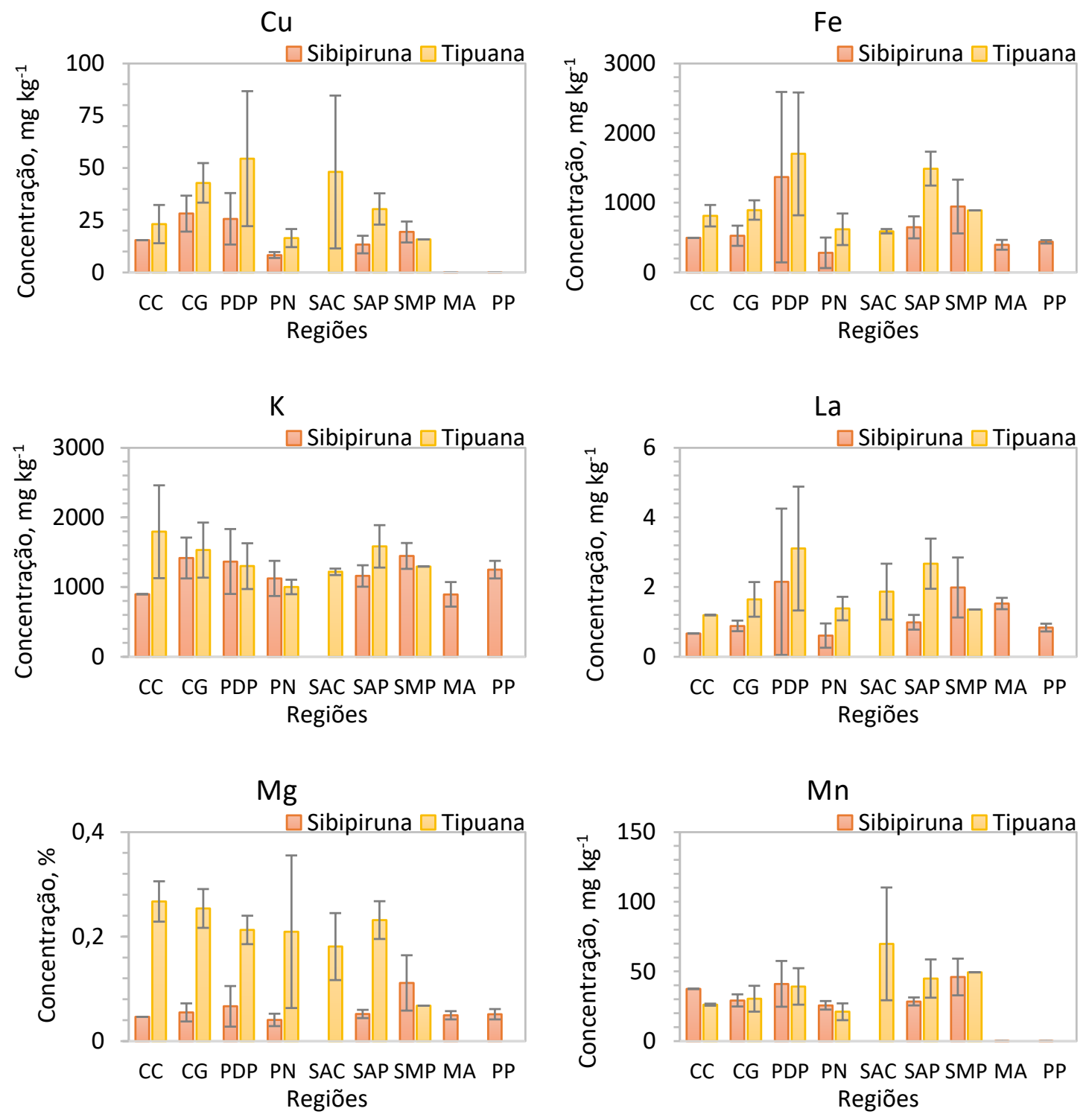

$\mathrm{Ni}$

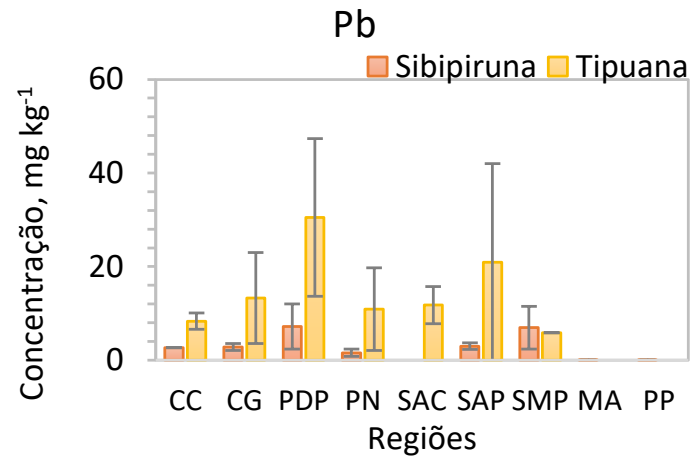

Figura 16. Concentrações médias de $\mathrm{Cu}, \mathrm{Fe}, \mathrm{K}, \mathrm{La}, \mathrm{Mg}, \mathrm{Mn}, \mathrm{Ni}, \mathrm{Pb}$ nas cascas de Tipuana e Sibipiruna coletadas em Cerqueira César (CC), Congonhas (CG), Parque Dom Pedro II (PDP), Pinheiros (PN), Santo André - Capuava (SAC), Santo André Paço municipal (SAP), São Miguel Paulista (SMP), Marília (MA) e Presidente Prudente (PP). 

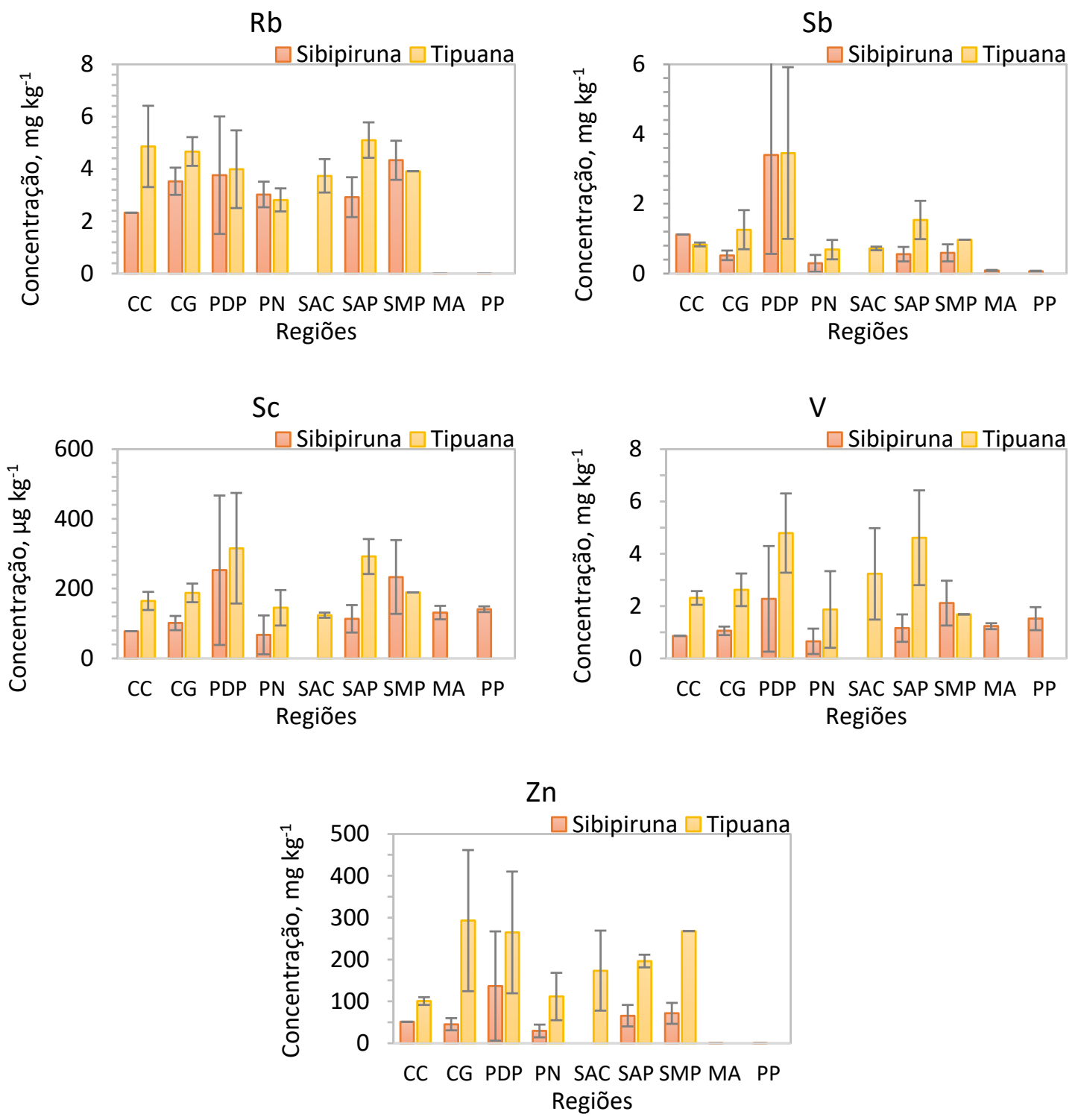

Figura 17. Concentrações médias de Rb, Sb, Sc, $\mathrm{V}$ e Zn nas cascas de Tipuana e Sibipiruna coletadas em Cerqueira César (CC), Congonhas (CG), Parque Dom Pedro II (PDP), Pinheiros (PN), Santo André - Capuava (SAC), Santo André Paço municipal (SAP), São Miguel Paulista (SMP), Marília (MA) e Presidente Prudente (PP).

Para associar os resultados das Figuras 14 a 16 com o nível de poluição, são apresentadas nas Figuras de B1 a B9 do Apêndice B, os pontos de amostragem das cascas. 


\section{Ponto de amostragem da região Cerqueira César (Figura B.1)}

Os resultados obtidos para a espécie Sibipiruna foram determinados somente de uma amostra composta para espécie Sibipiruna localizada no ponto CC1. As concentrações de Ca obtidas nas cascas de Sibipiruna coletadas nesta região foram as mais altas em relação às demais regiões de amostragem.

As amostras obtidas a partir das cascas de Tipuana apresentaram elevadas concentrações médias de $\mathrm{Cl}, \mathrm{K}, \mathrm{Mg}$ e $\mathrm{Rb}$ sendo da mesma ordem de grandeza das concentrações obtidas nas regiões de Congonhas e Santo André Paço Municipal. A alta circulação de ônibus no ponto de amostragem CC3 (Vide Figuras B.1 no Apêndice B) localizado na Avenida Doutor Arnaldo pode ser responsável pelas elevadas concentrações de $\mathrm{Ca}$ e $\mathrm{Mg}$, uma vez que estes elementos compõem grande parte do material particulado gerado pela queima de óleo diesel (WANG et al., 2003).

Os resultados obtidos correspondentes ao ponto de amostragem CC3 apresentaram elevadas concentrações de $\mathrm{Rb}, \mathrm{As}, \mathrm{K}, \mathrm{Cs}, \mathrm{Sc}, \mathrm{Cl}$ e $\mathrm{Cu}$ em relação ao ponto CC2, podendo ser devido ao maior fluxo de veículos no ponto CC3.

Um estudo da poluição atmosférica realizado em diferentes regiões da RMSP apresentou elevado enriquecimento de Sb em amostras de bromélias da espécie Tillandsia usneoides $L$. coletadas na região de Cerqueira César (FIGUEIREDO et al., 2007) e foi correlacionado às emissões veiculares.

\section{Ponto de amostragem da região de Congonhas (figura B.2)}

$\mathrm{Na}$ região de Congonhas os elementos que apresentaram maior variabilidade nas suas concentrações foram $\mathrm{Br}, \mathrm{Cu}, \mathrm{Ni}$ e $\mathrm{Zn}$ para a espécie Sibipiruna devido às altas concentrações destes elementos encontradas nas amostras coletadas nos ponto de amostragem CG3 e CG6, ambos próximos ao Corredor Norte-Sul e a Avenida dos Bandeirantes, sendo estas duas vias de alta circulação de veículos leves e pesados. Os resultados das concentrações para a espécie Tipuana foram mais elevadas para os elementos As e Zn para o ponto de amostragem CG5 e, Cd, Co, Mn, Pb para o ponto CG2, ambos os pontos próximos à vias de intenso fluxo veicular.

Vale ainda ressaltar que as amostras de Tipuana coletadas na região de Congonhas apresentaram maior concentração média de $\mathrm{Zn}$ em relação às demais regiões da RMSP. Os pontos de amostragem CG3, CG5 e CG6 apresentaram altas 
concentrações de Zn, uma vez que estes pontos estão de maior proximidade do cruzamento do Corredor Norte-Sul com a Avenida dos Bandeirantes e da pista do aeroporto de Congonhas. As elevadas concentrações de Zn podem estar relacionadas às emissões do desgaste de pneus dos veículos bem como das aeronaves que circulam pelo aeroporto. Em um estudo realizado por Valotto et al. (2014) foi relatado que altas concentrações de Zn podem estar presentes no material particulado fino $\left(\mathrm{MP}_{1}\right)$ das emissões de aeronaves devido ao intenso desgastes dos pneus dos aviões durante o pouso. Fuga et al. (2008) também encontraram concentrações de Zn mais elevadas em líquens coletados na região de Congonhas em relação aos coletados em outros distritos da RMSP.

No estudo de Figueiredo et al. (2007) foi observado elevado enriquecimento de $\mathrm{Ba}$ e $\mathrm{Ca}$ nas amostras de $T$. usneoides $L$. coletadas na região de Congonhas e estes dois elementos foram correlacionados à emissões provenientes de motores a diesel, uma vez que estes elementos estão presentes em aditivos redutores de fumaça da queima de diesel.

Pontos de amostragem da região do Parque Dom Pedro II (Figura B.3)

A região do Parque Dom Pedro II foi a que apresentou maior variabilidade nas concentrações dos elementos para ambas as espécies devido às amostras coletadas no ponto de amostragem DP4 que, dentre os demais pontos de amostragem da região, foi o que apresentou altas concentrações para a maioria dos elementos, provavelmente devido ao intenso fluxo de carros, ônibus e principalmente caminhões que frequentam os mercados cerealistas deste local.

As concentrações médias de As, Cd, Fe e Sb foram as mais elevadas na região do Parque Dom Pedro II em relação às demais regiões da RMSP para ambas as espécies estudadas, podendo indicar que o tráfego veicular intenso nesta região provoca o incremento destes elementos no material particulado suspenso na região.

Em relação às amostras de cascas da espécie Tipuana coletadas no Parque Dom Pedro II, as concentrações de Cu, La, Pb e Sc foram mais elevadas em comparação as demais regiões da RMSP, ao passo que para a espécie Sibipiruna, as concentrações mais elevadas foram para os elementos $\mathrm{Cr}$ e $\mathrm{Zn}$. As altas concentrações destes elementos nesta região de amostragem podem ser 
ocasionadas pela ressuspensão de poeira do solo, queima de combustíveis fósseis e desgaste de peças dos motores.

Foi verificado elevado acúmulo de $\mathrm{Ba}$ em amostras de T. usneoides coletadas na região Parque Dom Pedro II (FIGUEIREDO et al., 2007) sendo também relacionado às emissões veiculares.

\section{Pontos de amostragem da região de Pinheiros (Figura B.4)}

A região de Pinheiros foi a que apresentou baixas concentrações médias de As, Cd, Cr, Cs, Cu, Mn, Ni, V e Zn para ambas as espécies em relação à aquelas obtidas nas cascas de árvores das demais regiões de amostragem da RMSP. O estudo realizado por meio de biomonitoramento com cascas de árvores em diferentes distritos da RMSP feito por Oliveira et al. (2017) também indicou menores concentrações dos elementos nas amostras coletadas na região de Pinheiros em relação aos demais distritos da RMSP. Além disso, as concentrações obtidas nas cascas coletadas em Pinheiros foram semelhantes às obtidas neste trabalho, com concentração mediana de $\mathrm{Mn}$ de $27,435 \mathrm{mg} \mathrm{kg}^{-1}$, valor baste aproximado aos obtidos no presente trabalho para ambas espécies arbóreas, Sibipiruna (25,65 mg $\mathrm{kg}^{-1}$ ) e Tipuana $\left(21,10 \mathrm{mg} \mathrm{kg}^{-1}\right)$. O mesmo foi observado para o $\mathrm{Fe}$, no trabalho de Oliveira et al. (2017) a concentração mediana de Fe foi de $472 \mathrm{mg} \mathrm{kg}^{-1}$, sendo este da mesma ordem de grandeza das concentrações obtidas no presente trabalho, correspondentes a $282 \mathrm{mg} \mathrm{kg}^{-1}$ e $619 \mathrm{mg} \mathrm{kg}^{-1}$ para as espécies Sibipiruna e Tipuana, respectivamente. Por fim, o elemento $\mathrm{Cu}$ apresentou concentração de $5,645 \mathrm{mg} \mathrm{kg}^{-1}$ no trabalho de Oliveira et al. (2017) valor mais aproximado ao obtido para as amostras de Sibipiruna $\left(8,3 \mathrm{mg} \mathrm{kg}^{-1}\right)$ obtido no presente trabalho.

No trabalho de Fuga et al. (2008), os líquens coletados em Pinheiros apresentaram concentrações dos elementos inferiores em relação às de demais distritos e no tratamento dos dados pela análise de clusters a região de Pinheiros agrupou com as regiões dos parques localizados na RMSP (Parque do Ibirapuera e Instituto de Botânica).

Os resultados obtidos por Figueiredo et al. (2007) também indicaram menores concentrações de $\mathrm{Cr}$ e $\mathrm{Zn}$ nas bromélias coletadas em Pinheiros em relação aos dos demais distrito da RMSP. O enriquecimentos obtido para estes elementos foi da mesma ordem de grandeza ou inferiores aos obtidos para as amostras coletadas na região do parque do Ibirapuera. 
Os resultados obtidos neste trabalho mostraram baixas concentrações de diversos elementos na região de Pinheiros. As vias dos pontos de amostragem desta região são de baixo fluxo veicular em relação às demais regiões estudadas, podendo justificar as baixas concentrações dos elementos obtidas. Além disso, estas regiões são amplamente arborizadas com árvores de copas densas e encorpadas, o que pode ocasionar menor acúmulo de material particulado por deposição úmida na superfície das cascas.

Pontos de amostragem da região de Santo André - Capuava (Figura B.5)

Dentre as espécies arbóreas escolhidas para o estudo, somente foram encontradas árvores de Tipuana em dois pontos de amostragem na região de Santo André-Capuava e as concentrações médias de elementos obtidas apresentaram ampla variabilidade entre os pontos. O ponto CA2 apresentou concentrações mais elevadas de $\mathrm{Cd}$, Co, Cu, La, Mn, Ni, Pb e V em relação ao ponto CA1. Isto pode ser devido ao polo petroquímico que está localizado mais próximo do ponto CA2, a uma distância de aproximadamente $400 \mathrm{~m}$, ao passo que o ponto CA1 está em torno de $1700 \mathrm{~m}$ de distância do polo petroquímico.

Vale destacar que a concentração média de Mn em Santo AndréCapuava foi a mais alta dentre as demais regiões de amostragem. $\mathrm{O}$ Mn presente em material particulado muitas vezes é associado à ressuspensão do solo devido à sua abundância na litosfera, entretanto estudos também tem associando ao enriquecimento deste elemento às emissões antrópicas. Os líquens coletados por Fuga et al. (2008) em Santo André-Capuava também apresentaram concentrações de Mn muito maiores do que as demais regiões da RMSP, e este fato foi associado às emissões industriais. Além disso, no trabalho de Paulino et al. (2014) foram encontrados elevados teores de Mn juntamente com $\mathrm{Ca}, \mathrm{Mg}$, Fe e Cu em material particulado fino $\left(\mathrm{MP}_{2,5}\right)$ próximo à indústria petroquímica.

Pontos de amostragem da região de Santo André - Paço Municipal (Figura B.6)

A região de Santo André -Paço Municipal foi a que apresentou teores mais elevados de Br nas amostras de ambas as espécies Tipuana e Sibipiruna em relação as demais regiões da RMSP, podendo ser proveniente das indústrias 
localizadas na região. No trabalho de Fuga et al. (2008) dentre as amostras de líquens coletadas na RMSP, aquelas coletadas na região central de Santo André foram as que apresentaram as maiores concentrações de $\mathrm{Br}$, e estes autores atribuíram à atividade industrial da região.

As amostras das cascas de Tipuana coletadas na região de Santo André - Paço Municipal apresentaram elevados teores $\mathrm{Cr}$, sendo da mesma ordem de grandeza das obtidas no Parque Dom Pedro II, podendo ser de origem de emissões veiculares. O trabalho de Figueiredo et al. (2007) relaciona os elevados teores de Cr presentes nas bromélias coletadas na região de Santo André com emissões industriais.

Pontos de amostragem da região de São Miguel Paulista (Figura B.7)

Na região de São Miguel Paulista destacaram-se os elementos Co e Ni que apresentaram concentrações médias muito elevadas em relação às de demais regiões de amostragem para ambas as espécies estudadas. Além disso, estes elementos apresentaram ampla variabilidade nas concentrações na região devido às amostras coletadas nos pontos SM4 e SM7 próximos à indústria de processamento de minério contendo estes metais. Líquens e bromélias coletadas na região de Santo André - Capuava também apresentaram concentrações de Co muito mais elevadas em relação as demais regiões da RMSP (FUGA et al., 2008; FIGUEIREDO et al., 2007).

Com relação às amostras da espécie Sibipiruna, foram observadas elevadas concentrações médias de $\mathrm{Cs}, \mathrm{Mg}, \mathrm{Mn}$ e Rb em comparação com as obtidas nas demais regiões da RMSP, devido provavelmente a ressuspensão do solo, emissões veiculares e às atividades industriais da região.

Pontos de amostragem das regiões de Marilia e Presidente Prudente (Figuras B.8 e B.9)

Os resultados obtidos das amostras coletadas nas regiões controle Marília e Presidente Prudente apresentaram concentrações médias de Cd, Cl, Cs, $\mathrm{Cu}, \mathrm{Mn}, \mathrm{Pb}, \mathrm{Rb}, \mathrm{Sb}$ e $\mathrm{Zn}$ inferiores em relação aos resultados obtidos na RMSP. Isto pode ser um indicativo de que estes elementos estejam relacionados aos níveis de emissões veiculares, uma vez que nas regiões controle a intensidade de fluxo veicular é muito menor do que na RMSP. 


\subsubsection{Estudo da correlação das concentrações de elementos obtidos nas cascas de árvore}

Aos resultados das análises das cascas de árvore foram aplicados testes estatísticos para verificar se há uma correlação entre os elementos determinados bem como os agrupamentos entre as diferentes regiões de amostragem e entre os elementos para identificar suas possíveis origens.

\subsubsection{Correlação entre os elementos}

Na Tabela 16 é apresentada a matriz de correlação de Pearson obtida para as concentrações dos elementos determinados nas cascas das espécies Sibipiruna e Tipuana. Os coeficientes de correlação de Pearson maiores que 0,70 estão em vermelho negrito nesta tabela.

Pode-se verificar que Co apresentou alta correlação com $\mathrm{Ni}$ e isto pode ser um indicativo de identificação de fonte industrial proveniente da metalúrgica localizada em São Miguel Paulista. Como visto no item 6.4.2 do Capítulo 6, esta região apresentou concentrações médias de Co e Ni superiores que as de outras regiões estudadas neste trabalho.

Também pode-se verificar na Tabela 16 que os elementos As, Cd, Cr, Cs, Fe, La, Sb, Sc, V e Zn apresentaram altas correlações que podem estar relacionadas com a ressuspensão do solo e com as emissões veiculares decorrentes da queima de combustíveis e desgaste de peças de veículos. As correlações existentes entre os elementos $\mathrm{Cr}$, Fe, $\mathrm{La}$ e $\mathrm{Pb}$ bem como as correlações entre Cr, Fe, La e Pb foram verificadas por Wang et al. (2003), Silva et al. (2010) e Guéguen et al. (2012).

As correlações entre $\mathrm{Cd}, \mathrm{Cu}, \mathrm{V}$ e $\mathrm{Zn}$ obtidas podem estar relacionadas com as emissões veiculares, uma vez que estes elementos podem se originar dos desgastes de peças de veículos e queima de óleo combustível, como relatado por Silva (2007).

Indícios de fonte de material particulado proveniente de aerossol marinho podem estar relacionados às correlações entre $\mathrm{Br}, \mathrm{Cl}, \mathrm{Mg}$ e $\mathrm{V}$ (CESARI et al., 2016; WANG et al., 2006).

No presente trabalho foi também verificada altas correlações do $\mathrm{Br}$ com os elementos $\mathrm{Mg}$ e $\mathrm{V}$ e do $\mathrm{Cl}$ com $\mathrm{Br}$ e Mg. Cesari et al. (2016) que analisaram material particulado na região central da Itália atribuíram a presença dos elementos 
$\mathrm{Br}, \mathrm{Cl}$ e Mg como de origem marinha. Já Wang et al. (2006) que analisaram material particulado da cidade de Guangzhou na China explicaram a origem do $\mathrm{Cl}$ como das emissões da combustão de carvão e da brisa marinha apesar do local de estudo estar localizado a mais de $150 \mathrm{~km}$ do mar.

O elemento Ca não apresentou coeficiente de correlação maior que 0,35 entre todos os elementos estudados. A atribuição de sua origem é bastante dificultada quando não há forte correlação entre elementos. Além disso, Ca é um elemento essencial para o metabolismo de plantas presente em muitos minerais e a sua presença na atmosfera tem sido correlacionada com as emissões veiculares. Figueiredo et al. (2007) reportaram que Ba associado ao Ca indicam emissões de combustão em motores a diesel.

Semelhante ao $\mathrm{Ca}$, o $\mathrm{Mn}$ apresentou baixa correlação com os elementos estudados e isto se deve ao fato que este elemento é absorvido pelas plantas. Além disso, o Mn é o elemento de maior abundância na litosfera dentre os elementos traço (KABATA-PENDIAS, 2011).

As correlações entre os pares de elementos Cs e Rb, K e Rb podem ser atribuídas a origem geogênica. $\mathrm{OK}$ e Rb são elementos traço abundantes na crosta terrestre e a razão entre seus teores é praticamente constante (KABATA-PENDIAS, 2011). Além disso, a similaridade química destes elementos favorece a alta correlação estar associar à estrutura da casca de árvore, uma vez que o K é um nutriente essencial da planta e os elementos Cs e Rb podem competir na absorção pela planta (WYTTENBACH et al., 1995). 
Tabela 16. Matriz de correlação de Pearson entre as concentrações dos elementos determinados nas cascas de Sibipiruna e Tipuana.

\begin{tabular}{|c|c|c|c|c|c|c|c|c|c|c|c|c|c|c|c|c|c|c|c|c|c|}
\hline & As & $\mathrm{Br}$ & $\mathrm{Ca}$ & $\mathrm{Cd}$ & $\mathrm{Cl}$ & Co & $\mathrm{Cr}$ & Cs & $\mathrm{Cu}$ & $\mathrm{Fe}$ & $\mathrm{K}$ & La & $\mathrm{Mg}$ & $\mathrm{Mn}$ & $\mathrm{Ni}$ & $\mathrm{Pb}$ & $\mathrm{Rb}$ & $\mathrm{Sb}$ & $\mathrm{Sc}$ & V & $\mathrm{Zn}$ \\
\hline As & 1,00 & & & & & & & & & & & & & & & & & & & & \\
\hline $\mathrm{Br}$ & $0,53^{*}$ & 1,00 & & & & & & & & & & & & & & & & & & & \\
\hline $\mathrm{Ca}$ & $-0,15$ & $-0,23$ & 1,00 & & & & & & & & & & & & & & & & & & \\
\hline $\mathrm{Cd}$ & $0,73^{\star}$ & $0,43^{*}$ & 0,02 & 1,00 & & & & & & & & & & & & & & & & & \\
\hline $\mathrm{Cl}$ & $0,39^{*}$ & $0,76^{*}$ & $-0,32^{*}$ & 0,14 & 1,00 & & & & & & & & & & & & & & & & \\
\hline Co & 0,18 & $-0,09$ & $-0,12$ & 0,04 & $-0,05$ & 1,00 & & & & & & & & & & & & & & & \\
\hline $\mathrm{Cr}$ & $0,85^{\star}$ & $0,55^{*}$ & $-0,18$ & $0,81^{*}$ & $0,30^{*}$ & 0,10 & 1,00 & & & & & & & & & & & & & & \\
\hline Cs & $0,82^{*}$ & $0,51^{*}$ & $-0,24$ & $0,69^{*}$ & $0,37^{*}$ & 0,15 & $0,81^{*}$ & 1,00 & & & & & & & & & & & & & \\
\hline $\mathrm{Cu}$ & $0,65^{*}$ & $0,61^{*}$ & $-0,26$ & $0,74^{\star}$ & $0,37^{*}$ & 0,02 & $0,68^{*}$ & $0,69^{*}$ & 1,00 & & & & & & & & & & & & \\
\hline $\mathrm{Fe}$ & $0,88^{*}$ & $0,51^{*}$ & $-0,14$ & $0,85^{*}$ & 0,26 & 0,11 & $0,96^{*}$ & $0,83^{*}$ & $0,66^{*}$ & 1,00 & & & & & & & & & & & \\
\hline $\mathrm{K}$ & $0,46^{*}$ & $0,35^{*}$ & $-0,23$ & $0,31^{*}$ & $0,48^{*}$ & 0,03 & $0,44^{*}$ & $0,49^{*}$ & $0,35^{*}$ & $0,47^{\star}$ & 1,00 & & & & & & & & & & \\
\hline La & $0,79^{*}$ & $0,50^{*}$ & $-0,17$ & $0,81^{*}$ & 0,26 & 0,10 & $0,90^{*}$ & $0,85^{*}$ & $0,68^{*}$ & $0,93^{*}$ & $0,38^{*}$ & 1,00 & & & & & & & & & \\
\hline $\mathrm{Mg}$ & $0,49^{*}$ & $0,75^{\star}$ & $-0,34^{*}$ & $0,33^{*}$ & $0,72^{*}$ & 0,06 & $0,45^{*}$ & $0,40^{*}$ & $0,44^{*}$ & $0,39^{*}$ & 0,27 & $0,37^{*}$ & 1,00 & & & & & & & & \\
\hline $\mathrm{Mn}$ & $0,44^{*}$ & $0,28^{*}$ & $-0,26$ & $0,37^{*}$ & 0,13 & $0,34^{\star}$ & $0,44^{*}$ & $0,64^{*}$ & $0,50^{*}$ & $0,45^{\star}$ & $0,30^{*}$ & $0,54^{*}$ & 0,06 & 1,00 & & & & & & & \\
\hline $\mathrm{Ni}$ & 0,17 & $-0,09$ & $-0,11$ & 0,03 & $-0,06$ & $1,00^{*}$ & 0,09 & 0,12 & 0,01 & 0,10 & 0,02 & 0,08 & 0,06 & $0,31^{*}$ & 1,00 & & & & & & \\
\hline $\mathrm{Pb}$ & $0,58^{*}$ & $0,60^{*}$ & $-0,15$ & $0,65^{*}$ & $0,37^{*}$ & 0,03 & $0,76^{*}$ & $0,55^{*}$ & $0,67^{*}$ & $0,70^{*}$ & 0,16 & $0,72^{*}$ & $0,49^{*}$ & 0,21 & 0,03 & 1,00 & & & & & \\
\hline $\mathrm{Rb}$ & $0,69^{*}$ & $0,51^{*}$ & $-0,35^{*}$ & $0,51^{*}$ & $0,50^{*}$ & 0,07 & $0,66^{*}$ & $0,76^{*}$ & $0,52^{*}$ & $0,69^{*}$ & $0,84^{\star}$ & $0,62^{*}$ & $0,39^{*}$ & $0,46^{*}$ & 0,05 & $0,37^{*}$ & 1,00 & & & & \\
\hline $\mathrm{Sb}$ & $0,77^{*}$ & $0,35^{*}$ & $-0,05$ & $0,81^{*}$ & 0,12 & $-0,04$ & $0,77^{\star}$ & $0,64^{*}$ & $0,63^{*}$ & $0,82^{*}$ & $0,28^{*}$ & $0,73^{*}$ & 0,28 & $0,31^{*}$ & $-0,05$ & $0,55^{*}$ & $0,43^{*}$ & 1,00 & & & \\
\hline $\mathrm{Sc}$ & $0,84^{\star}$ & $0,44^{*}$ & $-0,18$ & $0,76^{*}$ & 0,24 & 0,18 & $0,91^{*}$ & $0,84^{*}$ & $0,56^{*}$ & $0,96^{*}$ & $0,47^{*}$ & $0,94^{*}$ & $0,36^{*}$ & $0,47^{*}$ & 0,17 & $0,65^{*}$ & $0,68^{*}$ & $0,71^{*}$ & 1,00 & & \\
\hline $\mathrm{V}$ & $0,77^{*}$ & $0,70^{*}$ & $-0,21$ & $0,69^{*}$ & $0,47^{*}$ & 0,03 & $0,87^{\star}$ & $0,77^{\star}$ & $0,72^{*}$ & $0,85^{\star}$ & $0,35^{*}$ & $0,87^{*}$ & $0,49^{*}$ & $0,47^{*}$ & 0,02 & $0,88^{*}$ & $0,59^{*}$ & $0,63^{*}$ & $0,83^{*}$ & 1,00 & \\
\hline $\mathrm{Zn}$ & $0,76^{*}$ & $0,66^{*}$ & $-0,24$ & $0,73^{*}$ & $0,43^{*}$ & $-0,01$ & $0,72^{*}$ & $0,64^{*}$ & $0,78^{*}$ & $0,69^{*}$ & 0,26 & $0,65^{*}$ & $0,61^{*}$ & $0,40^{*}$ & $-0,02$ & $0,65^{*}$ & $0,53^{*}$ & $0,58^{\star}$ & $0,61^{*}$ & $0,70^{*}$ & 1,00 \\
\hline
\end{tabular}

* Correlação a um nível de significância de $5 \%$ 


\subsubsection{Análise de agrupamento (AA) dos elementos}

A análise de agrupamento (AA) foi aplicada a fim de se avaliar melhor as correlações entre os elementos, ou seja, o agrupamento dos elementos que apresentam maior similaridade. O dendrograma da Figura 18 foi obtido pelo método de Ward e as distâncias Euclidianas estão expressas em porcentagem em relação à distância máxima de ligação((Dlink/Dmax)*100).

O dendrograma gerado formou 3 grupos com aproximadamente $72 \%$ de dissimilaridade. O grupo 1 é composto por dois subgrupos com $58 \%$ de dissimilaridade, sendo eles, 1A composto pelos elementos $\mathrm{Ni}$ e $\mathrm{Co}$ e 1B pelo $\mathrm{Ca}$.

Os elementos presentes no grupo 2 foram separados em dois subgrupos com $52 \%$ de dissimilaridade. O grupo $2 \mathrm{~A}$ contém os elementos $\mathrm{Mn}, \mathrm{Rb}$ e $\mathrm{K}$, com $\mathrm{Rb}$ e $\mathrm{K}$ tendo maior similaridade. Em 2B estão presentes $\mathrm{Br}, \mathrm{Cl}$ e $\mathrm{Mg}$.

Os grupos formados apresentaram padrões semelhantes aos obtidos pela matriz de correlação de Pearson, confirmando os resultados das correlações obtidos entre os elementos.



Figura 18. Dendrograma obtido pela análise de agrupamento das concentrações dos elementos obtidas pela análise das cascas de árvore das espécies Sibipiruna e Tipuana. 


\subsubsection{Análise de componentes principais (PCA) dos dados de elementos químicos}

Uma análise exploratória mais detalhada foi realizada por meio do procedimento matemático da PCA a fim de se obter uma redução dos dados para melhor visualização dos padrões de similaridade entre os elementos determinados nas cascas de árvores. As componentes extraídas com seus respectivos autovalores e variância acumulada são apresentadas na Tabela 17. Utilizando o método de Kaiser, que consiste em considerar somente as componentes com autovalores maiores do que 1 , os resultados foram reduzidos pelas quatro primeiras componentes, os quais representam $80,97 \%$ da variância acumulada dos resultados. A matriz de correlação entre os elementos analisados e as quatro componentes principais extraídas após rotação Varimax normalizada dos eixos é apresentada na Tabela E.1 no Apêndice E.

Tabela 17. Autovalores e percentual da variância explicada das componentes extraída.

\begin{tabular}{ccccc}
\hline $\begin{array}{c}\text { Número de } \\
\text { componentes }\end{array}$ & Autovalores & $\begin{array}{c}\text { Variância } \\
\text { explicada }(\%)\end{array}$ & $\begin{array}{c}\text { Autovalores } \\
\text { acumulados }\end{array}$ & $\begin{array}{c}\text { Variância acumulada } \\
\text { explicada (\%) }\end{array}$ \\
\hline $\mathbf{1}$ & $\mathbf{1 1 , 2 5}$ & $\mathbf{5 3 , 5 7}$ & 11,25 & $\mathbf{5 3 , 5 7}$ \\
$\mathbf{2}$ & $\mathbf{2 , 3 3}$ & $\mathbf{1 1 , 0 9}$ & 13,58 & $\mathbf{6 4 , 6 6}$ \\
$\mathbf{3}$ & $\mathbf{2 , 0 4}$ & $\mathbf{9 , 7 2}$ & 15,62 & $\mathbf{7 4 , 3 8}$ \\
$\mathbf{4}$ & $\mathbf{1 , 3 8}$ & $\mathbf{6 , 5 8}$ & 17,00 & $\mathbf{8 0 , 9 7}$ \\
$\mathbf{5}$ & 0,91 & 4,35 & 17,92 & 85,32 \\
6 & 0,70 & 3,36 & 18,62 & 88,67 \\
$\mathbf{7}$ & 0,62 & 2,94 & 19,24 & 91,61 \\
$\mathbf{8}$ & 0,43 & 2,06 & 19,67 & 93,67 \\
9 & 0,30 & 1,42 & 19,97 & 95,10 \\
10 & 0,23 & 1,08 & 20,20 & 96,17 \\
11 & 0,20 & 0,95 & 20,40 & 97,12 \\
12 & 0,15 & 0,71 & 20,55 & 97,84 \\
13 & 0,14 & 0,68 & 20,69 & 98,51 \\
14 & 0,11 & 0,54 & 20,80 & 99,05 \\
15 & 0,07 & 0,33 & 20,87 & 99,38 \\
16 & 0,05 & 0,23 & 20,92 & 99,61 \\
17 & 0,04 & 0,18 & 20,96 & 99,79 \\
18 & 0,03 & 0,13 & 20,98 & 99,92 \\
19 & 0,01 & 0,05 & 20,99 & 99,97 \\
20 & 0,01 & 0,03 & 21,00 & 100,00 \\
\hline
\end{tabular}


Os gráficos das componentes CP 1 e CP 2 estão na Figura 19 e das componentes CP 3 e CP 4 na Figura 20. Na Figura 19 a primeira componente principal (CP 1) é composta pelos elementos As, Cd, Cr, Cs, Fe, La, Sb, Sc e V e juntos eles explicam $53,57 \%$ da variância dos resultados obtidos que podem estar relacionados aos elementos do material particulado proveniente de ressuspensão do solo, bem como de emissões veiculares. Na CP 2 os elementos predominantes foram $\mathrm{Co}$ e $\mathrm{Ni}$, explicando $11,09 \%$ da variância dos resultados cuja origem dos elementos pode ser relacionada à emissão da indústria metalúrgica localizada na região de São Miguel Paulista.

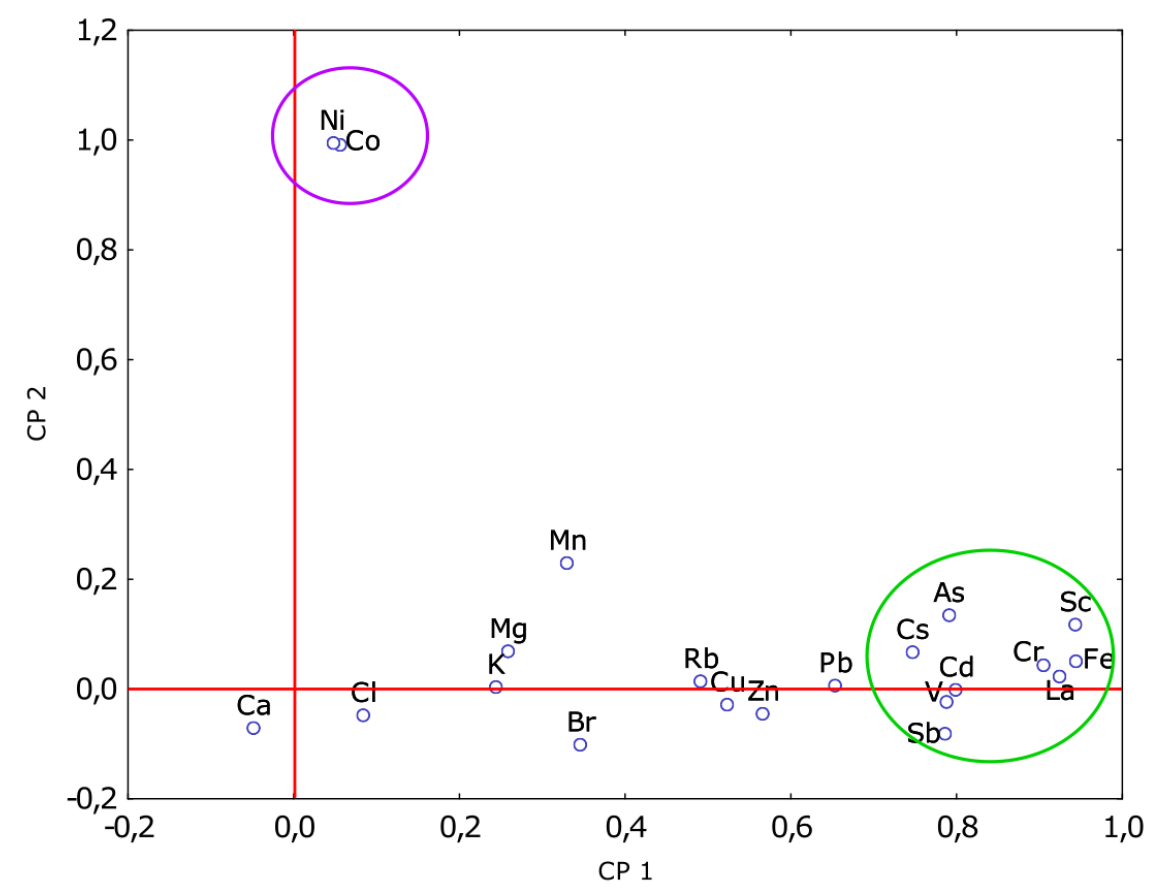

Figura 19. Gráfico das duas componentes principais (CP1 e CP2) da análise efetuada nos resultados de cascas de árvore. 


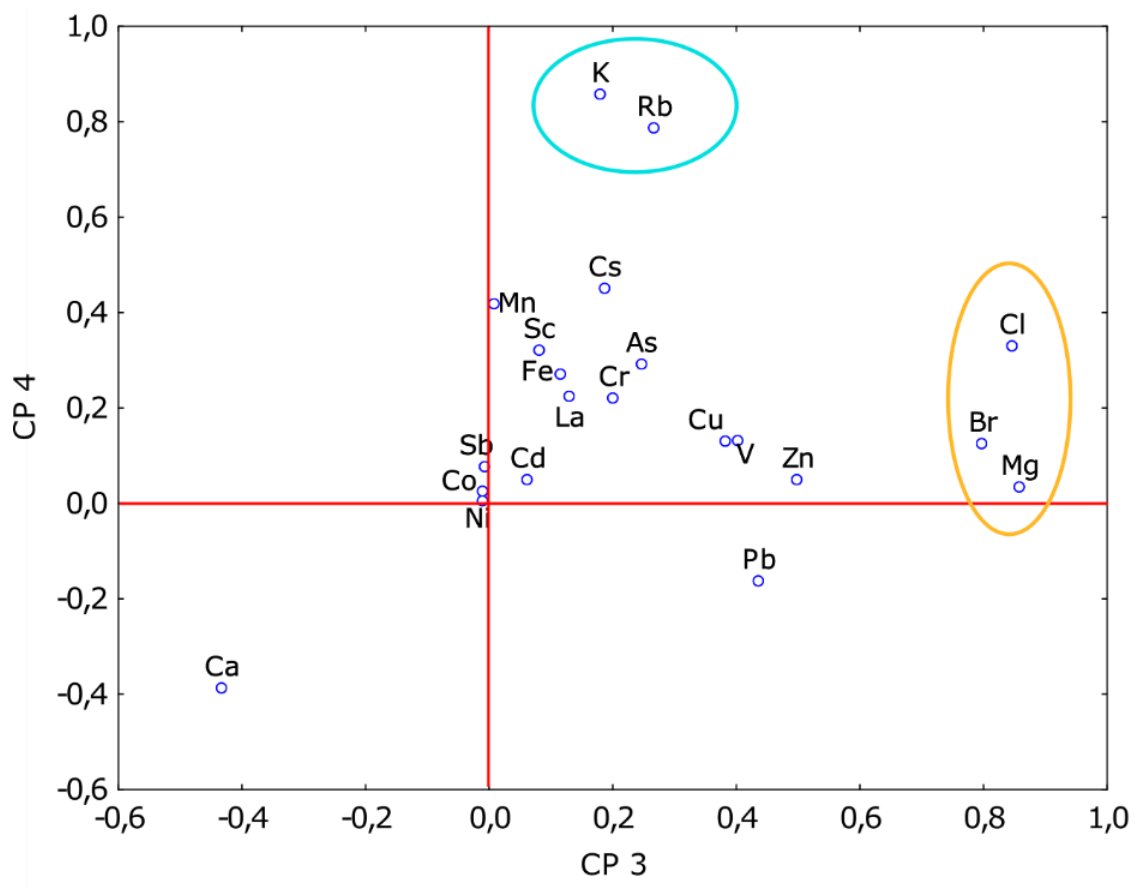

Figura 20. Gráfico das duas componentes principais (CP3 e CP4) da análise efetuada nos resultados de cascas de árvore.

$\mathrm{Na}$ Figura 20 os elementos que compõem a CP 3 são $\mathrm{Br}$, $\mathrm{Cl}$ e $\mathrm{Mg}$ e representa $9,72 \%$ da variância dos resultados. Nesta componente estão os elementos $\mathrm{Br}$ e $\mathrm{Cl}$ do material particulado constituinte de aerossol marinho, uma vez que a costa brasileira fica a $60 \mathrm{~km}$ de distância da capital paulista.

A CP 4 representa $6,58 \%$ da variância dos resultados e é composta pelos elementos $\mathrm{Rb}$ e K. Esta componente pode indicar elementos que estão relacionados à estrutura da casca de árvore e à composição do solo.

\subsubsection{Estudo da correlação entre as regiões de amostragem}

Para avaliar a correlação existente entre as regiões de amostragem, foram escolhidas as concentrações médias dos elementos determinados nas amostras de cascas da espécie Sibipiruna. Esta escolha foi feita com base nas diferenças entre o acúmulo de elementos entre as espécies e na maior disponibilidade da espécie arbórea encontrada nas regiões de amostragem. 


\subsubsection{Análise de agrupamento (AA) das regiões de amostragem}

Os resultados das análises das cascas foram submetidos à análise de agrupamento (AA) para classificação dos pontos de amostragem. O dendrograma obtido pela AA é apresentado na Figura 21 com a distância de ligação Euclidiana apresentada em porcentagem relativa à maior distância obtida ((Dlink/Dmax).100).

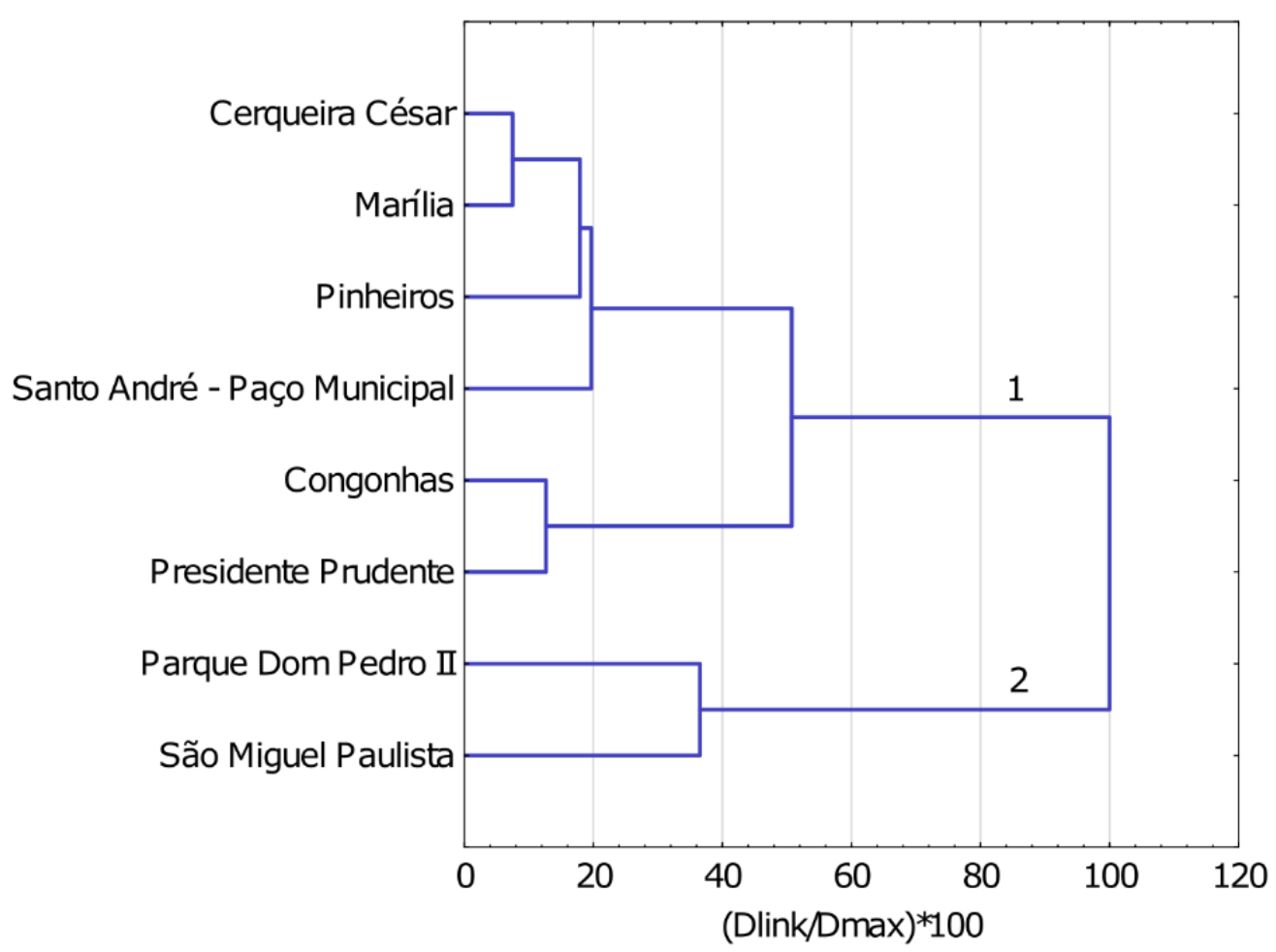

Figura 21. Dendrograma obtido na análise de agrupamento para as diferentes regiões de amostragem.

O grupo 1 gerado no dendrograma da Figura 21 é composto pelas regiões de amostragem de Cerqueira César, Marília, Pinheiros, Santo André - Paço Municipal, Congonhas e Presidente Prudente. No grupo 2 encontram-se as regiões Parque Dom Pedro II e São Miguel Paulista.

A partir do dendrograma gerado, pode-se concluir que as regiões escolhidas como controle não se diferenciaram das regiões localizadas na RMSP, isto pode ser devido aos pontos de amostragem na região controle estarem localizados também em áreas urbanas. 


\subsubsection{Análise de componentes principais (PCA) das regiões de amostragem}

$\mathrm{Na}$ Tabela 18 são apresentados os resultados das componentes extraídas e seus respectivos autovalores. Verifica-se nesta Tabela que $99 \%$ da variância explicada foi retida pela primeira componente principal, ou seja, não foi possível agrupar as regiões quanto as suas características de concentrações dos elementos presentes nas cascas de árvores pela PCA. Isto confirma que as amostras coletadas nas regiões escolhidas como controle não apresentaram diferenças significativas no perfil de acúmulo de elementos. A contribuição de cada região de amostragem para as componentes extraídas está detalhada na matriz de correlação apresentada na Tabela F.1 do Apêndice F.

Tabela 18. Autovalores e percentual da variância explicada das componentes extraídas a partir das médias das concentrações dos elementos presentes nas cascas de Sibipiruna.

\begin{tabular}{ccccc}
\hline $\begin{array}{c}\text { Número de } \\
\text { Componentes }\end{array}$ & Autovalores & $\begin{array}{c}\text { Variância } \\
\text { explicada (\%) }\end{array}$ & $\begin{array}{c}\text { Autovalores } \\
\text { acumulados }\end{array}$ & $\begin{array}{c}\text { Variância acumulada } \\
\text { explicada (\%) }\end{array}$ \\
\hline $\mathbf{1}$ & $\mathbf{7 , 9 9 8 7 4 6}$ & 99,98433 & 7,998746 & $\mathbf{9 9 , 9 8 4 3 3}$ \\
$\mathbf{2}$ & $\mathbf{0 , 0 0 0 9 1 1}$ & 0,01139 & 7,999657 & $\mathbf{9 9 , 9 9 5 7 2}$ \\
$\mathbf{3}$ & 0,000238 & 0,00297 & 7,999895 & 99,99869 \\
4 & 0,000104 & 0,00130 & 7,999999 & 99,99999 \\
\hline
\end{tabular}

A pequena diferença na contribuição de cada componente principal extraída pode ser observada na Figura 22. A primeira componente principal (CP 1) tem contribuição maior que 0,7 para as regiões de Congonhas, Presidente Prudente, Santo André - Paço Municipal, Marília, Cerqueira César e Pinheiros, ao passo que a CP 2 apresenta maior contribuição das regiões de São Miguel Paulista e Parque Dom Pedro II. Isto indica o porquê da separação entre dois grupos da análise de agrupamento, entretanto, pelo método de Kaiser aplicado à PCA, devese considerar que todas as regiões de amostragem pertencem ao mesmo grupo.

Os resultados obtidos pela PCA indicam que as regiões escolhidas como controle não apresentaram diferença significativa com relação aos teores dos elementos presentes nas amostras de cascas de árvores coletadas nas diferentes regiões de amostragem. A ampla variabilidade nos teores dos elementos em cada região de amostragem e a localização dos pontos de amostragem nas regiões 
controle de Presidente Prudente e Marília podem ter sido responsáveis pela não separação dos grupos.

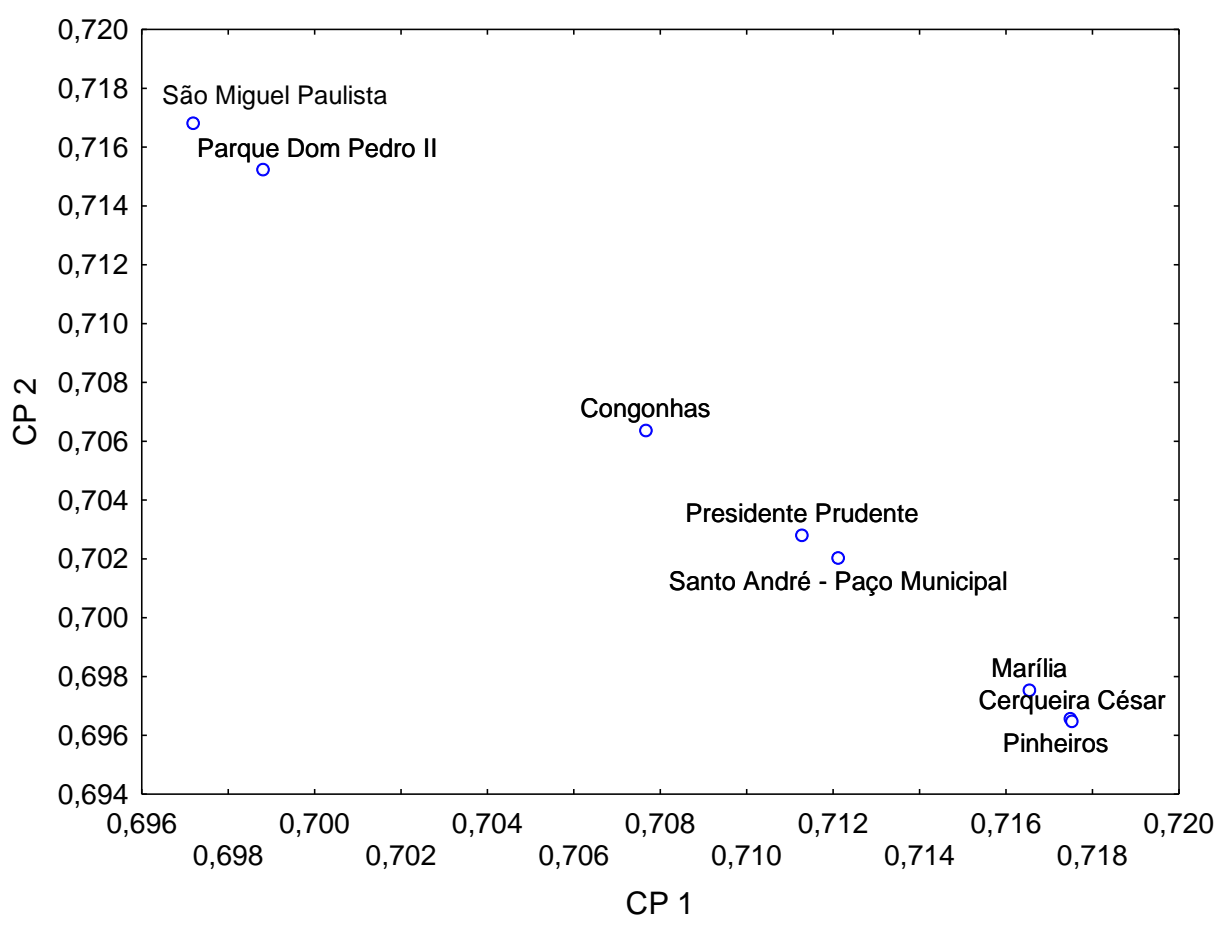

Figura 22. Gráfico representando as componentes principais (CP1 e CP2) e as regiões de amostragem.

\subsubsection{Fator de enriquecimento (FE)}

Para avaliar os níveis de contaminação por elementos químicos nas diferentes regiões de amostragem foi calculado o fator de enriquecimento (FE), cujos resultados são apresentados na Tabela 19. Em estudos de biomonitoramento da poluição do ar muitas vezes são utilizados como elementos de referências as concentrações de Sc ou Al obtidas para amostras coletadas em regiões consideradas não poluídas. Entretanto, como visto no item 6.4.4.2 deste capítulo, as regiões escolhidas como controle não apresentaram diferença significativa nas concentrações dos elementos com as das regiões da RMSP. Desta maneira foi utilizado como referência a concentração de Sc da UCC (Upper Continental Crust) (WEDEPOHL, 1995). 
Tabela 19. Fatores de enriquecimento (FEs) obtidos usando concentrações dos elementos nas cascas da espécie Sibipiruna coletadas nas diferentes regiões.

\begin{tabular}{ccccccccc}
\hline Elementos & CC & CG & PDP & PN & SAP & SMP & MA & PP \\
\hline $\mathrm{As}$ & $\mathbf{3 , 8}$ & $\mathbf{3 , 2}$ & $\mathbf{4 , 1}$ & $\mathbf{2 , 5}$ & $\mathbf{3 , 0}$ & $\mathbf{3 , 1}$ & $\mathbf{1 , 5}$ & $\mathbf{1 , 4}$ \\
$\mathrm{Br}$ & $\mathbf{1 3 8 , 8}$ & $\mathbf{7 3 , 8}$ & $\mathbf{3 8 , 9}$ & $\mathbf{9 6 , 2}$ & $\mathbf{1 0 8 , 5}$ & $\mathbf{5 2 , 3}$ & $\mathbf{5 4 , 5}$ & $\mathbf{2 5 , 4}$ \\
$\mathrm{Ca}$ & $\mathbf{1 3 4 , 1}$ & $\mathbf{8 2 , 6}$ & $\mathbf{3 6 , 5}$ & $\mathbf{1 4 4 , 2}$ & $\mathbf{8 6 , 1}$ & $\mathbf{3 6 , 4}$ & $\mathbf{7 0 , 4}$ & $\mathbf{6 0 , 9}$ \\
$\mathrm{Cd}$ & $\mathbf{3 4 6 , 5}$ & $\mathbf{2 2 5 , 4}$ & $\mathbf{3 4 9 , 9}$ & $\mathbf{2 1 7 , 8}$ & $\mathbf{1 8 7 , 2}$ & $\mathbf{1 2 9 , 7}$ & $\mathbf{2 4 , 1}$ & $\mathbf{2 8 , 2}$ \\
$\mathrm{Cl}$ & $\mathbf{6 , 8}$ & $\mathbf{4 , 1}$ & $\mathbf{2 , 6}$ & $\mathbf{5 , 9}$ & $\mathbf{4 , 3}$ & $\mathbf{5 , 2}$ & $\mathbf{1 , 2}$ & $\mathbf{2 , 6}$ \\
$\mathrm{Co}$ & $\mathbf{1 , 8}$ & $\mathbf{1 , 5}$ & $\mathbf{1 , 4}$ & $\mathbf{1 , 7}$ & $\mathbf{1 , 4}$ & $\mathbf{4 1 , 6}$ & 0,8 & $\mathbf{1 , 5}$ \\
$\mathrm{Cr}$ & $\mathbf{4 , 5}$ & $\mathbf{3 , 6}$ & $\mathbf{3 , 4}$ & $\mathbf{2 , 5}$ & $\mathbf{4 , 2}$ & $\mathbf{2 , 5}$ & $\mathbf{1 , 3}$ & $\mathbf{1 , 9}$ \\
$\mathrm{Cs}$ & 0,7 & 0,8 & 0,5 & 0,9 & 0,6 & 0,6 & 0,5 & 0,2 \\
$\mathrm{Cu}$ & $\mathbf{9 7 , 6}$ & $\mathbf{1 3 6 , 0}$ & $\mathbf{4 9 , 6}$ & $\mathbf{6 0 , 3}$ & $\mathbf{5 7 , 7}$ & $\mathbf{4 0 , 7}$ & $\mathbf{3 6 , 5}$ & $\mathbf{2 2 , 0}$ \\
$\mathrm{Fe}$ & $\mathbf{1 , 4}$ & $\mathbf{1 , 2}$ & $\mathbf{1 , 2}$ & 0,9 & $\mathbf{1 , 3}$ & 0,9 & 0,7 & 0,7 \\
$\mathrm{~K}$ & $\mathbf{2 , 8}$ & $\mathbf{3 , 4}$ & $\mathbf{1 , 3}$ & $\mathbf{4 , 1}$ & $\mathbf{2 , 5}$ & $\mathbf{1 , 5}$ & $\mathbf{1 , 7}$ & $\mathbf{2 , 2}$ \\
$\mathrm{La}$ & $\mathbf{1 , 9}$ & $\mathbf{1 , 9}$ & $\mathbf{1 , 8}$ & $\mathbf{2 , 0}$ & $\mathbf{1 , 9}$ & $\mathbf{1 , 8}$ & $\mathbf{2 , 5}$ & $\mathbf{1 , 3}$ \\
$\mathrm{Mg}$ & $\mathbf{3 , 1}$ & $\mathbf{2 , 8}$ & $\mathbf{1 , 4}$ & $\mathbf{3 , 1}$ & $\mathbf{2 , 4}$ & $\mathbf{2 , 5}$ & $\mathbf{1 , 9}$ & $\mathbf{1 , 9}$ \\
$\mathrm{Mn}$ & $\mathbf{6 , 4}$ & $\mathbf{3 , 8}$ & $\mathbf{2 , 2}$ & $\mathbf{5 , 1}$ & $\mathbf{3 , 3}$ & $\mathbf{2 , 6}$ & $\mathbf{3 , 6}$ & $\mathbf{2 , 7}$ \\
$\mathrm{Pb}$ & $\mathbf{1 4 , 1}$ & $\mathbf{1 1 , 4}$ & $\mathbf{1 1 , 7}$ & $\mathbf{9 , 7}$ & $\mathbf{1 0 , 8}$ & $\mathbf{1 2 , 3}$ & $\mathbf{2 , 1}$ & $\mathbf{1 , 1}$ \\
$\mathrm{Rb}$ & $\mathbf{1 , 9}$ & $\mathbf{2 , 2}$ & 0,9 & 2,9 & $\mathbf{1 , 6}$ & $\mathbf{1 , 2}$ & 0,9 & $\mathbf{1 , 5}$ \\
$\mathrm{Sb}$ & $\mathbf{3 2 6 , 9}$ & $\mathbf{1 1 6 , 4}$ & $\mathbf{3 0 3 , 8}$ & $\mathbf{9 8 , 3}$ & $\mathbf{1 1 1 , 2}$ & $\mathbf{5 7 , 3}$ & $\mathbf{1 5 , 0}$ & $\mathbf{1 1 , 1}$ \\
$\mathrm{V}$ & $\mathbf{1 , 5}$ & $\mathbf{1 , 4}$ & $\mathbf{1 , 2}$ & $\mathbf{1 , 3}$ & $\mathbf{1 , 3}$ & $\mathbf{1 , 2}$ & $\mathbf{1 , 2}$ & $\mathbf{1 , 4}$ \\
$\mathrm{Zn}$ & $\mathbf{8 9 , 0}$ & $\mathbf{6 0 , 2}$ & $\mathbf{7 2 , 8}$ & $\mathbf{5 8 , 7}$ & $\mathbf{7 8 , 0}$ & $\mathbf{4 1 , 3}$ & $\mathbf{2 2 , 9}$ & $\mathbf{1 4 , 0}$ \\
\hline
\end{tabular}

$C C=$ Cerqueira César; $C G=$ Congonhas $; P D P=$ Parque Dom Pedro II; PN = Pinheiros; SAP = Santo André - Paço Municipal; SMP = São Miguel Paulista; MA = Marília; PP = Presidente Prudente. Os FEs maiores que 1 estão em negrito.

Os FEs obtidos foram superiores a 1 para a maioria dos elementos em todos os pontos de amostragem, indicando que a contribuição para 0 enriquecimento destes elementos é de origem antrópica. O único elemento que apresentou valores de FE abaixo de 1 para todas as regiões de amostragem foi 0 Cs, indicando que não houve contribuição antrópica para o acúmulo deste elemento.

Os elementos $\mathrm{As}, \mathrm{Cd}, \mathrm{Cr}, \mathrm{Cu}, \mathrm{Sb}, \mathrm{Pb}$ e $\mathrm{Zn}$ apresentaram maiores valores de enriquecimento nas regiões da RMSP em relação aos de Presidente Prudente e Marília. Isto indica que existe maior contribuição antrópica para o enriquecimento destes elementos na cidade de São Paulo em relação às regiões controle, em grande parte, devido às diferenças nas intensidades das emissões veiculares entre estas regiões. 
Os FEs para o Co variaram entre 1,4 e 1,8 na RMSP com exceção da região de São Miguel Paulista, onde o enriquecimento foi de 41,6, indicando que as emissões da indústria metalúrgica aumentou consideravelmente os teores deste elemento no material particulado desta região.

O Fe apresentou valores de FEs entre 0,7 e 1,4, indicando baixa contribuição antrópica para o enriquecimento deste elemento. As regiões de Pinheiros, São Miguel Paulista, Marília e Presidente Prudente apresentaram FEs abaixo de 1 para este elemento, indicando que os teores deste elemento são de origem geogênica. Outro elemento que apresentou baixa contribuição antrópica em seu enriquecimento foi o V. Os FEs obtidos variaram entre 1,2 e 1,5, em todas as regiões de amostragem.

Os elementos K e La apresentaram valores de FE na mesma ordem de grandeza para todas as regiões.

\subsection{6 Índice de geoacumulação (IGeo)}

Avaliação da contaminação por elementos químicos nas diferentes regiões de amostragem foi feita também pelo índice de geoacumulação (IGeo) e os valores obtidos são apresentados na Tabela 20. Foi utilizado como elemento de referência a concentração de Sc da UCC.

De um modo geral, de acordo com a classificação de IGeo, a maioria das regiões de amostragem foram classificadas como não poluídas, e somente para alguns elementos a classificação resultou entre pouco a moderadamente poluído para algumas regiões da RMSP. As regiões controle ficaram classificadas como não poluídas com relação à todos os elementos determinados.

Segundo este índice, a RMSP pode ser considerada de pouco a moderadamente poluídas por Cd uma vez que seus valores de IGeo estão entre 0 e 1. O mesmo vale para o Sb, com exceção da região de Pinheiros que apresentou IGeo menor que 0 .

A região do Parque Dom Pedro foi classificada como pouco a moderadamente poluída por Cu e Zn e Congonhas recebeu a mesma classificação para o Cu.

O elemento $\mathrm{Br}$ apresentou valores de IGeo entre 0 e 1 para as regiões de Cerqueira César, Santo André - Paço Municipal e São Miguel Paulista. 
Tabela 20. Índices de geoacumulação (IGeo) dos elementos determinados em cascas da espécie Sibipiruna para diferentes pontos de amostragem.

\begin{tabular}{ccccccccc}
\hline & $\mathrm{CC}$ & $\mathrm{CG}$ & $\mathrm{PDP}$ & $\mathrm{PN}$ & $\mathrm{SAP}$ & $\mathrm{SMP}$ & $\mathrm{MA}$ & $\mathrm{PP}$ \\
\hline $\mathrm{Sc}$ & $-2,13$ & $-2,02$ & $-1,62$ & $-2,19$ & $-1,97$ & $-1,65$ & $-1,90$ & $-1,87$ \\
$\mathrm{As}$ & $-1,55$ & $-1,52$ & $-1,01$ & $-1,80$ & $-1,50$ & $-1,16$ & $-1,71$ & $-1,73$ \\
$\mathrm{Br}$ & $\mathbf{0 , 0 1}$ & $-0,15$ & $-0,03$ & $-0,21$ & $\mathbf{0 , 0 7}$ & $\mathbf{0 , 0 7}$ & $-0,17$ & $-0,47$ \\
$\mathrm{Ca}$ & 0,00 & $-0,10$ & $-0,06$ & $-0,03$ & $-0,03$ & $-0,09$ & $-0,06$ & $-0,09$ \\
$\mathrm{Cd}$ & $\mathbf{0 , 4 1}$ & $\mathbf{0 , 3 4}$ & $\mathbf{0 , 9 3}$ & $\mathbf{0 , 1 5}$ & $\mathbf{0 , 3 1}$ & $\mathbf{0 , 4 6}$ & $-0,52$ & $-0,42$ \\
$\mathrm{Cl}$ & $-1,30$ & $-1,40$ & $-1,20$ & $-1,42$ & $-1,34$ & $-0,94$ & $-1,84$ & $-1,45$ \\
$\mathrm{Co}$ & $-1,87$ & $-1,83$ & $-1,48$ & $-1,95$ & $-1,82$ & $-0,03$ & $-2,00$ & $-1,70$ \\
$\mathrm{Cr}$ & $-1,48$ & $-1,46$ & $-1,09$ & $-1,80$ & $-1,34$ & $-1,26$ & $-1,78$ & $-1,60$ \\
$\mathrm{Cs}$ & $-2,26$ & $-2,12$ & $-1,92$ & $-2,23$ & $-2,18$ & $-1,91$ & $-2,22$ & $-2,51$ \\
$\mathrm{Cu}$ & $-0,14$ & $\mathbf{0 , 1 2}$ & $\mathbf{0 , 0 8}$ & $-0,41$ & $-0,21$ & $-0,04$ & $-0,34$ & $-0,53$ \\
$\mathrm{Fe}$ & $-1,97$ & $-1,94$ & $-1,53$ & $-2,21$ & $-1,85$ & $-1,69$ & $-2,07$ & $-2,02$ \\
$\mathrm{~K}$ & $-1,68$ & $-1,48$ & $-1,50$ & $-1,58$ & $-1,57$ & $-1,47$ & $-1,68$ & $-1,54$ \\
$\mathrm{La}$ & $-1,86$ & $-1,74$ & $-1,35$ & $-1,90$ & $-1,69$ & $-1,39$ & $-1,50$ & $-1,76$ \\
$\mathrm{Mg}$ & $-1,64$ & $-1,57$ & $-1,48$ & $-1,70$ & $-1,59$ & $-1,26$ & $-1,61$ & $-1,59$ \\
$\mathrm{Mn}$ & $-1,32$ & $-1,43$ & $-1,28$ & $-1,49$ & $-1,44$ & $-1,24$ & $-1,35$ & $-1,44$ \\
$\mathrm{~Pb}$ & $-0,98$ & $-0,96$ & $-0,55$ & $-1,21$ & $-0,93$ & $-0,56$ & $-1,58$ & $-1,82$ \\
$\mathrm{Rb}$ & $-1,85$ & $-1,67$ & $-1,64$ & $-1,74$ & $-1,75$ & $-1,58$ & $-1,97$ & $-1,69$ \\
$\mathrm{Sb}$ & $\mathbf{0 , 3 8}$ & $\mathbf{0 , 0 5}$ & $\mathbf{0 , 8 6}$ & $-0,20$ & $\mathbf{0 , 0 8}$ & $\mathbf{0 , 1 0}$ & $-0,73$ & $-0,82$ \\
$\mathrm{~V}$ & $-1,97$ & $-1,88$ & $-1,54$ & $-2,09$ & $-1,84$ & $-1,58$ & $-1,81$ & $-1,72$ \\
$\mathrm{Zn}$ & $-0,18$ & $-0,24$ & $\mathbf{0 , 2 4}$ & $-0,42$ & $-0,08$ & $-0,04$ & $-0,54$ & $-0,73$ \\
\hline
\end{tabular}

$\mathrm{CC}=$ Cerqueira César; $\mathrm{CG}=$ Congonhas; $\mathrm{PDP}=$ Parque Dom Pedro II; PN = Pinheiros; SAP = Santo André - Paço Municipal; SMP = São Miguel Paulista; MA = Marília; PP = Presidente Prudente.

Os valores de IGeo maiores que 0 estão em negrito.

\subsubsection{Avaliação da relação entre concentrações de elementos obtidos nas cascas de árvore com as concentrações de material particulado e com dados de mortalidade.}

6.4.7.1 Avaliação da relação existente entre as concentrações dos elementos das cascas de Sibipiruna e as de material particulado (MP $\left.\mathbf{P}_{10}\right)$.

Para o estudo desta relação, foram definidos inicialmente intervalos de concentrações para cada elemento com base na amplitude das concentrações médias obtidas nas cascas de árvores por região de amostragem. As regiões que apresentaram concentração média do elemento nas cascas dentro do intervalo definido foram agrupadas. Este intervalo de concentrações dos elementos foi avaliado em relação a variação das concentrações anuais médias de $\mathrm{MP}_{10}$ medidos pelas estações de monitoramento da CETESB entre os anos de 2009 e 2016 (CETESB, SD). Na Figura 23 estão os gráficos em box plot das faixas de 
concentrações dos elementos que apresentaram melhor relacionaram com as concentrações de $\mathrm{MP}_{10}$. Isto é, há um ligeiro aumento nas concentrações destes elementos com o aumento da concentração de $\mathrm{MP}_{10}$. Os gráficos para os demais elementos estão apresentados no Apêndice $\mathrm{G}$ e os dados de $\mathrm{MP}_{10}$ utilizados são apresentados no Anexo A.
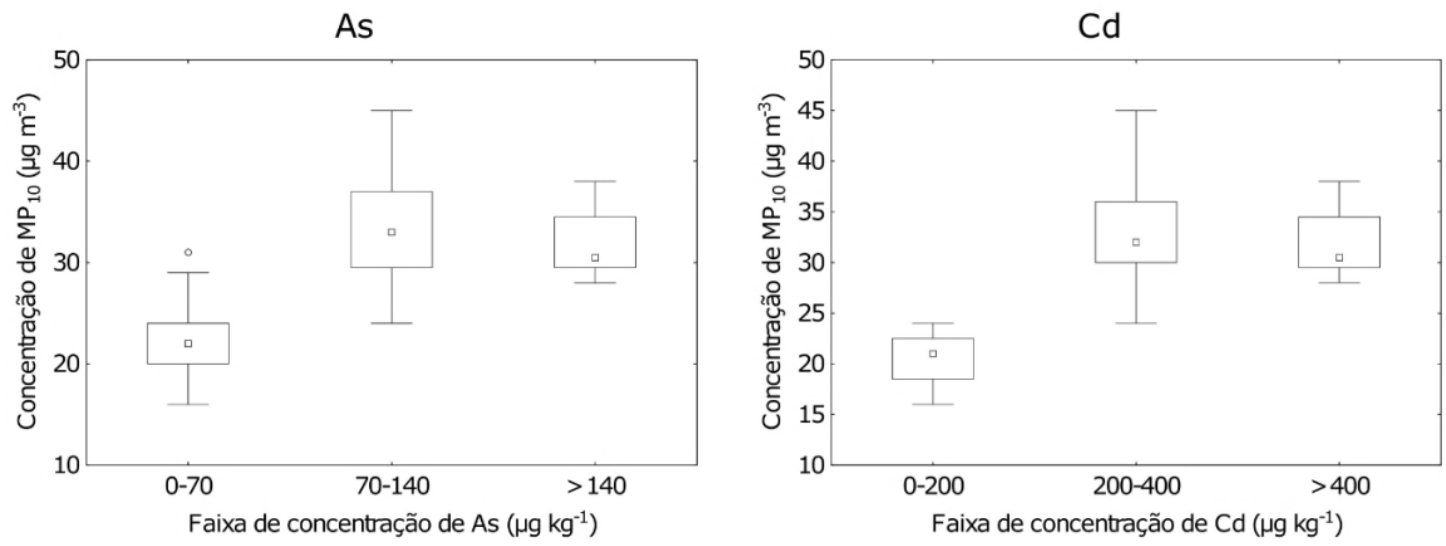

Co

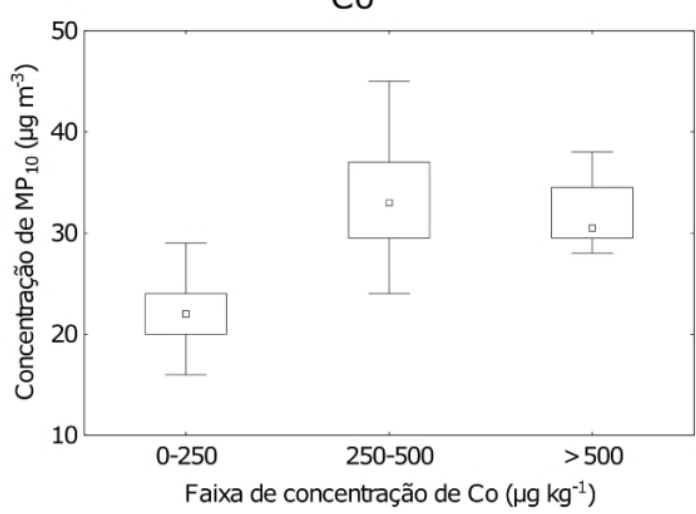

$\mathrm{Pb}$

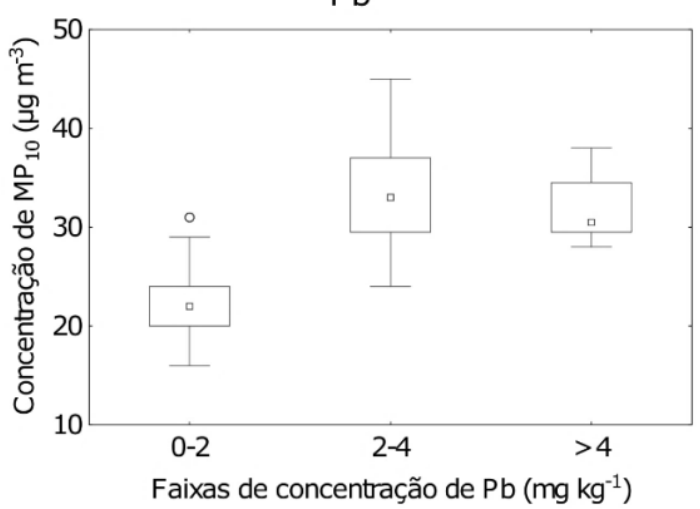

$\mathrm{Zn}$

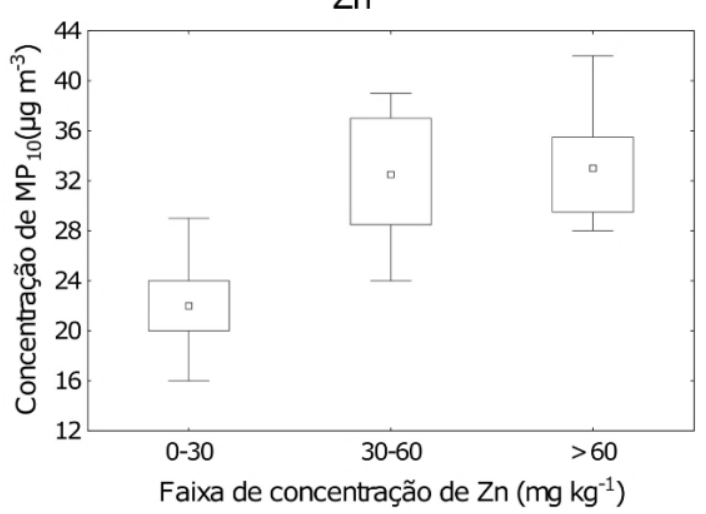

Figura 23. Representação box plot das concentrações de MP10 em função da faixa de teores dos elementos $\mathrm{As}, \mathrm{Cd}$, $\mathrm{Co}, \mathrm{Pb}$ e $\mathrm{Zn}$ determinados nas cascas de árvore da espécie Sibipiruna. 
Os elementos As, Cd, Co, $\mathrm{Pb}$ e $\mathrm{Zn}$ apresentaram uma relação crescente das faixas de concentrações dos elementos das cascas com as do MP10. Estes elementos são geralmente considerados daqueles presentes no material particulado fino $\left(\mathrm{MP}_{2,5}\right)$ proveniente de emissões antrópicas. Entretanto, existe uma distribuição destes elementos entre as diferentes frações de material particulado, não podendo descartar a contribuição destes elementos na constituição do $\mathrm{MP}_{10}$ (ALMEIDA et al., 2012).

Todos estes elementos, As, Cd, Co, $\mathrm{Pb}$ e $\mathrm{Zn}$, apresentaram fatores de enriquecimento maiores na RMSP em relação às regiões controle, isto contribui na confirmação de que a origem destes elementos pode ser proveniente de emissões veiculares.

O estudo da correlação das faixas de concentrações dos elementos das cascas com a variação temporal das de $\mathrm{PM}_{10}$ não foi realizado devido ao pequeno número de amostras de analisadas para cada região.

\subsubsection{Correlação entre as concentrações dos elementos das cascas de Sibipiruna $e$ as taxas de mortalidade de adultos por doenças cardiorrespiratórias}

A correlação de Pearson entre as concentrações dos elementos e as taxas de mortalidade de adultos por doenças cardiorrespiratórias e seus respectivos níveis de significância para elementos são apresentados no APÊNDICE H (Tabelas H.1 e H.2). Na Figura 24 são apresentadas as taxas de mortalidade em função dos teores dos elementos $\mathrm{Cl}$, Co, $\mathrm{Mg}$ e $\mathrm{Ni}$ das cascas de árvore e apresentaram correlação a um nível de significância menor que 0,05.

Apesar do Co ser um elemento essencial, quando inalado como elemento do material particulado apresenta propriedades tóxicas e está relacionado ao desenvolvimento de asma brônquica e a fibrose pulmonar quando em níveis elevados (ALVES e ROSA, 2003).

O Ni é um elemento potencialmente tóxico e sua presença no material particulado inalado pode afetar células brônquio epiteliais (HEUVEL et al., 2016).

Os elementos Co e Ni são comumente associados devido suas origens geogênicas, entretanto, neste trabalho as suas origens foram fortemente relacionados à emissões da indústria metalúrgica localizada na região de São Miguel Paulista. Visto que estes dois elementos apresentaram alta correlação com 
dados de mortalidade por doenças cardiorrespiratórias, faz-se necessária uma investigação mais detalhada dos efeitos à saúde na população desta região provocados pelas emissões destes elementos.

$\mathrm{O} \mathrm{Cl}$ é um elemento essencial e não é considerado potencialmente tóxico quando na forma de material particulado, pois este elemento normalmente está associado às emissões naturais. A correlação encontrada para este elemento com os dados de mortalidade deve ser melhor investigada. Já o Mg apesar de não ser considerado um elemento tóxico ele pode estar indiretamente relacionado com os efeitos adversos à saúde, uma vez que Mg está associado à queima de óleo diesel (JANDACKA et al., 2017).

$\mathrm{Cl}$

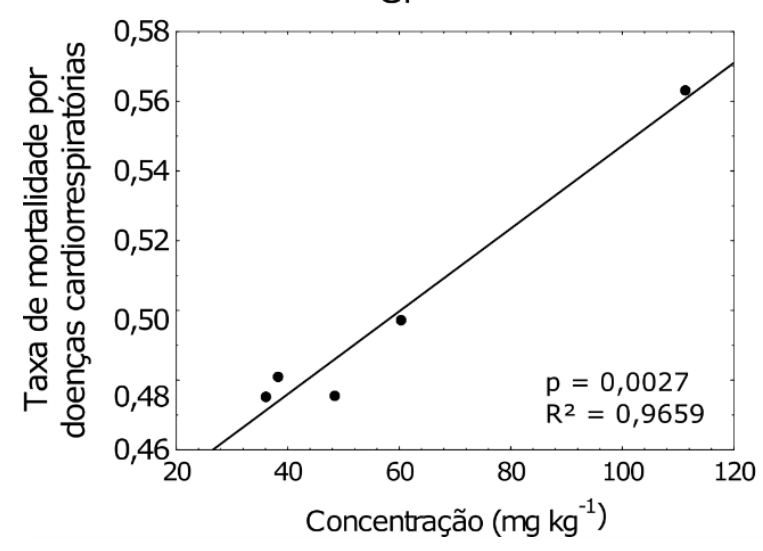

$\mathrm{Mg}$

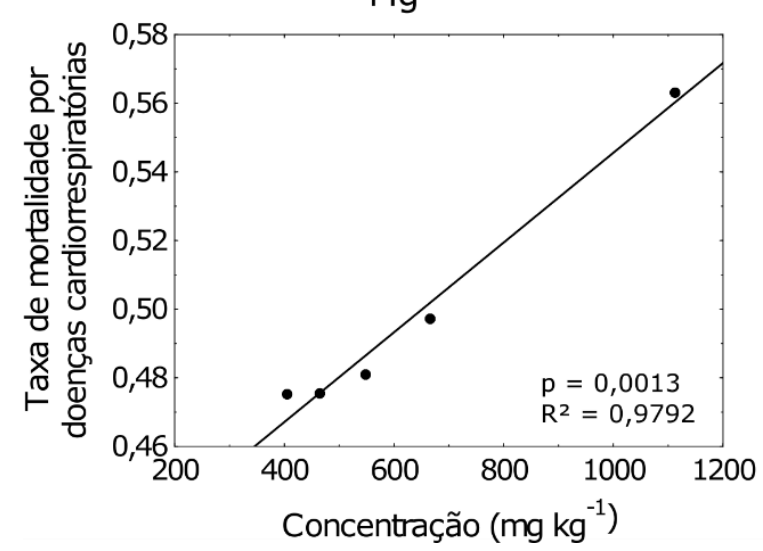

Co

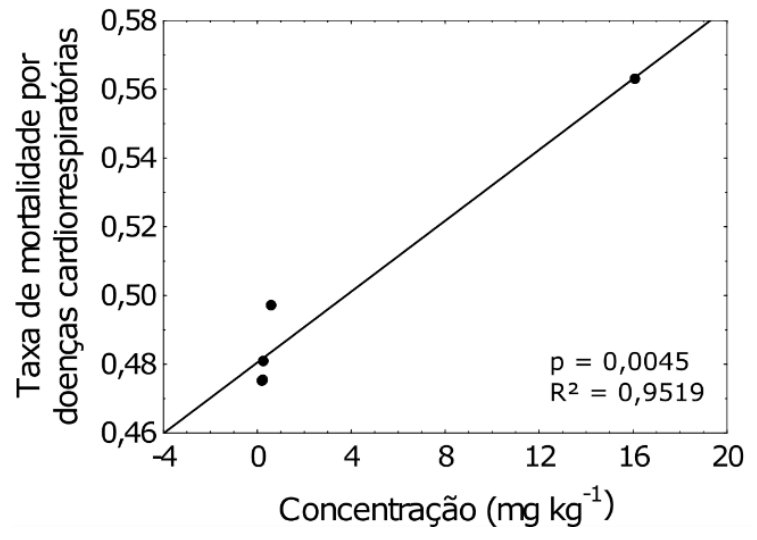

$\mathrm{Ni}$



Figura 24. Taxas de mortalidade por doenças cardiorrespiratórias em função das concentrações médias de $\mathrm{Cl}$, Co, Mg e Ni obtidas nas cascas de Sibipiruna. 


\section{CONCLUSÕES}

Os resultados obtidos neste trabalho permitiram concluir que as cascas de árvores podem ser utilizadas na avaliação da poluição aérea de elementos químicos.

Com relação à qualidade analítica dos resultados obtidos pelos métodos de NAA e AAS, as análises dos materiais de referência apresentaram resultados concordantes com os valores certificados. Os valores $Z$ score obtidos estão dentro do intervalo considerado adequado entre -2 e 2. As duas técnicas analíticas forneceram resultados com boa exatidão e precisão. Além disso, as concentrações dos elementos presentes nas cascas foram superiores aos limites de detecção, indicando que as metodologias foram apropriadas para análise de amostras de cascas de árvore.

Os ensaios preliminares realizados para tratamento das cascas de árvore para análise demonstraram que o procedimento adotado foi adequado, isto é, as análises em replicata indicaram boa homogeneidade das amostras com relação aos elementos determinados.

Também no preparo das amostras de cascas de árvores, concluiu-se que, altas concentrações na camada externa são provavelmente devido ao maior depósito de material particulado na superfície, de modo que foi estabelecido remover $2 \mathrm{~mm}$ de espessura da camada superficial externa para análise. Além disso, a verificação dos teores dos elementos nas diferentes faces do tronco da árvore indicou a necessidade de coletar as cascas nos entornos dos troncos a fim de se obter amostras representativas.

Com relação às espécies arbóreas, foi verificado que existe variabilidade nas concentrações dos elementos entre as espécies Tipuana e Sibipiruna, devido às diferenças estruturais entre as cascas destas duas espécies. Com base neste estudo, optou-se a utilizar somente os resultados da espécie Sibipiruna quando na comparação entre as concentrações de cascas de árvores de diferentes regiões.

Pelos resultados das análises das cascas coletadas em cada região de amostragem pôde-se concluir que há uma ampla variabilidade devido às diferenças entre características de emissões entre pontos de amostragem de uma região. Os pontos de amostragem próximos às vias de alto fluxo veicular apresentaram teores de $\mathrm{As}, \mathrm{Cd}, \mathrm{Pb}, \mathrm{Sb}$ e $\mathrm{Zn}$ mais elevadas, enquanto que os pontos de amostragem de 
menor fluxo veicular apresentaram menores teores de $\mathrm{Cd}, \mathrm{Cu}, \mathrm{Mn}, \mathrm{Pb}, \mathrm{Rb}, \mathrm{Sb}$ e $\mathrm{Zn}$.

Nos resultados das análises das cascas de distintas regiões, foram verificadas as possíveis fontes de origem dos elementos determinados. Na região de Congonhas foi observada elevadas concentrações de $\mathrm{Zn}$, devido às emissões veicular e de aeronaves. A região do Parque Dom Pedro II foi a que apresentou maior variabilidade nas concentrações de elementos devido provavelmente às diferenças de fluxo veicular entre os pontos de amostragem, bem como da ressuspensão de poeira. Pinheiros foi a região da RMSP que apresentou as mais baixas concentrações médias para a maioria dos elementos relacionados à ressuspensão do solo e às emissões veiculares devido ao menor fluxo de veículos nos pontos de amostragem e as características das copas das árvores. Na região de Santo André - Capuava, as amostras coletadas nas proximidades do polo petroquímico apresentaram concentrações mais elevadas de Cd, Co, Cu, La, Mn, $\mathrm{Ni}, \mathrm{Pb}$ e $\mathrm{V}$. Além disso, a concentração média de $\mathrm{Mn}$ foi maior em relação às demais regiões da RMSP, indicando possível origem industrial. As amostras coletadas na região de Santo André - Paço Municipal foram as que apresentaram maiores teores de $\mathrm{Br}$, provavelmente oriundo de fontes industriais da região. Em São Miguel Paulista as altas concentrações de Co e Ni encontradas se deve à indústria metalúrgica localizada nesta região que processa estes dois metais. As regiões controle localizadas no interior de São Paulo, Marília e Presidente Prudente, foram as que apresentaram as mais baixas concentrações de $\mathrm{Cd}, \mathrm{Cl}, \mathrm{Cs}, \mathrm{Cu}, \mathrm{Mn}, \mathrm{Pb}, \mathrm{Rb}$, $\mathrm{Sb}$ e $\mathrm{Zn}$ em relação às $\mathrm{RMSP}$.

Os resultados dos estudos das correlações pelo AA e pela PCA entre os elementos determinados nas cascas de árvores permitiram concluir que há quatro fontes distintas com relação às origens dos elementos, a saber, da ressuspensão do solo juntamente com as emissões veiculares, da indústria, do aerossol marinho e da própria estrutura da casca de árvore.

Com relação aos estudos das correlações (AA e PCA) entre as regiões, foi possível de distinguir dois grupos de regiões, sendo estes: grupo 1 composta por Cerqueira César, Marília, Pinheiros, Santo André-Paço Municipal, Congonhas e Presidente Prudente; grupo 2: Parque Dom Pedro II, São Miguel Paulista. Entretanto, pelo tratamento de PCA não foi verificada uma diferença significativa entre estes dois grupos de regiões, o que pode-se concluir que as regiões 
pertencem a um mesmo grupo. O resultado esperado era que as regiões de controle e as de RMSP formassem dois grupos distintos, uma vez que as concentrações dos elementos foram diferentes. Provavelmente a não formação de pelo menos dois grupos no estudo da correlação entre as regiões se deve ao fato que as origens dos elementos serem do mesmo tipo de fonte de emissões.

Os fatores de enriquecimento (FE) calculados foram maiores que 1 para todos os elementos, em todos os pontos de amostragem, indicando que 0 enriquecimento destes elementos é de origem antrópica. O Cs foi o único elemento considerado de origem geológica $(F E<1)$ para todos as regiões de amostragem. Os elementos $\mathrm{As}, \mathrm{Cd}, \mathrm{Cr}, \mathrm{Cu}, \mathrm{Sb}, \mathrm{Pb}$ e $\mathrm{Zn}$ apresentaram valores de FE maiores na RMSP em relação aos das regiões controle, indicando que a intensidade do tráfego veicular pode influencia no enriquecimento destes elementos.

De acordo com o índice de geoacumulação (IGeo) as regiões de amostragem foram classificadas como não poluídas para a maioria dos elementos determinados. A região de Parque Dom Pedro foi a que apresentou IGeo maior que 0,8 para $\mathrm{Cd}$, e Sb, sendo classificada entre pouco e moderadamente contaminada por estes elementos.

Os resultados obtidos nas análises das cascas de árvore e os dados das estações de monitoramento da CETESB foi possível observar uma relação crescente entre as concentrações de As, Cd, Co, $\mathrm{Pb}$ e $\mathrm{Zn}$ e as concentrações de $\mathrm{MP}_{10}$. Além disso, estes elementos apresentaram valores de FE maiores para as regiões da RMSP em relação aos das regiões controle, indicando que a origem destes elementos pode ser proveniente de emissões veiculares. Este estudo pode ser estendido por meio de uma avaliação temporal das concentrações dos elementos das cascas em função das de PM10 medidos em diferentes faixas de tempo. Esta análise poderá permitir estimar o intervalo de tempo o qual pode ser considerada as medidas de poluição atmosférica a partir das cascas de árvore.

As correlações entre as concentrações dos elementos determinados nas cascas de árvore e as taxas de mortalidade por doenças cardiorrespiratórias foram significativas para os elementos $\mathrm{Cl}, \mathrm{Co}, \mathrm{Mg}$ e $\mathrm{Ni}$, indicando que estes elementos podem estar relacionados com os efeitos adversos à saúde. Devido à restrição ao acesso à informação dos dados de mortalidade mais detalhados, no presente trabalho, foram utilizados os dados dos distritos onde estão localizadas as estações de monitoramento, abrangendo a população de uma área maior em relação à de 
coleta das cascas de árvore. Este estudo poderá ser aprimorado utilizando dados de saúde da população residente dentro da área de estudo. Estas são análises preliminares que exigem um estudo mais aprofundado e detalhado sobre qual a relação das informações sobre poluição atmosférica obtidas pelas análises de cascas de árvore com a saúde humana, com maiores pontos de amostragem e com dados mais detalhados sobre casos de mortalidade para se ter correlações mais robustas. 
APÊNDICE A - Dados das amostras coletadas em Cerqueira César, Congonhas, Parque Dom Pedro II, Pinheiros, Santo André - Capuava, Santo André - Paço Municipal, Marília e Presidente Prudente.

Tabela A. 1 - Dados das amostras de cascas de árvore coletadas em Cerqueira César e Congonhas.

\begin{tabular}{|c|c|c|c|c|c|c|c|}
\hline $\begin{array}{c}\text { Região de } \\
\text { amostragem }\end{array}$ & $\begin{array}{l}\text { Período } \\
\text { de coleta }\end{array}$ & $\begin{array}{c}\text { Ponto de } \\
\text { amostragem }\end{array}$ & $\begin{array}{l}\text { Tipo de } \\
\text { via }^{*}\end{array}$ & Amostra & $\begin{array}{l}\text { Diâmetro } \\
\text { do tronco } \\
(\mathrm{cm})\end{array}$ & $\begin{array}{c}\text { Amostra } \\
\text { composta }\end{array}$ & $\begin{array}{l}\text { Espécie } \\
\text { arbórea }\end{array}$ \\
\hline \multirow{8}{*}{$\begin{array}{l}\text { Cerqueira } \\
\text { César }\end{array}$} & \multirow{8}{*}{$\begin{array}{c}\text { Fevereiro } \\
\text { de } 2016\end{array}$} & \multirow{3}{*}{$\mathrm{CC} 1$} & \multirow{3}{*}{ coletora } & EL88 & 49,3 & \multirow{3}{*}{ A34 } & \multirow{3}{*}{ Sibipiruna } \\
\hline & & & & EL89 & 49,7 & & \\
\hline & & & & EL90 & 53,2 & & \\
\hline & & \multirow{3}{*}{$\mathrm{CC} 2$} & \multirow{3}{*}{ coletora } & EL91 & 63,7 & \multirow{3}{*}{ A35 } & \multirow{3}{*}{ Tipuana } \\
\hline & & & & EL92 & 72,6 & & \\
\hline & & & & EL93 & 73,2 & & \\
\hline & & \multirow{2}{*}{ CC3 } & \multirow{2}{*}{ coletora } & EL94 & 100,9 & \multirow{2}{*}{ A36 } & \multirow{2}{*}{ Tipuana } \\
\hline & & & & EL95 & 106,6 & & \\
\hline \multirow{15}{*}{ Congonhas } & \multirow{15}{*}{$\begin{array}{l}\text { Janeiro } \\
\text { de } 2016\end{array}$} & \multirow{3}{*}{ CG1 } & \multirow{3}{*}{ coletora } & EL36 & 50,0 & \multirow{3}{*}{ A11 } & \multirow{3}{*}{ Sibipiruna } \\
\hline & & & & EL37 & 57,6 & & \\
\hline & & & & EL38 & 70,0 & & \\
\hline & & \multirow{2}{*}{ CG2 } & \multirow{2}{*}{ local } & EL39 & 70,0 & \multirow{2}{*}{ A12 } & \multirow{2}{*}{ Tipuana } \\
\hline & & & & EL40 & 74,5 & & \\
\hline & & \multirow{2}{*}{ CG3 } & \multirow{2}{*}{ local } & EL41 & 42,7 & \multirow{2}{*}{ A13 } & \multirow{2}{*}{ Sibipiruna } \\
\hline & & & & EL42 & 47,4 & & \\
\hline & & \multirow{4}{*}{ CG4 } & \multirow{4}{*}{ local } & EL43 & 42,7 & \multirow{3}{*}{ A14 } & \multirow{3}{*}{ Sibipiruna } \\
\hline & & & & EL44 & 44,9 & & \\
\hline & & & & EL45 & 53,5 & & \\
\hline & & & & EL46 & 70,0 & A15 & Tipuana \\
\hline & & \multirow{3}{*}{ CG5 } & & EL47 & 61,4 & A16 & Sibipiruna \\
\hline & & & local & EL48 & 53,8 & A17 & Tinun \\
\hline & & & & EL49 & 60,8 & מדו & Ipuaria \\
\hline & & CG6 & coletora & EL50 & 50,0 & A18 & Sibipiruna \\
\hline
\end{tabular}

* Conforme lista de classificação das vias do Município de São Paulo (SMUL, SD). 


\section{APÊNDICE A - Continuação}

Tabela A. 2 - Dados das amostras de cascas de árvore coletadas no Parque Dom Pedro II e em Pinheiros.

\begin{tabular}{|c|c|c|c|c|c|c|c|}
\hline $\begin{array}{l}\text { Região de } \\
\text { amostragem }\end{array}$ & $\begin{array}{l}\text { Período } \\
\text { de coleta }\end{array}$ & $\begin{array}{l}\text { Ponto de } \\
\text { amostragem }\end{array}$ & $\begin{array}{l}\text { Tipo de } \\
\text { via * }\end{array}$ & Amostra & $\begin{array}{l}\text { Diâmetro } \\
\text { do tronco } \\
(\mathrm{cm})\end{array}$ & $\begin{array}{l}\text { Amostra } \\
\text { composta }\end{array}$ & $\begin{array}{l}\text { Espécie } \\
\text { arbórea }\end{array}$ \\
\hline \multirow{14}{*}{$\begin{array}{l}\text { Parque Dom } \\
\text { Pedro II }\end{array}$} & \multirow{14}{*}{$\begin{array}{l}\text { Janeiro } \\
\text { de } 2016\end{array}$} & \multirow{6}{*}{ DP1 } & \multirow{6}{*}{ N3 } & EL74 & 39,8 & \multirow{3}{*}{$\mathrm{A} 27$} & \multirow{3}{*}{ Sibipiruna } \\
\hline & & & & EL75 & 49,7 & & \\
\hline & & & & EL76 & 51,2 & & \\
\hline & & & & EL77 & 54,4 & \multirow{3}{*}{ A28 } & \multirow{3}{*}{ Tipuana } \\
\hline & & & & EL78 & 56,0 & & \\
\hline & & & & EL79 & 83,1 & & \\
\hline & & \multirow{3}{*}{ DP2 } & \multirow{3}{*}{$* *$} & EL80 & 60,5 & \multirow{3}{*}{ A29 } & \multirow{3}{*}{ Tipuana } \\
\hline & & & & EL81 & 66,5 & & \\
\hline & & & & EL82 & 71,3 & & \\
\hline & & \multirow{3}{*}{ DP3 } & \multirow{3}{*}{ N3 } & EL83 & 61,1 & A30 & Sibipiruna \\
\hline & & & & EL84 & 79,9 & \multirow{2}{*}{ A31 } & \multirow{2}{*}{ Tipuana } \\
\hline & & & & EL85 & 79,9 & & \\
\hline & & \multirow{2}{*}{ DP4 } & \multirow{2}{*}{ N3 } & EL86 & 42,0 & A32 & Sibipiruna \\
\hline & & & & EL87 & 71,9 & A33 & Tipuana \\
\hline \multirow{14}{*}{ Pinheiros } & \multirow{14}{*}{$\begin{array}{l}\text { Janeiro } \\
\text { de } 2016\end{array}$} & \multirow{4}{*}{ PN1 } & \multirow{4}{*}{ local } & EL55 & 44,9 & \multirow{4}{*}{ A19 } & \multirow{4}{*}{ Sibipiruna } \\
\hline & & & & EL56 & 47,1 & & \\
\hline & & & & EL57 & 59,8 & & \\
\hline & & & & EL58 & 74,8 & & \\
\hline & & \multirow{2}{*}{ PN2 } & \multirow{2}{*}{ local } & EL59 & 85,3 & A20 & Tipuana \\
\hline & & & & EL60 & 66,8 & A21 & Sibipiruna \\
\hline & & \multirow{2}{*}{ PN3 } & \multirow{2}{*}{ local } & EL61 & 42,7 & A22 & Sibipiruna \\
\hline & & & & EL62 & 102,8 & A23 & Tipuana \\
\hline & & \multirow{2}{*}{ PN4 } & \multirow{2}{*}{ local } & EL63 & 57,3 & \multirow{2}{*}{ A24 } & Tinuana \\
\hline & & & & EL64 & 74,8 & & 11puana \\
\hline & & PN5 & Jocal & EL65 & 37,9 & $\Delta 25$ & Sininirun \\
\hline & & RINS & local & EL66 & 46,5 & $A<5$ & SIDIpiruna \\
\hline & & PNG & local & EL67 & 81,2 & $A 26$ & Tinuana \\
\hline & & & & EL68 & 84,0 & & \\
\hline
\end{tabular}

* Conforme lista de classificação das vias do Município de São Paulo (SMUL, SD).

** Ponto de amostragem localizado dentro do parque. 


\section{APÊNDICE A - Continuação}

Tabela A. 3 - Dados das amostras de cascas de árvore coletadas em São Miguel Paulista.

\begin{tabular}{ccccccc}
\hline $\begin{array}{c}\text { Região de } \\
\text { amostragem }\end{array}$ & $\begin{array}{c}\text { Período de } \\
\text { coleta }\end{array}$ & $\begin{array}{c}\text { Ponto de } \\
\text { amostragem }\end{array}$ & Tipo de via & $\begin{array}{c}\text { Amostra } \\
\begin{array}{c}\text { Diâmetro } \\
\text { do tronco } \\
(\mathrm{cm})\end{array}\end{array}$ & $\begin{array}{c}\text { Espécie } \\
\text { arbórea }\end{array}$ \\
\hline & & SM1 & local & E63 & 29,0 & Sibipiruna \\
& SM2 & local & E64 & 30,0 & Sibipiruna \\
São Miguel & Julho de & SM3 & coletora & E65 & 33,1 & Sibipiruna \\
Paulista & SM4 & coletora & E66 & 36,9 & Sibipiruna \\
& & SM5 & local & E67 & 38,2 & Sibipiruna \\
& & SM6 & local & E68 & 38,2 & Sibipiruna \\
& & SM7 & coletora & E69 & 51,6 & Tipuana \\
& & SM8 & local & E70 & 56,1 & Sibipiruna \\
& & SM9 & coletora & E71 & 64,6 & Sibipiruna \\
\hline
\end{tabular}




\section{APÊNDICE A - Continuação}

Tabela A. 4 - Dados das amostras de cascas de árvore coletadas em Santo André - Capuava e Santo André - Paço Municipal.

\begin{tabular}{|c|c|c|c|c|c|c|}
\hline $\begin{array}{l}\text { Região de } \\
\text { amostragem }\end{array}$ & $\begin{array}{l}\text { Período de } \\
\text { coleta }\end{array}$ & $\begin{array}{c}\text { Ponto de } \\
\text { amostragem }\end{array}$ & Amostra & $\begin{array}{c}\text { Diâmetro } \\
\text { do tronco } \\
(\mathrm{cm})\end{array}$ & $\begin{array}{l}\text { Amostra } \\
\text { composta }\end{array}$ & $\begin{array}{l}\text { Espécie } \\
\text { arbórea }\end{array}$ \\
\hline \multirow{6}{*}{$\begin{array}{l}\text { Santo André - } \\
\text { Capuava }\end{array}$} & \multirow{6}{*}{$\begin{array}{l}\text { Dezembro } \\
\text { de } 2015\end{array}$} & \multirow{2}{*}{ CA1 } & EL1 & 56,3 & \multirow{2}{*}{ A9 } & \multirow{2}{*}{ Tipuana } \\
\hline & & & EL2 & 68,4 & & \\
\hline & & \multirow{4}{*}{ CA2 } & EL3 & 47,7 & \multirow{4}{*}{$\mathrm{A} 10$} & \multirow{4}{*}{ Tipuana } \\
\hline & & & EL4 & 62,7 & & \\
\hline & & & EL5 & 65,6 & & \\
\hline & & & EL6 & 71,3 & & \\
\hline \multirow{18}{*}{$\begin{array}{l}\text { Santo André - } \\
\text { Paço Municipal }\end{array}$} & \multirow{18}{*}{$\begin{array}{l}\text { Dezembro } \\
\text { de } 2015\end{array}$} & \multirow{3}{*}{ SA1 } & EL14 & 40,4 & \multirow{3}{*}{$\mathrm{A} 1$} & \multirow{3}{*}{ Sibipiruna } \\
\hline & & & EL15 & 47,7 & & \\
\hline & & & EL16 & 57,3 & & \\
\hline & & \multirow{2}{*}{ SA2 } & EL26 & 39,8 & \multirow{2}{*}{$\mathrm{A} 2$} & \multirow{2}{*}{ Sibipiruna } \\
\hline & & & EL27 & 42,3 & & \\
\hline & & \multirow{3}{*}{ SA3 } & EL22 & 55,4 & \multirow{3}{*}{ A3 } & \multirow{3}{*}{ Sibipiruna } \\
\hline & & & EL23 & 57,3 & & \\
\hline & & & EL34 & 54,7 & & \\
\hline & & \multirow{3}{*}{ SA4 } & EL8 & 49,0 & \multirow{3}{*}{ A4 } & \multirow{3}{*}{ Sibipiruna } \\
\hline & & & EL9 & 50,3 & & \\
\hline & & & EL10 & 50,9 & & \\
\hline & & \multirow{2}{*}{ SA5 } & EL30 & 59,5 & \multirow{2}{*}{ A5 } & \multirow{2}{*}{ Tipuana } \\
\hline & & & EL31 & 65,6 & & \\
\hline & & \multirow{2}{*}{ SA6 } & EL24 & 47,1 & \multirow{2}{*}{ A6 } & \multirow{2}{*}{ Tipuana } \\
\hline & & & EL25 & 50,0 & & \\
\hline & & SA7 & EL17 & 86,9 & A7 & Tipuana \\
\hline & & \multirow{2}{*}{ SA8 } & EL28 & 42,7 & \multirow{2}{*}{ A8 } & \multirow{2}{*}{ Tipuana } \\
\hline & & & EL29 & 61,1 & & \\
\hline
\end{tabular}




\section{APÊNDICE A - Continuação}

Tabela A. 5 - Dados das amostras de cascas de árvore coletadas em Marília e Presidente Prudente.

\begin{tabular}{|c|c|c|c|c|c|c|}
\hline $\begin{array}{l}\text { Região de } \\
\text { amostragem }\end{array}$ & $\begin{array}{l}\text { Período } \\
\text { de coleta }\end{array}$ & $\begin{array}{l}\text { Ponto de } \\
\text { amostragem }\end{array}$ & Amostra & $\begin{array}{l}\text { Diâmetro } \\
\text { do tronco } \\
(\mathrm{cm})\end{array}$ & $\begin{array}{l}\text { Amostra } \\
\text { Composta }\end{array}$ & $\begin{array}{l}\text { Espécie } \\
\text { arbórea }\end{array}$ \\
\hline \multirow{9}{*}{ Marília } & \multirow{9}{*}{$\begin{array}{c}\text { Julho de } \\
2016\end{array}$} & \multirow{4}{*}{ MA1 } & EL103 & 45,5 & \multirow{4}{*}{ A40 } & \multirow{4}{*}{ Sibipiruna } \\
\hline & & & EL104 & 46,8 & & \\
\hline & & & EL105 & 56,0 & & \\
\hline & & & EL106 & 85,3 & & \\
\hline & & \multirow{2}{*}{ MA2 } & EL107 & 46,5 & \multirow{2}{*}{ A41 } & \multirow{2}{*}{ Sibipiruna } \\
\hline & & & EL108 & 52,8 & & \\
\hline & & \multirow{3}{*}{ MA3 } & EL110 & 53,2 & \multirow{3}{*}{ A42 } & \multirow{3}{*}{ Sibipiruna } \\
\hline & & & EL111 & 63,0 & & \\
\hline & & & EL112 & 66,8 & & \\
\hline \multirow{7}{*}{$\begin{array}{l}\text { Presidente } \\
\text { Prudente }\end{array}$} & \multirow{7}{*}{$\begin{array}{c}\text { Julho de } \\
2016\end{array}$} & PP1 & EL96 & 65,3 & A37 & Sibipiruna \\
\hline & & \multirow{4}{*}{ PP2 } & EL97 & 61,8 & \multirow{4}{*}{ A38 } & \multirow{4}{*}{ Sibipiruna } \\
\hline & & & EL98 & 54,1 & & \\
\hline & & & EL99 & 78,3 & & \\
\hline & & & EL100 & 80,9 & & \\
\hline & & \multirow{2}{*}{ PP3 } & EL101 & 72,6 & \multirow{2}{*}{ A39 } & \multirow{2}{*}{ Sibipiruna } \\
\hline & & & EL102 & 75,8 & & \\
\hline
\end{tabular}


APÊNDICE B - Localização dos pontos de amostragem das regiões Cerqueira César, Congonhas, Parque Dom Pedro II, Pinheiros, Santo André - Capuava, Santo André - Paço Municipal, São Miguel Paulista, Marília, Presidente Prudente.

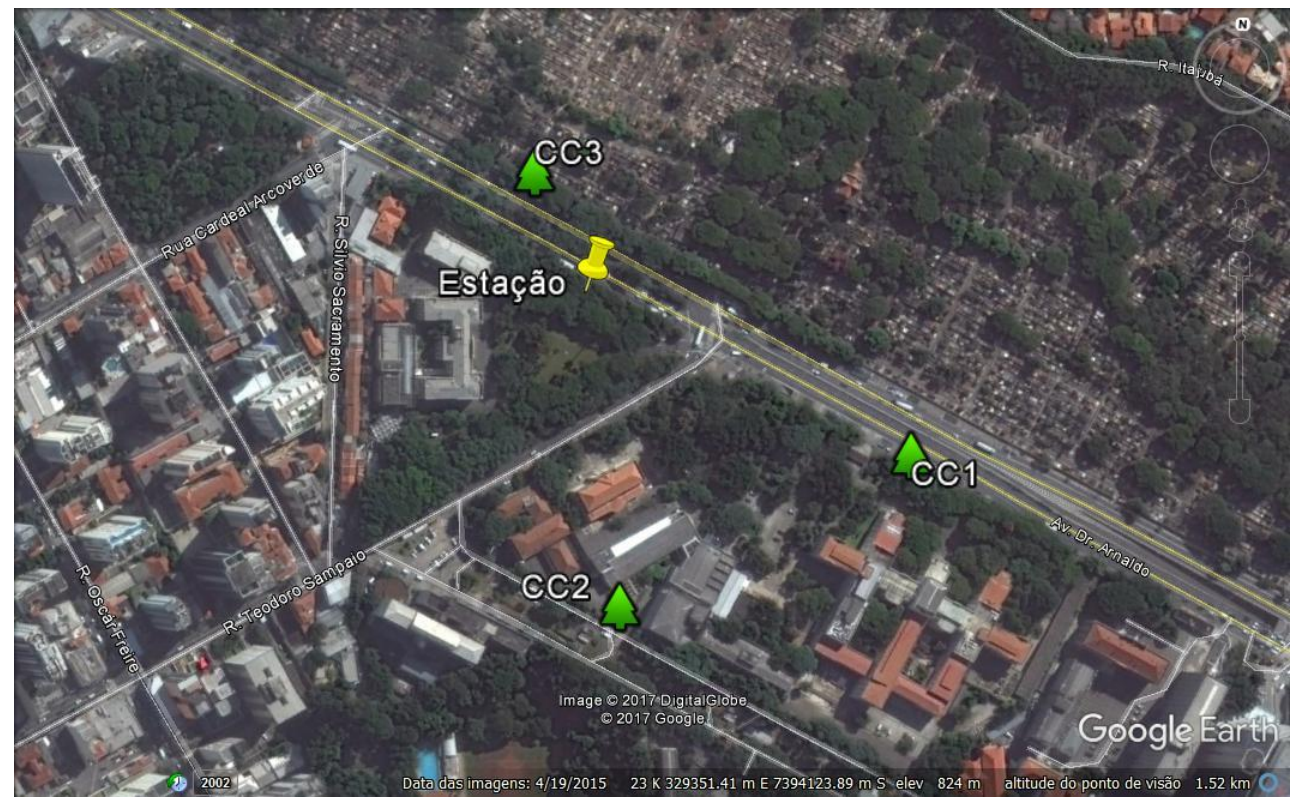

Figura B. 1 - Pontos de amostragem das cascas de árvores e localização da estação de monitoramento automático da CETESB na região Cerqueira César.

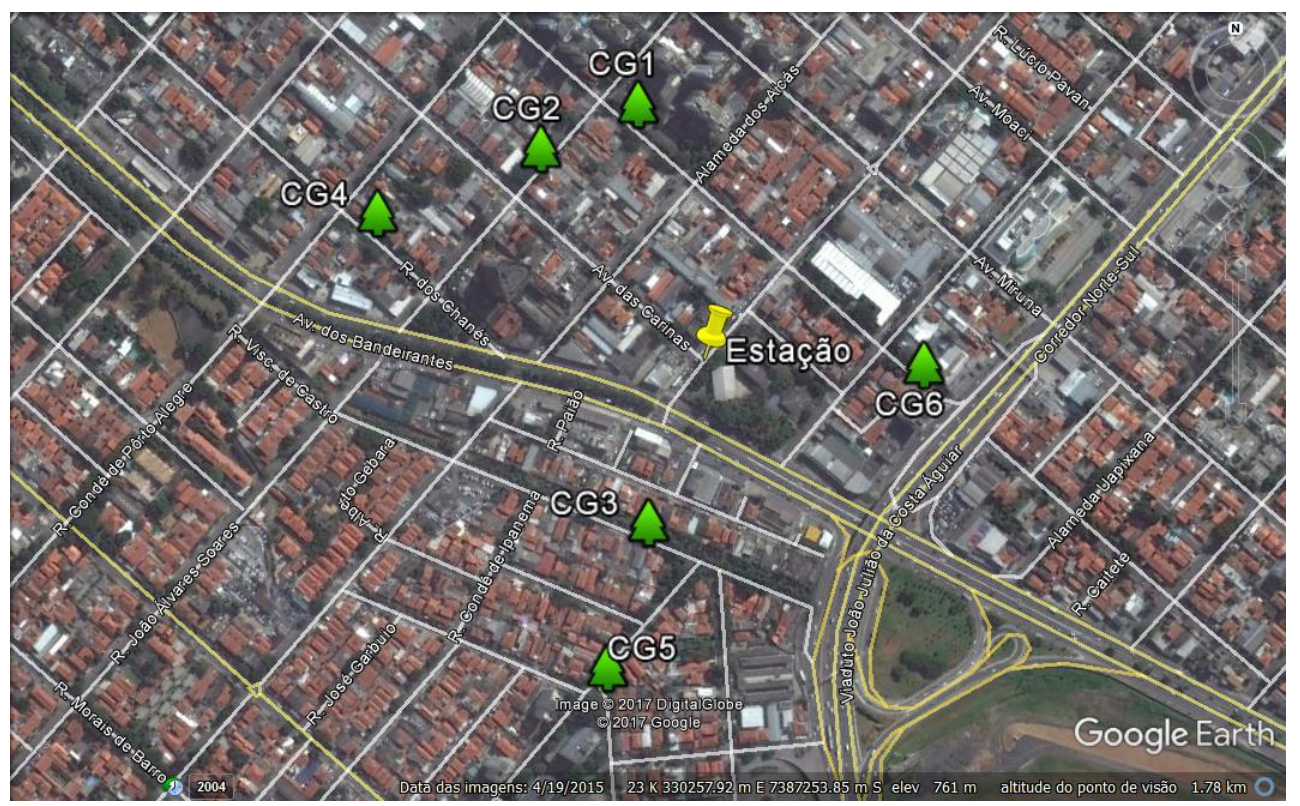

Figura B. 2 - Pontos de amostragem das cascas de árvores e localização da estação de monitoramento automático da CETESB na região Congonhas. 


\section{APÊNDICE B - Contiuação}

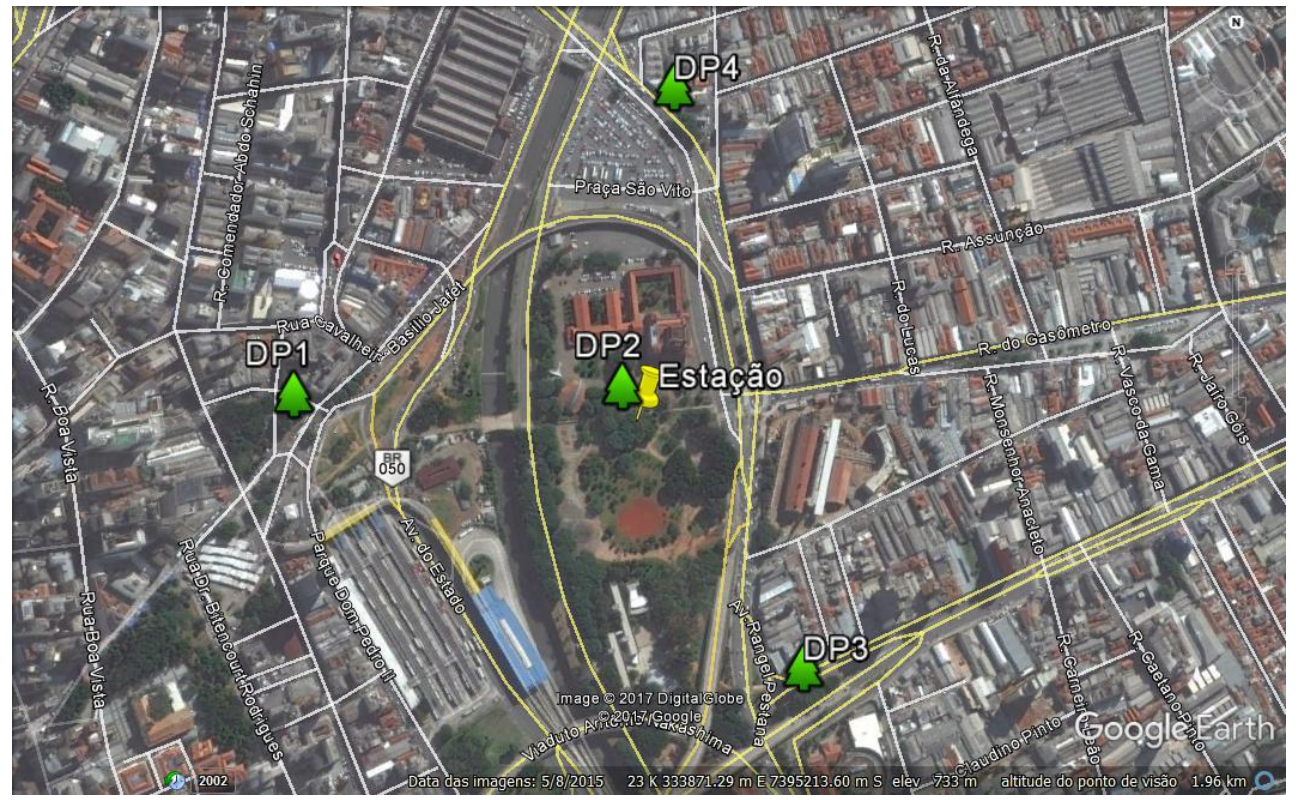

Figura B. 3 - Pontos de amostragem das cascas de árvores e localização da estação de monitoramento automático da CETESB na região Parque Dom Pedro II.

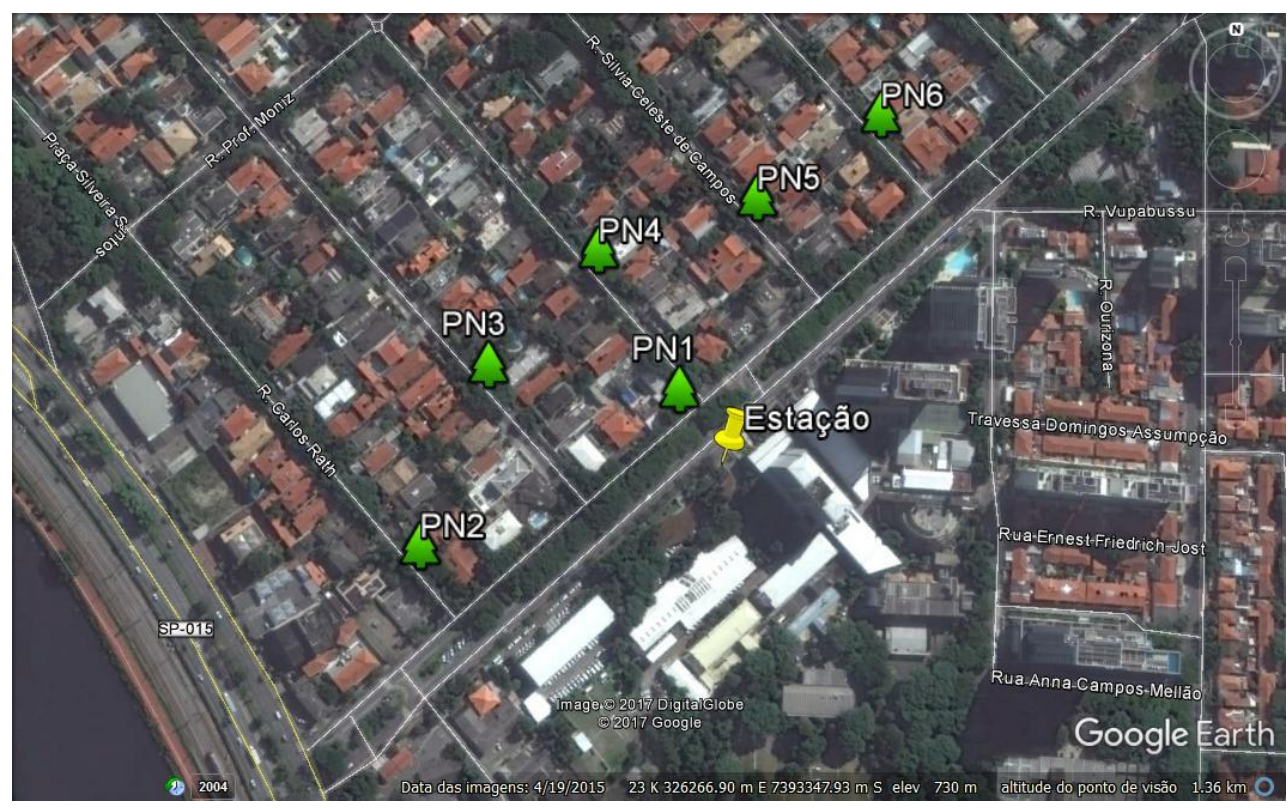

Figura B. 4 - Pontos de amostragem das cascas de árvores e localização da estação de monitoramento automático da CETESB na região Pinheiros. 
APÊNDICE B - Continuação

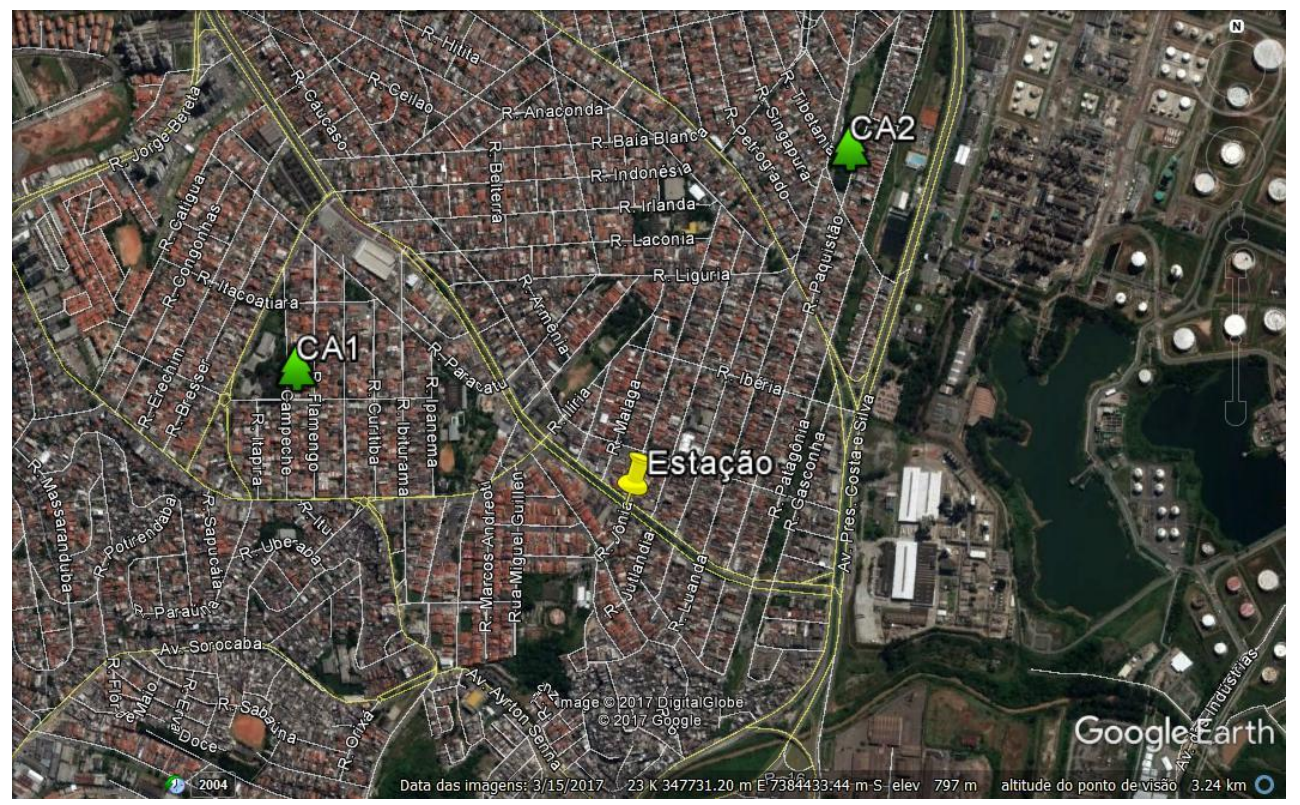

Figura B. 5 - Pontos de amostragem das cascas de árvores e localização da estação de monitoramento automático da CETESB na região Santo André Capuava.



Figura B. 6 - Pontos de amostragem das cascas de árvores e localização da estação de monitoramento automático da CETESB na região Santo André - Paço Municipal. 


\section{APÊNDICE B - Continuação}

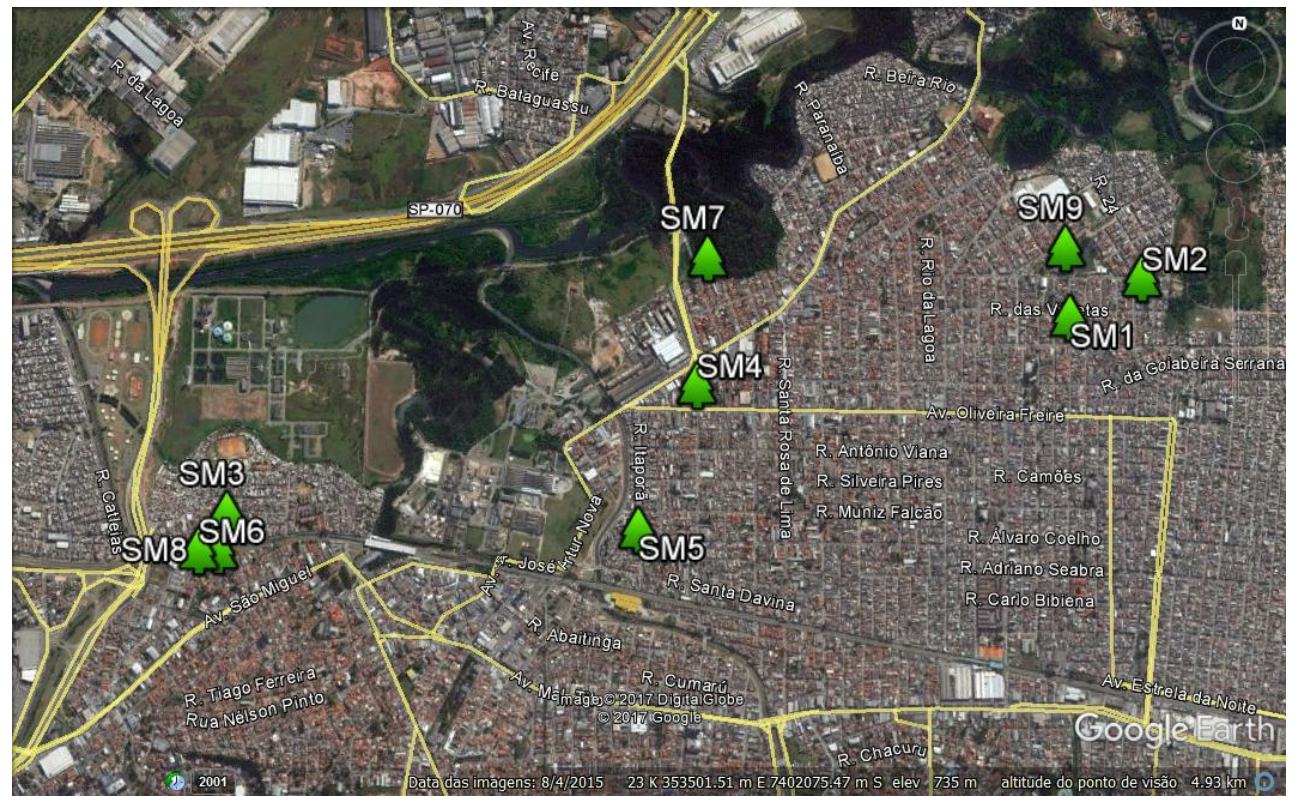

Figura B. 7 - Pontos de amostragem das cascas de árvores e localização da estação de monitoramento automático da CETESB na região São Miguel Paulista.

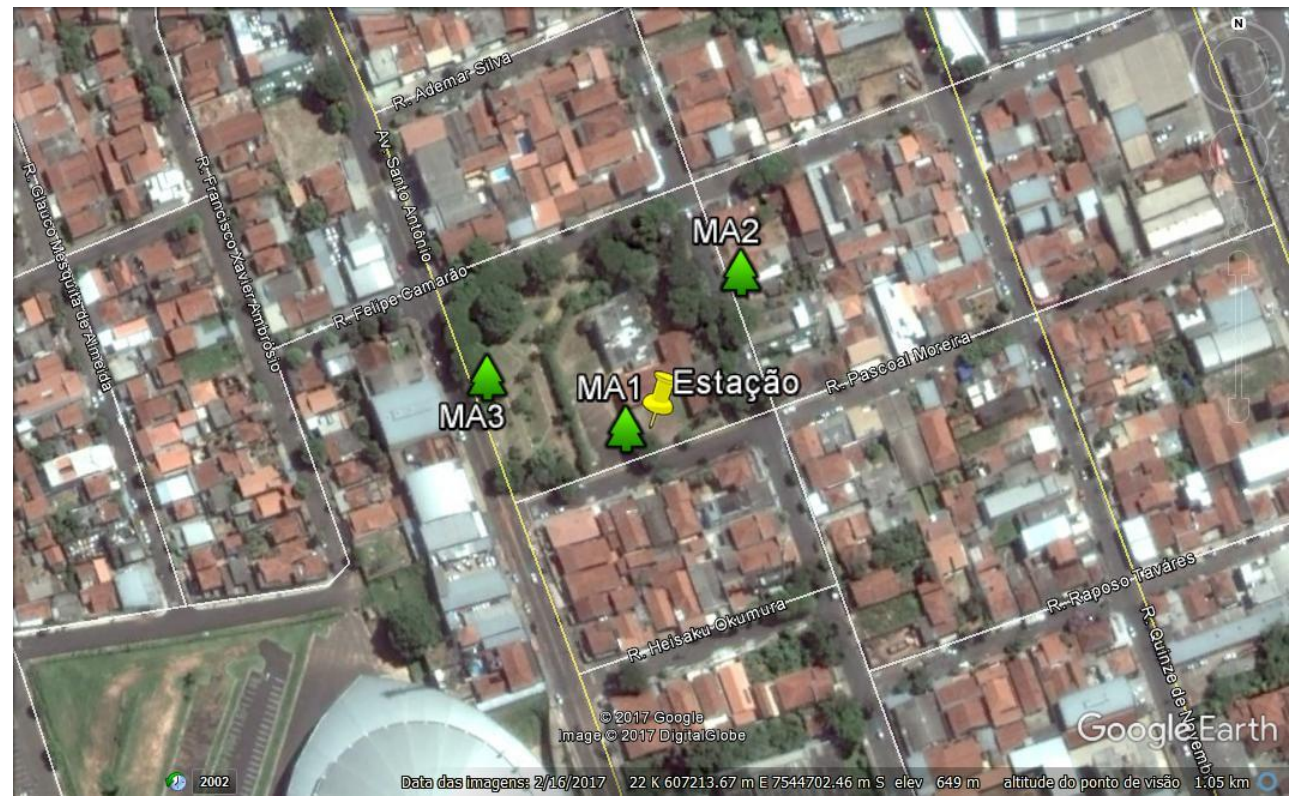

Figura B. 8 - Pontos de amostragem das cascas de árvores e localização da estação de monitoramento automático da CETESB na região Marília. 


\section{APÊNDICE B - Continuação}

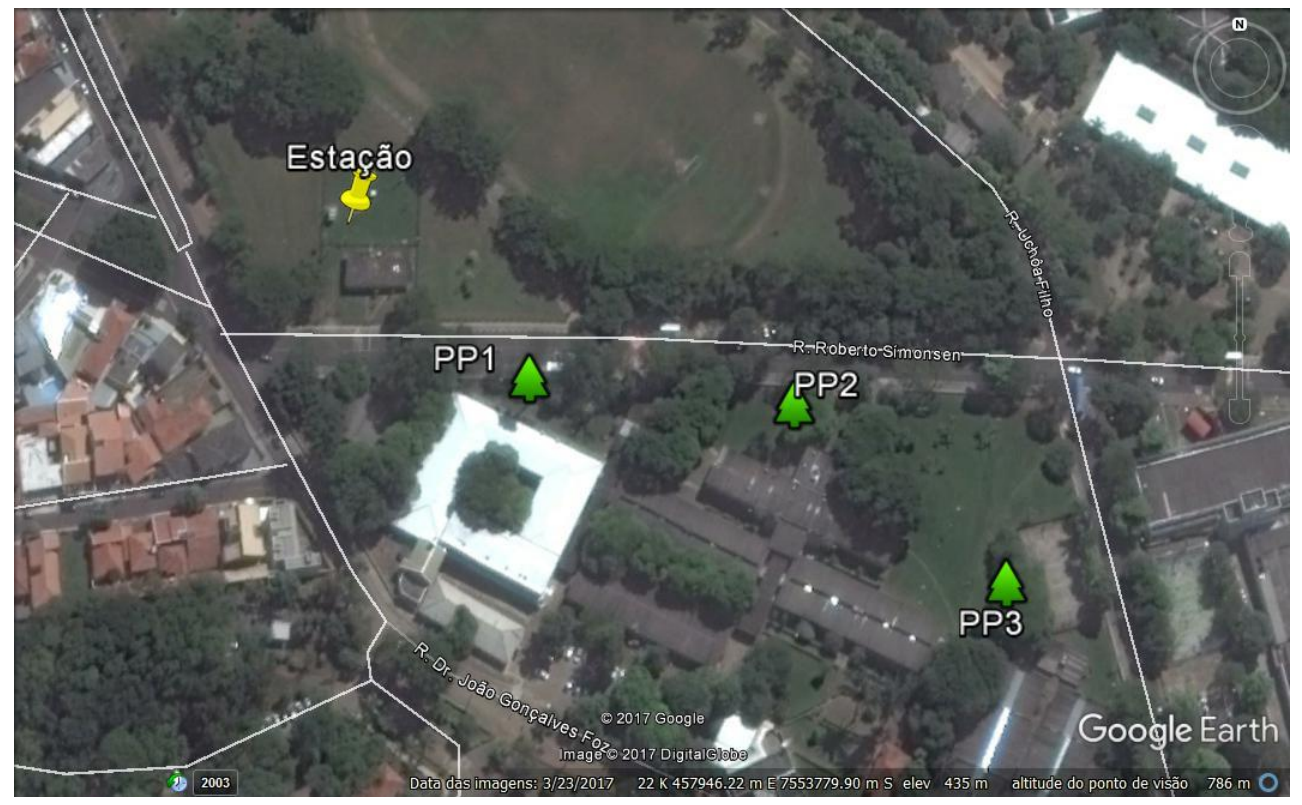

Figura B. 9 - Pontos de amostragem das cascas de árvores e localização da estação de monitoramento automático da CETESB na região Presidente Prudente. 


\section{APÊNDICE C - Concentrações dos elementos $\left(\mathrm{mg} \mathrm{kg}^{-1}\right)$ determinados nas}

\section{cascas de árvore.}

Tabela C. 1 - Concentrações dos elementos $\left(\mathrm{mg} \mathrm{kg}^{-1}\right) \mathrm{As}, \mathrm{Br}, \mathrm{Ca}, \mathrm{Cd}, \mathrm{Cl}$, Co e $\mathrm{Cr}$ determinados nas cascas de árvore.

\begin{tabular}{|c|c|c|c|c|c|c|c|c|c|}
\hline $\begin{array}{l}\text { Código da } \\
\text { amostra }\end{array}$ & $\begin{array}{c}\text { Ponto de } \\
\text { amostragem }\end{array}$ & $\begin{array}{l}\text { Espécie } \\
\text { arbórea }\end{array}$ & As & $\mathrm{Br}$ & $\mathrm{Ca}$ & $\mathrm{Cd}$ & $\mathrm{Cl}$ & Co & $\mathrm{Cr}$ \\
\hline E63 & SM1 & Sibipiruna & 0,273 & 1,99 & 35229 & 0,594 & 93,5 & 2,99 & 5,66 \\
\hline E64 & SM2 & Sibipiruna & 0,179 & 3,29 & 43144 & 0,251 & 157,6 & 1,81 & 2,41 \\
\hline E65 & SM3 & Sibipiruna & 0,165 & 2,92 & 30692 & 0,258 & 128,1 & 2,23 & 1,46 \\
\hline E66 & SM4 & Sibipiruna & 0,336 & 1,88 & 33815 & 0,499 & 87,4 & 75,85 & 4,12 \\
\hline E67 & SM5 & Sibipiruna & 0,099 & 1,40 & 40683 & 0,246 & 75,8 & 4,25 & 1,16 \\
\hline E69 & SM7 & Sibipiruna & 0,162 & 6,05 & 35417 & 0,871 & 187,1 & 31,78 & 2,07 \\
\hline E70 & SM8 & Sibipiruna & 0,188 & 2,40 & 32271 & 0,317 & 82,3 & 8,77 & 2,88 \\
\hline E71 & SM9 & Sibipiruna & 0,262 & 2,38 & 34375 & 0,492 & 78,7 & 0,92 & 3,48 \\
\hline E68 & SM6 & Tipuana & 0,244 & 1,53 & 34374 & 0,337 & 44,4 & 4,65 & 2,45 \\
\hline $\mathrm{A} 1$ & SA1 & Sibipiruna & 0,074 & 2,76 & 34265 & 0,181 & 45,2 & 0,27 & 2,60 \\
\hline $\mathrm{A} 2$ & SA2 & Sibipiruna & 0,096 & 2,51 & 47803 & 0,501 & 35,8 & 0,24 & 2,27 \\
\hline $\mathrm{A} 3$ & SA3 & Sibipiruna & 0,150 & 2,75 & 43602 & 0,330 & 55,9 & 0,31 & 2,68 \\
\hline A4 & SA4 & Sibipiruna & 0,063 & 3,22 & 38392 & 0,225 & 40,3 & 0,23 & 2,02 \\
\hline A5 & SA5 & Tipuana & 0,248 & 15,70 & 38270 & 0,456 & 487,0 & 0,62 & 4,49 \\
\hline $\mathrm{A} 6$ & SA6 & Tipuana & 0,235 & 20,21 & 31599 & 0,642 & 223,7 & 0,86 & 4,31 \\
\hline A7 & SA7 & Tipuana & 0,324 & 14,18 & 28826 & 0,584 & 919,2 & 0,83 & 4,77 \\
\hline A8 & SA8 & Tipuana & 0,313 & 11,29 & 33279 & 0,721 & 267,5 & 0,71 & 7,22 \\
\hline A9 & $\mathrm{CA} 1$ & Tipuana & 0,128 & 8,58 & 31456 & 0,369 & 291,3 & 0,73 & 3,51 \\
\hline A10 & $\mathrm{CA} 2$ & Tipuana & 0,182 & 12,94 & 31994 & 0,698 & 464,2 & 2,17 & 2,50 \\
\hline A11 & CG11 & Sibipiruna & 0,072 & 1,36 & 40611 & 0,225 & 32,0 & 0,19 & 1,46 \\
\hline A13 & CG3 & Sibipiruna & 0,091 & 2,75 & 33246 & 0,363 & 45,9 & 0,35 & 1,85 \\
\hline A14 & CG4 & Sibipiruna & 0,127 & 2,07 & 40063 & 0,386 & 30,8 & 0,23 & 2,15 \\
\hline A16 & CG5 & Sibipiruna & 0,064 & 1,03 & 31789 & 0,412 & 43,3 & 0,21 & 1,20 \\
\hline A18 & CG6 & Sibipiruna & 0,105 & 1,34 & 30431 & 0,279 & 39,3 & 0,30 & 2,54 \\
\hline A12 & CG2 & Tipuana & 0,198 & 10,12 & 33267 & 1,118 & 404,9 & 0,90 & 3,65 \\
\hline A15 & CG4 & Tipuana & 0,183 & 13,56 & 38485 & 0,421 & 652,6 & 0,42 & 2,24 \\
\hline $\mathrm{A} 17$ & CG5 & Tipuana & 0,452 & 9,24 & 29912 & 0,720 & 319,2 & 0,53 & 3,63 \\
\hline A19 & PN1 & Sibipiruna & 0,042 & 19,55 & 36441 & 0,205 & 48,0 & 0,20 & 0,84 \\
\hline $\mathrm{A} 21$ & PN2 & Sibipiruna & 0,038 & 1,17 & 38780 & 0,185 & 35,8 & 0,20 & 0,58 \\
\hline A22 & PN3 & Sibipiruna & 0,012 & 1,23 & 44826 & 0,165 & 33,8 & 0,15 & 0,20 \\
\hline A25 & PN5 & Sibipiruna & 0,099 & 1,58 & 43513 & 0,300 & 26,7 & 0,23 & 1,72 \\
\hline $\mathrm{A} 20$ & PN2 & Tipuana & 0,167 & 8,41 & 30866 & 0,580 & 429,8 & 0,64 & 2,50 \\
\hline A23 & PN3 & Tipuana & 0,093 & 5,23 & 35722 & 0,142 & 179,9 & 0,23 & 1,18 \\
\hline A24 & PN4 & Tipuana & 0,227 & 6,73 & 43908 & 0,374 & 163,2 & 0,53 & 2,60 \\
\hline A26 & PN6 & Tipuana & 0,059 & 4,73 & 30305 & 0,265 & 225,9 & 0,39 & 1,87 \\
\hline $\mathrm{A} 27$ & DP1 & Sibipiruna & 0,177 & 1,73 & 34215 & 0,510 & 68,8 & 0,43 & 3,14 \\
\hline A30 & DP3 & Sibipiruna & 0,103 & 1,63 & 40309 & 0,509 & 55,0 & 0,22 & 1,52 \\
\hline A32 & DP4 & Sibipiruna & 0,608 & 3,39 & 41868 & 2,848 & 57,2 & 1,09 & 8,08 \\
\hline A28 & DP1 & Tipuana & 0,246 & 8,94 & 37668 & 0,857 & 357,6 & 0,79 & 3,92 \\
\hline A29 & DP2 & Tipuana & 0,300 & 10,37 & 44481 & 0,425 & 187,8 & 0,82 & 2,78 \\
\hline A31 & DP3 & Tipuana & 0,462 & 10,25 & 29794 & 1,411 & 149,8 & 1,12 & 5,75 \\
\hline АЗ3 & DP4 & Tipuana & 0,419 & 16,23 & 40636 & 3,450 & 173,4 & 1,57 & 8,72 \\
\hline A34 & $\mathrm{CC} 1$ & Sibipiruna & 0,084 & 2,46 & 43747 & 0,392 & 48,4 & 0,24 & 1,75 \\
\hline A35 & $\mathrm{CC} 2$ & Tipuana & 0,231 & 9,64 & 40769 & 0,370 & 247,0 & 0,42 & 2,03 \\
\hline A36 & $\mathrm{CC} 3$ & Tipuana & 0,319 & 10,80 & 36442 & 0,445 & 697,3 & 0,43 & 2,60 \\
\hline A37 & PP1 & Sibipiruna & 0,057 & 0,83 & 34987 & 0,062 & 29,4 & 0,39 & 1,42 \\
\hline A38 & PP2 & Sibipiruna & 0,058 & 0,93 & 35588 & 0,079 & 43,0 & 0,38 & 1,38 \\
\hline А39 & PP3 & Sibipiruna & 0,052 & 0,70 & 37902 & 0,033 & 30,2 & 0,26 & 1,14 \\
\hline A40 & MA1 & Sibipiruna & 0,045 & 1,78 & 33983 & 0,062 & 6,5 & 0,20 & 0,92 \\
\hline A41 & MA2 & Sibipiruna & 0,081 & 1,49 & 44792 & 0,041 & 28,9 & 0,14 & 0,96 \\
\hline A42 & MA3 & Sibipiruna & 0,048 & 1,63 & 37843 & 0,035 & 6,5 & 0,17 & 0,72 \\
\hline
\end{tabular}




\section{C - Continuação.}

Tabela C. 2 - Concentrações dos elementos $\left(\mathrm{mg} \mathrm{kg}^{-1}\right) \mathrm{Cs}, \mathrm{Cu}, \mathrm{Fe}, \mathrm{K}, \mathrm{La}, \mathrm{Mg}$ e Mn determinados nas cascas de árvore.

\begin{tabular}{|c|c|c|c|c|c|c|c|c|c|}
\hline $\begin{array}{l}\text { Código da } \\
\text { amostra }\end{array}$ & $\begin{array}{c}\text { Ponto de } \\
\text { amostragem }\end{array}$ & $\begin{array}{l}\text { Espécie } \\
\text { arbórea }\end{array}$ & Cs & $\mathrm{Cu}$ & $\mathrm{Fe}$ & $\mathrm{K}$ & $\mathrm{La}$ & $\mathrm{Mg}$ & $\mathrm{Mn}$ \\
\hline E63 & SM1 & Sibipiruna & 0,127 & 19,9 & 1477 & 1750 & 3,54 & 1336 & 49,4 \\
\hline E64 & SM2 & Sibipiruna & 0,153 & 22,5 & 787 & 1445 & 1,54 & 1015 & 53,7 \\
\hline E65 & SM3 & Sibipiruna & 0,076 & 24,2 & 641 & 1372 & 1,95 & 587 & 44,2 \\
\hline E66 & SM4 & Sibipiruna & 0,117 & 25,6 & 1270 & 1383 & 2,16 & 1320 & 71,0 \\
\hline E67 & SM5 & Sibipiruna & 0,047 & 12,6 & 422 & 1475 & 0,79 & 1073 & 39,7 \\
\hline E69 & SM7 & Sibipiruna & 0,086 & 21,1 & 689 & 1123 & 1,62 & 2123 & 28,7 \\
\hline E70 & SM8 & Sibipiruna & 0,108 & 16,2 & 896 & 1621 & 1,48 & 1090 & 48,0 \\
\hline E71 & SM9 & Sibipiruna & 0,145 & 12,9 & 1388 & 1411 & 2,84 & 356 & 33,4 \\
\hline E68 & SM6 & Tipuana & 0,072 & 15,8 & 889 & 1297 & 1,36 & 675 & 49,3 \\
\hline $\mathrm{A} 1$ & SA1 & Sibipiruna & 0,053 & 10,5 & 602 & 1331 & 0,95 & 547 & 31,9 \\
\hline $\mathrm{A} 2$ & SA2 & Sibipiruna & 0,046 & 19,4 & 621 & 971 & 0,87 & 617 & 25,2 \\
\hline $\mathrm{A} 3$ & SA3 & Sibipiruna & 0,076 & 13,1 & 867 & 1223 & 1,30 & 478 & 29,7 \\
\hline A4 & SA4 & Sibipiruna & 0,057 & 10,5 & 499 & 1114 & 0,83 & 440 & 27,1 \\
\hline A5 & SA5 & Tipuana & 0,102 & 28,4 & 1245 & 1578 & 1,96 & 2709 & 35,5 \\
\hline $\mathrm{A} 6$ & SA6 & Tipuana & 0,117 & 24,5 & 1365 & 1571 & 2,27 & 1909 & 62,0 \\
\hline A7 & SA7 & Tipuana & 0,138 & 27,3 & 1538 & 1964 & 2,87 & 2505 & 49,6 \\
\hline A8 & SA8 & Tipuana & 0,136 & 41,3 & 1806 & 1221 & 3,59 & 2130 & 32,5 \\
\hline A9 & CA1 & Tipuana & 0,061 & 22,2 & 569 & 1187 & 1,30 & 2262 & 41,2 \\
\hline A10 & $\mathrm{CA} 2$ & Tipuana & 0,160 & 73,9 & 613 & 1252 & 2,44 & 1357 & 98,4 \\
\hline A11 & CG11 & Sibipiruna & 0,048 & 27,5 & 423 & 1893 & 0,81 & 468 & 29,9 \\
\hline $\mathrm{A} 13$ & CG3 & Sibipiruna & 0,069 & 30,6 & 485 & 1408 & 0,98 & 574 & 33,6 \\
\hline A14 & CG4 & Sibipiruna & 0,060 & 17,5 & 563 & 1139 & 1,00 & 733 & 30,3 \\
\hline A16 & CG5 & Sibipiruna & 0,068 & 24,5 & 404 & 1215 & 0,65 & 299 & 21,8 \\
\hline A18 & CG6 & Sibipiruna & 0,083 & 40,8 & 760 & 1428 & 0,99 & 667 & 30,5 \\
\hline $\mathrm{A} 12$ & CG2 & Tipuana & 0,101 & 43,1 & 1048 & 1408 & 2,22 & 2154 & 37,7 \\
\hline A15 & CG4 & Tipuana & 0,067 & 33,2 & 775 & 1973 & 1,37 & 2570 & 20,0 \\
\hline A17 & CG5 & Tipuana & 0,109 & 52,2 & 864 & 1213 & 1,34 & 2892 & 33,5 \\
\hline A19 & PN1 & Sibipiruna & 0,044 & 8,0 & 273 & 943 & 0,53 & 427 & 23,3 \\
\hline $\mathrm{A} 21$ & PN2 & Sibipiruna & 0,057 & 8,3 & 204 & 1494 & 0,47 & 417 & 29,7 \\
\hline A22 & PN3 & Sibipiruna & 0,033 & 6,7 & 69 & 985 & 0,32 & 243 & 23,3 \\
\hline A25 & PN5 & Sibipiruna & 0,069 & 10,2 & 584 & 1072 & 1,11 & 534 & 26,4 \\
\hline $\mathrm{A} 20$ & PN2 & Tipuana & 0,081 & 21,0 & 780 & 1081 & 1,65 & 2568 & 26,3 \\
\hline A23 & PN3 & Tipuana & 0,049 & 12,1 & 350 & 852 & 1,09 & 1819 & 12,4 \\
\hline A24 & PN4 & Tipuana & 0,104 & 19,2 & 827 & 1065 & 1,71 & 249 & 23,8 \\
\hline A26 & PN6 & Tipuana & 0,083 & 13,5 & 521 & 1008 & 1,10 & 3732 & 21,8 \\
\hline $\mathrm{A} 27$ & DP1 & Sibipiruna & 0,072 & 20,4 & 911 & 1506 & 1,28 & 497 & 35,8 \\
\hline A30 & DP3 & Sibipiruna & 0,039 & 16,8 & 440 & 847 & 0,64 & 392 & 27,9 \\
\hline A32 & DP4 & Sibipiruna & 0,201 & 39,7 & 2751 & 1748 & 4,55 & 1109 & 59,4 \\
\hline A28 & DP1 & Tipuana & 0,071 & 31,5 & 1187 & 1126 & 1,94 & 1890 & 28,4 \\
\hline A29 & DP2 & Tipuana & 0,061 & 24,4 & 826 & 941 & 1,47 & 2159 & 27,6 \\
\hline A31 & DP3 & Tipuana & 0,155 & 68,8 & 1990 & 1468 & 3,63 & 1964 & 48,6 \\
\hline A33 & DP4 & Tipuana & 0,174 & 92,9 & 2804 & 1667 & 5,38 & 2497 & 52,2 \\
\hline A34 & $\mathrm{CC} 1$ & Sibipiruna & 0,048 & 15,5 & 496 & 898 & 0,67 & 465 & 37,5 \\
\hline A35 & $\mathrm{CC} 2$ & Tipuana & 0,081 & 16,7 & 705 & 1324 & 1,19 & 2945 & 26,7 \\
\hline A36 & $\mathrm{CC} 3$ & Tipuana & 0,113 & 29,6 & 922 & 2264 & 1,20 & 2399 & 25,6 \\
\hline A37 & PP1 & Sibipiruna & 0,025 & 7,2 & 435 & 1257 & 0,72 & 402 & 29,3 \\
\hline A38 & PP2 & Sibipiruna & 0,030 & 6,4 & 467 & 1122 & 0,86 & 566 & 30,6 \\
\hline А39 & PP3 & Sibipiruna & 0,025 & 5,4 & 417 & 1372 & 0,94 & 579 & 25,5 \\
\hline A40 & MA1 & Sibipiruna & 0,055 & 11,3 & 473 & 1050 & 1,54 & 555 & 43,1 \\
\hline A41 & MA2 & Sibipiruna & 0,057 & 8,4 & 332 & 934 & 1,69 & 523 & 33,3 \\
\hline A42 & MA3 & Sibipiruna & 0,045 & 9,7 & 388 & 702 & 1,3623 & 402 & 29,7 \\
\hline
\end{tabular}




\section{C - Continuação}

Tabela C. 3 - Concentrações dos elementos $\left(\mathrm{mg} \mathrm{kg}^{-1}\right) \mathrm{Ni}, \mathrm{Pb}, \mathrm{Rb}, \mathrm{Sb}, \mathrm{Sc}, \mathrm{V}$ e Zn determinados nas cascas de árvore.

\begin{tabular}{|c|c|c|c|c|c|c|c|c|c|}
\hline $\begin{array}{l}\text { Código da } \\
\text { amostra }\end{array}$ & $\begin{array}{c}\text { Ponto de } \\
\text { amostragem }\end{array}$ & $\begin{array}{l}\text { Espécie } \\
\text { arbórea }\end{array}$ & $\mathrm{Ni}$ & $\mathrm{Pb}$ & $\mathrm{Rb}$ & $\mathrm{Sb}$ & Sc & V & $\mathrm{Zn}$ \\
\hline E63 & SM1 & Sibipiruna & 24,2 & 14,26 & 5,26 & 1,04 & 0,365 & 3,56 & 98,2 \\
\hline E64 & SM2 & Sibipiruna & 14,2 & 2,01 & 4,95 & 0,53 & 0,198 & 1,82 & 46,9 \\
\hline E65 & SM3 & Sibipiruna & 24,0 & 2,21 & 4,51 & 0,33 & 0,150 & 1,27 & 91,6 \\
\hline E66 & SM4 & Sibipiruna & 1081,7 & 9,48 & 4,12 & 0,73 & 0,309 & 2,50 & 106,5 \\
\hline E67 & SM5 & Sibipiruna & 45,1 & 3,11 & 3,24 & 0,23 & 0,083 & 0,94 & 47,3 \\
\hline E69 & SM7 & Sibipiruna & 448,2 & 11,90 & 3,24 & 0,60 & 0,167 & 1,84 & 78,0 \\
\hline E70 & SM8 & Sibipiruna & 66,0 & 6,11 & 4,71 & 0,67 & 0,220 & 2,08 & 57,4 \\
\hline E71 & SM9 & Sibipiruna & 7,8 & 6,47 & 4,61 & 0,60 & 0,374 & 2,91 & 46,3 \\
\hline E68 & SM6 & Tipuana & 37,0 & 5,84 & 3,91 & 0,97 & 0,189 & 1,68 & 267,5 \\
\hline $\mathrm{A} 1$ & SA1 & Sibipiruna & $<\mathrm{LD}$ & 2,57 & 3,49 & 0,33 & 0,096 & 0,81 & 43,1 \\
\hline A2 & SA2 & Sibipiruna & $<\mathrm{LD}$ & 3,31 & 1,82 & 0,72 & 0,108 & 1,10 & 98,2 \\
\hline A3 & SA3 & Sibipiruna & $<\mathrm{LD}$ & 3,80 & 3,39 & 0,75 & 0,170 & 1,92 & 73,8 \\
\hline A4 & SA4 & Sibipiruna & $<\mathrm{LD}$ & 2,22 & 2,99 & 0,42 & 0,080 & 0,79 & 47,4 \\
\hline A5 & SA5 & Tipuana & 4,0 & 7,52 & 4,67 & 1,26 & 0,237 & 2,76 & 177,4 \\
\hline A6 & SA6 & Tipuana & 4,6 & 10,32 & 5,39 & 1,17 & 0,267 & 3,89 & 212,0 \\
\hline A7 & SA7 & Tipuana & 5,6 & 13,65 & 5,91 & 1,36 & 0,314 & 4,75 & 204,6 \\
\hline A8 & SA8 & Tipuana & 6,2 & 52,34 & 4,42 & 2,35 & 0,351 & 7,03 & 190,8 \\
\hline A9 & CA1 & Tipuana & 3,7 & 8,94 & 3,28 & 0,68 & 0,118 & 2,00 & 106,0 \\
\hline A10 & $\mathrm{CA} 2$ & Tipuana & 7,4 & 14,59 & 4,19 & 0,76 & 0,129 & 4,46 & 240,8 \\
\hline A11 & CG1 & Sibipiruna & $<\mathrm{LD}$ & 1,85 & 3,48 & 0,48 & 0,088 & 0,95 & 32,0 \\
\hline A13 & CG3 & Sibipiruna & 3,9 & 3,26 & 3,03 & 0,53 & 0,099 & 1,13 & 64,2 \\
\hline A14 & CG4 & Sibipiruna & $<\mathrm{LD}$ & 3,60 & 3,24 & 0,60 & 0,108 & 1,10 & 53,9 \\
\hline A16 & CG5 & Sibipiruna & $<\mathrm{LD}$ & 2,19 & 4,38 & 0,32 & 0,079 & 0,84 & 29,5 \\
\hline A18 & CG6 & Sibipiruna & 2,0 & 3,08 & 3,50 & 0,69 & 0,132 & 1,26 & 47,1 \\
\hline A12 & CG2 & Tipuana & 5,6 & 24,44 & 4,12 & 1,91 & 0,218 & 3,27 & 269,6 \\
\hline A15 & CG4 & Tipuana & 4,1 & 6,68 & 5,22 & 0,96 & 0,167 & 2,03 & 137,2 \\
\hline $\mathrm{A} 17$ & CG5 & Tipuana & 4,4 & 8,67 & 4,65 & 0,91 & 0,178 & 2,57 & 472,1 \\
\hline A19 & PN1 & Sibipiruna & $<\mathrm{LD}$ & 1,80 & 3,07 & 0,28 & 0,067 & 0,69 & 38,4 \\
\hline A21 & PN2 & Sibipiruna & $<\mathrm{LD}$ & 0,95 & 3,69 & 0,20 & 0,044 & 0,42 & 21,5 \\
\hline A22 & PN3 & Sibipiruna & $<\mathrm{LD}$ & 1,02 & 2,65 & 0,07 & 0,014 & 0,19 & 12,2 \\
\hline A25 & PN5 & Sibipiruna & $<$ LD & 2,56 & 2,67 & 0,63 & 0,144 & 1,31 & 45,5 \\
\hline A20 & PN2 & Tipuana & 3,4 & 21,23 & 3,10 & 0,98 & 0,179 & 3,27 & 98,0 \\
\hline A23 & PN3 & Tipuana & $<$ LD & 2,95 & 2,18 & 0,39 & 0,081 & 0,81 & 49,9 \\
\hline A24 & PN4 & Tipuana & 3,3 & 15,20 & 3,14 & 0,85 & 0,192 & 2,97 & 113,0 \\
\hline A26 & PN6 & Tipuana & $<$ LD & 4,25 & 2,84 & 0,53 & 0,128 & 0,41 & 186,5 \\
\hline $\mathrm{A} 27$ & DP1 & Sibipiruna & 2,0 & 5,30 & 3,47 & 1,77 & 0,182 & 1,53 & 69,7 \\
\hline A30 & DP3 & Sibipiruna & $<$ LD & 3,61 & 1,67 & 1,76 & 0,083 & 0,73 & 53,5 \\
\hline A32 & DP4 & Sibipiruna & 6,0 & 12,68 & 6,14 & 6,68 & 0,494 & 4,56 & 287,1 \\
\hline A28 & DP1 & Tipuana & 6,6 & 39,38 & 3,09 & 2,06 & 0,215 & 4,54 & 225,9 \\
\hline A29 & DP2 & Tipuana & 7,0 & 11,67 & 2,51 & 1,18 & 0,166 & 3,22 & 133,9 \\
\hline A31 & DP3 & Tipuana & 8,4 & 21,85 & 4,57 & 6,75 & 0,368 & 4,54 & 226,8 \\
\hline АЗ3 & DP4 & Tipuana & 10,9 & 49,05 & 5,79 & 3,82 & 0,515 & 6,86 & 472,8 \\
\hline A34 & $\mathrm{CC} 1$ & Sibipiruna & $<$ LD & 2,66 & 2,32 & 1,12 & 0,078 & 0,86 & 51,3 \\
\hline A35 & $\mathrm{CC} 2$ & Tipuana & 2,7 & 7,12 & 3,76 & 0,80 & 0,146 & 2,13 & 94,4 \\
\hline A36 & $\mathrm{CC} 3$ & Tipuana & 2,3 & 9,57 & 5,96 & 0,87 & 0,183 & 2,50 & 107,2 \\
\hline A37 & PP1 & Sibipiruna & $<\mathrm{LD}$ & 0,33 & 3,30 & 0,08 & 0,145 & 1,48 & 14,3 \\
\hline A38 & PP2 & Sibipiruna & $<\mathrm{LD}$ & 0,51 & 3,17 & 0,07 & 0,147 & 1,98 & 14,9 \\
\hline A39 & PP3 & Sibipiruna & $<$ LD & 0,33 & 3,61 & 0,05 & 0,132 & 1,10 & 14,8 \\
\hline A40 & MA1 & Sibipiruna & $<\mathrm{LD}$ & 0,61 & 2,06 & 0,10 & 0,153 & 1,35 & 29,8 \\
\hline A41 & MA2 & Sibipiruna & $<\mathrm{LD}$ & 0,60 & 1,83 & 0,07 & 0,115 & 1,13 & 17,8 \\
\hline A42 & MA3 & Sibipiruna & $<\mathrm{LD}$ & 0,79 & 1,45 & 0,09 & 0,12 & 1,22 & 19,3 \\
\hline
\end{tabular}


APÊNDICE D - Concentrações dos elementos determinados nas cascas de Tipuana e Sibipiruna coletadas na RMSP e regiões controle.

Tabela D. 1 - Concentrações médias e faixas de concentrações dos elementos em cascas de árvore coletadas nas regiões Cerqueira César e Congonhas.

\begin{tabular}{|c|c|c|c|c|c|c|c|}
\hline \multirow[b]{3}{*}{ Elementos } & \multicolumn{3}{|c|}{ Cerqueira César } & \multicolumn{4}{|c|}{ Congonhas } \\
\hline & \multicolumn{2}{|c|}{ Tipuana } & \multirow{2}{*}{$\begin{array}{c}\text { Sibipiruna } \\
\text { C }\end{array}$} & \multicolumn{2}{|c|}{ Tipuana } & \multicolumn{2}{|c|}{ Sibipiruna } \\
\hline & $\mathrm{M} \pm \mathrm{DP}$ & $\begin{array}{l}\text { Intervalo de } \\
\text { concentração }\end{array}$ & & $M \pm D P$ & $\begin{array}{l}\text { Intervalo de } \\
\text { concentração }\end{array}$ & $M \pm D P$ & $\begin{array}{l}\text { Intervalo de } \\
\text { concentração }\end{array}$ \\
\hline As, $\mu \mathrm{g} \mathrm{kg}^{-1}$ & $275 \pm 62$ & $231-319$ & 84 & $277 \pm 151$ & $183-452$ & $92 \pm 26$ & $64-127$ \\
\hline $\mathrm{Br}, \mathrm{mg} \mathrm{kg}^{-1}$ & $10,22 \pm 0,82$ & $9,64-10,8$ & 2,00 & $11,0 \pm 2,3$ & $9,2-13,6$ & $1,71 \pm 0,70$ & $1,03-2,75$ \\
\hline $\mathrm{Ca}, \%$ & $38,6 \pm 3,1$ & $36,4-40,8$ & 44,0 & $33,9 \pm 4,3$ & $29,9-38,5$ & $35,2 \pm 4,8$ & $30,4-40,6$ \\
\hline $\mathrm{Cd}, \mu \mathrm{g} \mathrm{kg}{ }^{-1}$ & $408 \pm 53$ & $370-445$ & 392 & $753 \pm 350$ & $421-1118$ & $333 \pm 78$ & $225-412$ \\
\hline $\mathrm{Cl}, \mu \mathrm{g} \mathrm{kg}^{-1}$ & $472 \pm 318$ & $247-697$ & 48 & $459 \pm 173$ & $319-653$ & $38,3 \pm 6,7$ & $30,8-45,9$ \\
\hline $\mathrm{Co}, \mu \mathrm{g} \mathrm{kg}^{-1}$ & $421,7 \pm 7,4$ & $416,4-426,9$ & 237 & $617 \pm 252$ & $422-902$ & $255 \pm 68$ & $195-354$ \\
\hline $\mathrm{Cr}, \mathrm{mg} \mathrm{kg}^{-1}$ & $2,31 \pm 0,41$ & $2,03-2,6$ & 1,75 & $3,17 \pm 0,80$ & $2,24-3,65$ & $1,84 \pm 0,53$ & $1,20-2,54$ \\
\hline $\mathrm{Cs}, \mu \mathrm{g} \mathrm{kg}^{-1}$ & $97 \pm 22$ & $81-113$ & 48 & $93 \pm 22$ & $67-109$ & $66 \pm 13$ & $48-83$ \\
\hline $\mathrm{Cu}, \mathrm{mg} \mathrm{kg}^{-1}$ & $23,1 \pm 9,2$ & $16,7-29,6$ & 15,5 & $42,8 \pm 9,5$ & $33,2-52,2$ & $28,2 \pm 8,6$ & $17,5-40,8$ \\
\hline $\mathrm{Fe}, \mathrm{mg} \mathrm{kg}^{-1}$ & $813 \pm 154$ & $705-922$ & 496 & $896 \pm 139$ & $775-1048$ & $527 \pm 144$ & $404-760$ \\
\hline $\mathrm{K}, \mathrm{mg} \mathrm{kg}^{-1}$ & $1794 \pm 664$ & $1324-2264$ & 898 & $1531 \pm 395$ & $1213-1973$ & $1417 \pm 293$ & $1139-1893$ \\
\hline $\mathrm{La}, \mathrm{mg} \mathrm{kg}^{-1}$ & $1,197 \pm 0,011$ & $1,189-1,205$ & 0,669 & $1,64 \pm 0,50$ & $1,34-2,22$ & $0,89 \pm 0,16$ & $0,65-1,00$ \\
\hline $\mathrm{Mg}, \mathrm{mg} \mathrm{kg}^{-1}$ & $2672 \pm 386$ & $2399-2945$ & 465 & $2539 \pm 370$ & $2154-2892$ & $548 \pm 171$ & $299-733$ \\
\hline $\mathrm{Mn}, \mathrm{mg} \mathrm{kg}^{-1}$ & $26,14 \pm 0,78$ & $25,59-26,70$ & 37,50 & $30,4 \pm 9,3$ & $20,0-37,7$ & $29,2 \pm 4,4$ & $21,8-33,6$ \\
\hline $\mathrm{Ni}, \mathrm{mg} \mathrm{kg}^{-1}$ & $2,49 \pm 0,32$ & $2,27-2,72$ & $<$ LD & $4,72 \pm 0,82$ & $4,10-5,65$ & $1,2 \pm 1,7$ & $<L D-3,9$ \\
\hline $\mathrm{Pb}, \mathrm{mg} \mathrm{kg}^{-1}$ & $8,3 \pm 1,7$ & $7,1-9,6$ & 2,66 & $13,3 \pm 9,7$ & $6,7-24,4$ & $2,79 \pm 0,74$ & $1,85-3,60$ \\
\hline $\mathrm{Rb}, \mathrm{mg} \mathrm{kg}^{-1}$ & $4,9 \pm 1,6$ & $3,8-6,0$ & 2,32 & $4,66 \pm 0,55$ & $4,12-5,22$ & $3,53 \pm 0,52$ & $3,03-4,38$ \\
\hline $\mathrm{Sb}, \mu \mathrm{g} \mathrm{kg}^{-1}$ & $834 \pm 55$ & $795-873$ & 1123 & $1257 \pm 562$ & $905-1905$ & $523 \pm 137$ & $323-687$ \\
\hline Sc, $\mu \mathrm{g} \mathrm{kg}^{-1}$ & $165 \pm 26$ & $146-183$ & 77,6 & $188 \pm 27$ & $167-218$ & $101 \pm 20$ & $79-132$ \\
\hline $\mathrm{V}, \mathrm{mg} \mathrm{kg}^{-1}$ & $2,31 \pm 0,26$ & $2,13-2,50$ & 0,86 & $2,62 \pm 0,62$ & $2,03-3,27$ & $1,06 \pm 0,16$ & $0,84-1,26$ \\
\hline $\mathrm{Zn}, \mathrm{mg} \mathrm{kg}^{-1}$ & $100,8 \pm 9,1$ & $94,4 \quad 107,2$ & 51,3 & $293 \pm 169$ & $137-472$ & $45 \pm 15$ & $30-64$ \\
\hline
\end{tabular}




\section{D - Continuação.}

Tabela D. 2 - Concentrações médias e respectivas faixas de concentrações de elementos em amostras de cascas de árvore coletadas nas regiões Parque Dom Pedro II e Pinheiros.

\begin{tabular}{|c|c|c|c|c|c|c|c|c|}
\hline \multirow[b]{3}{*}{ Elementos } & \multicolumn{4}{|c|}{ Parque Dom Pedro II } & \multicolumn{4}{|c|}{ Pinheiros } \\
\hline & \multicolumn{2}{|c|}{ Tipuana } & \multicolumn{2}{|c|}{ Sibipiruna } & \multicolumn{2}{|c|}{ Tipuana } & \multicolumn{2}{|c|}{ Sibipiruna } \\
\hline & $M \pm D P$ & $\begin{array}{l}\text { Intervalo de } \\
\text { concentração }\end{array}$ & $\mathrm{M} \pm \mathrm{DP}$ & $\begin{array}{l}\text { Intervalo de } \\
\text { concentração }\end{array}$ & $M \pm D P$ & $\begin{array}{l}\text { Intervalo de } \\
\text { concentração }\end{array}$ & $\mathrm{M} \pm \mathrm{DP}$ & $\begin{array}{l}\text { Intervalo de } \\
\text { concentração }\end{array}$ \\
\hline As, $\mu \mathrm{g} \mathrm{kg}^{-1}$ & $357 \pm 101$ & $246-462$ & $296 \pm 273$ & $103-608$ & $136 \pm 75$ & $59-227$ & $48 \pm 37$ & $12-99$ \\
\hline $\mathrm{Br}, \mathrm{mg} \mathrm{kg}^{-1}$ & $11,4 \pm 3,3$ & $8,9-16,2$ & $2,25 \pm 0,99$ & $1,63-3,39$ & $6,3 \pm 1,7$ & $4,7-8,4$ & $5,9 \pm 9,1$ & $1,2-19,6$ \\
\hline $\mathrm{Ca}, \%$ & $38,1 \pm 6,2$ & $29,8-44,5$ & $38,8 \pm 4,0$ & $34,2-41,9$ & $35,2 \pm 6,3$ & $30,3-43,9$ & $40,9 \pm 3,9$ & $36,4-44,8$ \\
\hline $\mathrm{Cd}, \mu \mathrm{g} \mathrm{kg}{ }^{-1}$ & $1536 \pm 1338$ & $425-3450$ & $1289 \pm 1350$ & $509-2848$ & $340 \pm 186$ & $142-580$ & $214 \pm 60$ & $165-300$ \\
\hline $\mathrm{Cl}, \mu \mathrm{g} \mathrm{kg}^{-1}$ & $217 \pm 95$ & $150-358$ & $60,3 \pm 7,4$ & $55,0-68,8$ & $250 \pm 123$ & $163-430$ & $36,1 \pm 8,9$ & $26,7-48,0$ \\
\hline Co, $\mu \mathrm{kg}^{-1}$ & $1074 \pm 361$ & $794-1568$ & $582 \pm 455$ & $222-1094$ & $450 \pm 178$ & $233-644$ & $195 \pm 30$ & $154-227$ \\
\hline $\mathrm{Cr}, \mathrm{mg} \mathrm{kg}^{-1}$ & $5,3 \pm 2,6$ & $2,8-8,7$ & $4,2 \pm 3,4$ & $1,5-8,1$ & $2,03 \pm 0,66$ & $1,18-2,60$ & $0,83 \pm 0,65$ & $0,20-1,72$ \\
\hline Cs, $\mu \mathrm{g} \mathrm{kg}^{-1}$ & $115 \pm 57$ & $61-174$ & $104 \pm 86$ & $39-201$ & $79 \pm 23$ & $49-104$ & $51 \pm 15$ & $33-69$ \\
\hline $\mathrm{Cu}, \mathrm{mg} \mathrm{kg}^{-1}$ & $54 \pm 32$ & $24-93$ & $26 \pm 12$ & $17-40$ & $16,4 \pm 4,3$ & $12,1-21,0$ & $8,3 \pm 1,4$ & $6,7-10,2$ \\
\hline $\mathrm{Fe}, \mathrm{mg} \mathrm{kg}^{-1}$ & $1702 \pm 881$ & $826-2804$ & $1367 \pm 1221$ & $440-2751$ & $619 \pm 225$ & $350-827$ & $283 \pm 218$ & $69-584$ \\
\hline $\mathrm{K}, \mathrm{mg} \mathrm{kg}^{-1}$ & $1301 \pm 328$ & $941-1667$ & $1367 \pm 466$ & $847-1748$ & $1002 \pm 104$ & $852-1081$ & $1123 \pm 253$ & $943-1494$ \\
\hline $\mathrm{La}, \mathrm{mg} \mathrm{kg}^{-1}$ & $3,1 \pm 1,8$ & $1,5-5,4$ & $2,2 \pm 2,1$ & $0,6-4,5$ & $1,39 \pm 0,34$ & $1,09-1,71$ & $0,61 \pm 0,35$ & $0,32-1,11$ \\
\hline $\mathrm{Mg}, \mathrm{mg} \mathrm{kg}^{-1}$ & $2127 \pm 272$ & $1890-2497$ & $666 \pm 388$ & $392-1109$ & $2092 \pm 1459$ & $249-3732$ & $405 \pm 120$ & $243-534$ \\
\hline $\mathrm{Mn}, \mathrm{mg} \mathrm{kg}^{-1}$ & $39 \pm 13$ & $28-52$ & $41 \pm 16$ & $28-59$ & $21,1 \pm 6,1$ & $12,4-26,3$ & $25,7 \pm 3,0$ & $23,3-29,7$ \\
\hline $\mathrm{Ni}, \mathrm{mg} \mathrm{kg}^{-1}$ & $8,2 \pm 1,9$ & $6,6-10,9$ & $2,7 \pm 3,0$ & $<\mathrm{DL}-6,0$ & $1,7 \pm 1,9$ & $<$ LD - 3,4 & $<$ LD & - \\
\hline $\mathrm{Pb}, \mathrm{mg} \mathrm{kg}^{-1}$ & $30 \pm 17$ & $12-49$ & $7,2 \pm 4,8$ & $3,6-12,7$ & $10,9 \pm 8,8$ & $3,0-21,2$ & $1,58 \pm 0,76$ & $0,95-2,56$ \\
\hline $\mathrm{Rb}, \mathrm{mg} \mathrm{kg}^{-1}$ & $4,0 \pm 1,5$ & $2,5-5,8$ & $3,8 \pm 2,2$ & $1,7-6,1$ & $2,81 \pm 0,44$ & $2,18-3,14$ & $3,02 \pm 0,49$ & $2,65-3,69$ \\
\hline $\mathrm{Sb}, \mu \mathrm{kg}^{-1}$ & $3452 \pm 2460$ & $1177-6754$ & $3402 \pm 2835$ & $1764-6676$ & $686 \pm 276$ & $388-984$ & $294 \pm 239$ & $68-627$ \\
\hline Sc, $\mu \mathrm{g} \mathrm{kg}^{-1}$ & $316 \pm 158$ & $166-515$ & $253 \pm 214$ & $83-494$ & $145 \pm 51$ & $81-192$ & $67 \pm 56$ & $14-144$ \\
\hline $\mathrm{V}, \mathrm{mg} \mathrm{kg}^{-1}$ & $4,8 \pm 1,5$ & $3,2-6,9$ & $2,3 \pm 2,0$ & $0,7-4,6$ & $1,9 \pm 1,5$ & $0,4-3,3$ & $0,65 \pm 0,49$ & $0,19-1,31$ \\
\hline $\mathrm{Zn}, \mathrm{mg} \mathrm{kg}^{-1}$ & $265 \pm 145$ & $134-473$ & $137 \pm 130$ & $54-287$ & $112 \pm 57$ & $50-186$ & $29 \pm 15$ & $12-45$ \\
\hline
\end{tabular}




\section{D - Continuação.}

Tabela D. 3 - Concentrações médias e respectivas faixas de concentrações de elementos determinados em cascas de árvore coletadas nas regiões Santo André - Capuava e Santo André - Paço Municipal.

\begin{tabular}{|c|c|c|c|c|c|c|}
\hline \multirow[b]{3}{*}{ Elementos } & \multirow{2}{*}{\multicolumn{2}{|c|}{$\begin{array}{c}\text { Santo André - Capuava } \\
\text { Tipuana }\end{array}$}} & \multicolumn{4}{|c|}{ Santo André - Paço Municipal } \\
\hline & & & \multicolumn{2}{|c|}{ Tipuana } & \multicolumn{2}{|c|}{ Sibipiruna } \\
\hline & $M \pm D P$ & $\begin{array}{l}\text { Intervalo de } \\
\text { concentração }\end{array}$ & $M \pm D P$ & $\begin{array}{l}\text { Intervalo de } \\
\text { concentração }\end{array}$ & $M \pm D P$ & $\begin{array}{l}\text { Intervalo de } \\
\text { concentração }\end{array}$ \\
\hline As, $\mu \mathrm{g} \mathrm{kg}^{-1}$ & $155 \pm 38$ & $128-182$ & $280 \pm 45$ & $235-324$ & $96 \pm 39$ & $63-150$ \\
\hline $\mathrm{Br}, \mathrm{mg} \mathrm{kg}^{-1}$ & $10,8 \pm 3,1$ & $8,6-12,9$ & $15,3 \pm 3,7$ & $11,3-20,2$ & $2,81 \pm 0,3$ & $2,51-3,22$ \\
\hline $\mathrm{Ca}, \%$ & $3,172 \pm 0,038$ & $3,146-3,199$ & $33 \pm 4$ & $28,8-38,3$ & $4,102 \pm 0,592$ & $3,426-4,78$ \\
\hline $\mathrm{Cd}, \mu \mathrm{g} \mathrm{kg}^{-1}$ & $534 \pm 233$ & $369-698$ & $601 \pm 112$ & $456-721$ & $309 \pm 142$ & $181-501$ \\
\hline $\mathrm{Cl}, \mu \mathrm{g} \mathrm{kg}^{-1}$ & $378 \pm 122$ & $291-464$ & $474 \pm 318$ & $224-919$ & $44,3 \pm 8,6$ & $35,8-55,9$ \\
\hline Co, $\mu \mathrm{g} \mathrm{kg}^{-1}$ & $1448 \pm 1014$ & $731-2165$ & $753 \pm 109$ & $623-859$ & $262 \pm 33$ & $235-308$ \\
\hline $\mathrm{Cr}, \mathrm{mg} \mathrm{kg}^{-1}$ & $3,01 \pm 0,71$ & $3,51-2,50$ & $5,2 \pm 1,4$ & $4,3-7,2$ & $2,39 \pm 0,31$ & $2,02-2,68$ \\
\hline Cs, $\mu \mathrm{g} \mathrm{kg}^{-1}$ & $111 \pm 70$ & $61-160$ & $123 \pm 17$ & $102-138$ & $58 \pm 13$ & $46-76$ \\
\hline $\mathrm{Cu}, \mathrm{mg} \mathrm{kg}^{-1}$ & $48 \pm 37$ & $22-74$ & $30,4 \pm 7,5$ & $24,5-41,3$ & $13,4 \pm 4,2$ & $10,5-19,4$ \\
\hline $\mathrm{Fe}, \mathrm{mg} \mathrm{kg}^{-1}$ & $591 \pm 31$ & $569-613$ & $1488 \pm 243$ & $1245-1806$ & $647 \pm 156$ & $499-867$ \\
\hline $\mathrm{K}, \mathrm{mg} \mathrm{kg}^{-1}$ & $1220 \pm 46$ & $1187-1252$ & $1583 \pm 304$ & $1221-1964$ & $1160 \pm 154$ & $971-1331$ \\
\hline $\mathrm{La}, \mathrm{mg} \mathrm{kg}^{-1}$ & $1,87 \pm 0,80$ & $1,30-2,44$ & $2,67 \pm 0,72$ & $1,96-3,59$ & $0,99 \pm 0,21$ & $0,83-1,30$ \\
\hline $\mathrm{Mg}, \mathrm{mg} \mathrm{kg}^{-1}$ & $1810 \pm 640$ & $2262-1357$ & $2313 \pm 361$ & $1909-2709$ & $520 \pm 79$ & $440-617$ \\
\hline $\mathrm{Mn}, \mathrm{mg} \mathrm{kg}^{-1}$ & $70 \pm 40$ & $41-98$ & $45 \pm 14$ & $32-62$ & $28,5 \pm 2,9$ & $25,2-31,9$ \\
\hline $\mathrm{Ni}, \mathrm{mg} \mathrm{kg}^{-1}$ & $5,5 \pm 2,6$ & $3,7-7,4$ & $5,10 \pm 0,98$ & $4,02-6,22$ & $<L D$ & - \\
\hline $\mathrm{Pb}, \mathrm{mg} \mathrm{kg}^{-1}$ & $11,8 \pm 4,0$ & $8,9-14,6$ & $21 \pm 21$ & $8-52$ & $2,98 \pm 0,71$ & $2,22-3,80$ \\
\hline $\mathrm{Rb}, \mathrm{mg} \mathrm{kg}^{-1}$ & $3,735 \pm 0,641$ & $3,281-4,188$ & $5,10 \pm 0,68$ & $4,42-5,91$ & $2,92 \pm 0,76$ & $1,82-3,49$ \\
\hline $\mathrm{Sb}, \mu \mathrm{g} \mathrm{kg}^{-1}$ & $719 \pm 54$ & $681-758$ & $1538 \pm 549$ & $1175-2354$ & $558 \pm 210$ & $335-754$ \\
\hline Sc, $\mu \mathrm{g} \mathrm{kg}^{-1}$ & $123,8 \pm 7,7$ & $118,4-129,3$ & $292 \pm 50$ & $237-351$ & $113 \pm 39$ & $80-170$ \\
\hline $\mathrm{V}, \mathrm{mg} \mathrm{kg}^{-1}$ & $3,2 \pm 1,7$ & $2,0-4,5$ & $4,6 \pm 1,8$ & $2,8-7,0$ & $1,16 \pm 0,53$ & $0,79-1,92$ \\
\hline $\mathrm{Zn}, \mathrm{mg} \mathrm{kg}^{-1}$ & $173 \pm 95$ & $106-241$ & $196 \pm 15$ & $177-212$ & $66 \pm 26$ & $43-98$ \\
\hline
\end{tabular}




\section{D - Continuação.}

Tabela D. 4 - Concentrações médias e respectivas faixas de concentrações de elementos em cascas de árvore coletadas em São Miguel Paulista.

\begin{tabular}{|c|c|c|c|}
\hline \multirow[b]{2}{*}{ Elementos } & \multirow{2}{*}{$\begin{array}{c}\text { Tipuana } \\
\text { C }\end{array}$} & \multicolumn{2}{|c|}{ Sibipiruna } \\
\hline & & $M \pm D P$ & $\begin{array}{l}\text { Intervalo de } \\
\text { concentração }\end{array}$ \\
\hline As, $\mu \mathrm{g} \mathrm{kg}^{-1}$ & 244 & $208 \pm 76$ & $99-336$ \\
\hline $\mathrm{Br}, \mathrm{mg} \mathrm{kg}^{-1}$ & 1,53 & $2,8 \pm 1,4$ & $1,4-6,0$ \\
\hline $\mathrm{Ca}, \%$ & 34,4 & $35,7 \pm 4,2$ & $30,7-43,1$ \\
\hline $\mathrm{Cd}, \mu \mathrm{g} \mathrm{kg}^{-1}$ & 337 & $441 \pm 219$ & $246-871$ \\
\hline $\mathrm{Cl}, \mu \mathrm{g} \mathrm{kg}^{-1}$ & 44,4 & $111 \pm 42$ & $76-187$ \\
\hline Co, $\mu \mathrm{g} \mathrm{kg}^{-1}$ & 4648 & $16075 \pm 26211$ & $924-75853$ \\
\hline $\mathrm{Cr}, \mathrm{mg} \mathrm{kg}^{-1}$ & 2,45 & $2,9 \pm 1,5$ & $1,2-5,7$ \\
\hline Cs, $\mu \mathrm{g} \mathrm{kg}^{-1}$ & 72,5 & $108 \pm 36$ & $47-153$ \\
\hline $\mathrm{Cu}, \mathrm{mg} \mathrm{kg}^{-1}$ & 15,8 & $19,4 \pm 5,0$ & $12,6-25,6$ \\
\hline $\mathrm{Fe}, \mathrm{mg} \mathrm{kg}^{-1}$ & 889 & $946 \pm 386$ & $422-1477$ \\
\hline $\mathrm{K}, \mathrm{mg} \mathrm{kg}^{-1}$ & 1297 & $1447 \pm 185$ & $1123-1750$ \\
\hline $\mathrm{La}, \mathrm{mg} \mathrm{kg}^{-1}$ & 1,36 & $1,99 \pm 0,86$ & $0,79-3,54$ \\
\hline $\mathrm{Mg}, \mathrm{mg} \mathrm{kg}^{-1}$ & 675 & $1112 \pm 531$ & $356-2123$ \\
\hline $\mathrm{Mn}, \mathrm{mg} \mathrm{kg}^{-1}$ & 49,3 & $46 \pm 13$ & $29-71$ \\
\hline $\mathrm{Ni}, \mathrm{mg} \mathrm{kg}^{-1}$ & 37,0 & $214 \pm 380$ & $8-1082$ \\
\hline $\mathrm{Pb}, \mathrm{mg} \mathrm{kg}^{-1}$ & 5,84 & $6,9 \pm 4,6$ & $2,0-14,3$ \\
\hline $\mathrm{Rb}, \mathrm{mg} \mathrm{kg}^{-1}$ & 3,91 & $4,33 \pm 0,75$ & $3,24-5,26$ \\
\hline $\mathrm{Sb}, \mu \mathrm{kg}^{-1}$ & 973 & $592 \pm 246$ & $232-1039$ \\
\hline Sc, $\mu \mathrm{g} \mathrm{kg}^{-1}$ & 189 & $233 \pm 106$ & $83-374$ \\
\hline $\mathrm{V}, \mathrm{mg} \mathrm{kg}^{-1}$ & 1,68 & $2,12 \pm 0,86$ & $0,94-3,56$ \\
\hline $\mathrm{Zn}, \mathrm{mg} \mathrm{kg}^{-1}$ & 267 & $72 \pm 25$ & $46-107$ \\
\hline
\end{tabular}




\section{D - Concentração.}

Tabela D. 5 - Concentrações médias e respectivas faixas de concentrações dos elementos em cascas de árvore coletadas em Marília e Presidente Prudente.

\begin{tabular}{cccc}
\hline & Marília & Presidente Prudente \\
$M \pm D P$ & $\begin{array}{c}\text { Intervalo de } \\
\text { concentração }\end{array}$ & $M \pm D P$ & $\begin{array}{c}\text { Intervalo de } \\
\text { concentração }\end{array}$ \\
\hline $58 \pm 20$ & $45-81$ & $55,5 \pm 3,2$ & $51,8-57,8$ \\
$1,64 \pm 0,14$ & $1,49-1,78$ & $0,82 \pm 0,11$ & $0,70-0,93$ \\
$38,9 \pm 5,5$ & $34,0-44,8$ & $36,2 \pm 1,5$ & $35,0-37,9$ \\
$46 \pm 14$ & $35-62$ & $58 \pm 24$ & $33-79$ \\
$14 \pm 13$ & $7-29$ & $34,2 \pm 7,7$ & $29,4-43,0$ \\
$172 \pm 28$ & $144-201$ & $347 \pm 73$ & $263-394$ \\
$0,87 \pm 0,13$ & $0,72-0,96$ & $1,31 \pm 0,15$ & $1,14-1,42$ \\
$52,4 \pm 6,2$ & $45,3-56,5$ & $26,8 \pm 3,2$ & $24,7-30,4$ \\
$9,8 \pm 1,4$ & $8,4-11,3$ & $6,34 \pm 0,88$ & $5,43-7,18$ \\
$398 \pm 71$ & $332-473$ & $440 \pm 25$ & $417-467$ \\
$895 \pm 177$ & $702-1050$ & $1250 \pm 125$ & $1122-1372$ \\
$1,53 \pm 0,16$ & $1,36-1,69$ & $0,84 \pm 0,11$ & $0,72-0,94$ \\
$493 \pm 80$ & $402-555$ & $515 \pm 99$ & $402-579$ \\
$35,4 \pm 6,9$ & $29,7-43,1$ & $28,5 \pm 2,6$ & $25,5-30,6$ \\
$<\mathrm{LD}$ & - & $<\mathrm{LD}$ & - \\
$0,67 \pm 0,11$ & 1,6 & $0,39 \pm 0,11$ & $0,33-0,51$ \\
$1,78 \pm 0,31$ & $1,60-0,79$ & $3,36 \pm 0,23$ & $3,17-3,61$ \\
$87 \pm 14$ & $1,45-2,06$ & $70 \pm 14$ & $54-81$ \\
$131 \pm 19$ & $70-96$ & $141,1 \pm 8,3$ & $1,10-1,98$ \\
$1,23 \pm 0,11$ & $115-153$ & $1,52 \pm 0,44$ & $14,31-14,87$ \\
$22,3 \pm 6,6$ & $1,13-1,35$ & &
\end{tabular}


APÊNDICE E - Resultados obtidos pela análise de componentes principais (PCA) aplicada às concentrações dos elementos determinados nas cascas de Sibipiruna.

Tabela E. 1 - Matriz de correlação entre os elementos determinados nas cascas de árvore da espécie Sibipiruna e as componentes principais extraídas.

\begin{tabular}{ccccc}
\hline & \multicolumn{4}{c}{ Componentes principais* } \\
Elementos & $\mathrm{CP} \mathrm{1}$ & $\mathrm{CP} 2$ & $\mathrm{CP} 3$ & $\mathrm{CP} 4$ \\
\hline $\mathrm{As}$ & $\mathbf{0 , 7 9 1}$ & 0,134 & 0,267 & 0,226 \\
$\mathrm{Br}$ & 0,346 & $-0,101$ & $\mathbf{0 , 8 0 8}$ & 0,112 \\
$\mathrm{Ca}$ & $-0,049$ & $-0,071$ & $-0,177$ & $-0,123$ \\
$\mathrm{Cd}$ & $\mathbf{0 , 7 9 9}$ & $-0,001$ & 0,070 & 0,098 \\
$\mathrm{Cl}$ & 0,084 & $-0,048$ & $\mathbf{0 , 8 9 6}$ & 0,301 \\
$\mathrm{Co}$ & 0,056 & $\mathbf{0 , 9 9 2}$ & $-0,026$ & 0,013 \\
$\mathrm{Cr}$ & $\mathbf{0 , 9 0 5}$ & 0,043 & 0,184 & 0,184 \\
$\mathrm{Cs}$ & $\mathbf{0 , 7 4 7}$ & 0,067 & 0,209 & 0,267 \\
$\mathrm{Cu}$ & 0,523 & $-0,028$ & 0,269 & 0,123 \\
$\mathrm{Fe}$ & $\mathbf{0 , 9 4 4}$ & 0,051 & 0,134 & 0,223 \\
$\mathrm{~K}$ & 0,244 & 0,004 & 0,183 & $\mathbf{0 , 9 3 9}$ \\
$\mathrm{La}$ & $\mathbf{0 , 9 2 4}$ & 0,023 & 0,141 & 0,111 \\
$\mathrm{Mg}$ & 0,259 & 0,069 & $\mathbf{0 , 8 3 0}$ & 0,050 \\
$\mathrm{Mn}$ & 0,330 & 0,230 & 0,017 & 0,146 \\
$\mathrm{Ni}$ & 0,048 & $\mathbf{0 , 9 9 5}$ & $-0,022$ & $-0,001$ \\
$\mathrm{~Pb}$ & 0,653 & 0,007 & 0,317 & $-0,059$ \\
$\mathrm{Rb}$ & 0,491 & 0,014 & 0,238 & $\mathbf{0 , 7 3 1}$ \\
$\mathrm{Sb}$ & $\mathbf{0 , 7 8 6}$ & $-0,081$ & 0,039 & 0,052 \\
$\mathrm{Sc}$ & $\mathbf{0 , 9 4 3}$ & 0,117 & 0,100 & 0,223 \\
$\mathrm{~V}$ & $\mathbf{0 , 7 8 8}$ & $-0,024$ & 0,368 & 0,078 \\
$\mathrm{Zn}$ & 0,566 & $-0,045$ & 0,393 & 0,038 \\
\hline
\end{tabular}

* Método de rotação: rotação Varimax normalizada. 
APÊNDICE F- Resultados obtidos pela análise de componentes principais (PCA) aplicada às concentrações médias dos elementos determinados nas diferentes regiões de amostragem para as cascas de árvore da espécie Sibipiruna.

Tabela F. 1 - Matriz de correlação entre as regiões de amostragem e as componentes principais extraídas das médias das concentrações dos elementos em cascas de Sibipiruna.

\begin{tabular}{lcc}
\hline & \multicolumn{2}{c}{ Componentes principais ${ }^{*}$} \\
Região de amostragem & CP 1 & CP 2 \\
\hline Cerqueira César & $\mathbf{0 , 7 1 7 4 8 5}$ & 0,696570 \\
Congonhas & $\mathbf{0 , 7 0 7 6 6 6}$ & $\mathbf{0 , 7 0 6 3 7 4}$ \\
Marília & $\mathbf{0 , 7 1 6 5 4 4}$ & 0,697534 \\
Parque Dom Pedro II & 0,698807 & $\mathbf{0 , 7 1 5 2 4 1}$ \\
Pinheiros & $\mathbf{0 , 7 1 7 5 2 3}$ & 0,696471 \\
Presidente Prudente & $\mathbf{0 , 7 1 1 2 8 0}$ & $\mathbf{0 , 7 0 2 8 0 2}$ \\
Santo André - Paço Municipal & $\mathbf{0 , 7 1 2 1 1 9}$ & $\mathbf{0 , 7 0 2 0 3 3}$ \\
São Miguel Paulista & 0,697191 & $\mathbf{0 , 7 1 6 8 2 0}$ \\
\hline
\end{tabular}

*Método de rotação: Varimax normalizada 
APÊNDICE G - Relação das concentrações dos elementos determinados nas cascas de Sibipiruna e com as concentrações de material particulado grosso (MP10).


Figura G. 1 - Representação box plot da variação na concentração de $\mathrm{MP}_{10}$ medido pelas estações de monitoramento da CETESB entre 2009 e 2016 em função das concentrações de $\mathrm{Ca}, \mathrm{Cl}, \mathrm{Cs}, \mathrm{Fe}, \mathrm{K}$ e La determinados nas cascas de árvore da espécie Sibipiruna. 
G - Continuação.
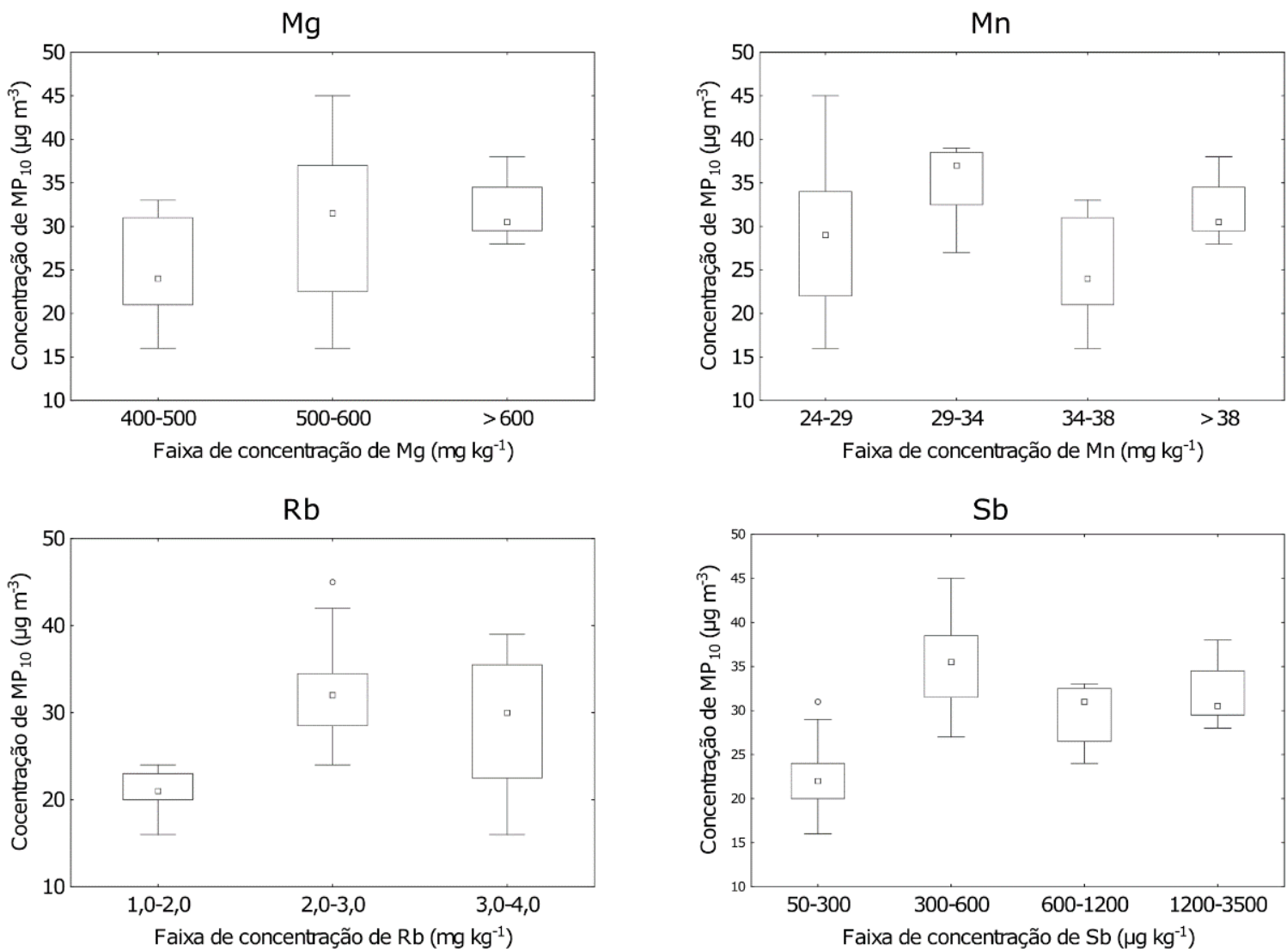

Sc
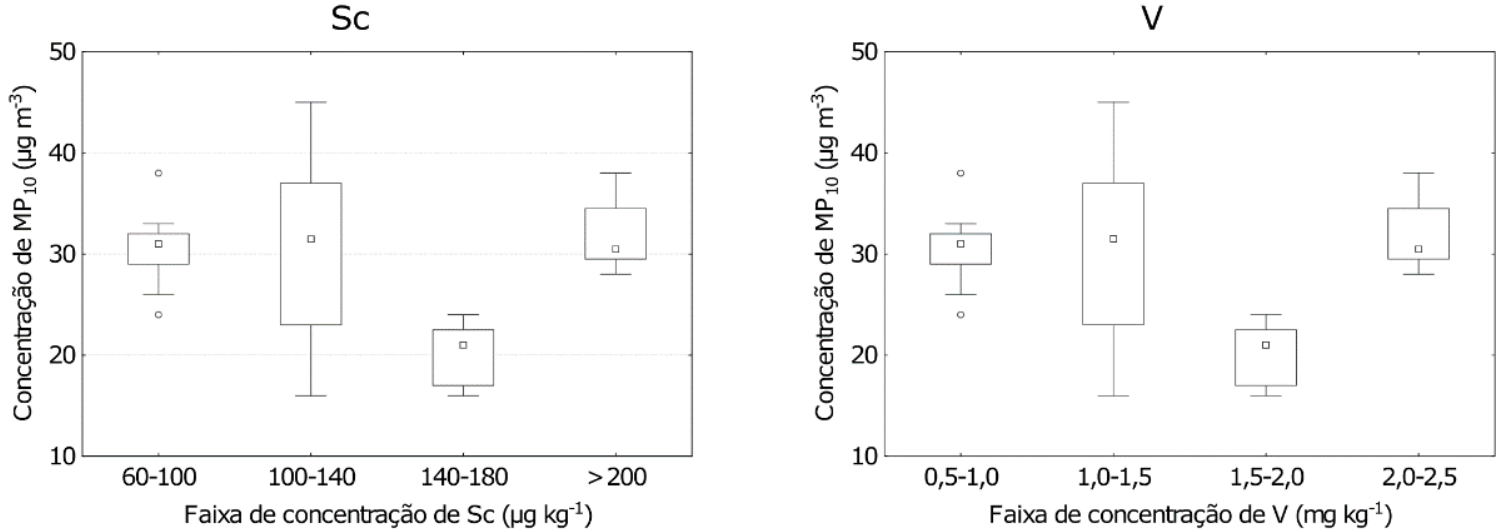

Figura G. 2 - Representação box plot da variação na concentração de $\mathrm{MP}_{10}$ medido pelas estações de monitoramento da CETESB entre 2009 e 2016 em função das concentrações de Mg, Mn, Rb, Sb, Sc e V determinados nas cascas de árvore da espécie Sibipiruna. 
APÊNDICE H - Relação entre as concentrações do elementos determinados nas cascas de árvore e as taxas de mortalidade de adultos por doenças cardiorrespiratórias.

Tabela H. 1 - Concentrações médias de elementos em cascas de Sibipiruna e taxas de mortalidade por região de amostragem.

\begin{tabular}{|c|c|c|c|c|c|c|c|c|c|c|c|c|}
\hline $\begin{array}{l}\text { Região de } \\
\text { amostragem da } \\
\text { RMSP }\end{array}$ & $\begin{array}{l}\text { Taxa de } \\
\text { mortalidade }\end{array}$ & $\begin{array}{l}\text { As, } \\
\mu \mathrm{g} \mathrm{kg}^{-1}\end{array}$ & $\begin{array}{c}\mathrm{Br} \\
\mathrm{mg} \mathrm{kg}^{-1}\end{array}$ & $\begin{array}{l}\mathrm{Ca} \\
\%\end{array}$ & $\begin{array}{l}\text { Cd, } \\
\mu \mathrm{gg}^{-1}\end{array}$ & $\begin{array}{c}\mathrm{Cl}, \\
\mathrm{mg} \mathrm{kg}^{-1}\end{array}$ & $\begin{array}{l}\text { Co, } \\
\mu \mathrm{kg}^{-1}\end{array}$ & $\begin{array}{c}\mathrm{Cr}, \\
\mathrm{mg} \mathrm{kg}^{-1}\end{array}$ & $\begin{array}{l}\text { Cs, } \\
\mu \mathrm{kg}^{-1}\end{array}$ & $\begin{array}{c}\mathrm{Cu}, \\
\mathrm{mg} \mathrm{kg}^{-1}\end{array}$ & $\begin{array}{c}\mathrm{Fe}, \\
\mathrm{mg} \mathrm{kg}^{-1}\end{array}$ & $\begin{array}{c}\mathrm{K}, \\
\mathrm{mg} \mathrm{kg}^{-1}\end{array}$ \\
\hline Cerqueira César & 0,475 & 84 & 2,46 & 4,37 & 392 & 48 & 237 & 1,75 & 48 & 15 & 496 & 898 \\
\hline Congonhas & 0,481 & 92 & 1,71 & 3,52 & 333 & 38 & 255 & 1,84 & 66 & 28 & 527 & 1417 \\
\hline Parque Dom Pedro II & 0,497 & 296 & 2,25 & 3,88 & 1289 & 60 & 582 & 4,25 & 104 & 26 & 1367 & 1367 \\
\hline Pinheiros & 0,475 & 48 & 1,48 & 4,09 & 214 & 36 & 195 & 0,83 & 51 & 8,30 & 283 & 1123 \\
\hline São Miguel Paulista & 0,563 & 208 & 2,79 & 3,57 & 441 & 111 & 16075 & 2,91 & 108 & 19 & 946 & 1447 \\
\hline \multicolumn{2}{|c|}{ Correlação de Pearson } & 0,550 & 0,715 & $-0,562$ & 0,113 & 0,983 & 0,976 & 0,470 & 0,796 & 0,156 & 0,504 & 0,592 \\
\hline & Valor de $p$ & 0,337 & 0,175 & 0,324 & 0,856 & 0,003 & 0,005 & 0,424 & 0,108 & 0,802 & 0,387 & 0,293 \\
\hline
\end{tabular}




\section{APÊNDICE H - Continuação.}

Tabela H. 2 - Concentrações médias de elementos em cascas de Sibipiruna e taxas de mortalidade por região de amostragem (continuação).

\begin{tabular}{|c|c|c|c|c|c|c|c|c|c|c|c|}
\hline $\begin{array}{c}\text { Região de } \\
\text { amostragem }\end{array}$ & $\begin{array}{c}\text { Taxa de } \\
\text { mortalidade }\end{array}$ & $\begin{array}{c}\mathrm{La}, \\
\mu \mathrm{g} \mathrm{kg}{ }^{-1}\end{array}$ & $\begin{array}{c}\mathrm{Mg}, \\
\mathrm{mg} \mathrm{kg}^{-1}\end{array}$ & $\begin{array}{c}\mathrm{Mn}, \\
\mathrm{mg} \mathrm{kg}^{-1}\end{array}$ & $\begin{array}{c}\mathrm{Ni}, \\
\mathrm{mg} \mathrm{kg}^{-1}\end{array}$ & $\begin{array}{c}\mathrm{Pb} \\
\mathrm{mg} \mathrm{kg}^{-1}\end{array}$ & $\begin{array}{c}\mathrm{Rb} \\
\mathrm{mg} \mathrm{kg}^{-1}\end{array}$ & $\begin{array}{c}\mathrm{Sb}, \\
\mu \mathrm{g} \mathrm{kg}{ }^{-1}\end{array}$ & $\begin{array}{c}\mathrm{Sc} \\
\mu \mathrm{g} \mathrm{kg}{ }^{-1}\end{array}$ & $\begin{array}{c}\mathrm{V} \\
\mathrm{mg} \mathrm{kg-1}\end{array}$ & $\begin{array}{c}\text { Zn, } \\
\mathrm{mg} \mathrm{kg}^{-1}\end{array}$ \\
\hline Cerqueira César & 0,475 & 669 & 465 & 37 & 1,09 & 2,66 & 2,32 & 1123 & 78 & 0,86 & 51 \\
\hline Congonhas & 0,481 & 886 & 548 & 29 & 1,83 & 2,79 & 3,53 & 523 & 101 & 1,06 & 45 \\
\hline Parque Dom Pedro II & 0,497 & 2153 & 666 & 41 & 3,02 & 7,20 & 3,76 & 3402 & 253 & 2,27 & 137 \\
\hline \multirow[t]{3}{*}{ São Miguel Paulista } & 0,563 & 1989 & 1112 & 46 & 214 & 6,94 & 4,33 & 592 & 233 & 2,12 & 72 \\
\hline & o de Pearson & 0,728 & 0,989 & 0,774 & 0,973 & 0,751 & 0,802 & $-0,039$ & 0,728 & 0,726 & 0,291 \\
\hline & Valor de $p$ & 0,163 & 0,001 & 0,125 & 0,005 & 0,144 & 0,102 & 0,951 & 0,163 & 0,165 & 0,634 \\
\hline
\end{tabular}


ANEXO A - Concentrações anuais médias de material particulado grosso $\left(\mathrm{MP}_{10}\right)$ determinados pelas estações de monitoramento automático da CETESB no período de 2009 a 2016.

TABELA I. 1 - Concentrações anuais médias de $\mathrm{MP}_{10}$ nas diferentes regiões de amostragem da RMSP.

\begin{tabular}{lcccccccc}
\hline $\begin{array}{l}\text { Localização da estação } \\
\text { de monitoramento }\end{array}$ & 2009 & 2010 & 2011 & 2012 & 2013 & 2014 & 2015 & 2016 \\
\hline Cerqueira César & 26 & 30 & 32 & 33 & 32 & 33 & 27 & 24 \\
Congonhas & 39 & 38 & 38 & 39 & 34 & 36 & 31 & 27 \\
Marília & 21 & 24 & 24 & 21 & 20 & 22 & 20 & 16 \\
Parque D. Pedro II & 34 & 31 & 38 & 35 & 30 & 29 & 28 & 30 \\
Pinheiros & 31 & 31 & 38 & - & - & 31 & 29 & - \\
Presidente Prudente & 16 & 24 & 22 & 23 & 20 & 22 & 17 & 17 \\
S. André-Paço Municipal & 42 & 45 & 34 & 35 & 32 & 36 & 29 & 28 \\
\hline
\end{tabular}

FONTE - CETESB - Companhia Ambiental do Estado de São Paulo, Qualar - Qualidade do ar. Disponível: < http://ar.cetesb.sp.gov.br/qualar/>. Acesso em 27 de fevereiro de 2016. 


\section{REFERÊNCIAS BIBLIOGRÁFICAS}

ALAHABADI, A.; EHRAMPOUSH, M.H.; MIRI, M.; AVAL, H.E.A.; YOUSEFZADEH, S.; GHAFFARI, H.R.; AHMADI, E.; TALEBI, P.; FATHABADI, Z.A.; BARBAI, A.N.; SHARAFI, K.; HOSSEINI-BANDEGHARAEI, A. comparative study on capability of different tree species in accumulating heavy metal from soil and ambient air. Chemosphere, v. 172, p.459-467, 2017.

ALMEIDA, S.M.; RAMOS, C.A.; MARQUES, A.M.; SILVA, A.V.; FREITAS, M.C.; FARINHA, M.M.; REIS, M.; MARQUES, A.P. Use of INAA and PIXE for multipollutant air quality assessment and management. Journal of Radioanalytical and Nuclear Chemistry. v. 294, p. 343-347, 2012.

ALVES, A.N.L.; ROSA, H,V,D. Exposição ocupacional ao cobalto: aspectos toxicológicos. Revista Brasileira de Ciências Farmacêuticas, v. 39, n. 2, 2003.

AMATO-LOURENCO, L.F.; MOREIRA, T.C.L.; SOUZA, V.C.O.; BARBOSA JÚNIOR, F.; SAIKI, M.; SALDIVA, P.H.N.; MAUAD, T. The influence of atmospheric particles on the elemental content of vegetables in urban gardens of São Paulo, Brazil. Environmental Pollution, v. 216, p. 125-134, 2016.

AMATO-LOURENCO, L.F; LOBO, D.J.A.; GUIMARÃES, E.T.; MOREIRA, T.C.L.; CARVALHO-OLIVEIRA, R.; SAIKI, M.; SALDIVA, P.H.N.; MAUAD, T. Biomonitoring of genotoxic effects and elemental accumulation derived from air pollution in community urban gardens. Science of the Total Environment, v. 575, p. 14381444, 2017.

BARGAGLI, R. The elemental composition of vegetation and the possible incidence of soil contamination of samples. Science of the Total Environment, v. 176, p. 121-128, 1995.

BARGAGLI, R. Trace elements in terrestrial plants: an ecophysiological approach to biomonitoring and biorecovery. Berlin: Springer, 1998.

BEATY, R.D.; KERBER, J.D. Concepts, instrumentation and techniques in atomic absorption spectrophotometry. 2.ed. Norwalk, CT: The Perkin-Elmer Corporation, 1993. 
BELIVERMIS, M.; KILIC, O.; COTUK, Y.; TOPCUOGLU, S.; KALAYCI, G.; PESTRELI, D. The usability of tree barks as long term biomonitors of atmospheric radionuclide deposition. Applied Radiation and Isotopes, v. 68, p. 2433-2437, 2010.

BERLIZOV, A.N.; BLUM, OB.; FILBY, RH.; MALLYUK, I.A.; TRYSHYN, V.V. Testing applicability of black poplar (Populus nigra L.) bark to heavy metal air pollution monitoring in urban and industrial regions. Science of the Total Environment, v. 372, p. 693-706, 2007.

BING, H.; WU, Y.; ZHOU, J.; SUN, H. Biomonitoring trace metal contamination by seven sympatric alpine species in Eastern Tibetan Plateau. Chemosphere, v. 165, p. 388-398, 2016.

CAMILO, J. Sibipiruna \{Poincianella pluviosa var. peltophoroides (Benth.) L.P. Queiroz\}, $2014 . \quad$ Disponível em: <http://www.aplantadavez.com.br/2014/11/sibipiruna-poincianella-pluviosavar.html >. Acesso em: 12 abr. 2017.

CARVALHO-OLIVEIRA, R.; AMATO-LOURENCO, L. F.; MOREIRA, T.C.L.; SILVA, D.R.R.; VIEIRA, B.D.; MAUAD, T.; SAIKI, M.; SALDIVA, P.H.N. Effectiveness of traffic-related elements in tree bark and pollen abortion rates for assessing air pollution exposure on respiratory mortality rates. Environment International, v. 99, p. 161-169, 2017.

CASIMIRO, R. Foto de Tipuana, Lisboa, SD. Disponível em: <https://br.pinterest.com/pin/17099673558559955/>. Acesso em: 12 mar. 2017.

CATINON, M.; AYRAULT, S., BOUDOUMA, O.; ASTA, J.; TISSUT, M.; RAVANEL, $P$. Atmospheric element deposit on tree barks: The opposite effects of rain and transpiration. Ecological Indicators, v. 14, p. 170-177, 2012.

CESARI, D.; DONATEO, A.; CONTE, M.; CONTINI, D. Inter-comparison source apportionment of $\mathrm{PM}_{10}$ using $\mathrm{PMF}$ and $\mathrm{CMB}$ in three sites nearby an industrial area in central Italy. Atmospheric Research, v. 182, p. 282-293, 2016. 
CETESB - Companhia Ambiental do Estado de São Paulo. Qualar - Qualidade do ar, SD. Disponível em: <http://ar.cetesb.sp.gov.br/qualar/>. Acesso em: em 27 fev. 2016.

CETESB - Companhia Ambiental do Estado de São Paulo. Emissões veiculares no Estado de São Paulo, 2013. Disponível em: <http://www.cetesb.sp.gov.br>. Acesso em: 01 mai. 2017.

CHIARANTINI, L.; RIMONDI, V.; BENVENUTI, M.; BEUTEL, M.W.; COSTAGLIOLA, P.; GONNELLI, C.; LATTANZI, P.; PAOLIERI, M. Black pine (Pinnus nigra) barks as biomonitors of airborne mercury pollution. Science of the Total Environment, v. 569-570, p. 105-113, 2016.

CUCU-MAN, S.M.; STEINNES, E. Analysis of selected biomonitors to evalyate the suitability for their complementary use in monitoring trace elemento atmospheric deposition. Environmental Monitoring Assessment, v. 185, p. 7775-7791, 2013.

CURRIE, L.A. Detection and quantification limits: origins and historical overview. Analytical Chimica Acta, v. 391, p. 127-134, 1999.

CURRIE, L.A.; Limits for qualitative detection and quantitative determination. Anal. Chem. v. 40, p. 586-593, 1968.

DATASUS - Departamento de informática do SUS, SD. Disponível em: $<$ http://tabnet.saude.prefeitura.sp.gov.br/cgi/deftohtm3.exe?secretarias/saude/TAB NET/SIM/obito.def $>$. Acesso em: 03 out. 2016.

DE SOETE, D.; GILBELS, R.; HOSTE, J. Neutron activation analysis. New York: Wiley-Interscience, p. 140, 1972.

EL KHOUKHI, T.; CHERKAOUI, R.M.; GUADRY, A.; AYRAULT, S.; SENHOU, A.; CHOUAK, A.; MOUTIA, Z.; CHARKIR, E. Air pollution biomonitoring survey in Morrocco using $\mathrm{k}_{0}$-INAA. Nuclear Instruments and Methods in Physics Research B, v. 213, p. 770-774, 2004.

FERREIRA, M.M.C. Quimiometria - conceitos, métodos e aplicações. Campinhas, SP: Editora da Unicamp, 2015. 
FIGUEIREDO, A.M.G.; NOGUEIRA, C.A.; SAIKI, M.; MILLIAN, F.M.; DOMINGOS, M. Assessment of atmospheric metallic pollution in the metropolitan region of São Paulo, Brazil, employing Tillandsia usneoides L. as biomonitor. Environmental Pollution, v. 145, p. 279-292, 2007.

FIGUEIREDO FILHO, D.B.; SILVA JÚNIOR, J.A. Visão além do alcance: uma introdução à análise fatorial. Opinião Pública, v. 16, n.1, p. 160-184, 2010.

FRIEDLANDER, M.; KENNEDY, J. W.; MILLER, J. M. Nuclear and radiochemistry. New York: John Wiley \& Sons, 1981.

FUGA, A.; SAIKI, M.; MARCELLI, M. P.; SALDIVA, P. H. N. Atmospheric pollutants monitoring by analysis of epiphytic lichens. Environmental Pollution, v. 151, p. 334-340, 2008.

FUJIWARA, F.G.; GÓMEZ, D.R.; DRAWIDOWSKI, L.; PERELMAN, P.; FAGGI, A. Metals associated with airborne particulate matter in road dust and tree bark collected in a megacity (Buenos Aires, Argentina). Ecological Indicators, v. 11, p.240-247, 2011.

GRESENS, R.L. Composition-volume relationships of metasomatism. Chemical Geology, v. 2, p. 47-55, 1967.

GUÉGUEN, F.; STILLE, P.; MILLET, M. Air quality by tree bark biomonitoring in urban, industrial and rural environments of the Thine Valley: PCDD/Fs, PCBs and trace metal evidence. Chemosphere, v. 85, p. 195-202, 2011.

GUÉGUEN, F.; STILLE P.; GEAGEA, M.L.; BOUTIN, R. Atmospheric pollution in urban environment by tree bark biomonitoring. Part I: Trace element analysis. Chemosphere. v.86, p. 1013-1019, 2012.

HABERMANN, M.; GOUVEIA, N.; Tráfego veicular e mortalidade por doenças do aparelho circulatório em homens adultos. Revista de Saúde Pública, v. 46(1), p. 26-33, 2012.

HEUVEL, R.V.D.H.; HOND, E.D.; GOVARTS, E.; COLLES, A.; KOPPEN, G.; STAELENS, J.; MAMPAEY, M.; JANSSEN, N.; SCHOETERS, G. Identification of 
MP10 characteristics involved in cellular responses in human bronchial epithelial cells (Beas-2B). Environmental Research, v.149, p. 48-56, 2016.

HOLLER, F. J.; SKOOG, D.A.; CROUCH, S.R. Princípios de análise instrumental. 6.ed. São Paulo, SP: Artimed editora S.A, 2009.

INMETRO - Instituto Nacional de Metrologia, Qualidade e Tecnologia. Orientação sobre validação de métodos analíticos (DOQ-CGCRE-008), 2007.

JANDACKA, D.; DURCANSKA, D.; BUJDOS, M. The contribution of road traffic to particulate matter and metals in air pollution in the vicinity of an urban road. Transportation Research Part D, v. 50, p. 397-408, 2017.

KABATA-PENDIAS, A. Trace elements in soil and plants. Boca Raton: CRC Press, 2011.

KILIC, O. Biomonitoring of ${ }^{137} \mathrm{Cs},{ }^{40} \mathrm{~K},{ }^{232} \mathrm{Th}$ and ${ }^{238} \mathrm{U}$ using oak bark in Belgrade Forest, Istanbul, Turkey. Nuclear Technology and Radiation Protection, v. 27, p. 137-143, 2012.

KONIECZKA, P.; NAMIEŚNIK, J. Quality assurance and quality control in the analytical chemical laboratory - A practical approach, New York: CRC Press, p. 27, 2009.

LEWIS, G.P. Poincianella. Lista de Espécies da Flora do Brasil. Jardim Botânico do Rio de Janeiro, 2015. Disponível em: <http://floradobrasil.jbri.gov.br/jabot/floradobrasil/FB109778>. Acesso em: 12 abr. 2017.

LEPAGE, E.S, (coord.) Manual de preservação de madeiras. São Paulo, IPT/SICCT, 1986.

MARTIN, C.A. Virtual Library of Phoenix Landscape Plants, Plant html files, Tipuana tipu bark, Arizona State University, SD. Disponível em: <http://www.public.asu.edu/ camartin/plants/>. Acesso em: 12 abr. 2017.

MARTINS, G.A. Estatística geral e aplicada. São Paulo, SP: Editora Atlas S.A., 2010. 
MOREIRA, T.C.L.; OLIVEIRA, R.C.; AMATO, L.F.L; KANG, C.M.; SALDIVA, P.H.N.; SAIKI, M. Intra-urban biomonitoring: source apportionment using tree barks to identify air pollution sources. Environment International, v. 91, p. 271-275, 2016.

MORENO, R.G.M.; OLIVEIRA, E.; OLIVEIRA, V.P. Uma célula eletroquímica para modificação permanente de tubo de grafite empregado em absorção atômica. Química Nova, v. 24, n. 3, p. 404-407, 2001.

MÜLLER, G. Index of geoacummulation in sediments of the Rhine River. GeoJournal, v. 2, n. 3, p. 108-118, 1969.

ODABASI, M.; OZGUNERGE, F.E.; TUNA, G.; ALTIOK, H.; KARA, M.; DUMANOGLU, Y.; BAYRAM, A.; TOLUNAY, D.; ELBIR, T. Biomonitoring the spatial and historical variations of persistent organic pollutants (POPs) in industrial region. Environmental Science and Technology, v. 49, p. 2105-2114, 2015.

OLIVEIRA, R.C.; LOURENÇO, L.F.; MOREIRA, T.C.L.; SILVA, D.R.R.; VIEIRA, B.D.; MAUAD, T.; SAIKI, M.; SALDIVA, P.H.N. Effectiveness of traffic-related elements in tree bark and pollen abortion rates for assessing air pollution exposure on respiratory mortality rates. Environment International, v. 99, p. 161-169, 2017.

PACHECO, A.M.G; FREITAS, M.C.; BARROS, L.I.C.; FIGUEIRA, R. Investigating tree barks as an air-pollution biomonitor by means of neutron activation analysis. Journal of Radioanalytical and Nuclear Chemistry, v. 249, n.2, p. 327-331, 2001. PACHECO, A.M.G.; FREITAS, M.C.; BAPTISTA, M.S.; VASCONCELOS, M.T.S.D.; CABRAL, J.P. Elemental levels in tree-bark and epiphytic-lichen transplant at a mixed environment in mainland Portugal and comparison with an in situ lichen. Environmental Pollution, v. 151, p. 326-333, 2008.

PATRICK, G.J.; FARMER, J.G. A lead isotopic assessment of tree bark as a biomonitor of contemporary atmosphere lead. Science of the Total Environment, v. 388, p. 343-356, 2007.

PAULINO, S.A.; OLIVEIRA, R.L.; LOYOLA, J.; MINHO, A.S.; ARBILLA, G.; QUITERIO, S.L.; ESCALEIRA, V. Trace metals in $\mathrm{PM}_{10}$ and $\mathrm{PM}_{2,5}$ samples collected in a highly industrialized chemical/petrochemical area and its urbanized 
surrounding. Bulletin of Environmental Contamination and Toxicology, v. 92, 5 ed., p. 590-595, 2014.

PUETT, R.C.; HARTZ, J.E.; YANOSKY, J.D.; SPIEGELMANN, D.; WANG, M.; FISHER, J.A.; HONG, B.; LADEN, F. Particulate matter air pollution exposure, distance to road, and incident lung cancer in the nurses' health study cohort. Environmental Health Perspective, v. 122, n. 9, p. 926-932, 2014.

REDE Interagencial de Informação para a Saúde. Indicadores básicos para a saúde no Brasil: conceitos e aplicações, Brasília. 2.ed. Organização PanAmericana da Saúde, 2008.

RICH, D.Q.; ÖZKAYNAK, H.; CROOKS, J.; BAXTER, L.; BURKE, J.; OHMANSTRICKLAND, P.; THEVENET-MORRISON, K.; KIPEN, H.M.; ZHANG, J.; KOSTIS, J.B.; LUNDEN, M.; HODAS, N.; TURPIN, BJ. The triggering of myocardial infarction by fine particles is enhanced when particles are enriched in secondary species. Environmental Science and Technology, v. 47, p. 9414-9423, 2013.

SAIKI, M.; SANTOS, O.J.; ALVES, E.R.; GENEZINI, F.A.; MARCELLI, M.P.; SALDIVA, P.H.N. Correlation study of air pollution and cardio-respiratory diseases through NAA of an atmospheric pollutant biomonitor. Journal of Radioanalytical and Nuclear Chemistry, v. 299, p. 773-779, 2014.

SANTAMARÍA, J.M.; MARTÍN, A. Tree bark as a bioindicator of air pollution in Navarra, Spain. Water, Air Soil Pollution, v. 98, p. 381-387, 1997.

SAVÓIA, E.J.L.; DOMINGOS, M.; GUIMARÃES, E.T.; BRUMATI, F.; SALDIVA, P.H.N. Biomonitoring genotoxic risks under the urban weather conditions and polluted atmosphere in Santo André, SP, through Trad-MCN bioassay. Ecotoxicology and Environmental Safety, v.72, p. 255-260, 2009.

SCHULZ, H.; POPP, P.; HULN, G.; STARK, H.J.; SCHUURMANN, G. Biomonitoring of air airborne inorganic and organic pollutants by means of pine tree barks. I. Temporal and spatial variations. Science of the Total Environment, v. 232, p. 4958, 1999. 
SEADE - Fundação Sistema Estadual de Análise de Dados, A frota de veículos no estado de São Paulo, 2014. Disponível em: < www./produtos/midia/radar/radar seade n4.pdf>. Acesso em: 13 mai. 2017.

SILVA, L. F.; LIMA, A. M. L. P.; SILVA, D. F.; COUTO, H.T.Z. Interceptação da chuva pelas copas das espécies de Caesalpinia pluviosa DC. (Sibipiruna) e Tipuana tipu O. Kuntze (Tipuana) em arborização urbana. Scientia Forestalis, v. 36, n. 80, p. 307-315, 2008.

SILVA, M.F. Emissão de metais por veículos automotores e seus efeitos à saúde pública. 2007. Dissertação (Mestrado) - Faculdade de Saúde Pública, Universidade de São Paulo, São Paulo. Disponível em: $<$ http://www.teses.usp.br/teses/disponiveis/6/6134/tde-08112007-152445/ptbr.php>. Acesso em: 14 mai. 2017.

SILVA, M.F.; ASSUNÇÃO, J.V.; ANDRADE, M.F.; PESQUERO, C.R. Characterization of metal and trace element contents of particulate matter $\left(\mathrm{PM}_{10}\right)$ emitted by vehicles running on Brazilian fuels - hydrated ethanol and gasoline with $22 \%$ of anhydrous ethanol. Journal of Toxicology and Environmental Health, Part A, v. 73, p. 901-909, 2010.

SKRBIC, B.; MILOVAC, S.; MATAVULJ, M. Multielement profiles of soil, road dust, tree bark and wood-rotten fungi collected at various distances from high-frequency road in urban area. Ecological Indicators, v. 13, p. 168-177, 2012.

SMLU - Secretaria Municipal de Urbanismo e Licenciamento. Classificação de vias, SD. Disponível em: <http://www.prefeitura.sp.gov.br/cidade/secretarias/urbanismo/ licenciamentos/servicos/index.php?p=3303 >. Acesso em: 03 ago. 2017.

STEINDOR, K.; FRANIEL, I.J.; BIERZA, W.M.; PAWKAK, B.; PALOWSKI, B.F.. Assessment of heavy metal pollution in surface soils and plant material in the postindustrial city of Katowice, Poland. Journal of Environmental Science and Health, Part A, v. 0, p. 1-9, 2016.

SUCHARA, I.; Temporal and spatial changes in spruce bark acidity at the scale of the Czech Republic in the last two decades, and the current abundance of epiphytic lichens. Water Air Soil Pollution, v. 223, p. 1685-1697. 
VALOTTO, G.; SQUIZZATO, S.; MASIOL, M.; ZANNONI, D.; VISIN, F.; RAMPAZZO, G. Elemental characterization, source and wind dependence of $\mathrm{PM}_{1}$ near Venice, Italy. Atmospheric Research, v. 143, p. 371-379, 2014.

VICINI, L.; SOUZA, A.M. Análise multivariada da teoria à prática. Santa Maria: UFSM, CCNE, 2015.

WANG, Y.F.; HUANG, K.L.; LI, C.T.; MI, H.H.; LUO, J.H.; TSAI, P.J. Emissions of fuel metals content from a diesel vehicle engine. Atmospheric Environment, v. 37, p. 4637-4643, 2003.

WANG, X.; SATO, T.; XING, B.; TAMAMURA, S.; TAO, S. Source identification, size distribution and indicator screening of airborne trace metals in Kanazawa, Japan. Journal of Aerosol Science, v. 36, p. 197-210, 2005.

WANG, X; BI, X.; SHENG, G.; FU, J. Chemical composition and sources of PM10 and PM2,5 aerosols in Guangzhou, China. Environmental Monitoring and Assessment, v. 119, p. 425-439, 2006.

WEDEPOHL, K. H. The composition of the continental crust. Geochimica et Cosmochimica Acta, v. 59, p. 1217-1232, 1995.

WELZ, B.; SPERLING, M. Atomic absorption spectrometry. 3.ed. Weinheim, Germany: Wiley-VCH, 1999.

WHO - World Health Organization. Health effects of particulate matter. Policy for countries in eastern Europe, Caucasus and central Asia, 2013. Disponível em: $<$ http://www.euro.who.int/ data/assets/pdf file/0006/189051/Health-effects-ofparticulate-matter-final-Eng.pdf>. Acesso em: 03 mai. 2017.

WYTTENBACH, A.; FURRER, V.; TOBLER, L. The concentration ratios plant to soil for the stable elements $\mathrm{Cs}, \mathrm{Rb}$ and $\mathrm{K}$. The Science of the Total Environment, $\mathrm{v}$. 173/174, p. 361-367, 1995.

YUAN, H.; JIN, J.; BAI, Y.; LI, Q.; WANG, Y.; HU, J. Concentrations and distribution of polybrominated diphenyl ethers and novel brominated flame retardants in tree 
barks and human hair from Yunnan Province, China. Environmental Science and Technology, v. 42, p. 6046-6051, 2008.

ZHAO, Y.; YANG, L.; WANG, Q. Modeling persistent organic pollutant (POP) partitioning between tree bark and air and its application to spatial monitoring of atmospheric POPs in Mainland China. Environmental Science and Technology, v. 42 , p. $6046-6051,2008$. 